\title{
SPATIOTEMPORAL VARIABILITY IN THE MACROINVERTEBRATE COMMUNITY OF A SMALL COASTAL CALIFORNIA STREAM, LITTLE CREEK, DAVENPORT, CALIFORNIA
}

\author{
A Thesis \\ presented to \\ the Faculty of California Polytechnic State University, \\ San Luis Obispo \\ In Partial Fulfillment \\ of the Requirements for the Degree \\ Master of Science in Forestry Sciences
}

by

John Patrick Hardy

December 2017 
(C) 2017

John Patrick Hardy

ALL RIGHTS RESERVED 
TITLE:

AUTHOR:

DATE SUBMITTED:

COMMITTEE CHAIR:

COMMITTEE MEMBER:

COMMITTEE MEMBER:
Spatiotemporal Variability in the Macroinvertebrate Community of a Small Coastal California Stream, Little Creek, Davenport, California

John Patrick Hardy

December 2017

Brian C. Dietterick, Ph.D., P.H., Director, Swanton Pacific Ranch, College of Agriculture, Food, and Environmental Sciences, California Polytechnic State University, San Luis Obispo

John H. Walker, Ph.D., Professor of Statistics, Statistics Department, California Polytechnic State University, San Luis Obispo

Joseph D. Kiernan, Ph.D., Research Ecologist, NOAA Fisheries, Southwest Fisheries Science Center, Fisheries Ecology Division 


\begin{abstract}
Spatiotemporal Variability in the Macroinvertebrate Community of a Small Coastal California Stream, Little Creek, Davenport, California
\end{abstract}

John Hardy

Macroinvertebrate community structure was characterized along the channel gradient of a headwater stream in a coast redwood forest on Cal Poly's Swanton Pacific Ranch in Davenport, California. The significance of physical habitat characteristics in describing macroinvertebrate assemblage structure was assessed in an effort to create a framework to better understand the expected biological response to riparian canopy manipulation. Seven study reaches were established in 2015. These study reaches were evenly spaced throughout the Little Creek watershed, an approximately $4.8 \mathrm{~km}^{2}$ drainage characterized by steep inner-gorge areas and dense riparian vegetation. Macroinvertebrate samples were collected seasonally (i.e., spring, summer, and fall) during 2015 and 2016 using the Reachwide Benthos procedure described by the Surface Water Ambient Monitoring Program's bioassessment protocol and all captured organisms were identified at family level taxonomic resolution. Non-metric multidimensional scaling (NMDS) and Analysis of Variance (ANOVA) procedures were performed to describe longitudinal patterns in community composition and determine the significance of collected environmental variables as predictors of community structure. The majority of taxa collected belonged to the orders Ephemeroptera, Plecoptera, Trichoptera, and Diptera. Macroinvertebrate density and biomass were significantly associated with study reach, with relatively depauperate macroinvertebrate assemblages occurring in the upper study reaches and significantly larger, more diverse assemblages in the lower study reaches. Significantly higher density and biomass was observed during the summer sample period across all sites. A clear site level separation was observed at the South Fork study reaches where significantly higher abundances of Diptera taxa colonized the primarily bedrock channel at those sites. The most diverse and pollution-intolerant assemblages were observed in riffle habitat types. Stream shading and solar radiation were not significantly associated with any macroinvertebrate community metric examined, making it difficult to predict instream response to a riparian canopy manipulation. However, trophic interactions that influence secondary production in the study reaches could be inferred based on temporal patterns in feeding guild composition; the relative abundance of shredder taxa coincided with seasonal detrital inputs indicating that food webs largely depended on allochthonous energy sources. Therefore, there is significant opportunity for further investigation of energy production and utilization in the study reaches to guide riparian canopy management practices toward enhancing key trophic interactions. This study provides an extensive and novel biological baseline for macroinvertebrate communities in Little Creek. 


\section{ACKNOWLEDGMENTS}

I'd like to thank Al Smith, who changed my life by gifting Swanton Pacific Ranch to Cal Poly. The ranch is a remarkably beautiful place that is home to many amazing people. My time here will always have a special place in my heart and mark an important chapter in my life. I'd also like to thank my advisor, Brian Dietterick, for allowing me to return to the ranch as a graduate student. Thanks to Nick Macias for being an integral part of this project's experimental design and data collection. Dr. Walker provided essential assistance with the statistical analysis and Dr. Kiernan was invaluable in interpreting results and editing this document. The hundreds of hours that many undergraduates dedicated to processing samples made it possible to complete this project in less than a decade. Finally, thank you to my family and girlfriend, Alli, for applying some extra necessary pressure to get me to the finish line. This project was funded by Cal Fire and McIntire Stennis. 


\section{TABLE OF CONTENTS}

Page

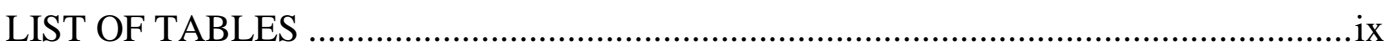

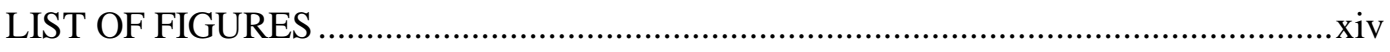

CHAPTER 1. Introduction ........................................................................ 1

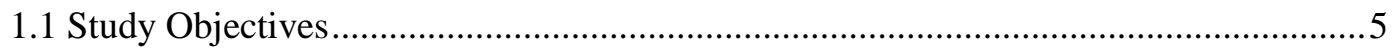

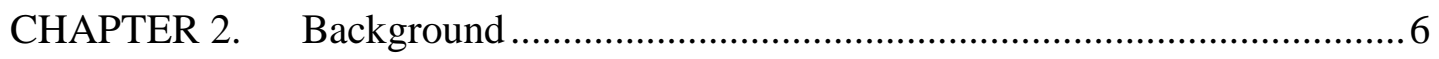

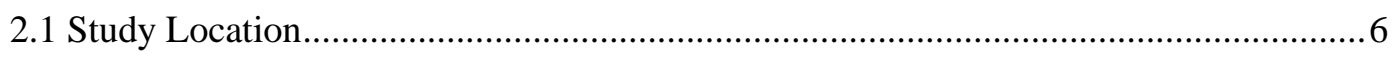

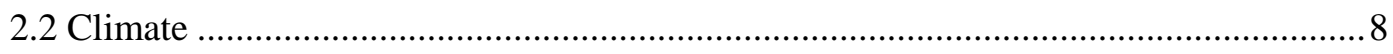

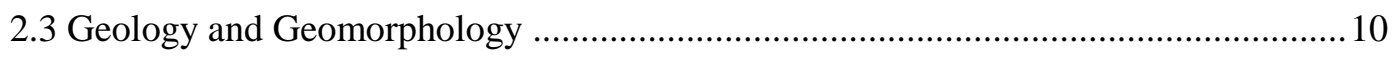

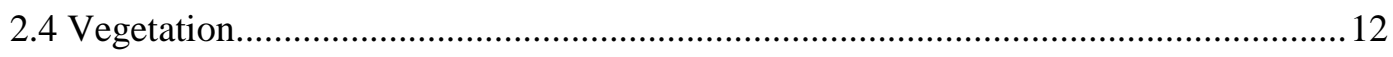

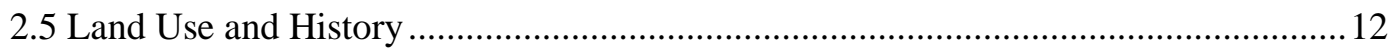

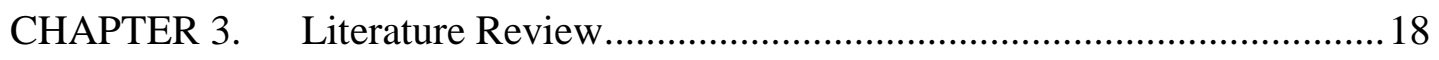

3.1 Food Web Dynamics of Lotic Ecosystems .......................................................... 18

3.2 Metrics of Macroinvertebrate Community Structure ….........................................2 20

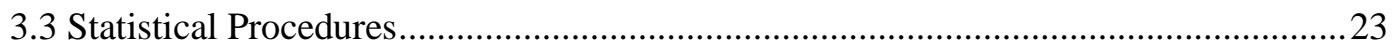

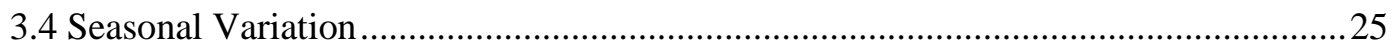

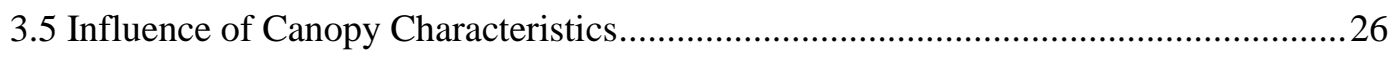

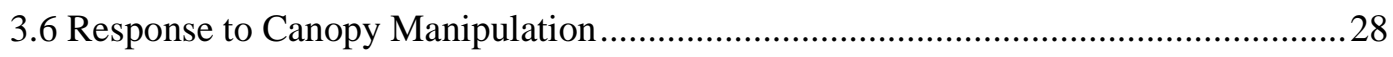

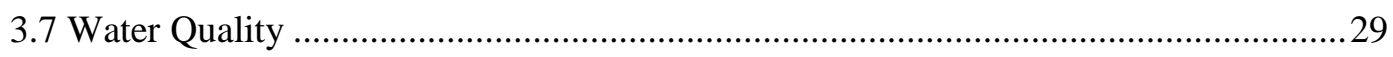

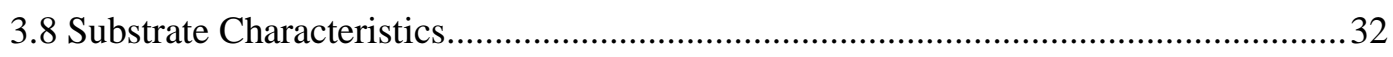

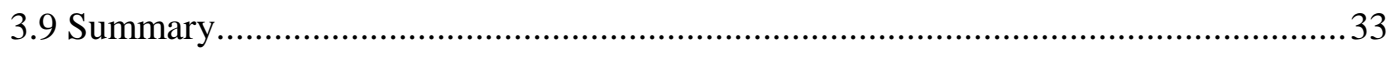

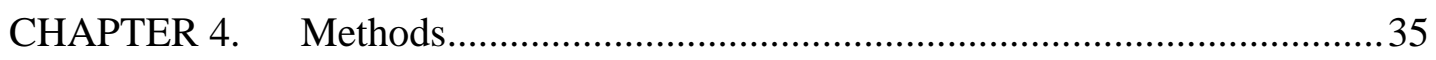

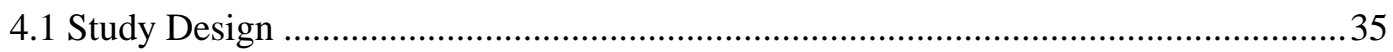




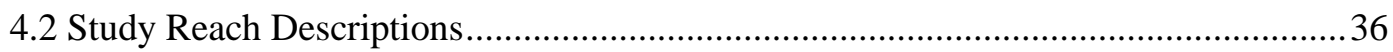

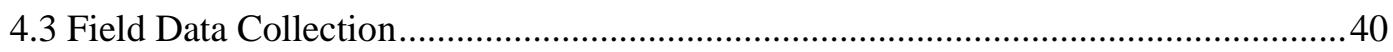

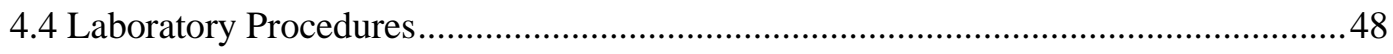

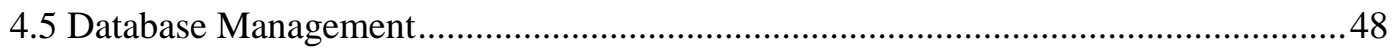

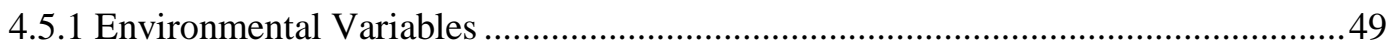

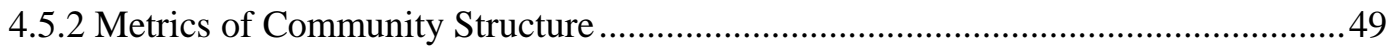

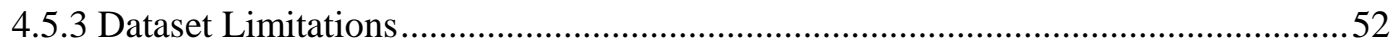

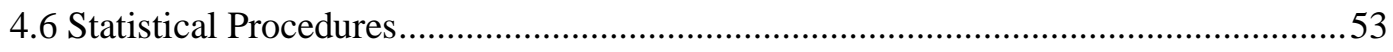

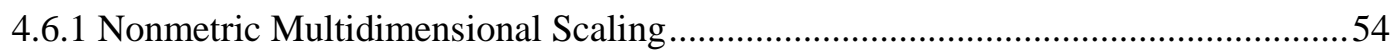

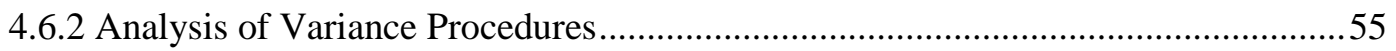

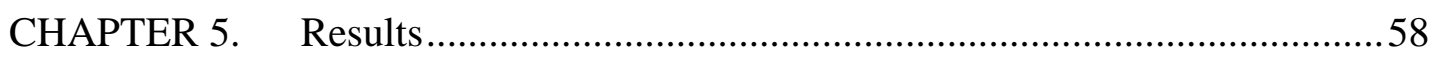

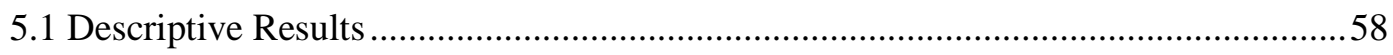

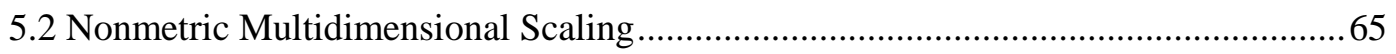

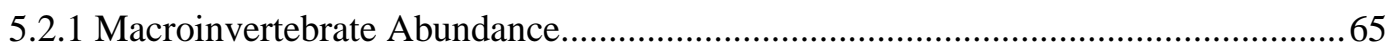

5.2.2 Functional Feeding Group Composition …...................................................... 71

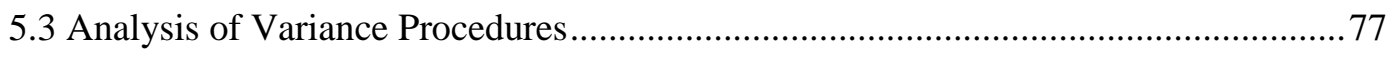

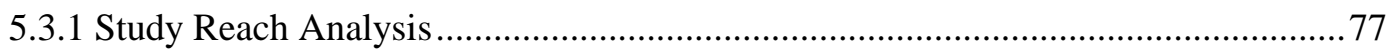

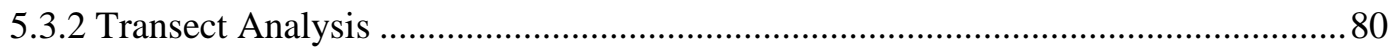

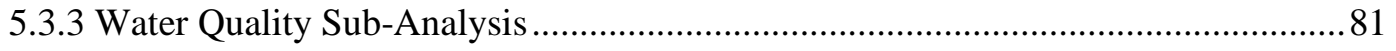

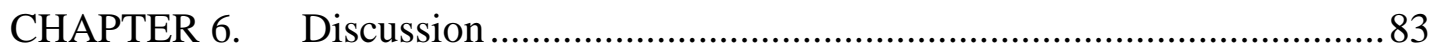

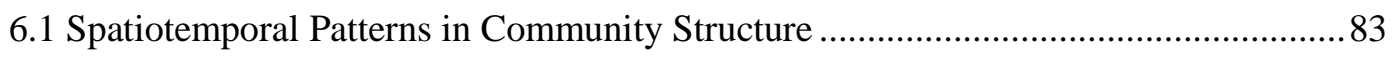

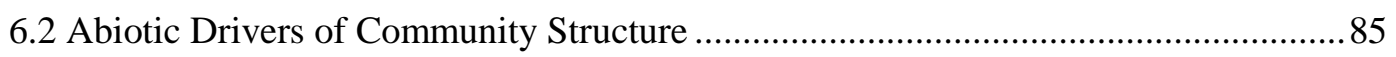

6.3 Predicting Instream Response to Canopy Manipulation.......................................... 86

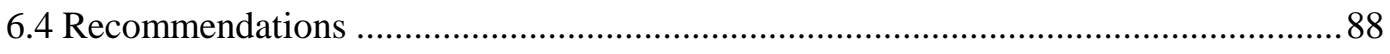

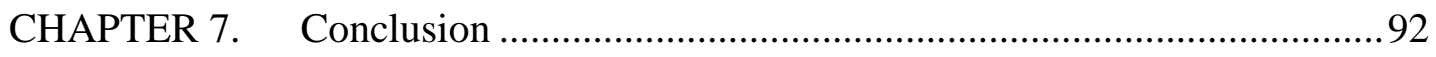




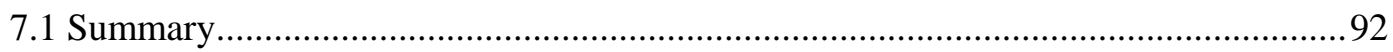

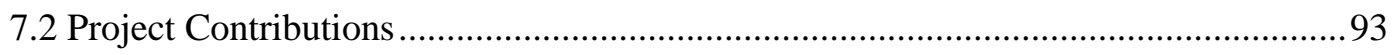

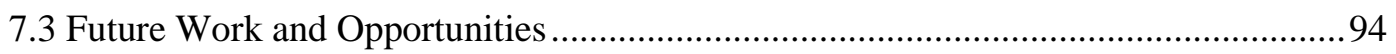

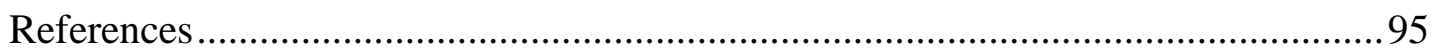

\section{APPENDICES}

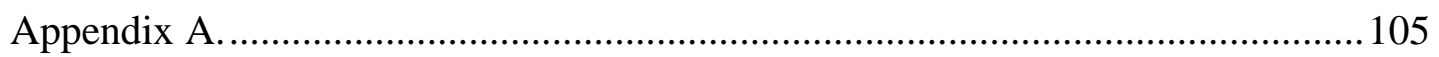

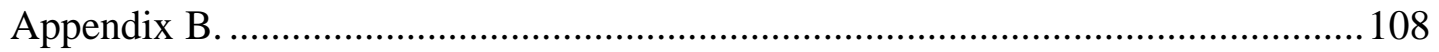

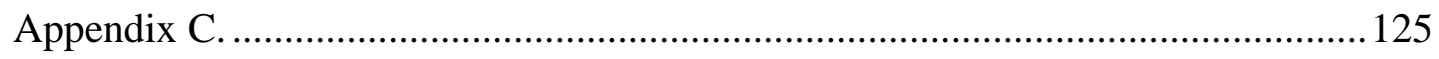

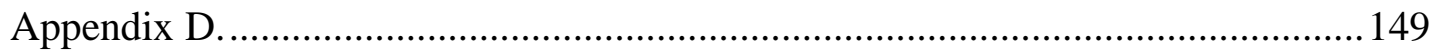




\section{LIST OF TABLES}

Page

Table 1.1 Prescribed protection measures for Class I Watercourse and Lake

Protection Zones in the coastal anadromy zone (Cal Fire 2017) .......................3

Table 4.1 Metrics of macroinvertebrate community structure...............................51

Table 4.2 Evaluation of water quality using the family-level Hilsenhoff biotic index (Brinkhurst et al. 2009, Hilsenhoff 1988) ...................................51

Table 5.1 Primary functional feeding group (FFG), tolerance value designation, and mean density for each macroinvertebrate family observed in Little Creek, 2015-2016.

Table 5.2 Environmental data collected in spring, summer, and fall of 2015. Percentage stream shading, solar radiation, and cross-sectional area were measured at each main transect location and averaged here. 61

Table 5.3 Environmental data collected in spring, summer, and fall of 2016. Percentage stream shading, solar radiation, and cross-sectional area were measured at each main transect location and averaged here. 62

Table 5.4 Biological data collected in spring, summer, and fall of 2015.

Density was calculated by dividing the total number of individuals collected at a study reach by the total area sampled. Biomass, Hilsenhoff Family Biotic Index (FBI), and Shannon's Diversity Index $\left(\mathrm{H}^{\prime}\right)$ were averaged for each study reach. 63

Table 5.5 Biological data collected in spring, summer, and fall of 2016. Density was calculated by dividing the total number of individuals 
collected at a study reach by the total area sampled. Biomass, Hilsenhoff Family Biotic Index (FBI), and Shannon's Diversity Index $\left(\mathrm{H}^{\prime}\right)$ were averaged for each study reach. 64

Table 5.6 ANOVA results of models created from the study reach dataset............. 78

Table 5.7 ANOVA results of models created from the transect dataset....................80

Table 5.8 ANOVA results of models created from the water quality subdataset. 82

Table C.1 Tukey HSD test results for differences in mean macroinvertebrate density among the study reaches.

Table C.2 Tukey HSD test results for differences in mean \% EPT among the study reaches. 126

Table C.3 Parameter coefficient of flow $\left(\mathrm{m}^{3} / \mathrm{s}\right)$ as a predictor of $\%$ EPT. 126

Table C.4 Parameter coefficient estimate of D-50( $\mathrm{mm})$ as a predictor of

$\%$ R-strategist.

Table C.5 Tukey HSD test results for differences in mean \% Diptera among the study reaches. 128

Table C.6 Parameter coefficient estimate of D-50 (mm) as a predictor of $\%$ Diptera. 128

Table C.7 Tukey HSD test results for differences in mean FBI among the study reaches.

Table C.8 Tukey HSD test results for differences in mean $\mathrm{H}^{\prime}$ among the study reaches. 130 
Table C.9 Tukey HSD test results for differences in mean \% SH among the study reaches.

Table C.10 Tukey HSD test results for differences in mean \% SH among seasons

Table C.11 Tukey HSD test results for differences in mean \% CG among the study reaches.

Table C.12 Tukey HSD test results for differences in mean $\log 10$ (density) among the study reaches.

Table C.13 Tukey HSD test results for differences in mean log10(density) among seasons.

Table C.14 Tukey HSD test results for differences in mean $\log 10$ (biomass+1) among the study reaches.....

Table C.15 Tukey HSD test results for differences in mean log10(biomass+1) among seasons.

Table C.16 Tukey HSD test results for differences in mean EPT taxa among the study reaches.

Table C.17 Tukey HSD test results for differences in mean EPT taxa among seasons. 136

Table C.18 Tukey HSD test results for differences in mean EPT taxa among habitat types. 136

Table C.19 Tukey HSD test results for differences in mean percentage EPT among the study reaches. 
Table C.20 Tukey HSD test results for differences in mean percentage EPT among seasons.

Table C.21 Tukey HSD test results for differences in mean percentage Rstrategist taxa among the study reaches. 138

Table C.22 Tukey HSD test results for differences in mean percentage Rstrategist taxa among seasons. 138

Table C.23 Tukey HSD test results for differences in mean cube root transformed percentage Diptera among the study reaches.

Table C.24 Tukey HSD test results for differences in mean cube root transformed percentage Diptera among seasons.

Table C.25 Tukey HSD test results for differences in mean cube transformed FBI among seasons

Table C.26 Tukey HSD test results for differences in mean cube transformed $\mathrm{H}^{\prime}$ among the study reaches.

Table C.27 Tukey HSD test results for differences in mean cube transformed $\mathrm{H}^{\prime}$ among seasons.

Table C.28 Tukey HSD test results for differences in mean cube transformed $\mathrm{H}^{\prime}$ among habitat type. 141

Table C.29 Tukey HSD test results for differences in mean cube root transformed relative shredder abundance among the study reaches. 142

Table C.30 Tukey HSD test results for differences in mean cube root transformed relative shredder abundance among the habitat types. 142 
Table C.31 Tukey HSD test results for differences in mean cube root transformed relative collector-gatherer abundance among the study reaches.

Table C.32 Tukey HSD test results for differences in mean cube root transformed relative predator abundance among seasons........................... 144

Table C.33 Parameter coefficient estimate of $\mathrm{pH}$ as a predictor of EPT taxa. ........ 145

Table C.34 Parameter coefficient estimate of $\mathrm{pH}$ as a predictor of \% EPT.............145

Table C.35 Parameter coefficient estimate of temperature $\left({ }^{\circ} \mathrm{C}\right)$ as a predictor of $\%$ R-strategist. 146

Table C.36 Parameter coefficient estimate of temperature $\left({ }^{\circ} \mathrm{C}\right)$ as a predictor of FBI. 147

Table C.37 Parameter coefficient estimate of $\mathrm{pH}$ as a predictor of $\mathrm{H}^{\prime}$..... 148 


\section{LIST OF FIGURES}

Page

Figure 1.1 Class I Watercourse and Lake Protection zone distances for confined channels in watersheds within the coastal anadromy zone. The various buffer zones are delineated starting with the watercourse transition line (WTL) and extending to the Outer Zone, $150 \mathrm{ft}$ (45.7 m) from the WTL. Figure adopted from the California Forest Practice

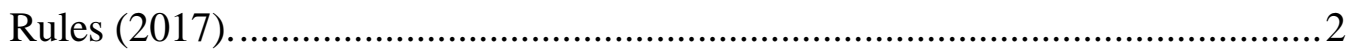

Figure 2.1 Location map of the Scotts Creek watershed (yellow outline) in Santa Cruz County, California. The shaded region shows the Little Creek subwatershed, the Swanton Pacific Ranch property boundary is delineated in red, and the location of the Landing 23 rain gage is marked by an orange point.

Figure 2.2 Cumulative rainfall at the Landing 23 rain gage for water years 2012-2017.

Figure 2.3 Geologic map with the Little Creek watershed outlined in white and the Swanton Pacific Ranch property boundary delineated in red. Qal (orange) - Quaternary alluvial deposits; Tsc (brown) Santa Cruz Mudstone; sch (purple) - schist; qd (pink) - quartz diorite; Tsm (yellow) - Santa Margarita Sandstone. (Brabb 1989).

Figure 2.4 1920 photograph of Shay railroad logging in the Santa Cruz Mountains (Swanton Pacific Railroad Society).... 
Figure 2.5 1956 Aerial photograph showing deposits from the 1955 debris torrent. Image from the Scotts Creek Watershed Council website.

Figure 2.6 The Lockheed fire burning on the southern ridgeline of the Little Creek watershed with Swanton Pacific Ranch's barn in the foreground (Dellamonica 2009). 16

Figure 4.1 Shaded relief map of the study reaches in Little Creek. The study reaches were named according to location in the watershed; Mainstem (MS), Upper Mainstem (UMS), North Fork (NF), Tranquility Flats (TF), Upper North Fork (UNF), South Fork (SF), and Upper South Fork (USF). 35

Figure 4.2 Longitudinal profiles of the study reaches derived in GIS using a 2011 digital elevation model. 37

Figure 4.3 Comparison of hardwood vs. conifer tree species through the seven study reaches in the Little Creek watershed, August 2016. Dominant hardwood species included red alder, tan oak, bay laurel, and big leaf maple. Dominant conifer species included coast redwood and Douglas-fir. 38

Figure 4.4 Comparison of total basal/hectare $(\mathrm{m} 2)$ through the study reaches, August 2016. Basal area was measured by measuring diameter at breast height $(\mathrm{DBH})$ of all trees within tenth acre plots. 39 
Figure 4.5 Study reach layout. Biological sampling and physical habitat observations occurred at 11 main transect locations (A-K). Physical habitat observations were also recorded at 10 supplemental inter-transect locations (AB-JK). (Ode 2007)................................................ 41

Figure 4.6 Surber sampler placed at the center of main transect NF-C....................42

Figure 5.1 NMDS plot of macroinvertebrate community composition (relative abundance). Final stress $(S)=0.13$. Label priority was given to most abundant families. Lower priority families that were obscured by higher priority families were represented by points. Families oriented more closely together were commonly observed together at the same sampling locations. 66

Figure 5.2 NMDS plot macroinvertebrate community composition (relative abundance) fitted with $95 \%$ confidence interval ellipses for the weighted average of each study reach.

Figure 5.3 NMDS plot of macroinvertebrate community composition (relative abundance) fitted with $95 \%$ confidence interval ellipses for the weighted average of each season. 68

Figure 5.4 NMDS plot of macroinvertebrate community composition (relative abundance) fitted with significant environmental variables $(\alpha=0.05)$. The significant linear associations of cross-sectional area $\left(\mathrm{XS}\right.$. Area; $\left.\mathrm{m}^{2}\right)\left(\mathrm{p}=0.001, \mathrm{R}^{2}=0.08\right)$ and solar radiation $\left(\mathrm{W} / \mathrm{m}^{2}\right)$ $\left(\mathrm{p}=0.024, \mathrm{R}^{2}=0.02\right)$ data to macroinvertebrate abundance were represented by vector arrows, with the length and direction of each 
arrow representing the magnitude and direction of the association.

The abundance plot was fitted with $95 \%$ confidence interval ellipses

for the weighted average of each habitat type $\left(\mathrm{p}=0.001, \mathrm{R}^{2}=0.06\right)$.

Figure 5.5 NMDS plot of macroinvertebrate community composition (relative abundance) fitted with significant water quality parameters $(\alpha=0.05)$. The significant linear associations of dissolved oxygen $(\%)\left(\mathrm{p}=0.02, \mathrm{R}^{2}=0.07\right)$ and $\mathrm{pH}\left(\mathrm{p}=0.003, \mathrm{R}^{2}=0.09\right)$ data to macroinvertebrate abundance was represented by vector arrows, with the length and direction of each arrow representing the magnitude and direction of the association.

Figure 5.6 NMDS plot of functional feeding group composition. Stress = 0.11. Functional feeding groups oriented more closely together were commonly observed together at the same sampling locations. 72

Figure 5.7 NMDS plot of functional feeding group composition fitted with 95\% confidence interval ellipses for the weighted average of each season.

Figure 5.8 NMDS plot of functional feeding group composition fitted with significant environmental variables $(\alpha=0.05)$. The significant linear associations of percentage shaded $\left(\mathrm{p}=0.038, \mathrm{R}^{2}=0.01\right)$, solar radiation $\left(\mathrm{W} / \mathrm{m}^{2}\right)\left(\mathrm{p}=0.001, \mathrm{R}^{2}=0.06\right)$, and cross-sectional area $\left(\right.$ XS.Area; $\left.\mathrm{m}^{2}\right)\left(\mathrm{p}=0.001, \mathrm{R}^{2}=0.05\right)$ data to functional feeding group composition were represented by vector arrows, with the length and direction of each arrow representing the magnitude and direction of 
the association. The abundance plot was fitted with $95 \%$ confidence interval ellipses for the weighted average of each habitat type

$\left(\mathrm{p}=0.001, \mathrm{R}^{2}=0.09\right)$

Figure 5.9 NMDS plot of functional feeding composition was fitted with significant water quality parameters $(\alpha=0.05)$. The linear fit of $\mathrm{pH}$ $\left(\mathrm{p}=0.017, \mathrm{R}^{2}=0.07\right)$ and temperature $\left(\mathrm{p}=0.04, \mathrm{R}^{2}=0.05\right)$ data to functional feeding group was represented by vector arrows, with the length and direction of each arrow representing the magnitude and direction of the association. 76

Figure A.1 Frontside of field data sheet.................................................. 105

Figure A.2 Backside of field data sheet. .................................................. 106

Figure A.3 Laboratory processing data sheet. ............................................ 107

Figure B.1 Shepard plot of macroinvertebrate community composition............ 108

Figure B.2 NMDS plot of macroinvertebrate abundance fitted with solar radiation $\left(\mathrm{W}^{*} \mathrm{~m}^{2}\right)$.

Figure B.3 NMDS plot of macroinvertebrate abundance fitted with crosssectional area $\left(\mathrm{m}^{2}\right)$ 110

Figure B.4 NMDS plot of macroinvertebrate abundance fitted with $\mathrm{pH}$.

Figure B.5 NMDS plot of macroinvertebrate abundance fitted with dissolved oxygen $(\%)$ 112

Figure B.6 Shepard plot of functional feeding group composition. 
Figure B.7 NMDS plot of functional feeding group composition fitted with fitted with $95 \%$ confidence interval ellipses for the weighted average of each study reach.

Figure B.8 NMDS plot of functional feeding group composition fitted with percent shaded.

Figure B.9 NMDS plot of functional feeding group composition fitted with solar radiation.

Figure B.10 NMDS plot of functional feeding group composition fitted with cross-sectional area $\left(\mathrm{m}^{2}\right)$

Figure B.11 NMDS plot of functional feeding group composition fitted with $\mathrm{pH}$. 118

Figure B.12 NMDS plot of functional feeding group composition fitted with temperature $\left({ }^{\circ} \mathrm{C}\right)$.

Figure C.1 Distribution of studentized residuals of the Density model from the study reach dataset.

Figure C.2 Distribution of studentized residuals of the \%EPT model from the study reach dataset. 126

Figure C.3 Distribution of studentized residuals of the \% R-strategist model from the study reach dataset.

Figure C.4 Distribution of studentized residuals of the \%Diptera model from the study reach dataset. 128

Figure C.5 Distribution of studentized residuals of the FBI model from the study reach dataset. 129 
Figure C.6 Distribution of studentized residuals of the $\mathrm{H}^{\prime}$ model from the study reach dataset. 130

Figure C.7 Distribution of studentized residuals of the $\% \mathrm{SH}$ model from the study reach dataset. 131

Figure C.8 Distribution of studentized residuals of the \%CG model from the study reach dataset.

Figure C.9 Distribution of studentized residuals of the Density model from the transect dataset.

Figure C.10 Distribution of studentized residuals of the Biomass model from the transect dataset.

Figure C.11 Distribution of studentized residuals of the EPT taxa model from the transect dataset.

Figure C.12 Distribution of studentized residuals of the \% EPT model from the transect dataset. 136

Figure C.13 Distribution of studentized residuals of the \% R-strategist model from the transect dataset.

Figure C.14 Distribution of studentized residuals of the \% Diptera model from the transect dataset. 138

Figure C.15 Distribution of studentized residuals of the FBI model from the transect dataset.

Figure C.16 Distribution of studentized residuals of the $\mathrm{H}^{\prime}$ model from the transect dataset. 140 
Figure C.17 Distribution of studentized residuals of the \%SH model

from the transect dataset.

Figure C.18 Distribution of studentized residuals of the \%CG model

from the transect dataset.

Figure C.19 Distribution of studentized residuals of the \%P model from

the transect dataset.

Figure C.20 Distribution of studentized residuals of the EPT taxa model

from the water quality sub-dataset.

Figure C.21 Distribution of studentized residuals of the \% EPT model

from the water quality sub-dataset.

Figure C.22 Distribution of studentized residuals of the \% R-strategist

model from the water quality sub-dataset.

Figure C.23 Distribution of studentized residuals of the FBI model from

the water quality sub-dataset.

Figure C.24 Distribution of studentized residuals of the $\mathrm{H}^{\prime}$ model from

the water quality sub-dataset.

Figure D.1 Exoskeleton of a stonefly (Plecoptera: Perlidae).

Figure D.2 Nick Macias with two dragonfly (Odonata: Cordulegastridae)

pupae collected at the Mainstem study reach.

Figure D.3 Tranquility Flats study reach at sampling location TF-J. 151

Figure D.4 Looking upstream at the North Fork study reach. 152

Figure D.5 Looking upstream at the Upper North Fork study reach. 153

Figure D.6 Large woody debris at the Upper South Fork study reach. 154 
Figure D.7 Brian Clark collecting stream shading data with the Solar Pathfinder $^{\mathrm{TM}}$ at the Upper South Fork study reach................................ 155 


\section{CHAPTER 1. INTRODUCTION}

Riparian zones are the interface between land and stream. Riparian areas typically support diverse, interconnected biological communities that play key roles in energy processing and nutrient cycling along the length of the channel gradient. Riparian vegetation along forested streams directly and indirectly controls the exchange of nutrients between terrestrial and aquatic ecosystems. In low-order (i.e., headwater) forested streams, litter derived from riparian vegetation is the dominant base of food chains (Cummins 2002). As stream order increases, riparian vegetation becomes less dense and more sunlight reaches the streambed. This promotes the production of photosynthetic organisms (e.g., algae and aquatic plants) which predominantly serve as the energetic base of riverine food webs in these reaches (Power 1992). Consequently, quantitative and qualitative aspects of riparian vegetation often serve as robust predictors of riverine ecosystem structure, function, and health (Jones et al. 2006).

Timber management practices within riparian zones have long been debated and explored. Today in California, a complex set of riparian management strategies is required. In 2009, the California State Board of Forestry and Fire Protection adopted the Anadromous Salmonid Protection (ASP) rule package, with an emphasis on protection measures for sensitive biota and important ecosystem processes. These protection measures, implemented in the form of Watercourse and Lake Protection Zones (WLPZs), are buffer zones that range from no-cut zones to varying degrees of tree removal and equipment limitations further from the channel, with requirements changing depending on the forest district. Figure 1.1 illustrates an example of a WLPZ designation for confined channels within the zone of anadromy. The goal of implementing buffer zones 
around streams is to leave riparian vegetation intact to a degree necessary to protect scenic and natural qualities and protect the beneficial uses of water (Cal Fire 2017). For watercourses with anadromous salmonids protected under state and federal Endangered Species Acts (Class I), silvicultural prescriptions are principally intended to enhance bank stability and stream shading through the establishment of high basal area and canopy retention (Table 1.1).

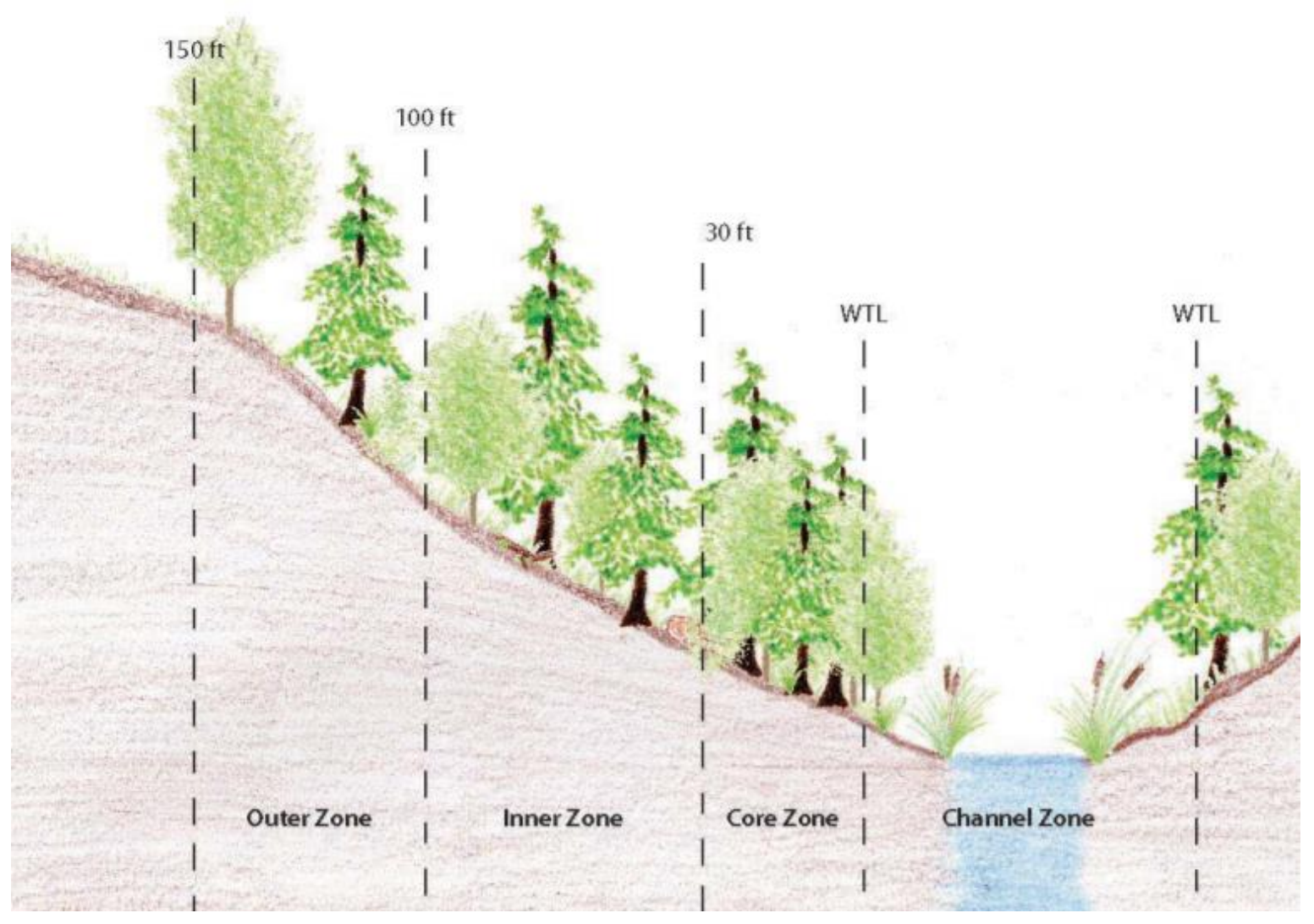

Figure 1.1 Class I Watercourse and Lake Protection zone distances for confined channels in watersheds within the coastal anadromy zone. The various buffer zones are delineated starting with the watercourse transition line (WTL) and extending to the Outer Zone, 150 $\mathrm{ft}(45.7 \mathrm{~m})$ from the WTL. Figure adopted from the California Forest Practice Rules (2017). 
Table 1.1 Prescribed protection measures for Class I Watercourse and Lake Protection Zones in the coastal anadromy zone (Cal Fire 2017).

\begin{tabular}{|c|c|c|c|c|c|c|}
\hline \multicolumn{7}{|c|}{ Pursuant to 14 CCR 916.9[936.9,956.9](f)(2) } \\
\hline $\begin{array}{c}\text { Zone } \\
\text { Designation }\end{array}$ & $\begin{array}{c}\text { Zone } \\
\text { width } \\
\text { (ft.) }\end{array}$ & \multicolumn{2}{|c|}{$\begin{array}{l}\text { Overstory Canopy } \\
\text { Cover }\end{array}$} & $\begin{array}{l}\text { Large Tree } \\
\text { Retention }\end{array}$ & $\begin{array}{c}\text { Silviculture } \\
\text { Requirements }\end{array}$ & $\begin{array}{l}\text { Operational } \\
\text { Requirements }\end{array}$ \\
\hline $\begin{array}{l}\text { Channel } \\
\text { Zone }\end{array}$ & Variable & \multicolumn{2}{|c|}{$\begin{array}{c}\text { Retain all trees except } \\
\text { per } 916.9 \text { [936.9, } \\
\text { 956.9] (e)(1) AF or } \\
916.9 \text { [936.9 956.9] (v) }\end{array}$} & $\begin{array}{c}\text { Retain all trees } \\
\text { except per } \\
916.9[936.9 \\
956.9](\mathrm{e})(1) \\
\text { A-F or } 916.9 \\
{[936.9956 .9]} \\
(\mathrm{v})\end{array}$ & $\begin{array}{c}\text { Retain all trees } \\
\text { except per } 916.9 \\
{[936.9,956.9]} \\
(\mathrm{e})(1) \mathrm{A}-\mathrm{F} \text { or } \\
916.9[936.9 \\
956.9](\mathrm{v})\end{array}$ & $\begin{array}{c}\text { No timber } \\
\text { operations } \\
\text { except per } 916.9 \\
{[936.9,956.9]} \\
\text { (e)(1) A-F or } \\
916.9[936.9 \\
956.9](\mathrm{v}) ; \\
\end{array}$ \\
\hline $\begin{array}{c}\text { Core Zone } \\
\text { per } 916.9 \\
{[936.9} \\
956.9] \\
(f)(2)(\mathrm{A})\end{array}$ & $30 \mathrm{ft}$. & \multicolumn{2}{|c|}{$\begin{array}{c}\text { Retain all trees except } \\
\text { per } 916.9 \text { [936.9, } \\
\text { 956.9] (e)(1) AF or } \\
916.9 \text { [936.9 956.9] (v) }\end{array}$} & $\begin{array}{c}\text { Retain all trees } \\
\text { except per } \\
916.9[936.9 \\
956.9](\mathrm{e})(1) \\
\text { A-F or } 916.9 \\
{[936.9956 .9]} \\
\text { (v) }\end{array}$ & $\begin{array}{c}\text { Retain all trees } \\
\text { except per 916.9 } \\
{[936.9,956.9](\mathrm{e})} \\
(1) \text { A-F or 916.9 } \\
{[936.9,956.9](\mathrm{v})} \\
\text { no sanitation } \\
\text { salvage except } \\
916.9(\mathrm{~s})(\mathrm{t}) \text { and }(\mathrm{u}) . \\
\end{array}$ & $\begin{array}{c}\text { No timber } \\
\text { operations } \\
\text { except per } 916.9 \\
{[936.9,956.9]} \\
\text { (e)(1) A-F or } \\
916.9[936.9, \\
956.9](\mathrm{v}) ;\end{array}$ \\
\hline $\begin{array}{c}\text { Inner Zone } \\
\text { per } 916.9 \\
{[936.9} \\
956.9] \\
(f)(2)(B)\end{array}$ & $70 \mathrm{ft}$. & $\begin{array}{c}80 \% \\
\text { Coast and } \\
\text { Southern } \\
\text { Forest } \\
\text { District of } \\
\text { Coastal } \\
\text { Anadromy } \\
\text { Zone per } \\
916.9 \\
{[936.9} \\
956.9] \\
\text { (f) }(2)(\mathrm{B}) 3 . \\
\end{array}$ & $\begin{array}{c}70 \% \text { in } \\
\text { Northern } \\
\text { Forest } \\
\text { District of } \\
\text { Coastal } \\
\text { Anadromy } \\
\text { Zone per } \\
916.9 \\
\text { [936.9 } \\
956.9] \\
\text { (f)(2)(B)3 }\end{array}$ & $\begin{array}{l}13 \text { largest trees } \\
\text { /ac. per } 916.9 \\
\text { [936.9 956.9] } \\
\text { (f)(2)(B)4. }\end{array}$ & $\begin{array}{c}\text { Increase QMD; No } \\
\text { sanitation salvage } \\
\text { except } 916.9(\mathrm{~s})(\mathrm{t}) \\
\text { and }(\mathrm{u}) ; \\
\text { commercial } \\
\text { thinning or single } \\
\text { tree selection only. }\end{array}$ & $\begin{array}{c}\text { Preferred } \\
\text { Management } \\
\text { Practices in } \\
\text { 916.9 [936.9, } \\
\text { 956.9] (f)(2)(D) }\end{array}$ \\
\hline $\begin{array}{c}\text { Outer Zone } \\
\text { per } 916.9 \\
{[936.9} \\
956.9] \\
(\mathrm{f})(2)(\mathrm{C}) \\
\text { Outer Zone } \\
\text { applicable } \\
\text { only where } \\
\text { even-aged } \\
\text { regeneration } \\
\text { used } \\
\text { adjacent to } \\
\text { the WLPZ } \\
\end{array}$ & $50 \mathrm{ft}$. & $\begin{array}{r}50 \% \text { per } 9 \\
956.9](f\end{array}$ & $\begin{array}{l}6.9[936.9 \\
(2)(C) .1\end{array}$ & NA & $\begin{array}{l}\text { Commercial } \\
\text { thinning or single } \\
\text { tree selection only; } \\
\text { Retain wind firm } \\
\text { trees. }\end{array}$ & $\begin{array}{c}\text { Preferred } \\
\text { Management } \\
\text { Practices in } \\
\text { 916.9 [936.9, } \\
\text { 956.9] (f)(2)(D) }\end{array}$ \\
\hline $\begin{array}{c}\text { Special } \\
\text { Operating } \\
\text { Zone per } \\
916.9[936.9 \\
956.9] \\
\text { (f) }(2)(\mathrm{E})\end{array}$ & $50 \mathrm{ft}$. & & & NA & $\begin{array}{l}\text { SOZ applicable } \\
\text { only where even- } \\
\text { aged regeneration } \\
\text { used adjacent to } \\
\text { the WLPZ. Retain } \\
\text { understory and } \\
\text { midstory trees per } \\
\text { 916.9 [936.9, } \\
\text { 956.9] (f)(2)(E) }\end{array}$ & $\begin{array}{l}\text { All other Forest } \\
\text { Practice Rules }\end{array}$ \\
\hline
\end{tabular}


Prior to the development of the ASP rule package, the Board of Forestry appointed a Technical Advisory Committee to conduct a review of the scientific literature on forest management effects on riparian functions in watersheds with anadromous salmonid fisheries. The committee's final report advised that "one size fits all" riparian buffer strategies may fall short in protecting or enhancing key riparian functions (SWC 2008). Furthermore, given the known biotic and nutrient influences of riparian vegetation on riverine ecosystem function, the committee concluded that targeted management practices could potentially be used to sustain and enhance stream ecosystem health. Accepting this advice, the Board adopted 14 CCR $§ 916.9[936.9,956.9]$ (v) that allows for spatially-explicit riparian management under the condition that the proposed management provides benefits to riparian zone functions equal to or more than those expected to result from management requirements of the standard ASP WLPZ rules (Cal Fire 2017). However, providing justification for a riparian vegetation treatment is challenging when the expected biological response is largely unknown.

Benthic macroinvertebrate community structure has become a widely-used metric to evaluate riverine biological condition and health. Macroinvertebrates are indicators of water quality because they display a wide range of tolerances to pollutants and physical stressors depending on taxa (Rosenberg and Resh 1993, Barbour et al. 1999, Worcester 2005, Ode 2007, Alvarez-Cabria et al. 2010, Reid et al. 2010, Lunde et al. 2013). Moreover, macroinvertebrates are essential trophic linkages in aquatic food webs, making basal energy inputs available to higher trophic levels (Rosi-Marshall et al. 2016). Classifying macroinvertebrates by their respective feeding strategies can describe localized food web dynamics. Therefore, monitoring responses of localized assemblages 
to environmental disturbance can allow for an effective analysis of impacts on stream health and ecosystem function.

Understanding energy and nutrient transfer through lotic (i.e. flowing) ecosystems provides a framework for integrating predictable biological responses to environmental change as a result of management actions. Identifying the primary biotic and abiotic factors that structure instream communities allows for a holistic approach to riparian management by making it possible for management practices to protect and enhance specific relationships. The goal of this project is to characterize macroinvertebrate assemblages and associated physical habitat characteristics along the channel gradient of Little Creek (a tributary to Scotts Creek in Santa Cruz County, California) to understand biological conditions and, ultimately, predict biologic responses to future canopy manipulation.

\subsection{Study Objectives}

This thesis has three objectives:

- Characterize macroinvertebrate community structure in representative stream reaches of the Little Creek watershed.

- Determine the influence of various physical habitat conditions on macroinvertebrate community structure.

- Create a framework from which biological responses to riparian canopy manipulation may be predicted. 


\section{CHAPTER 2. BACKGROUND}

\subsection{Study Location}

The study location is Little Creek on Cal Poly's Swanton Pacific Ranch near Davenport, California (Figure 2.1). Swanton Pacific Ranch is a $12.9 \mathrm{~km}^{2}$ property owned by Cal Poly Corporation and managed by the College of Agriculture, Food, and Environmental Sciences for educational and research purposes. The Little Creek watershed is an approximately $4.8 \mathrm{~km}^{2}$ drainage characterized by steep inner-gorge areas and dense riparian vegetation. It is selectively harvested for coast redwood (Sequoia sempervirens) and Douglas-fir (Pseudotsuga menziesii) at 10-15 year intervals as part of a non-industrial timber management plan (NTMP). Little Creek is a perennial tributary to Scotts Creek, which flows into the Pacific Ocean about $19 \mathrm{~km}$ north of Santa Cruz, California. Little Creek contains $1^{\text {st }}$ and $2^{\text {nd }}$ order stream channels as delineated by $1.0 \mathrm{~m}$ resolution LiDAR (Strahler 1957). The Scotts Creek watershed, considered an ecologic hotspot, encompasses at least $10-12 \%$ of California's native flora (West 2016) and is recognized as critical habitat for endangered coho salmon (Oncorhynchus kisutch) and threatened steelhead trout (anadromous Oncorhynchus mykiss). 


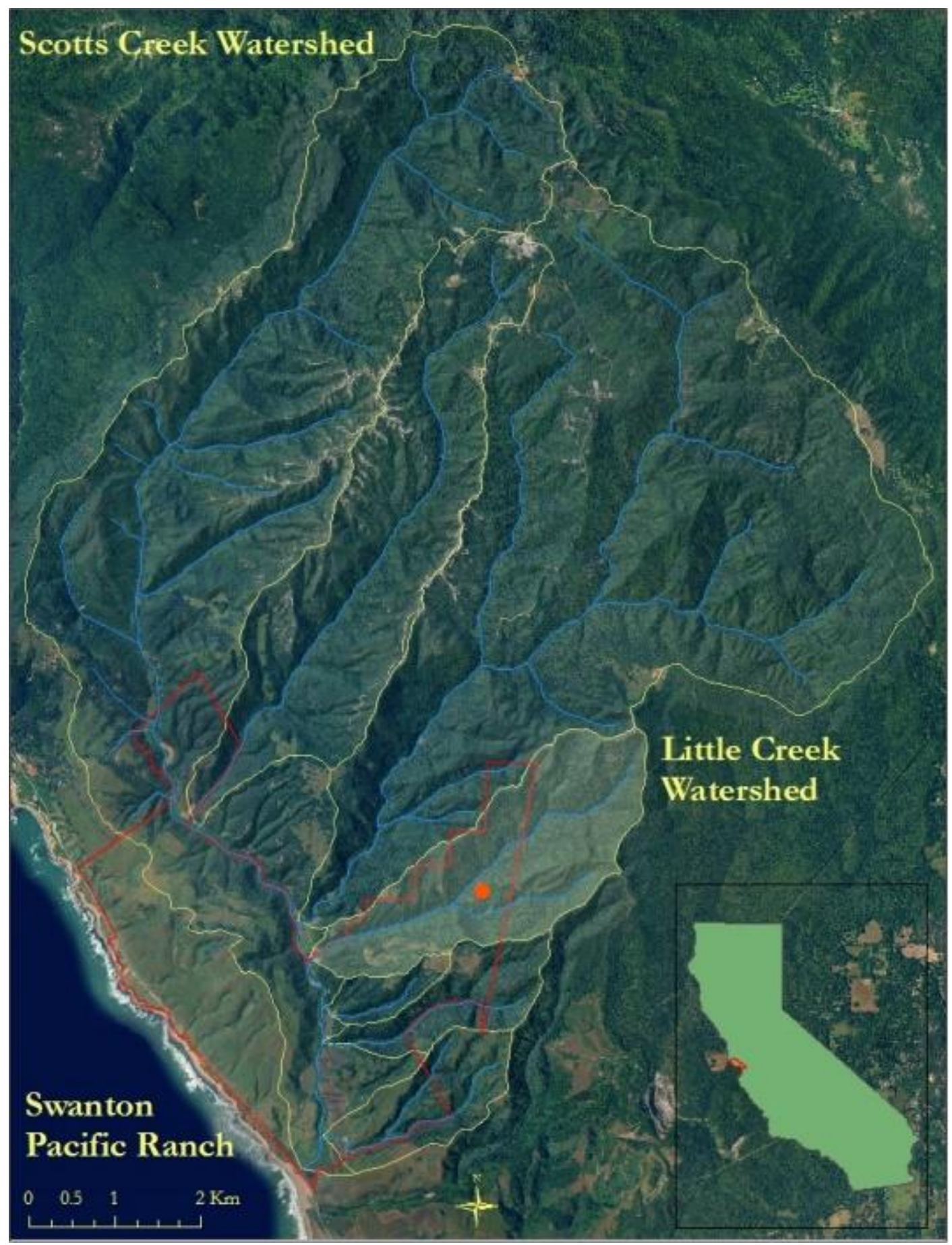

Figure 2.1 Location map of the Scotts Creek watershed (yellow outline) in Santa Cruz County, California. The shaded region shows the Little Creek subwatershed, the Swanton Pacific Ranch property boundary is delineated in red, and the location of the Landing 23 rain gage is marked by an orange point. 


\subsection{Climate}

The Little Creek watershed is influenced by a Mediterranean climate with cool, wet winters and foggy, dry summers. Weather is driven by elevation and aspect. In the summer, a persistent marine layer is present along the coast and lower elevations while ridgeline locations remain sunny. Most of the annual precipitation falls between October and April. Rainfall is driven by orographic processes and varies with elevation; mean annual precipitation is $75 \mathrm{~cm}$ at sea level and $125 \mathrm{~cm}$ at the upper ridgelines (Perkins 2012). At the time of the first sampling event in May 2015, California was experiencing a period of prolonged drought (USGS 2017). Annual precipitation was below average statewide in the four years preceding the study. Rainfall in the Little Creek watershed followed this trend (Figure 2.2). Precipitation data was collected at the Landing 23 rain gage, a tipping bucket gage located on the hillslope that separates the North Fork and the South Fork of Little Creek (Figure 2.1). Average annual rainfall at this location between 1998 and 2017 was $96.98 \mathrm{~cm}$. 


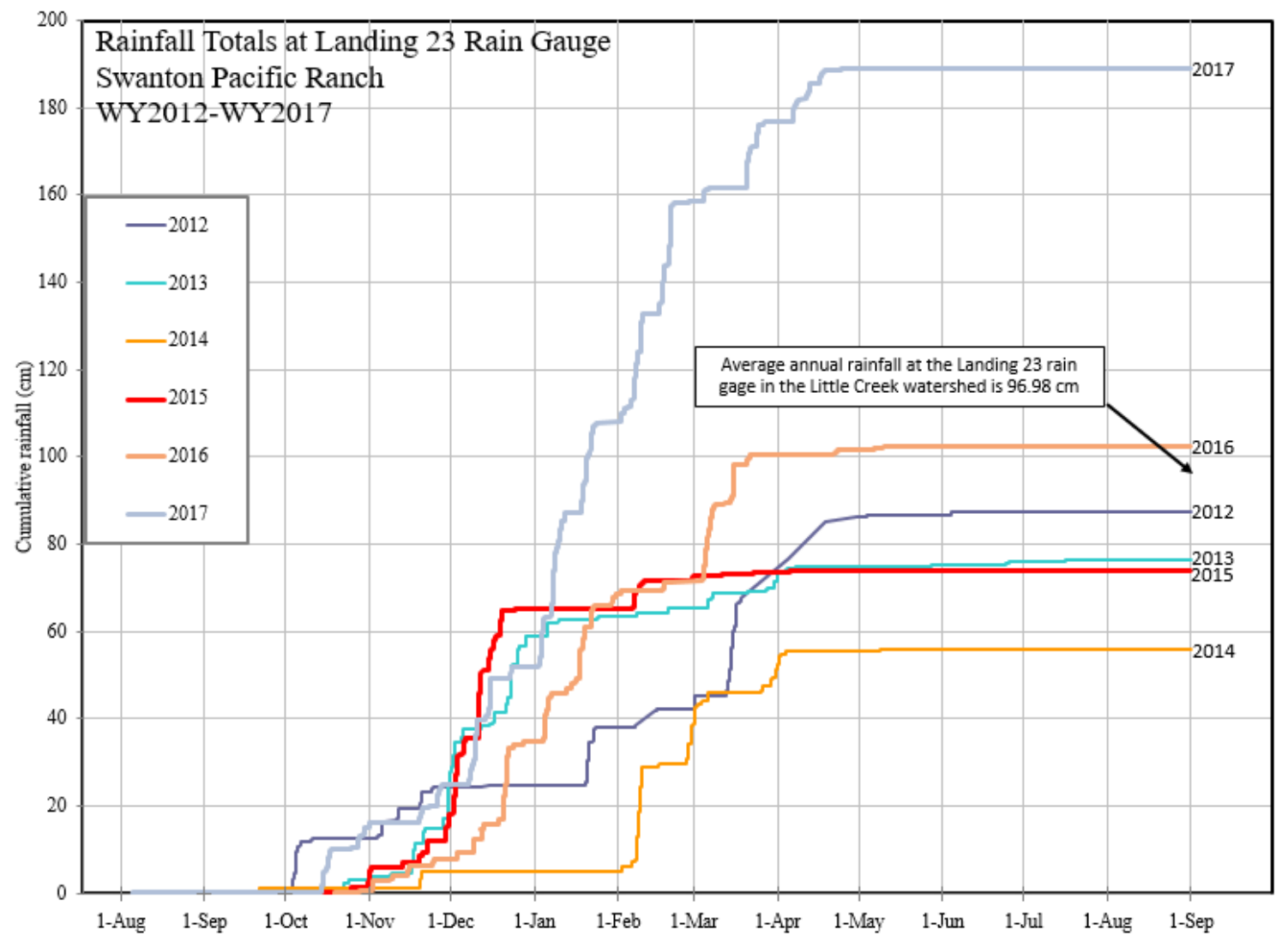

Figure 2.2 Cumulative rainfall at the Landing 23 rain gage for water years 2012-2017. 


\subsection{Geology and Geomorphology}

The Little Creek watershed is located on the southwest tilted Ben Lomond Mountain tectonic block, west of the San Andreas Fault. A restraining bend in the fault has caused rapid regional uplift, resulting in incised drainages with steep slopes (Anderson 1994). Elevation within the watershed ranges from $9 \mathrm{~m}$ at the confluence with Scotts Creek to $550 \mathrm{~m}$ on the highest ridgeline, and hill slopes of $70 \%$ or greater are common (White 2010). The riparian zone is characterized by steep inner-gorge areas with an average channel gradient of $45 \%$. Erosional events such as landslides, rotational slumps, and bank failures are common. Major changes in stream morphology typically correspond with high flow events and the presence of large woody debris (LWD) (Perkins 2012).

The watershed overlies four different rock types; Santa Cruz Mudstone, Santa Margarita Sandstone, quartz diorite, and metamorphic schist and marble (Figure 2.3). The Santa Cruz Mudstone and Santa Margarita Sandstone overlie quartz diorite and metamorphic basement rock. Sedimentary rock substrate is more prevalent in the lower watershed whereas substrate in the upper watershed is dominated by quartz diorite and schist (B. Dietterick pers. comm. 2015). The sedimentary substrate present has a relatively low density, making it highly mobile in moderate stream discharges. Bedrock channel bottoms are common in the upper watershed. 


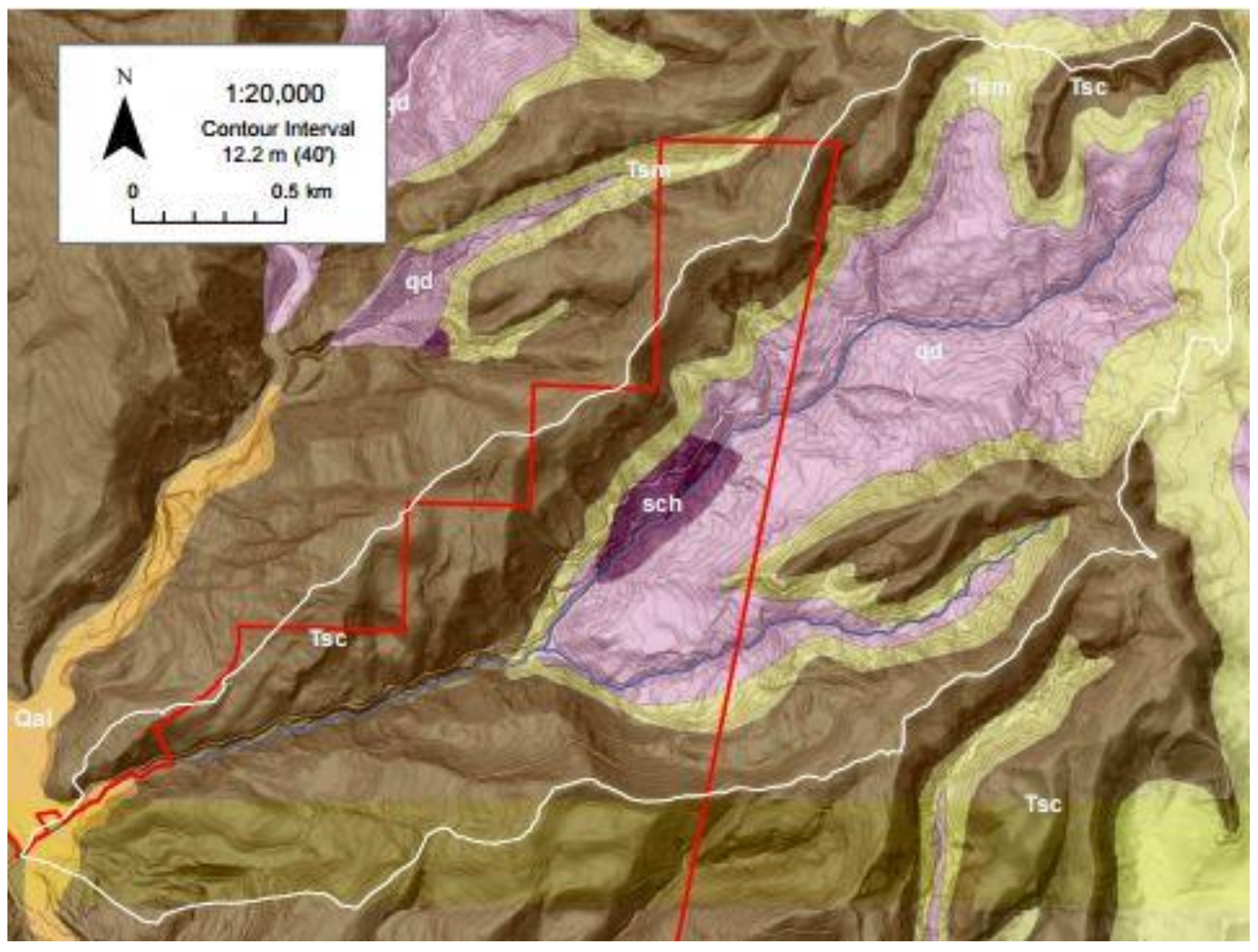

Figure 2.3 Geologic map with the Little Creek watershed outlined in white and the Swanton Pacific Ranch property boundary delineated in red. Qal (orange) - Quaternary alluvial deposits; Tsc (brown) - Santa Cruz Mudstone; sch (purple) - schist; qd (pink) quartz diorite; Tsm (yellow) - Santa Margarita Sandstone. (Brabb 1989). 


\subsection{Vegetation}

The Little Creek watershed is located within the narrow native range of coast redwood and is host to a diverse range of plant communities and forest types. A survey conducted along Little Creek road which parallels the mainstem and the North Fork of Little Creek, revealed over 120 plant species (West 2016). Dominant vegetation type in the Little Creek watershed changes with elevation. The riparian zone along the lower mainstem is dominated by an even-aged stand of red alder (Alnus rubra) with tanoak (Notholithocarpus densiforus), bay laurel (Umbellularia californica), and big leaf maple (Acer macrophyllum) also present. Red alder becomes less common in the North and South Forks as the gradient increases and the riparian canopy shifts to a mixed conifer assemblage of second-growth coast redwood and Douglas-fir. Common understory vegetation in the riparian zone includes redwood sorrel (Oxalis oregana), western sword fern (Polystichum munitum), five-finger fern (Adiantum aleuticum), lady fern (Athyrium filix-femina), nightshade (Atropa belladonna), California blackberry (Rubus ursinus), stinging nettle (Urtica dioica), and poison oak (Toxicodendron diversilobum). The upper ridgelines are colonized by knobcone pine (Pinus attenuata) and various chaparral species.

\subsection{Land Use and History}

Native Americans first settled the greater Santa Cruz, California area sometime between 1200 and 5000 years ago (Billiter 1985). These first known inhabitants were part of the Ohlone tribe. The coastal Ohlone people lived in settlements and did not migrate seasonally. They subsisted off fishing, hunting, and gathering. Anthropogenic burning was used as a method of landscape management, occasionally burning large areas of land 
to encourage colonization of favorable plant species and to increase access for hunting (Stephens and Fry 2005). Between 1770 and 1835, missionization destabilized the Ohlone tribe, and disease, disruption of environmental resources, low birth rates, and forced conversion caused their population to gradually collapse (Scaramozzino 2015). In 1843, the Mexican government granted Ramon Rodriguez and Francisco Alviso the property Agua Puerca y Las Trancas, land that is encompassed partly by Swanton Pacific Ranch today. In 1867, it was sold to James Archibald who managed it as a dairy. Archibald hired a Swiss dairyman, Ambrogio Gianone, to run the dairy. Gianone built the cheese house, Casa Verde, and the barn in the late 1800's which all stand today. In the early 1900's, the Santa Cruz Mountains were heavily logged and the entire Little Creek watershed was clearcut by the San Vicente Lumber Company using railroad logging and slash and burn techniques (Figure 2.4).

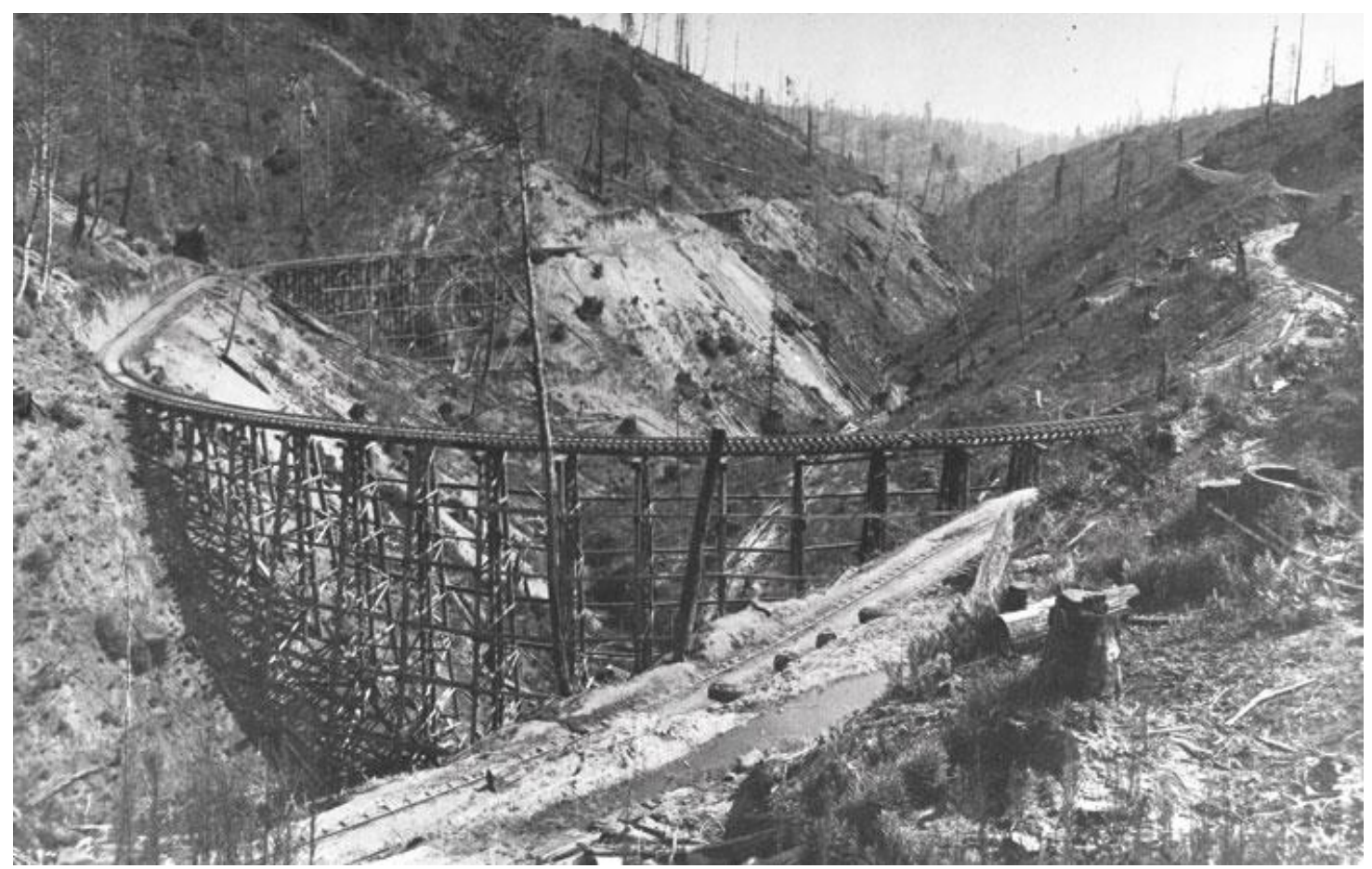

Figure 2.4 1920 photograph of Shay railroad logging in the Santa Cruz Mountains (Swanton Pacific Railroad Society). 
In December of 1955, a catastrophic debris torrent ripped through the Little Creek basin and claimed the life of a Swanton Valley resident. Although the exact origin of this event remains uncertain, contemporary LiDAR imagery suggests that the debris torrent originated from a large landslide in the South Fork subwatershed. When the stream water held behind the slide eventually broke through the debris dam, it scoured the entire length mainstem Little Creek before ultimately depositing debris and sediment in the Scotts Creek floodplain near the Little Creek confluence and upstream along Little Creek (Figure 2.5). The dominant stand of even-aged red alder present adjacent to the mainstem today was established following this debris flow event. 


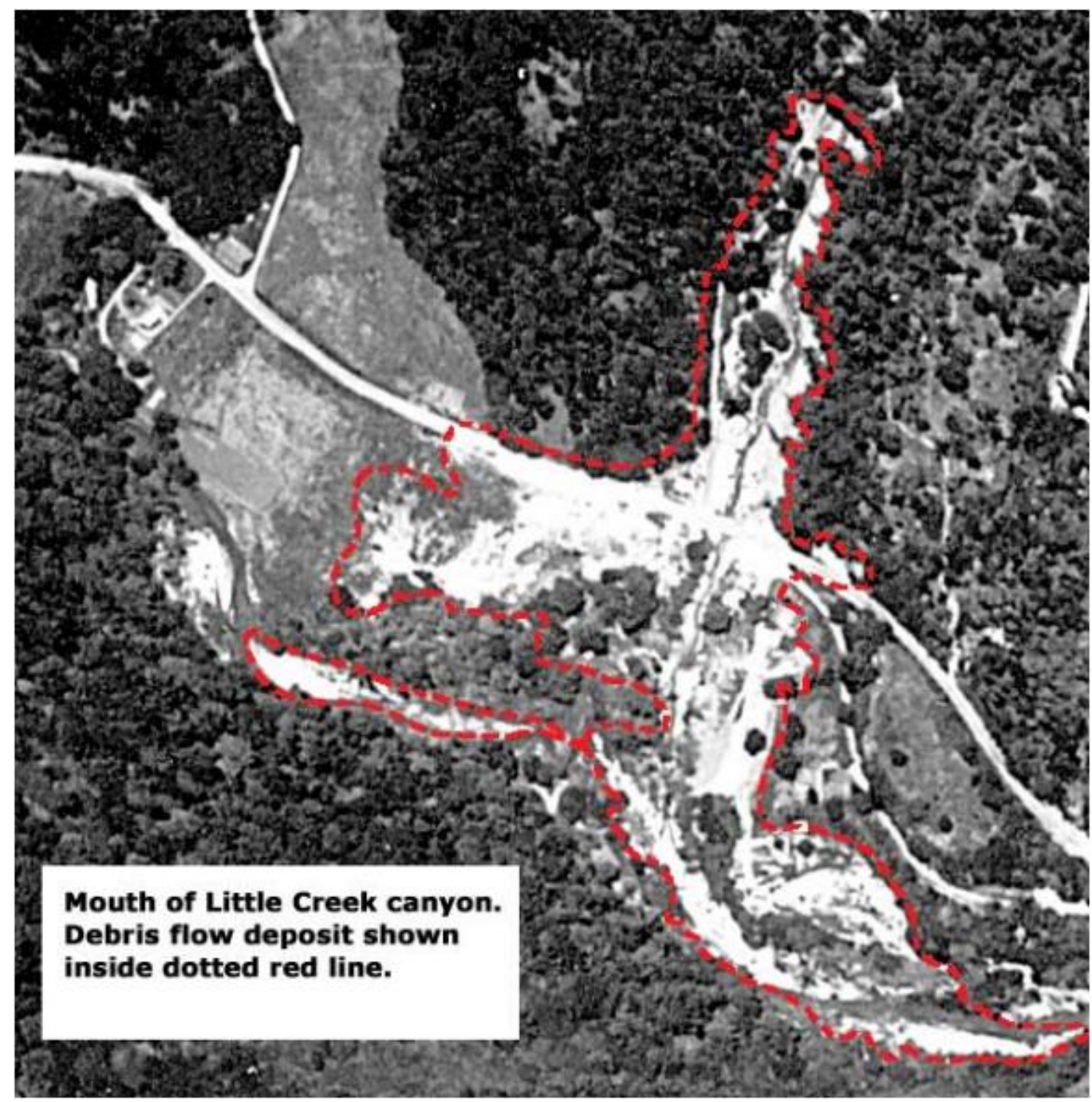

Figure 2.5 1956 Aerial photograph showing deposits from the 1955 debris torrent. Image from the Scotts Creek Watershed Council website. 
At 7:16 pm on 12 August, 2009, the Lockheed Fire started near the Lockheed Martin Facility outside of Bonny Doon, California (Dellamonica 2009). The fire was wind driven and quickly spread to the south, igniting ridgeline and hillslope areas in its path and backburning down into canyons. In total, the Lockheed Fire burned 7,817 acres over the course of more than 10 days and cost $\$ 26.6$ million to extinguish. Approximately $90 \%$ of the Little Creek watershed was burned. Fire intensity varied with topography and aspect, with highest burn severity occurring on southern facing slopes and ridgelines comprised of knobcone pine and chaparral species. A LWD survey indicated that red alder LWD in mainstem Little Creek increased by $245 \%$ in the 5 years following the fire (Theobald 2014). Effects of the fire are still present today as areas within the burn zone were colonized by early successional species and fire stressed trees continue to fall.

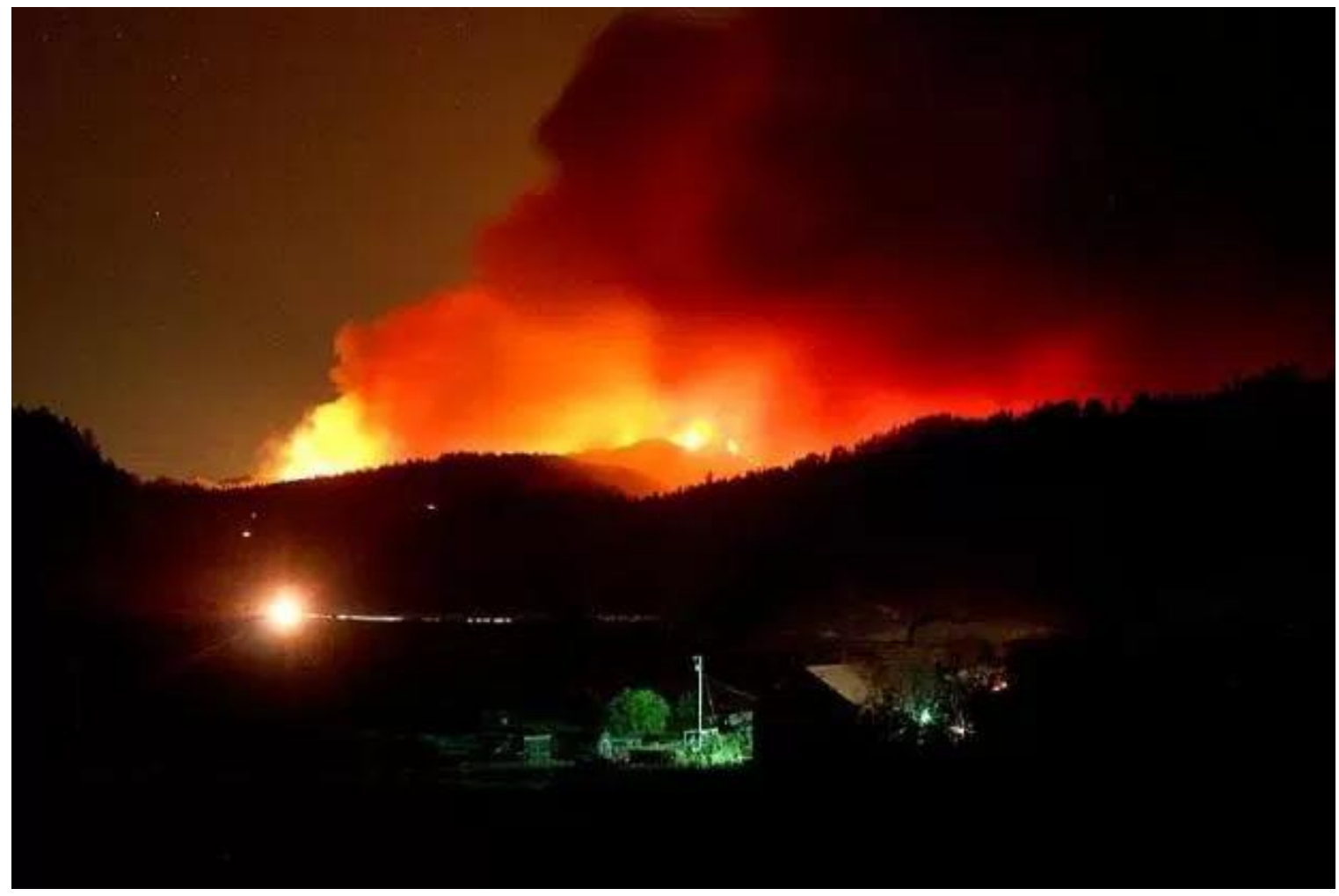

Figure 2.6 The Lockheed fire burning on the southern ridgeline of the Little Creek watershed with Swanton Pacific Ranch's barn in the foreground (Dellamonica 2009). 
Today, most of the Little Creek watershed is owned by Cal Poly Corporation as part of its Swanton Pacific Ranch. The property was gifted to Cal Poly by Albert B. Smith in 1993. Al, a Cal Poly alumnus and founder of Orchard Supply Hardware, wanted the ranch to be a living-learning laboratory for students to gain hands-on experience in natural resource management. The Little Creek watershed is currently managed under a non-industrial timber harvest plan (Swanton Pacific Ranch 2015), sustaining selective harvests every 10-15 years. The goal of this management document is to maintain a perpetual sustainable yield and a contiguous habitat component for wildlife. The Little Creek watershed is the school forest of Cal Poly's Natural Resources Management and Environmental Sciences Department, and provides educational and research opportunities for students in the College of Agriculture, Food, and Environmental Sciences. Approximately 500 students visit Swanton Pacific Ranch annually for field trips, short courses, internships, and research projects (B. Dietterick pers. comm. 2015). 


\section{CHAPTER 3. LITERATURE REVIEW}

Understanding relationships between characteristics of the physical environment and the structure and function of riverine communities are important for assessing the impacts of environmental disturbances within stream and riparian ecosystems. Identifying spatial and temporal variability in community composition provides the information necessary to make inferences regarding biologic responses to environmental change (e.g., natural environmental gradients, natural disturbances, land management practices, etc.). However, community structure can be highly variable over both time and space, making it difficult to determine the influence of physical habitat characteristics. Nonetheless, understanding the inherent variability of these communities can inform energy flow within a system and identify areas of biological productivity. Establishing primary energy pathways in an ecosystem can guide management strategies to benefit ecosystem function by influencing key relationships. The purpose of this literature review is to identify known relationships between physical habitat characteristics and associated stream macroinvertebrate communities.

\subsection{Food Web Dynamics of Lotic Ecosystems}

Lotic ecosystems are unique from most other ecosystems because they function in a state of continuous physical change. An ecosystem can be described by the way energy and material is processed, partitioned, and transferred among organisms at different trophic levels (Pickett and Cadenasso 2002). In the case of streams and rivers, energy processing occurs throughout the entire river network and is the product of myriad biotic and abiotic interactions (Richardson et al. 2006). Biotic communities are largely constrained by the quantity and quality of available energy resources and thus 
assemblages are highly variable within and among streams (Naiman et al. 1992). Basal energy sources in lotic systems are coarsely classified as being either of autochthonous or allochthonous origin, depending on whether they originate from within the system (e.g., bacteria, fungi, and autotrophic organisms) or outside the system (e.g., terrestrial organic matter and leaf litter), respectively (Cushing and Allan 2001). Community structure is context dependent and influenced both by the availability of energy resources (bottom-up controls) and by predatory consumption or environmental disturbances (top-down controls) (Power 1992). The availability of energy sources is the foundation of all subsequent trophic interactions in lotic systems, especially detrital-based food webs (McIntosh et al. 2005). As consumers at intermediate trophic levels, macroinvertebrates are subject to both bottom-up and top-down forces and serve as a central connection through which these ecological effects are propagated (Wallace and Webster 1996).

Benthic macroinvertebrates are a key linkage in riverine food webs because they process basal energy sources and likewise serve as prey for higher trophic levels such as fish (Rosenberg and Resh 1993). Hence, macroinvertebrate community composition provides important insight into stream ecology and food web dynamics (Rosi-Marshall et al. 2016). Food webs in forested stream ecosystems are typically fueled by allochthonous inputs (Vannote et al. 1980, Cheshire et al. 2005). Leaf litter that enters a lotic system is colonized and mechanically processed by microorganisms and macroinvertebrates (Gessner et al. 1999) which generates various size fractions of particulate organic matter that can be further processed by additional constituents of the food web (Cross et al. 2007). Characterizing aquatic food webs provides insight into energy and nutrient transfer through an ecosystem and offers a framework for integrating predictable 
biological responses to alterations in food resource availability in lotic systems (Vannote et al. 1980, Cross et al. 2007).

The River Continuum Concept (Vannote et al. 1980) predicts that lotic systems represent a continuous gradient of physical conditions from headwaters to mouth, and that these physical conditions structure biological communities. In unaltered stream systems, a continuum of species replacements functions to distribute energy utilization through space and time, with downstream communities formed based on the energy processing inefficiencies of upstream communities in the same river network. Classifying macroinvertebrates based on their feeding strategies effectively describes the distribution and utilization of energy along the channel gradient. However, this approach only provides indirect evidence of food use by macroinvertebrates and may lead to erroneous inferences regarding patterns of resource utilization by macroinvertebrates in food webs (Rosi-Marshall et al. 2016). Describing instream communities by established metrics of community structure allows for assemblages of different lotic systems to be compared and for patterns in community structuring to be identified and interpreted (Vannote et al. 1980, Cross et al. 2007, Rosi-Marshall et al. 2016).

\subsection{Metrics of Macroinvertebrate Community Structure}

Macroinvertebrates are commonly classified according to various feeding strategies: shredders, collector-gatherers, collector-filterers, scrapers, and predators. Functional feeding group composition is used to describe food chain interactions (Vannote et al.1980, Hawkins et al. 1982, Beche et al. 2006, Jackson et al. 2007, Melody and Richardson 2007, Oliver et al. 2012). Shredders colonize and mechanically process coarse particulate organic matter (CPOM; particle size > $1.0 \mathrm{~mm}$ ) (Vannote et al. 1980) 
which results in the production of fine particulate organic matter (FPOM; particle size 0.5 $\mu \mathrm{m}$ to $1.0 \mathrm{~mm}$ ) which is subsequently processed by collector-gatherers and/or collectorfilterers. Collector-gatherers harvest particles settled on the streambed, whereas, collector-filterers utilize specialized anatomical structures to capture and consume particulate matter suspended in the water column. Scrapers graze or scrape primary producers, such as periphyton and attached algae, from mineral and organic substrates. Predators feed on the tissue of other organisms. It has been shown that anthropogenic disturbances can cause shifts in stream food web structure that adversely affect energy flow and alter longitudinal patterns in fish and invertebrate community composition (Gray and Ward 1982, Cross et al. 2013, Wellard Kelly et al. 2013, Hawkins et al. 2015,). Therefore, spatiotemporal patterns in the relative proportions of different functional feeding groups can be used to make inferences about food web structure and function (Oliver et al. 2012, Wellard Kelly et al. 2013).

Macroinvertebrates display a wide range of tolerances to pollutants and physical stressors depending on taxa (Rosenberg and Resh 1993, Barbour et al. 1999, Worcester 2005, Ode 2007, Alvarez-Cabria et al. 2010, Reid et al. 2010, Lunde et al. 2013). Consequently, there are several common metrics of biotic condition that incorporate sensitivity to pollution and other disturbances. The most widely used metric is the proportion of EPT taxa (Barbour et al. 1999, Ode 2007, Alvarez-Cabria et al. 2010, Lunde et al. 2013,) which is defined as the proportion of the community represented by the insect orders Ephemeroptera (Mayflies), Plecoptera (Stoneflies), and Trichoptera (Caddisflies). The Hilsenhoff Family Biotic Index (FBI) is a composite index of community tolerance that ranges from 0 to 10 , where index values $>4$ indicate poor 
environmental conditions, values between 4 and 3.5 indicate moderate conditions, and values < 3.5 good conditions. (Hilsenhoff 1987). Instream community response to environmental disturbance can also be assessed by monitoring the proportion of Rstrategist taxa (Verkaik et al. 2015). These are taxa from the families Chironomidae (order Diptera), Simuliidae (order Diptera), and Baetidae (order Ephemeroptera), thought to be disturbance adapted because of their short generation times, high fecundity, and high dispersal rates (Zilli and Marchese 2011). A study in South America evaluated the effect of hydraulic connectivity on community structuring by comparing macroinvertebrate assemblages in a large river to assemblages found in the secondary channels of the same river. Significantly higher proportions of R-strategist taxa were observed in the secondary channel which exhibited intermittent flow regimes (Zilli and Marchese 2011). Proportion of R-strategist taxa has also been used to evaluate instream response to wildfire (Malison and Baxter 2010, Bixby et al. 2015, Verkaik et al. 2015). Diversity indices, such as the Shannon's Diversity Index, are commonly used in macroinvertebrate assemblage studies to compare diversity between sites (Sponseller et al. 2001, Beche et al. 2006). Macroinvertebrate community composition at different sites can compared using a similarity index. The Sorensen index is commonly used to describe the percentage of overlap in the taxa present between two sites (Kiffney et al. 2004, Beche et al. 2006).

Certain metrics are commonly used to characterize biological productivity. Total invertebrate biomass (standing stock) is often estimated by using established taxonspecific body length to mass relationships (Smock 1980, Benke et al. 1999, Sabo et al. 2002). Length-mass regression is the most commonly used technique for estimating 
biomass from samples because direct measurements of biomass are often impractical or impossible (Sabo et al. 2002). Sampling methods that utilize a set sampling area provide a spatially quantitative measure of the benthic invertebrate abundance and are more appropriate for most statistical analyses. Absolute density can be calculated by dividing the total number of individuals in a sample by the sampling area (Hawkins et al. 1982, Lesage et al. 2005).

\subsection{Statistical Procedures}

Identifying significant drivers of community structure requires multiple hypothesis tests to be run. Analysis of variance (ANOVA) is a well-established parametric technique for comparing means across groups (Sokal and Rohlf 1981) and is routinely applied to detect differences in macroinvertebrate community composition (Gray and Ward 1982, Hawkins et al. 1982, Beche et al. 2006, Oliver et al. 2012). For example, Bruce (2002) employed two-way ANOVA to assess differences in macroinvertebrate composition between study sties and sampling seasons in a Colorado watershed. Correspondingly, Li (2002) utilized ANOVA to test for differences in macroinvertebrate community structure among 16 western Oregon streams. Overall, the purpose of these analytical procedures is to identify community-wide changes or differences. Once significant differences are established, inferences may be made about the specific mechanisms that influence the observed community structure. ANOVA has the ability to partition variance in community structure to environmental variables (Norris and Georges 1992).

Conversely, ordination techniques are frequently utilized to explore patterns in community structuring. Ordination techniques typically illustrate compositional 
dissimilarity using ecological distance measures (e.g., Euclidean distance, Manhattan distance, Sorenson distance, and Bray-Curtis distance; McCune and Grace 2002) that condense differences in species composition and relative abundance between communities in a single distance statistic (Faith et. al. 1987). Ecologists favor the BrayCurtis dissimilarity calculation because it is not influenced by changes in units, additions/removals of species that are not present in two communities, the addition of a new community, and differences in total abundances when relative abundances are the same (Legendre and Legendre 1998). Non-metric multidimensional scaling (NMDS) is commonly regarded as the most robust unconstrained ordination method in community ecology (Minchin 1987). Unlike other ordination techniques which use abundance counts, NMDS uses rank orders and is therefore an extremely flexible technique that is compatible with a variety of different kinds of data (Clarke 1993). Importantly, NMDS is widely recommended for community-level analyses because it is a robust method for data that are non-normal or are on arbitrary, discontinuous, or otherwise questionable scales (McCune and Grace 2002). A study comparing two riffle-based sampling protocols utilized NMDS to depict differences in community structure metrics between the two procedures (Peterson and Zumberge 2006). A study on the Kootenai River in Northern Idaho and Western Montana used NMDS to depict the effect of nutrient addition on assemblage structuring and found it to be a powerful and sensitive tool (Shafii et al. 2013). A study in the central North Island of New Zealand used NMDS to assess the multivariate structure of the macroinvertebrate community and overlay environmental variables onto ordination plots (Tonkin 2014). Non-metric multidimensional scaling is often the method of choice for graphically representing community relationships and 
associated physical habitat characteristics which can be variable over space and time (Clarke 1993).

\subsection{Seasonal Variation}

Macroinvertebrate community structure is influenced by a wide range of physical, chemical, and biological attributes that often exhibit strong yet predictable season variability (Kosnicki and Sites 2010). This is especially true for streams in Mediterranean climate regions that experience distinct wet and dry seasons. In such systems, seasonal change is often reflected by macroinvertebrate assemblages that display cyclical patterns, with autumn and winter assemblages being more similar than spring and summer assemblages (Leunda et al. 2009, Armitage et al. 2001). In a multi-year survey of intermittent and perennial stream systems in northern California, Beche et al. (2005) reported that distinct invertebrate communities were present in each season, particularly in the intermittent stream. Similarly, Alvarez-Cabria et al. (2010) compared the robustness of a suite of bioassessment metrics in Mediterranean climate streams and recommended the use of percentage EPT, total EPT taxa, mean tolerance value, and total abundance to integrate biomonitoring results because these metrics were least sensitive to seasonal variability.

Macroinvertebrate assemblages are largely structured by available food resources, which change though time and space (Vannote et al. 1980). In forested stream ecosystems, the seasonal change in the availability of CPOM inputs results in a concomitant change in the relative abundance of different macroinvertebrate feeding guilds (Merritt and Cummins 2007). Junker and Cross (2014) reported that temporal patterns of secondary production and food resource availability co-varied significantly 
with primary production supporting the majority of macroinvertebrate production during warm periods and terrestrial litter supporting most of production during relatively cold months. A leaf pack study conducted in the Oregon Cascade Mountains found unique macroinvertebrate guilds associated with red alder dominated canopies, and that invertebrate life cycles were timed to seasonal litter inputs from the alder (Cummins 2002). Subsidies of energy and material that enter ecosystems often exhibit substantial temporal variability, making it important to measure seasonal variability when assessing environmental influences on macroinvertebrate community structure (Beche et al. 2006, Kosnicki and Sites 2010, Resh et al. 2013, Junker and Cross 2014).

\subsection{Influence of Canopy Characteristics}

Riparian canopy type influences the quality and quantity of trophic resources available to instream communities. Litter from riparian vegetation accounts for up to $90 \%$ of the energy flow in some forested streams (Richardson et al. 2006) and high input rates of allochthonous material have been correlated with higher macroinvertebrate (Picolo and Wipfli 2002). Additionally, it has been demonstrated that food resource quality can be more important than quantity in determining macroinvertebrate abundance in some cases (e.g., Hawkins et al. 1982, Richardson et al. 2004). Food resource quality varies among plant species and is largely determined by lignin and cellulose which affect breakdown rates and processing time (Richardson et al. 2004). Processing time of conifer litter, such as coast redwood and Douglas-fir, is significantly greater than the processing time of litter from most hardwoods, such as red alder, big-leaf maple, and shrubs (Petersen and Cummins 1974, Kominoski et al. 2011). An experimental study in southeastern Alaska comparing macroinvertebrate colonization rates between conifer and red alder leaf packs 
and woody debris in different decay classes found that alder wood debris in more advanced decay stages had the highest mean taxa richness and biomass (LeSage et al. 2005). Due to its nitrogen fixing capabilities, red alder also has the potential to increase primary production in cases where nitrogen is a limiting nutrient (Kominoski et al. 2011). In forested oligotrophic streams, nutrient availability can be a more important limiting factor for primary production than sunlight; hence, even modest nutrient inputs can enhance primary producer biomass (Veraart et al. 2008). Nutrient enrichment can have the opposite effects on basal resources of detrital food webs where increasing the availability of nutrients can reduce, rather than increase, carbon availability via increased microbial driven processing rates (Robinson and Gessner 2000). An experiment examining the effects of continuous nitrogen and phosphorus addition to a detrital food web observed leaf breakdown rates increase by 1.5 and 3 times during the first and second years of nutrient enrichment, respectively (Greenwood et al. 2007).

Canopy density directly controls the amount of light reaching the stream, which in turn affects standing stocks of autotrophic energy sources. Consequently, it has been hypothesized that the absence (or reduction) of a riparian canopy can increase primary production and benefit higher-order consumers via bottom-up trophic processes (Hawkins et al. 1982, Kiffney et al. 2004). Following a severe wildfire, canopy cover at a study site along Angora Creek, California was reduced from $88 \%$ to $22 \%$ and resulted in an increase in total macroinvertebrate abundance (Oliver et al. 2012). Hawkins et al. (1982) reported that canopy density had a stronger influence on invertebrate community structure than substrate composition and channel gradient. Moreover, a study comparing an open stream canopy to a heavily shaded stream found that macroinvertebrate 
abundance and production were significantly greater in the open canopy site, and that overall production at the open site was twice as high as at the shaded site (Behmer and Hawkins 2006). The authors attributed the observed differences to either the availability of higher quality food (algae and algal detritus) or a phototactic attraction to sunlit areas. Understanding the general energetic pathways that support stream food webs permits expected biological responses to be integrated into silviculture and riparian management.

\subsection{Response to Canopy Manipulation}

Harvesting timber creates a range of disturbances that can be potentially detrimental to the environment and forest ecosystems, especially when operations occur in or adjacent to riparian areas. Moreover, implementing non-disturbance buffers around riparian areas may fall short in protecting or enhancing key riparian energy transfers (SWC 2008). Buffer strategies often produce riparian canopies dominated by late seral conifer species which provide energy subsidies to streams, in the form of coarse litter, with substantially breakdown rates than early successional hardwood species. Given the strong ecological link between riparian canopy characteristics and macroinvertebrate community structure, several studies have investigated instream response to canopy thinning and/or removal. It has been found that selectively harvesting conifers within riparian buffer zones promotes instream primary production and colonization by pioneer species of deciduous hardwoods, which are associated with higher aquatic biological productivity via increased detrital inputs (Petersen and Cummins 1974, Picolo and Wipfli 2002). Typically, changes in macroinvertebrate community composition and abundance have not been detected in low-intensity logging sites (Kreutzweiser et al. 2005, Chizinski et al. 2010, Kreutzweiser et al. 2010, Jones et al. 2013), whereas studies that have 
implemented higher intensities of tree removal have reported mixed results. In a canopy manipulation experiment, Jackson et al. (2007) clearcut several study reaches with different buffer distances and found that clearcut streams supported higher densities of macroinvertebrate collectors and shredders, likely due to increased detrital resources. This response persisted for three years in all buffer treatments and included higher overall macroinvertebrate biomass in the buffered stream reaches as well. Macroinvertebrate response to a moderate-intensity logging event ( $42 \%$ basal area removal) in a northern hardwood forest was not found to be significantly different than an un-logged reference (control) site over a five-year period (Kreutzweiser et al. 2005). One study examined differences in macroinvertebrate communities subjected to timber harvest across 15 different streams found that the largest post-harvest changes in biotic indices and community structure occurred in streams draining relatively small to medium catchments; these changes included increased densities of Diptera, Mollusca, and Oligochaetes, and decreased densities of Ephemeroptera (Reid et al. 2010). However, it should be noted that the strong temporal variability inherent in macroinvertebrate communities may obscure the effects of canopy treatments in some climates (Beche et al. 2006, Melody and Richardson 2007, Kosnicki and Sites 2011,).

\subsection{Water Quality}

Benthic macroinvertebrates are sensitive to many abiotic factors and often require taxon-specific environmental conditions to thrive. Consequently, aquatic biological assessment (i.e., bioassessment) programs form the foundation of many water quality monitoring programs nationwide (Worcester 2005, Mazor and Schiff 2007, Ode 2007, Alvarez-Cabria et al. 2010, Bellucci et al. 2013). Aquatic bioassessment programs rely on 
the concept of indicator species, where certain taxa have narrow and known specific tolerances to a set of physical or chemical variables (Rosenberg and Resh 1993). Hence, the high relative abundance of tolerant organisms at a given location relative to the abundance of intolerant organisms suggests poor water quality (Armitage et al. 1983, Gray and Ward 1982). Furthermore, changes in macroinvertebrate community structure over time and space can indicate important changes in physical and/or chemical conditions within a watershed (Rosenberg and Resh 1993). Community composition can reveal long-term trends in water quality that may be missed by monitoring programs that rely on instantaneous measurements of water quality parameters (Ode 2007).

Differing land use types can affect a range of water quality parameters.

Community assemblage monitoring in various climates and land use types have established community structuring trends that are used in bioassessment monitoring (Alvarez-Cabria et al. 2010). A study in North Carolina compared macroinvertebrate assemblages in three streams to evaluate the effect of different dominant land use types (i.e., forested, agricultural, and urban; Lenat and Crawford 1992). The authors reported that high concentrations of metals $(\mathrm{Cr}, \mathrm{Cu}$, and $\mathrm{Pb})$ in the urban stream were associated with high abundances of oligochaetes, whereas, elevated nitrate concentration in the agricultural stream contributed to greater periphyton production and a concomitant increase in the relative abundance of scraper taxa (Lenat and Crawford 1992). A macroinvertebrate assemblage monitoring study in an Atlantic Forest region in Brazil found that downstream urbanization caused a decrease in dissolved oxygen and an increase in chloride which resulted in a significant decrease in the abundance EPT taxa, while Chironomidae and Simuliidae taxa were unaffected (Buss et al. 2002). 
Seasonal stream temperatures can also be a critical factor in maintaining macroinvertebrate community patterns. A study in South Africa found that water temperature was a strong predictor of community structure with tolerant taxa preferring sites with greater temperature variability and generalist taxa preferring those with more constant thermal regimes (Eady et al. 2013). Additionally, Grab (2014) reported that decreasing water temperatures and reduced stream width in headwater mountain streams supported less abundant, lower diversity macroinvertebrate assemblages. Impoundments and alteration of the natural flow regime can drastically alter temperature regimes within lotic environments. A study examining community response to flow and temperature across paired regulated and non-regulated streams found communities to be more sensitive to the timing of high flow events and less sensitive to thermal controls (White 2017). It has been observed that increased stream temperatures can shorten the length of food chains due to influence on species-specific tolerance limits, temperature dependent rates of resource use, and species interactions (Glazier 2012). An experiment that increased water temperature by $10^{\circ} \mathrm{C}$ in large outdoor artificial channels found that elevated temperature seasonally altered macroinvertebrate abundance and phenology (Arthur et al. 1982). Total macroinvertebrate density was appreciably higher in the heated channel riffles during the winter and spring months and in the control channel riffles during the summer months.

Macroinvertebrates have been found to be sensitive to low $\mathrm{pH}$. A study that artificially acidified a Colorado stream over the course of 7 days found significantly reduced abundances and drift rates (Courtney and Clements 1998). Reduced macroinvertebrate abundance was driven by a decrease in mayflies (Ephemeroptera) 
which were particularly sensitive to acidification. A leaf litter processing study in the central Appalachian Mountains compared processing rates between three streams of differing $\mathrm{pH}$ and found processing rates were fastest in the neutral $\mathrm{pH}$ stream, slowest in the acidic stream, and intermediate in the most alkaline stream (Griffith and Perry 1993). An invertebrate assemblage study in extremely acidic crater lakes and rivers in East Java, Indonesia found a complete lack of macroinvertebrate species at $\mathrm{pH}$ values below 2 (Lohr et al. 2006).

\subsection{Substrate Characteristics}

Benthic substrates commonly differ between habitats and can favor different macroinvertebrate taxa. Although species are not restricted to certain habitats, speciesspecific habitat preferences make certain species more common in certain habitats (Cummins and Merritt 1996). Habitat preferences are generally related to feeding strategies (Vannote et al. 1980). Species adapted to moving between or clinging to cobble substrate in riffle habitats will differ from those adapted to burrowing in sand substrate pools and other depositional habitats (Brodsky 1980). Furthermore, some taxa prefer hygropetric habitat, which consists of a thin film of water flowing over large, flat substrate such as boulders or bedrock (Miller and Perkins 2012). Diptera taxa, such as chironomids and simuliids, utilize hygropetric habitats in their larval forms to attach to substrates and filter-feed (Boothroyd 2005). The separation of macroinvertebrate species by substrate preferences has been well documented and six broad assemblages have been established, including guilds that prefer coarse substrate, gravel, sand, mud, bedrock, and woody debris (Ward 1992). In a substrate manipulation experiment Erman and Erman (1984) found that median particle size accounted for most of the variation observed in 
patterns of community colonization on the experimental substrates. Rocks with high surface roughness were colonized by more individuals (but not taxa) than rocks with low surface roughness. In a study that related biotic condition to land use management and channel structure, it was reported that substrate type explained more of the variation in macroinvertebrate biotic integrity than land use/cover alone (Lambert et al. 1999). Almost all taxa were found to be most abundant on large cobbles, indicating that substrate diameter was a strong predictor of macroinvertebrate productivity (Buss et al. 2004). Sand dominated substrate or substrate that has had its interstitial spaces filled in by sand or fine sediments provided little to no available habitat and, consequently, supported low diversity of invertebrate guilds (Gray and Ward 1982). Suspended fine particles that settle to the channel bottom during low flow conditions may also fill in and greatly eliminate macroinvertebrate habitat. This loss of access to fine gravels and cobbles can completely denude entire stream reaches of macroinvertebrate life (Wood and Armitage 1997). A study on the effects of sediment release from a reservoir on downstream macroinvertebrate communities found that invertebrate density decreased by as much as $90 \%$ immediately following the sediment release, but that populations rebounded after three weeks (Gray and Ward 1982).

\subsection{Summary}

Macroinvertebrate communities are highly variable and influenced by an array of direct and indirect biotic and abiotic interactions. Species-specific habitat preferences, life cycle adaptations, and the continuous physical change inherent in lotic ecosystems all contribute to this variability. Due to the number of environmental factors that potentially drive assemblage composition, it is often difficult to rank or quantify the influence of a 
single physical parameter. Specific water chemistry thresholds are difficult to establish because physiochemical tolerances can vary on a sub-species level. Nonetheless, generalities are possible and observed patterns in macroinvertebrate community structure form the foundation of aquatic bioassessment programs worldwide. Macroinvertebrate communities are an important trophic link in aquatic ecosystems, connecting basal energy sources and higher trophic levels. Consequently, characterizing macroinvertebrate communities by the relative abundance of different feeding guilds can inform energy processing dynamics. Studies that aim to characterize spatiotemporal variability in community structure often require a calibration period and suitable controls (i.e., reference stream reaches) to identify preliminary patterns and optimize sampling design. Assemblage patterns and influential abiotic factors may be investigated using multivariate ordination techniques and Analysis of Variance (ANOVA) procedures. 


\section{CHAPTER 4. METHODS}

\subsection{Study Design}

A study was conducted to characterize macroinvertebrate assemblages and physical habitat characteristics along the channel gradient of Little Creek. Seven study reaches were established in spring of 2015 (Figure 4.1). The study reaches were named according to location in the watershed; Mainstem (MS), Upper Mainstem (UMS), North Fork (NF), Tranquility Flats (TF), Upper North Fork (UNF), South Fork (SF), and Upper South Fork (USF). The study reaches were selected to be representative of proximal stream conditions and based on access from Little Creek Road.

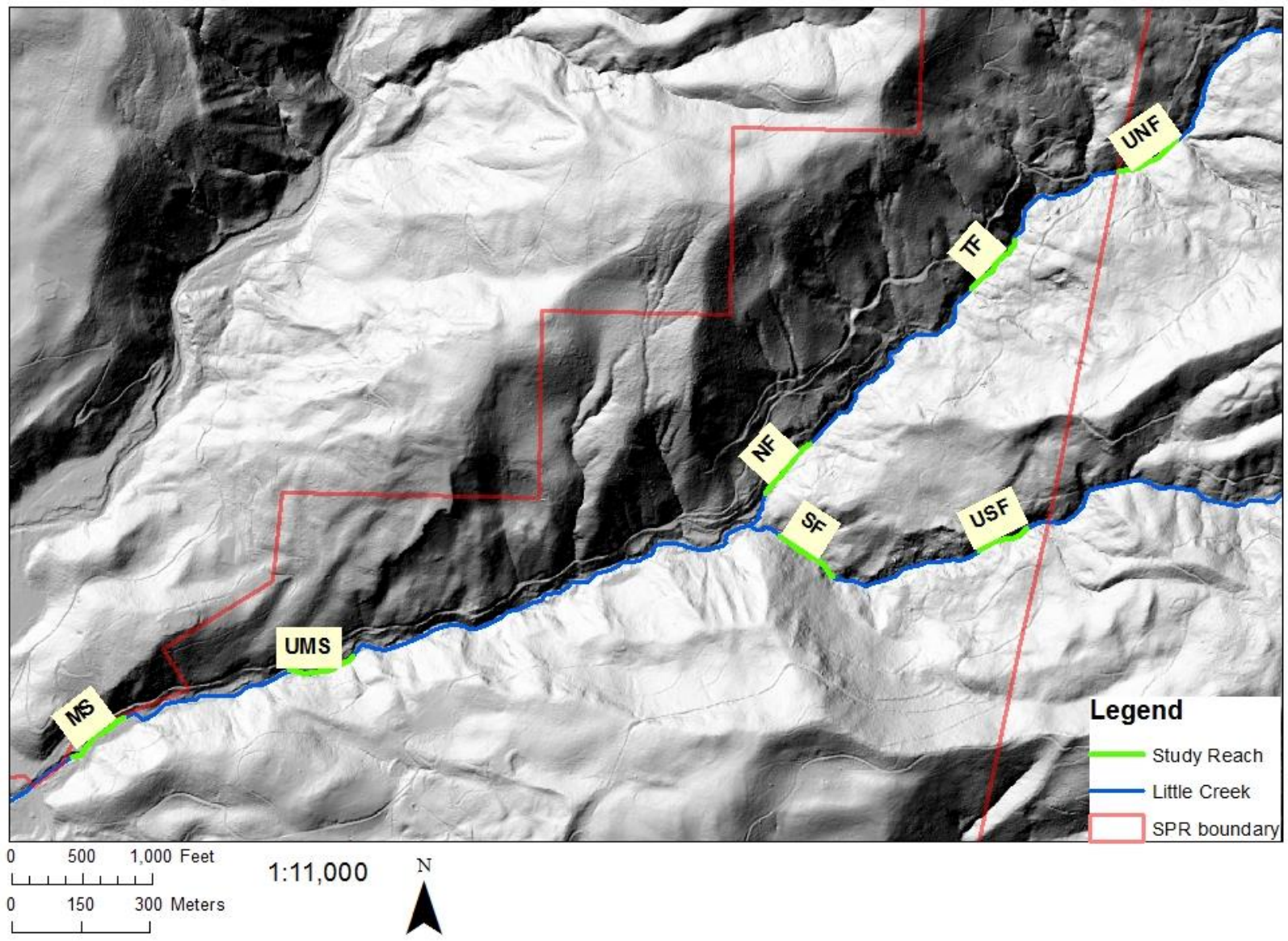

Figure 4.1 Shaded relief map of the study reaches in Little Creek. The study reaches were named according to location in the watershed; Mainstem (MS), Upper Mainstem (UMS), North Fork (NF), Tranquility Flats (TF), Upper North Fork (UNF), South Fork (SF), and Upper South Fork (USF). 


\subsection{Study Reach Descriptions}

The study reaches were chosen to be representative of the various physical habitat characteristics present in the riparian zone of the Little Creek watershed. These characteristics changed with elevation and aspect. Longitudinal profiles of the study reaches were derived in GIS from a 2011 LiDAR based digital elevation model (Figure 4.2). Channel gradient increased with distance from the Scotts Creek confluence, with the steepest gradients found in the Upper North Fork and Upper South Fork study reaches. Step pool morphology was common in these higher gradient reaches (Perkins 2012). Hydraulic properties that control substrate size distribution are influenced by channel gradient; steep channels have high ratios of transport capacity to sediment supply, whereas low-gradient channels have lower transport capacity to supply ratios (Montgomery and Buffington 1997). A pebble count was preformed through the study reaches using the California State Water Resources and Control Board's Surface Water and Ambient Monitoring Program bioassessment protocol in November 2016. Dominant size classes were cobble in the Mainstem (MS) study reach (mean diameter $=85 \mathrm{~mm}$ ), cobble in the Upper Mainstem (UMS) study reach (mean diameter $=88 \mathrm{~mm}$ ), coarse gravel in the North Fork (NF) study reach (mean diameter $=40 \mathrm{~mm}$ ), small boulder in the Tranquility Flats $(\mathrm{TF})$ study reach (mean diameter $=334 \mathrm{~mm}$ ), boulder in the Upper North Fork (UNF) study reach (mean diameter $=746 \mathrm{~mm}$ ), small boulder in the South Fork $(\mathrm{SF})$ study reach (mean diameter $=258 \mathrm{~mm}$ ), and large boulder in the Upper South Fork (USF) study reach (mean diameter $=2,225 \mathrm{~mm}$ ). The Upper South Fork had a predominantly bedrock channel bottom. 


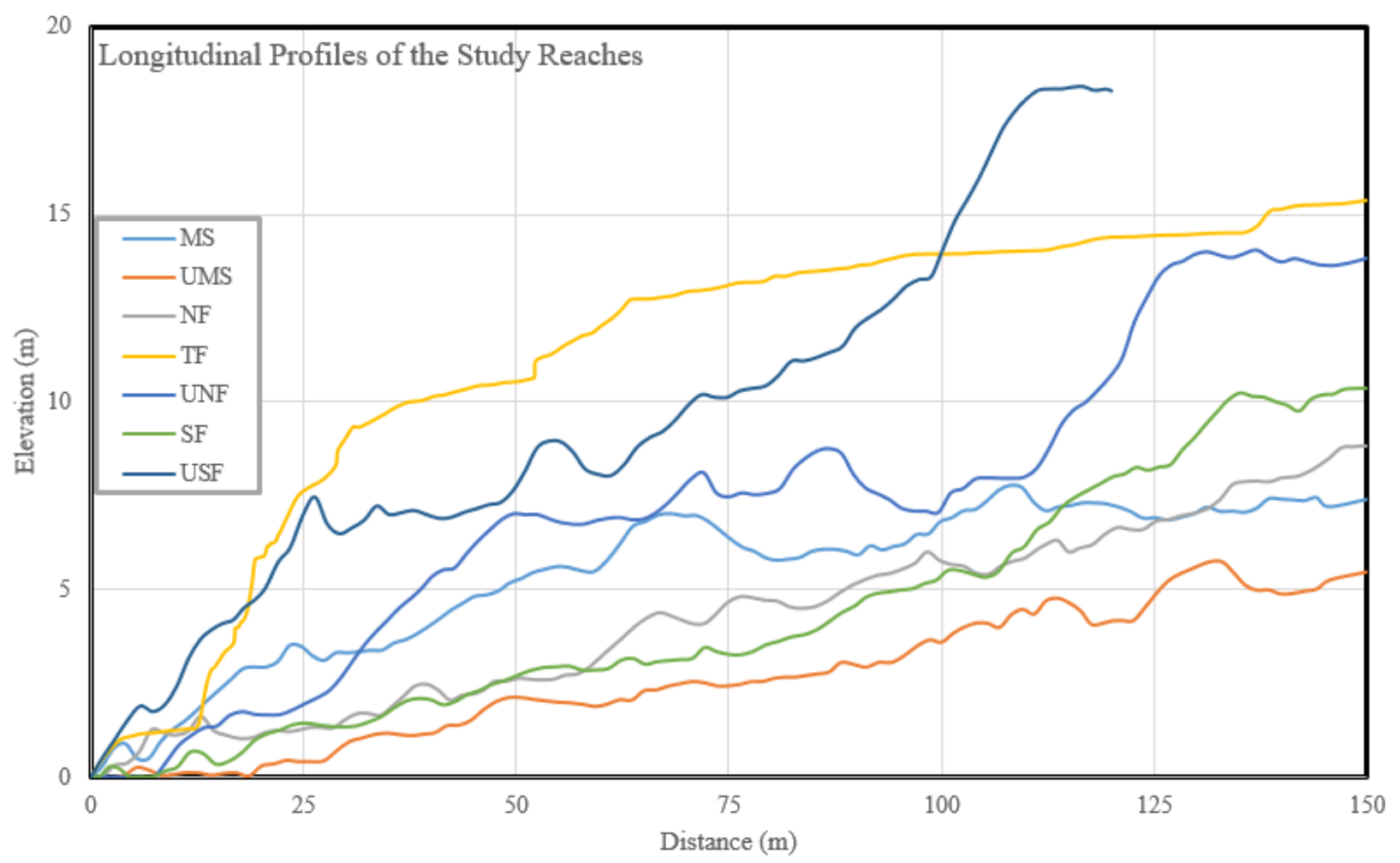

Figure 4.2 Longitudinal profiles of the study reaches derived in GIS using a 2011 digital elevation model.

A 2015 study examined stream temperatures in Little Creek and found localized temperature regimes to be significantly associated with solar radiation and riparian canopy shading (Louen 2016). Dominant riparian vegetation, in terms of abundance, changed along the channel gradient. The canopy at the Mainstem study reach was primarily composed of a stand of mature red alder that colonized the riparian zone following the 1955 debris torrent, while second growth coast redwood and Douglas-fir are more prevalent in the North Fork and South Fork study reaches. In August 2016, a forest inventory survey using tenth acre plots was conducted through the study reaches as part of a senior project (Botelho 2016). The survey delineated species composition between hardwood and conifer species and measured basal area per acre. The Mainstem 
study reach was composed of $72 \%$ hardwood species whereas the Upper North Fork and Upper South Fork reaches were composed of $90 \%$ and $100 \%$ conifer species, respectively (Figure 4.3). Total basal area per acre was highest in the Tranquility Flats $\left(321.51 \mathrm{ft}^{2}\right)$ and Upper North Fork (454.57 $\left.\mathrm{ft}^{2}\right)$ study reaches and lowest in the Mainstem $\left(114.22 \mathrm{ft}^{2}\right)$ and Upper Mainstem (30.58 $\left.\mathrm{ft}^{2}\right)$ (Figure 4.4).

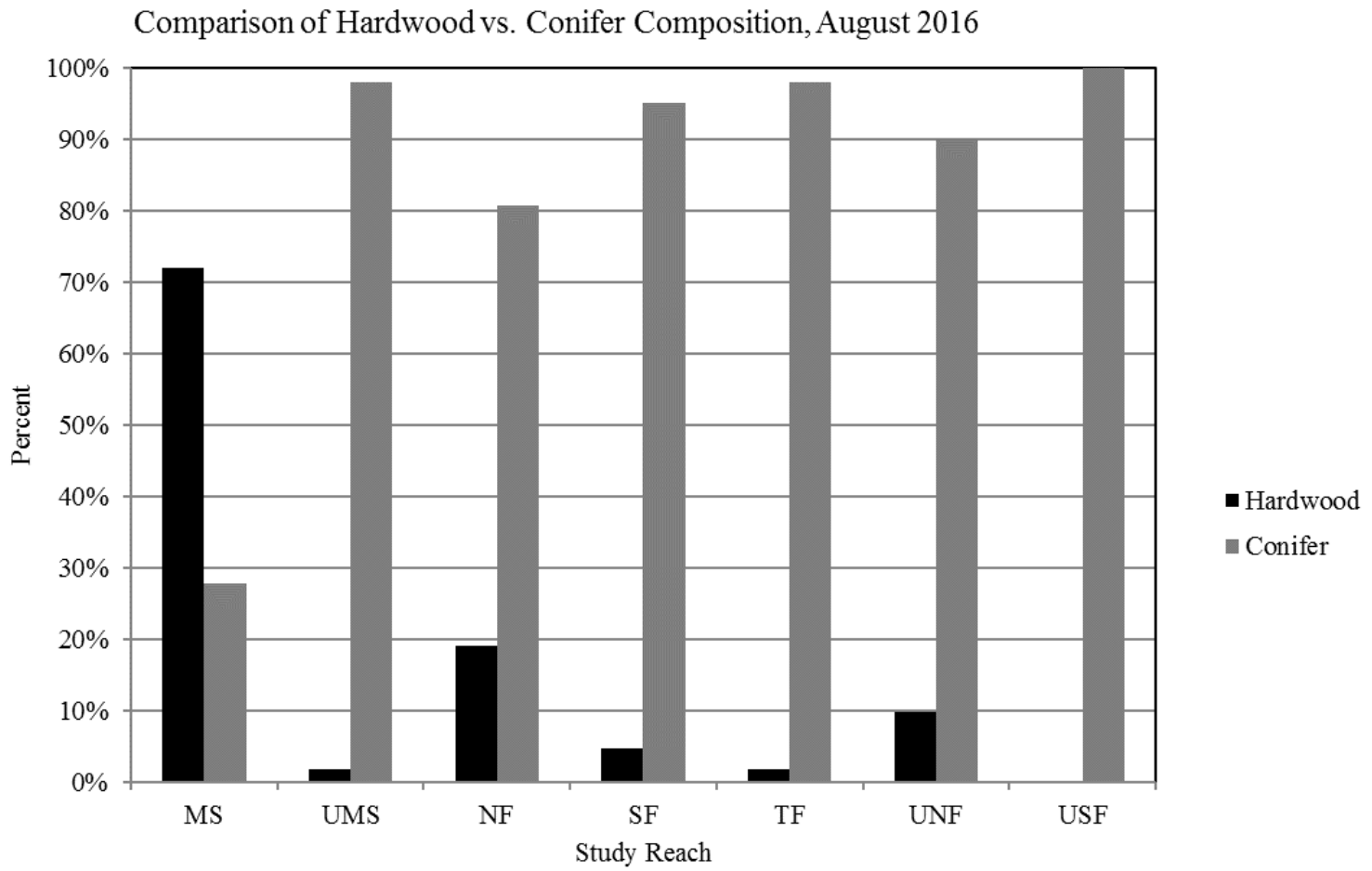

Figure 4.3 Comparison of hardwood vs. conifer tree species through the seven study reaches in the Little Creek watershed, August 2016. Dominant hardwood species included red alder, tan oak, bay laurel, and big leaf maple. Dominant conifer species included coast redwood and Douglas-fir. 
Comparison of Total Basal Area/Hectare, August 2016

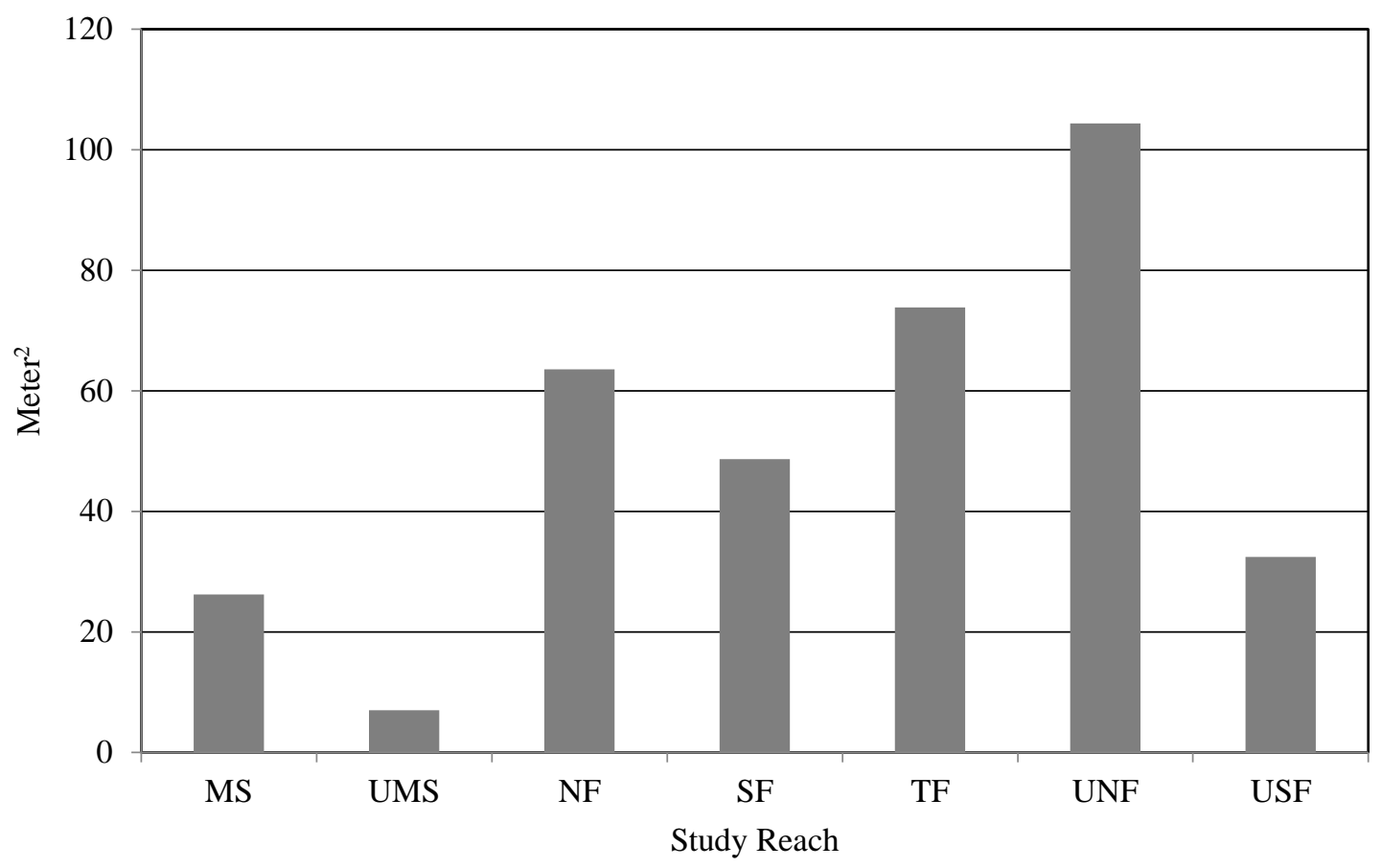

Figure 4.4 Comparison of total basal/hectare $\left(\mathrm{m}^{2}\right)$ through the study reaches, August 2016. Basal area was measured by measuring diameter at breast height (DBH) of all trees within tenth acre plots. 


\subsection{Field Data Collection}

Field sampling occurred during the spring, summer, and fall of 2015 and 2016. Field measurements and macroinvertebrate samples were collected using a modified version of the Reachwide Benthos (RWB) procedure described by the bioassessment protocol of the Surface Water Ambient Monitoring Program (SWAMP), a subprogram of the California State Water Resources Control Board (Ode 2007). Each study reach was $150 \mathrm{~m}$ long, except for USF which was $135 \mathrm{~m}$ due to high gradient cascades on the upstream and downstream ends of the reach. In each study reach, macroinvertebrate samples and physical habitat data were collected at 11 main transects (labeled A-K) spaced $15 \mathrm{~m}$ apart. Additional physical habitat data were collected at 10 supplemental inter-transect locations (labeled AB-JK) located $7.5 \mathrm{~m}$ upstream of each main transect (except main transect K; see Figure 4.5). Surveys started at the downstream end of each study reach. Each survey began by measuring water depth $( \pm 0.01 \mathrm{~m})$ and velocity $(\mathrm{m} / \mathrm{s})$ using a Marsh-McBirney Flo-Mate ${ }^{\mathrm{TM}}$ Model 2000 Portable Water Flow Meter (MarshMcBirney 1990), for subsequent calculation of stream discharge $\left(\mathrm{m}^{3} / \mathrm{s}\right)$ via the velocityarea method. 


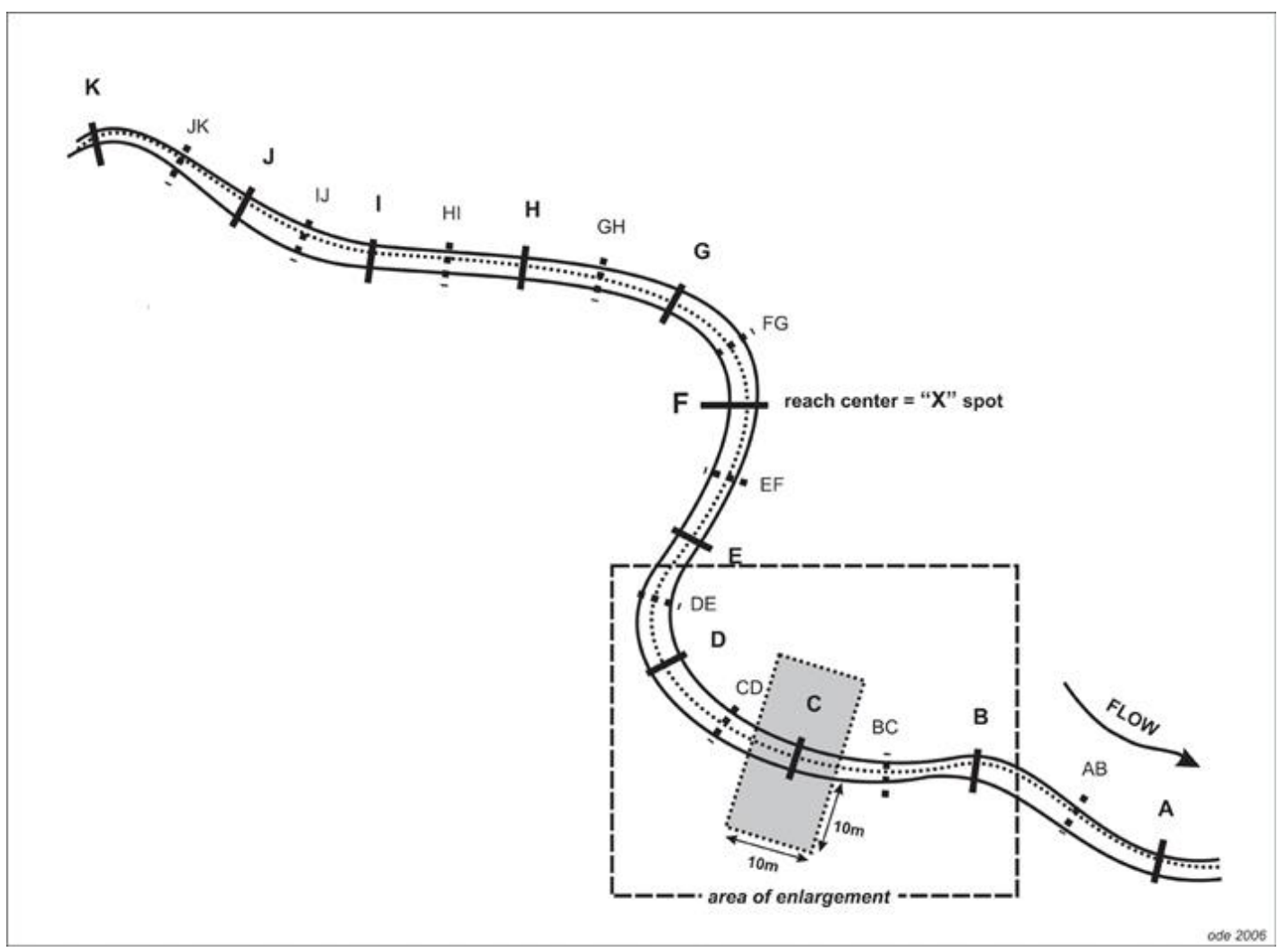

Figure 4.5 Study reach layout. Biological sampling and physical habitat observations occurred at 11 main transect locations (A-K). Physical habitat observations were also recorded at 10 supplemental inter-transect locations (AB-JK). (Ode 2007)

At each main transect, macroinvertebrates were collected at the center of the stream using a standard surber sampler, a $0.09 \mathrm{~m}^{2}\left(1 \mathrm{ft}^{2}\right)$ metal frame fitted with a $500 \mu \mathrm{m}$ net (Figure 4.6). Samples were collected by facing the surber sampler upstream and disturbing the area within the frame for 30 seconds, allowing the water current to carry loosened material into the net. Larger organisms were removed from the substrate and placed in the net by hand. The surber sampler was emptied into a labeled plastic bag, and the net was thoroughly rinsed to ensure all contents were transferred. 95\% ethanol was then added to the plastic bag to preserve the sample. 


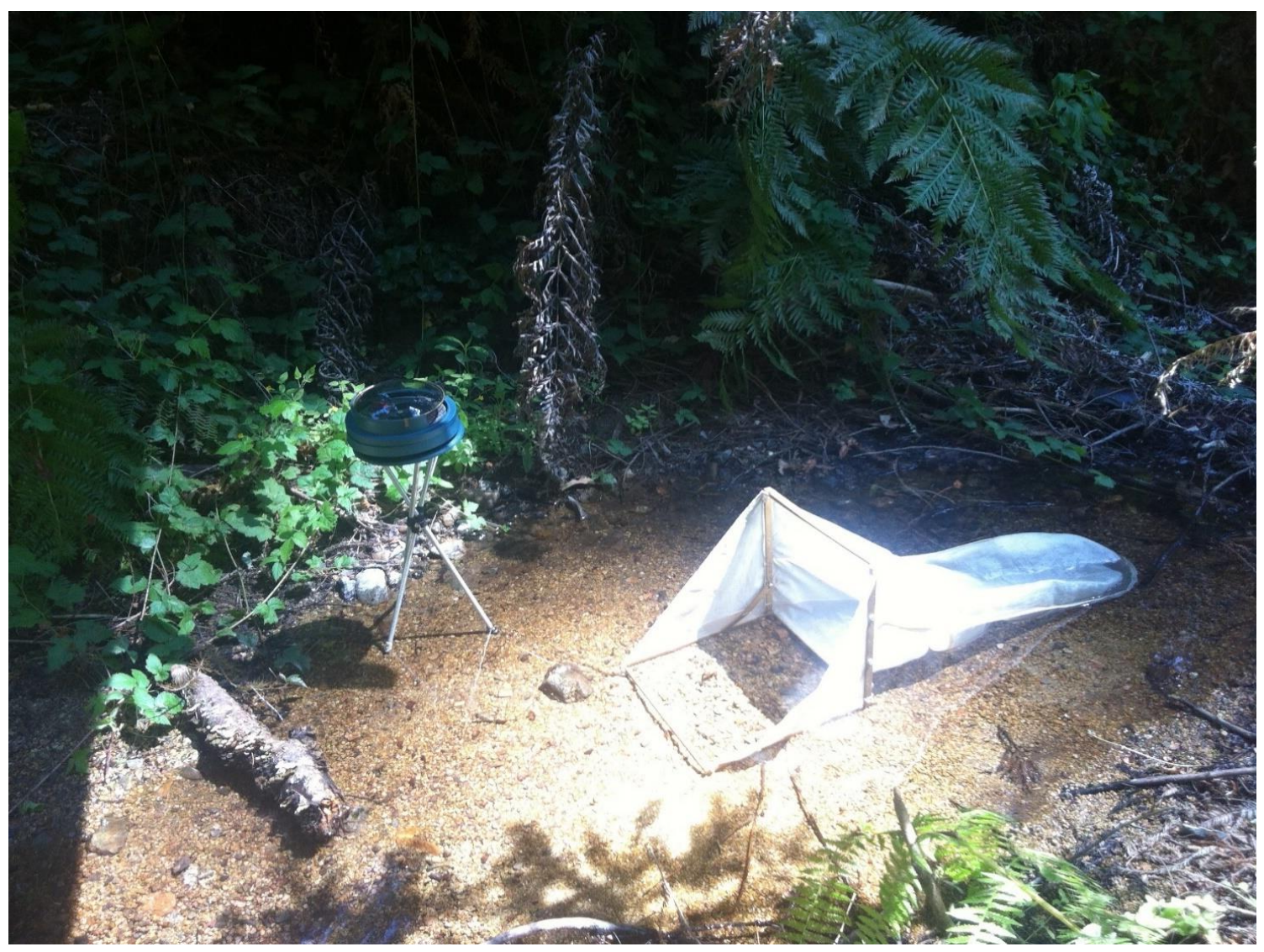

Figure 4.6 Surber sampler placed at the center of main transect NF-C.

Additionally, percentage stream shading and water quality parameters were measured at each main transect. A Solar Pathfinder ${ }^{\mathrm{TM}}$ was used to collect site-specific insolation data (Figure 4.7). A Solar Pathfinder ${ }^{\mathrm{TM}}$ is a reflective dome that sits on top of a sunpath diagram. A sunpath diagram is a table of horizontal arcs and vertical rays that represent months and solar hours, respectively. It has a specific range of latitudes that accounts for magnetic declination $\left(13.58^{\circ} \mathrm{E}\right)$. This platform was fitted to a tripod, levelled, and oriented facing south. Measurements were made by adding the solar hours that correspond to obstructed visible sky. Water quality data were collected at using a YSI Professional Plus ${ }^{\mathrm{TM}}$ handheld multiparameter meter. Temperature $\left({ }^{\circ} \mathrm{C}\right), \mathrm{pH}$, and dissolved oxygen $(\%)$ were measured by holding the probe in the center of the water 
column until the instrument stabilized. Water quality data were collected irregularly based on availability of the YSI Professional Plus ${ }^{\mathrm{TM}}$.

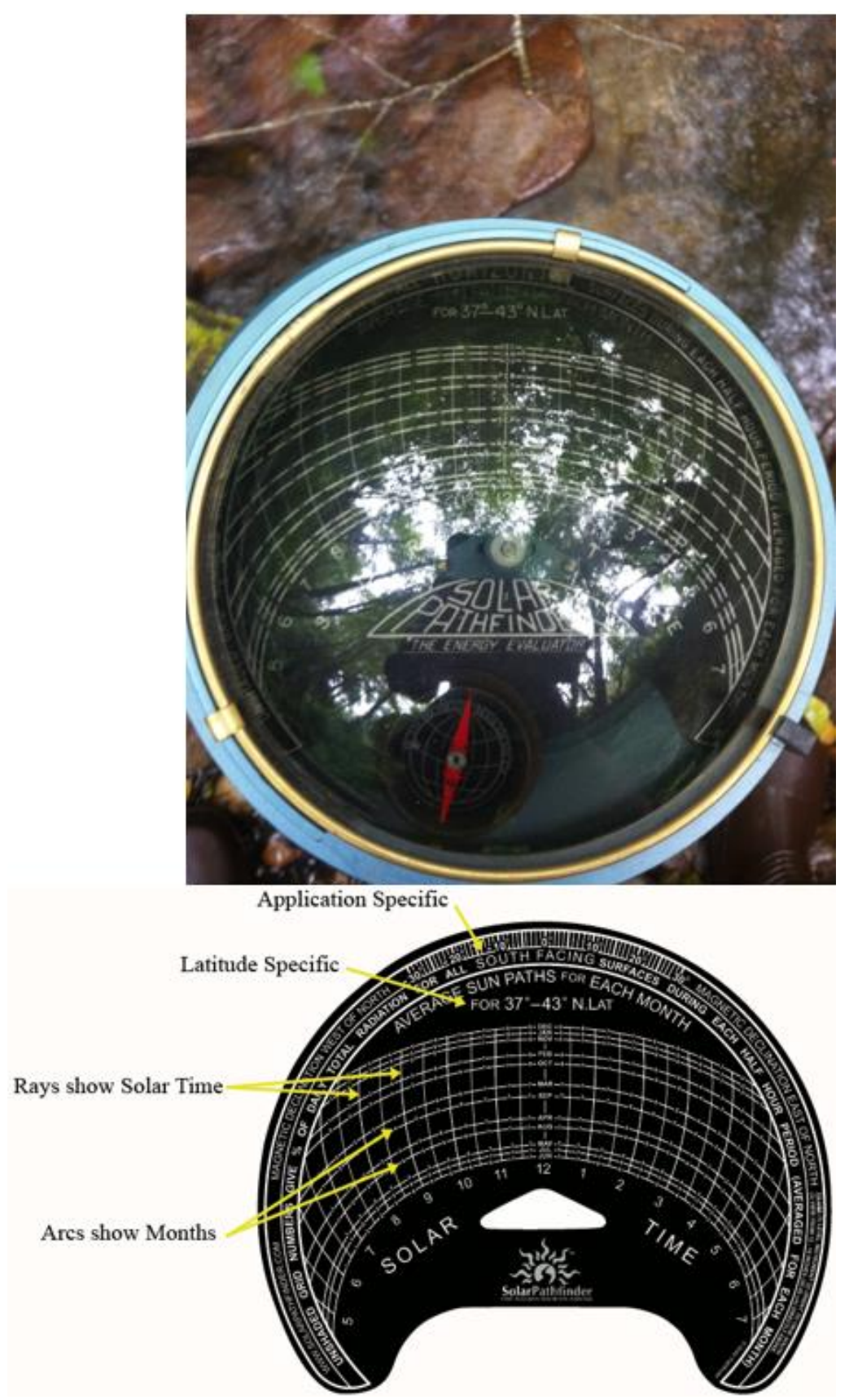

Figure 4.7 Solar Pathfinder ${ }^{\mathrm{TM}}$; a reflective dome sits on top of a sunpath diagram delineated with months and solar hours. Site-specific shading measurements were made by adding the percentage of month-specific arc where visible sky is obstructed (Solar Pathfinder 2017). 
Wetted width was measured at each main transect and inter-transect in each reach, and water depth was subsequently quantified at five equidistant points (i.e., $0 \%, 25 \%$, $50 \%, 75 \%$, and $100 \%$ of wetted width) along each transect using a stadia rod (Figure 4.6). At each point where water depth was measured, a piece of substrate was randomly collected, identified (i.e., Santa Cruz Mudstone, Santa Margarita Sandstone, quartz diorite, or schist), and measured along its intermediate axis (millimeters). Bedrock substrate was recorded as $4000 \mathrm{~mm}$. Channel cross-sectional area was estimated using width and depth measurements. Mean and median substrate diameter and the proportion of sedimentary rock were calculated using collected substrate data.

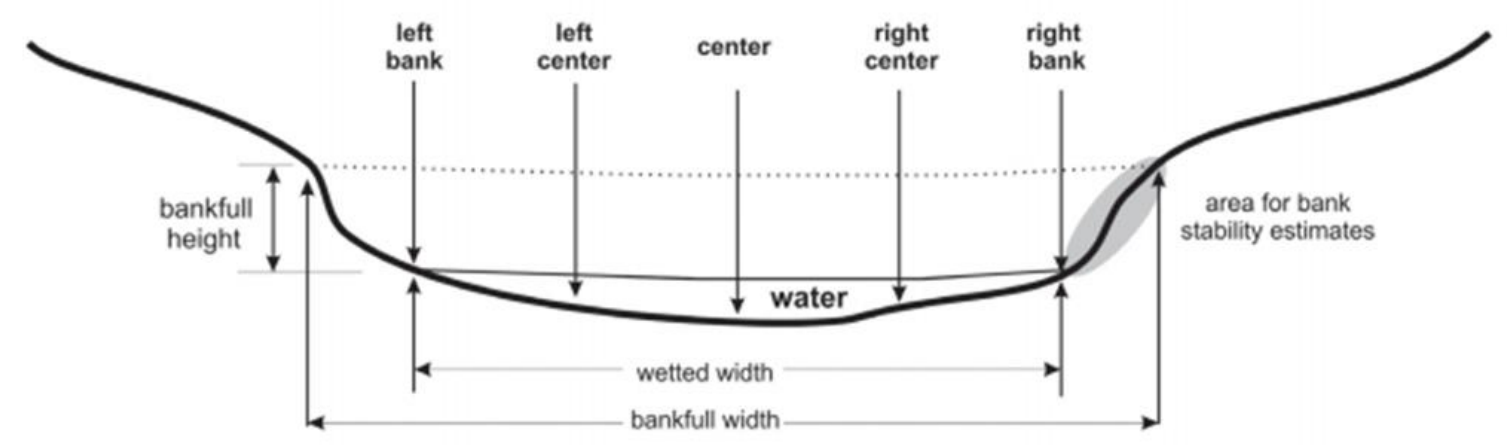

Figure 4.8 Locations of the equidistant points (i.e., $0 \%, 25 \%, 50 \%, 75 \%$, and $100 \%$ of wetted width) in every main transect and inter-transect. At each equidistant point, water depth was measured as well as the diameter of a randomly collected piece of substrate (Ode 2007). 
In the spring of 2017, a hemispherical canopy survey was conducted to quantify below canopy solar radiation at each main transect in each study reach. A Canon 70D SLR digital camera (14 megapixels) with a Sigma $4.5 \mathrm{~mm}$ fisheye lens attached to an auto-levelling tripod was used to capture images. At each main transect, the camera was placed in the middle of the stream and leveled to ensure that it was aimed directly above the sampling site (Figure 4.7). A marker was aligned with magnetic north and set in the camera's view so that pictures could be oriented during analysis. Pictures were analyzed using HemiView 2.1 software (Delta-T Devices 2013). Each picture was edited to separate visible sky pixels from obstructed pixels (Figure 4.8). The software applies a sunpath diagram to each picture based on coordinates and elevation of the main transect location. Specific sunpaths were used based on original sample collection date. A spreadsheet of multiple canopy parameters for each main transect location was derived, however, only solar radiation (watts per square meter; $\mathrm{W} / \mathrm{m}^{2}$ ) was used in the analysis because unique values were generated for each sampling event. 


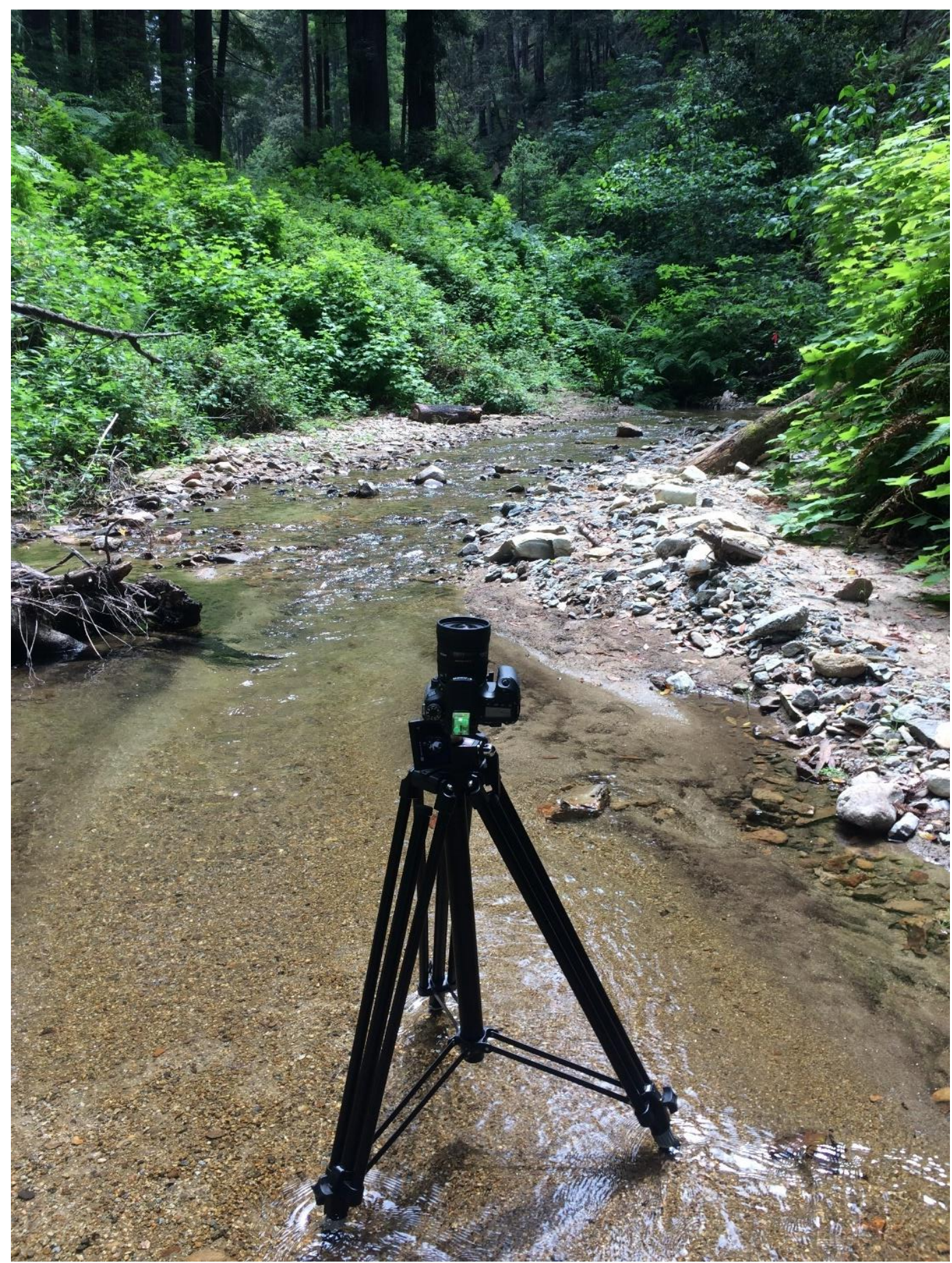

Figure 4.9 Hemispherical camera set up at main transect location UMS-B. The camera was fitted with a fisheye lens. Hemispherical photographs were taken at every main transect location through all the study reaches in spring 2017. 


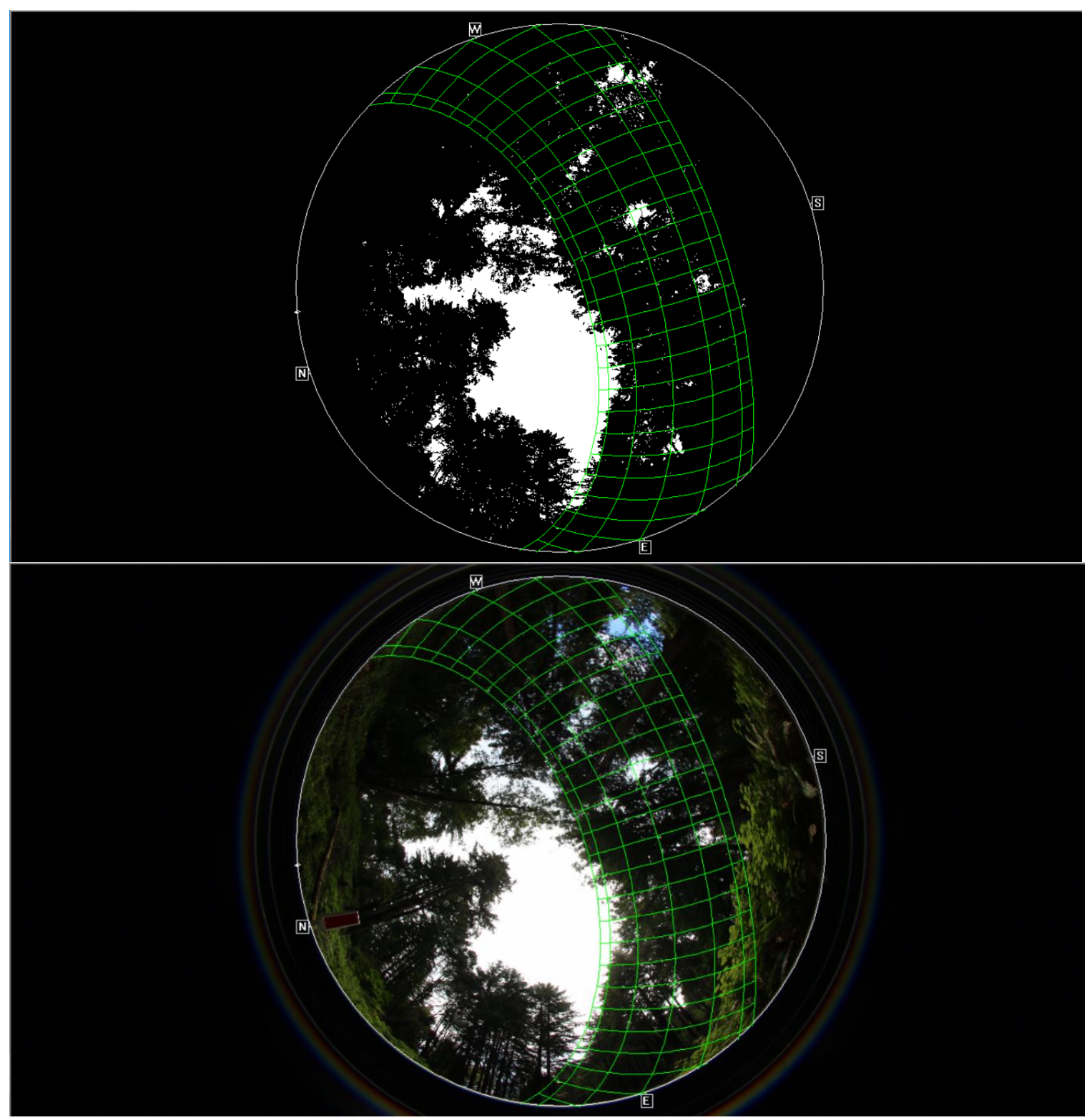

Figure 4.10 Unclassified and classified photos of UMS-B with sunpath diagrams applied in HemiView 2.1. The threshold of classified photos is adjusted to best delineate open sky pixels from obstructed pixels. 


\subsection{Laboratory Procedures}

A team of 14 undergraduate students was recruited to prepare macroinvertebrate samples for identification; six Cal Poly undergraduates worked in a laboratory on campus and eight UC Santa Cruz undergraduates worked in a laboratory at NOAA Fisheries Southwest Fisheries Science Center in Santa Cruz, CA. Laboratory sample processing involved transferring each sample from its plastic collection bag to a plastic container and thoroughly rinsing the bag to ensure all contents of the sample were transferred. This container was then labeled with the sample collection site and sampling date. Once the transfer was complete, a portion (subsample) of the total sample was transferred from the container to a petri dish and examined using a dissecting microscope. All macroinvertebrate specimens were separated from the subsample. This subsampling process continued until the entire sample was completed. All macroinvertebrate specimens were then transferred into a labeled vial and stored in 95\% ethanol.

Processed samples were identified under a dissecting microscope using The Bug Book: A Guide to the identification of Common Aquatic Benthic Macroinvertebrate Families of California and Western North America (Brinkhurst et al. 2009). Individual macroinvertebrate specimens were identified to the taxonomic level of family (Level II). A length measurement was recorded for each individual specimen using millimeter paper.

\subsection{Database Management}

Field and laboratory data were entered into Microsoft Excel ${ }^{\mathrm{TM}}$ spreadsheets. The database was comprised of several spreadsheets that were used to calculate biological metrics (see section 4.5.2). These metrics were calculated for each main transect location 
in the "Transect" spreadsheet and then composited by study reach in the "Study Reach" spreadsheet. These two spreadsheets contained the datasets used in all statistical analyses.

\subsubsection{Environmental Variables}

A set of environmental variables was compiled from collected field data. These variables represented physical conditions at both the study reach and transect levels. At the study reach level, stream discharge was calculated using the velocity-area method. Stream shading and cross-sectional area were averaged. A suite of substrate characteristics was calculated using pebble count data; this included average diameter $(\mathrm{mm})$, D-50 $(\mathrm{mm})$, and percentage sedimentary rock. At the transect level, stream shading, solar radiation, and habitat type (i.e., riffle, run, or pool) were recorded at each sample collection site. The influence of temperature $\left({ }^{\circ} \mathrm{C}\right), \mathrm{pH}$, and dissolved oxygen $(\%)$ was analyzed in sub-analyses of the transect dataset due to small sample sizes.

\subsubsection{Metrics of Community Structure}

A set of biological metrics were calculated to describe macroinvertebrate community structure (Table 4.1). Macroinvertebrate density (individuals $/ \mathrm{m}^{2}$ ) and biomass (mg dry mass $/ \mathrm{m}^{2}$ ) were calculated as proxies for secondary productivity. Density was calculated by dividing the total number of individuals collected in each surber sample by the area of the sampler $\left(0.09 \mathrm{~m}^{2}\right)$. Biomass was calculated by entering individual length measurements into published family level length-mass relationships (Smock 1980, Benke et al. 1999, Sabo et al. 2002).

A suite of metrics commonly used in bioassessment monitoring were selected. Specifically, EPT taxa richness, percentage EPT, percentage Diptera, tolerance level, and 
diversity. Taxa from the orders Ephemeroptera, Plecoptera, and Trichoptera are relatively intolerant to both pollution and environmental disturbance. Hence, higher values of both EPT taxa richness and percentage EPT were interpreted to represent good water quality and stream health. Percentage Diptera, the proportion of the sample represented by the relatively tolerant taxa, was also included and higher values were interpreted to indicate poorer conditions. Tolerance level was calculated for each sample using Hilsenhoff's Family Biotic Index (FBI). Families were assigned a tolerance number from 0 (most sensitive) to 10 (most tolerant) based on known sensitivity to organic pollutants (Brinkhurst et al. 2009). Index values represent varying degrees of organic pollution (Table 4.2). Diversity was calculated using Shannon's Diversity Index (H'). Shannon's Diversity Index increases as both the richness and the evenness of the community increase and values are generally between 1.5 and 3.5 in most studies, with values rarely greater than 4.0.

Percentage R-strategist taxa was also included in the dataset despite it not being a metric typically used in macroinvertebrate assemblage characterization studies. Rstrategists are defined here as taxa from the families Chironomidae, Simuliidae, and Baetidae that are generally disturbance adapted and indicators of adverse environmental change or stress (i.e., wildfire, extreme flows, and anthropogenic impacts). Therefore, if a canopy thinning were to take place, monitoring the proportion of the assemblage compromised of R-strategist taxa could provide an effective assessment of instream community disturbance and recovery. 
Table 4.1 Metrics of macroinvertebrate community structure.

\begin{tabular}{|c|c|c|}
\hline Metric & Formula & $\begin{array}{l}\text { Expected response to } \\
\text { disturbance/impairment }\end{array}$ \\
\hline \# Individuals & & Decrease \\
\hline Density (\# Individuals $/ \mathrm{m}^{2}$ ) & $\frac{\text { \# Individuals }}{0.09}$ & Decrease \\
\hline Biomass (mg dry mass $/ \mathrm{m}^{2}$ ) & $M=a L^{\mathrm{b}}$ & Decrease \\
\hline EPT Taxa & \# of distinct EPT taxa & Decrease \\
\hline Percentage EPT & $\frac{\# \text { Individuals of orders EPT }}{\text { Total \# individuals in sample }}$ & Decrease \\
\hline Percentage R-Strategist Taxa & $\frac{\# R-\text { Strategist Individuals }}{\text { Total \# individuals in sample }}$ & Increase \\
\hline Percentage Diptera & $\frac{\text { \# Individuals of order Diptera }}{\text { \# Individuals }}$ & Increase \\
\hline Shannon's Diversity Index $\left(\mathrm{H}^{\prime}\right)$ & $-\sum_{i=1}^{R} p_{i} * \ln (p i)$ & Decrease \\
\hline $\begin{array}{l}\text { Hilsenhoff Family Biotic Index } \\
\text { (FBI) }\end{array}$ & & Increase \\
\hline
\end{tabular}

Notes: The biomass calculation refers to the length-mass equation described by Benke et al. (1999) where $M=$ organism dry mass $(\mathrm{mg}), L=$ linear length $(\mathrm{mm})$, and $a$ and $b$ are constants. Shannon's Diversity Index refers to the equation described by Sponseller et al. (2001) where $p_{i}=$ the proportion of individuals found in the $i^{\text {th }}$ taxon and $R=$ the total number of taxon.

Table 4.2 Evaluation of water quality using the family-level Hilsenhoff biotic index (Brinkhurst et al. 2009, Hilsenhoff 1988)

\begin{tabular}{ccc}
\hline \hline Hilsenhoff Family & & \\
Biotic Index Score & Water Quality & Degree of Organic Pollution \\
\hline $0-3.75$ & Excellent & Organic pollution unlikely \\
$3.76-4.25$ & Very good & Possible slight organic pollution \\
$4.26-5.00$ & Good & Some organic pollution probable \\
$5.01-5.75$ & Fair & Fairly substantial pollution likely \\
$5.76-6.50$ & Fairly poor & Substantial pollution likely \\
$6.51-7.25$ & Poor & Very substantial pollution likely \\
$7.26-10.00$ & Very poor & Severe organic pollution likely \\
\hline
\end{tabular}




\subsubsection{Dataset Limitations}

Macroinvertebrate families were identified to the taxonomic level of family (Level II; Ode 2007). Although this level of taxonomic effort is common in the bioassessment literature, it must be noted that potentially important species-specific traits may be obscured. Functional feeding group membership and pollution tolerance values are generalized at the family level and are known to be variable among genera, species, and subspecies within the same family. While identifying samples to the genus/species level (i.e., Level III) would provide increased insight into macroinvertebrate community structure and function, this level of effort was not possible in the present study.

Water quality data were limited due to a lack of access to monitoring equipment through the course of the study. Measurements of temperature $(\mathrm{n}=362), \mathrm{pH}(\mathrm{n}=329)$, and dissolved oxygen $(\mathrm{n}=150)$ were only collected when a YSI multiprobe was available and properly calibrated for each parameter. The relatively smaller sample sizes of the water quality data set meant that these parameters could not be included in the main statistical analysis $(n=448)$ without significantly reducing the power of other variables. Therefore, sub analyses were conducted to evaluate the potential influence of these parameters on macroinvertebrate community structure.

Solar radiation data were collected using a hemispherical camera in spring 2017. These images were analyzed using sunpaths that produced unique data values for all the sampling events. It must be noted that these data were representative of spring 2017 canopy conditions and may not reflect shading levels that existed when macroinvertebrate samples were collected in 2015 and 2016. A simple linear regression was performed to compare solar radiation to percent shaded data that was collected alongside macroinvertebrate samples. It was found that solar radiation and percent shaded 
$\left(\arcsin \sqrt{ } x\right.$ transformed) were highly associated $\left(\mathrm{p}<0.0001, b_{l}=-83811\right.$, adjusted $\mathrm{R}^{2}=$ $0.17, \mathrm{DF}=448)($ Figure 4.11). Furthermore, no major discernable changes to the canopy occurred between study years. Therefore, it is likely that solar radiation values generated in 2017 were a reasonable proxy for conditions at the time of field sampling in 2015 and 2016. However, this variable should be viewed with a degree of skepticism.

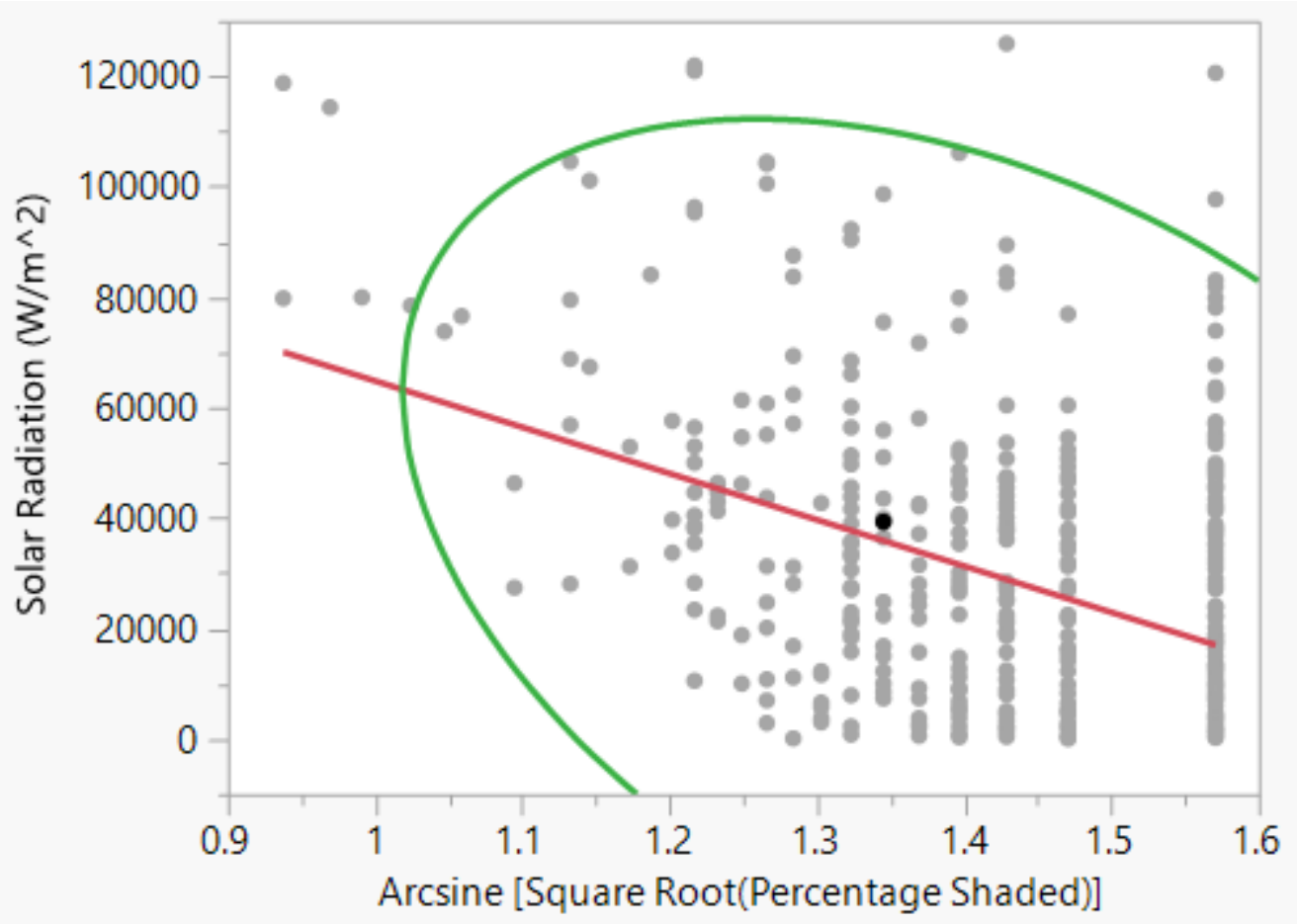

Figure 4.11 Bivariate fit of solar radiation $\left(\mathrm{W} / \mathrm{m}^{2}\right)$ by Arcsine transformed percentage shaded. The plot was fitted with a linear fit line and a 99\% density ellipse.

\subsection{Statistical Procedures}

Nonmetric multidimensional scaling (NMDS) and analysis of variance (ANOVA) procedures were used to (1) assess variability in macroinvertebrate community structure between and within study reaches, and (2) determine the significance of select physical habitat characteristics as drivers of community structure, respectively. 


\subsubsection{Nonmetric Multidimensional Scaling}

Nonmetric multidimensional scaling (NMDS) is an indirect gradient analysis which produces an ordination based on ecological distance measurements. NMDS attempts to display the dissimilarity between observations in a low-dimensional space. As an iterative algorithm, NMDS requires multiple runs to ensure a stable solution has been reached. Nonetheless, a stable solution, or a good correlation between community dissimilarities and ordination distances, can be difficult to reach because the iteration easily gets trapped in local optimum instead of finding the global optimum (Oksanen 2015). Therefore, it is commonplace and prudent to use several random starts and select the best solution obtained.

Stress $(\mathrm{S})$ is a goodness of fit statistic and the primary criterion used to assess the strength of a NMDS model. It is the disagreement between a 2-D configuration and predicted values from the regression. If the 2-D configuration perfectly preserves the original rank orders, then a plot of one against the other creates a positive linear relationship. The extent to which points on the 2-D relationship deviate from this line of best of fit determines the degree of stress. A commonly used criterion for stress is $<0.05$ provides an excellent representation in reduced dimensions, $<0.1$ is good, $<0.2$ is fair/suspect, and $<0.3$ is a poor representation (Oksanen 2015). This relationship can be visualized using a Shepard plot, where large scatter around the line of best fit suggests that ecological dissimilarities are not well preserved in the 2-D model.

NMDS was performed in the program R (R Core Team 2017). The community ecology package Vegan contains the function "metaMDS" and was used to produce all NMDS ordinations. This function preforms NMDS a user-specified number of times and selects the best solution. This function also automatically performs additional procedures 
such as data transformation, dissimilarity matrix calculation, and Principle Component Analysis rotation. NMDS was conducted on two datasets: macroinvertebrate abundance and functional feeding group composition. The macroinvertebrate abundance data were $\log _{10}(x+1)$ transformed in order to reduce the wide range of family counts per sample. This transformation significantly reduced the solution's final stress. The R functions “ordisurf" and "envfit" were used to assess the influence of select environmental variables on these datasets.

After selecting a model, interpreting NMDS plot is straightforward: objects that are ordinated closer to one another are likely to be more similar than those further apart (Legendre and Legendre 1998). Tight clusters of points that are separated from the rest of the points in ordination space may indicate meaningful sub-populations within the data. Environmental variables were fit onto ordinations to help visualize abiotic relationships and produced measures of correlation between physical and biological data in ordination space. Only variables that had a statistically significant $(\alpha=0.05)$ linear relationship with macroinvertebrate abundances in ordination space were included in the figures. For quantitative environmental variables, these relationships were represented using vector arrows, with arrows pointing toward the direction of the association and arrow length indicating the strength of the association. For categorical environmental variables, $95 \%$ confidence interval ellipses for the weighted average of each variable level were fitted to the plot.

\subsubsection{Analysis of Variance Procedures}

Analysis of variance (ANOVA) is a collection of statistical models used to detect significant differences among group means. ANOVA also partitions total variability of 
response variables to explanatory variables. This function makes it a useful tool in community ecology because it calculates the variability in community structure metrics that is explained by associated environmental data.

There are three major assumptions that must be met for ANOVA to be valid and appropriate: independence of cases, normality, and homoscedasticity of variances. Independence of cases is ensured by proper randomization. Normality is checked by plotting a model's studentized residuals and checking its fit in a normal quantile plot. Homoscedasticity of variances is checked by plotting a model's residuals by its predicted values. Any lack of independence among the transects in the same reach was modeled by nesting each main transect within its associated study reach and specifying the effect to be random. Non-normal biological data were transformed as necessary to meet the assumption of normality. Homoscedasticity of variances was also checked for each model.

ANOVA procedures were performed in the program JMP ${ }^{\circledR}$ Pro 13.0.0 (SAS Institute Inc. 2013). Each ANOVA model analyzed the significance of select environmental variables as predictors of a metric of macroinvertebrate community structure. The hypotheses tested in each model were:

$$
\begin{aligned}
& \mathrm{H}_{0}: \beta_{1}=\beta_{2}=\ldots=\beta_{\mathrm{k}}=0 \\
& \mathrm{H}_{\mathrm{a}}: \text { At least one } \beta \text { is not zero }
\end{aligned}
$$

The null hypothesis $\left(\mathrm{H}_{0}\right)$ claimed that there was no significant correlation between any of the environmental variables and the metric of macroinvertebrate community structure, whereas the alternative hypothesis $\left(\mathrm{H}_{\mathrm{a}}\right)$ claimed that at least one of the environmental variables was significantly associated with the response variable. The large number of 
variables included in each ANOVA model increased the risk of Type I error. Therefore, a significance level of $\alpha=0.01$ was used to reduce the risk of inflating the Type I error rate.

A separate ANOVA model was created for each metric of macroinvertebrate community structure. A set of control variables were kept in each model regardless of statistical significance; these were Study Reach, Season, Percent Shaded, and Solar Radiation. Models were constructed using an iterative stepwise procedure where nonsignificant environmental variables $(\mathrm{p} \geq 0.01)$ were removed one at a time until the best model was reached. Coefficient p-values were used to determine which environmental variables to keep in the regression model. For categorical environmental variables, the coefficient p-value indicated whether one category of that predictor influenced the mean of the response variable. For quantitative environmental variables, the coefficient p-value indicated whether the coefficient of that predictor, with respect to the mean of the response variable, was non-zero.

The adjusted $\mathrm{R}^{2}$ value of each model reported the amount variability in the response variable that the model explained. Significant quantitative independent variables were reported using parameter estimate tables which included slope coefficient estimates, allowing for the magnitude and direction of significant associations to be interpreted. The levels of significant categorical variables were compared using a Tukey's honest significant difference (HSD) Test. This test generates a connected letters report, which connects similar levels with letters while levels that are significantly different are not connected. 


\section{CHAPTER 5. RESULTS}

\subsection{Descriptive Results}

A total of 56,061 macroinvertebrates representing 46 different families were collected, identified, and measured (Table 5.1). Pooled across all study reaches and sampling events, the most abundant taxa (Order: Family), in order, were Diptera: Chironomidae, Plecoptera: Nemouridae, and larval Coleoptera: Elmidae. Conversely, the least abundant families were Coleoptera: Dystiscidae, Plecoptera: Capniidae, and Trichoptera: Sericostomatidae. Chironomids accounted for $18 \%$ of the total density and $13 \%$ of the total biomass, nemourids accounted for $15 \%$ of the total density and $5 \%$ of the total biomass, and larval elmids accounted for $14 \%$ of the total density and $11 \%$ of the total biomass. 
Table 5.1 Primary functional feeding group (FFG), tolerance value designation, and mean density for each macroinvertebrate family observed in Little Creek, 2015-2016.

\begin{tabular}{|c|c|c|c|c|}
\hline & Taxon & FFG & $\begin{array}{c}\text { Tolerance } \\
\text { Value }\end{array}$ & $\begin{array}{c}\text { Density } \\
\left(\text { Individuals } / \mathrm{m}^{2} \text { ) }\right.\end{array}$ \\
\hline \multicolumn{5}{|c|}{ Ephemeroptera } \\
\hline & Ameletidae & $\mathrm{cg}$ & 0 & 4.7 \\
\hline & Baetidae & $\mathrm{cg}$ & 4 & 180.6 \\
\hline & Ephemerellidae & $\mathrm{cg}$ & 1 & 18.8 \\
\hline & Heptageniidae & $\mathrm{sc}$ & 4 & 45.1 \\
\hline & Leptophlebiidae & $\mathrm{cg}$ & 4 & 54.9 \\
\hline \multicolumn{5}{|l|}{ Odonata } \\
\hline & Cordulegastridae & $\mathrm{p}$ & 3 & 18.6 \\
\hline \multicolumn{5}{|l|}{ Plecoptera } \\
\hline & Capniidae & sh & 1 & 0.2 \\
\hline & Chloroperlidae & $\mathrm{p}$ & 1 & 12.8 \\
\hline & Nemouridae & $\mathrm{sh}$ & 2 & 195.9 \\
\hline & Peltoperlidae & sh & 1 & 0.4 \\
\hline & Perlidae & $\mathrm{p}$ & 1 & 14.9 \\
\hline & Perlodidae & $\mathrm{p}$ & 2 & 8.6 \\
\hline \multicolumn{5}{|l|}{ Hemiptera } \\
\hline & Veliidae & $\mathrm{p}$ & 9 & 7.0 \\
\hline \multicolumn{5}{|l|}{ Megaloptera } \\
\hline & Sialidae & $\mathrm{p}$ & 4 & 0.2 \\
\hline \multicolumn{5}{|l|}{ Trichoptera } \\
\hline & Brachycentridae & $\mathrm{cg}$ & 3 & 27.2 \\
\hline & Calamoceratidae & sh & 1 & 6.6 \\
\hline & Glossosomatidae & $\mathrm{sc}$ & 1 & 11.8 \\
\hline & Goeridae & $\mathrm{sc}$ & 0 & 8.5 \\
\hline & Hydropsychidae & $\mathrm{cg}$ & 1 & 33.1 \\
\hline & Lepidostomatidae & $\mathrm{sh}$ & 4 & 18.9 \\
\hline & Odontoceridae & sh & 1 & 5.6 \\
\hline & Philopotamidae & $\mathrm{cf}$ & 3 & 9.0 \\
\hline & Polycentropodidae & $\mathrm{p}$ & 6 & 0.6 \\
\hline & Sericostomatidae & sh & 3 & 0.2 \\
\hline & Rhyacophilidae & $\mathrm{p}$ & 0 & 17.5 \\
\hline & Uenoidae & $\mathrm{cg}$ & 0 & 2.4 \\
\hline \multicolumn{5}{|l|}{ Coleoptera } \\
\hline & Dystiscidae & $\mathrm{p}$ & 5 & 0.2 \\
\hline & Elmidae & $\mathrm{cg}$ & 4 & 209.0 \\
\hline & Hydraenidae & $\mathrm{sc}$ & 5 & 1.4 \\
\hline & Hydrophilidae & $\mathrm{p}$ & 5 & 1.8 \\
\hline & Psephenidae & $\mathrm{sc}$ & 4 & 18.3 \\
\hline \multicolumn{5}{|l|}{ Diptera } \\
\hline & Ceratopogonidae & $\mathrm{p}$ & 6 & 11.2 \\
\hline & Chironomidae & $\mathrm{cg}$ & 6 & 238.3 \\
\hline
\end{tabular}




$\begin{array}{lccc}\text { Dixidae } & \mathrm{cg} & 2 & 7.7 \\ \text { Empididae } & \mathrm{p} & 6 & 6.4 \\ \text { Psychodidae } & \mathrm{cg} & 10 & 17.8 \\ \text { Simuliidae } & \mathrm{cf} & 6 & 28.5 \\ \text { Stratiomyidae } & \mathrm{cg} & 8 & 1.9 \\ \text { Tabanidae } & \mathrm{p} & 8 & 0.3 \\ \text { Tipulidae } & \mathrm{sh} & 3 & 6.5\end{array}$

Non-insects

$\begin{array}{lllc}\text { Acari } & \mathrm{p} & 5 & 11.7 \\ \text { Gastropoda } & \mathrm{sc} & 7 & 58.6 \\ \text { Oligochaeta } & \mathrm{cg} & 5 & 15.7 \\ \text { Ostracoda } & \mathrm{cg} & 8 & 3.5 \\ \text { Pelecypoda } & \mathrm{cf} & 8 & 4.0\end{array}$

Notes: Functional feeding group (FFG) designation are: $\mathrm{cg}=$ Collector-Gatherer, $\mathrm{cf}=$ Collector-Filterer, $\mathrm{p}=$ Predator, $\mathrm{sc}=$ Scraper, $\mathrm{sh}=$ Shredder. Family tolerance values (0 to 10) are based on known sensitivity of California macroinvertebrate taxon to organic pollutants (Brinkhurst et al. 2009).

Collected environmental data indicated that a gradient of physical conditions existed in Little Creek (Table 5.2, Table 5.3). Stream discharge decreased with distance from the outlet (i.e., confluence with mainstem Scotts Creek). Mean stream shading was high $(>90 \%)$ at each study reach and generally increased at each site from spring to fall (except Upper South Fork in summer 2015). Averaged across all study sites, mean \pm SE percent shaded was $94.1 \pm 2.9 \%$ in spring (range $=90.3 \%$ to $96.8 \%), 95.5 \pm 2.1 \%$ in summer $($ range $=92.8$ to $99.1 \%)$ and $98.31 \pm 1.5 \%$ in fall $($ range $=95.1 \%$ to $100 \%)$. Substrate diameter was consistently highest in the Upper South Fork where the channel bottom is predominantly bedrock and higher proportions of sedimentary rock substrate ( $\geq 40.0 \%$; Table 5.2, Table 5.3) were observed in the lower study reaches. 
Table 5.2 Environmental data collected in spring, summer, and fall of 2015. Percentage stream shading, solar radiation, and cross-sectional area were measured at each main transect location and averaged here.

\begin{tabular}{|c|c|c|c|c|c|c|c|c|}
\hline Season & $\begin{array}{l}\text { Study } \\
\text { Reach }\end{array}$ & $\begin{array}{c}\text { Discharge } \\
\left(\mathrm{m}^{3} / \mathrm{s}\right)\end{array}$ & $\begin{array}{l}\text { Mean } \\
\text { Shaded } \\
(\%)\end{array}$ & $\begin{array}{c}\text { Mean } \\
\text { Solar } \\
\text { Radiation } \\
\left(\mathrm{W} / \mathrm{m}^{2}\right)\end{array}$ & $\begin{array}{c}\text { Mean } \\
\text { Cross- } \\
\text { Sectional } \\
\text { Area } \\
\left(\mathrm{m}^{2}\right)\end{array}$ & $\begin{array}{c}\text { Mean } \\
\text { Substrate } \\
\text { Diameter } \\
(\mathrm{mm})\end{array}$ & $\begin{array}{c}\text { Substrate } \\
\text { D-50 } \\
(\mathrm{mm})\end{array}$ & $\begin{array}{c}\text { Sedimentary } \\
\text { Substrate } \\
(\%)\end{array}$ \\
\hline \multirow[t]{7}{*}{ Spring } & MS & 0.008 & 90.27 & 58365.52 & 0.12 & 1127.55 & 320.0 & 40.00 \\
\hline & UMS & 0.007 & 95.64 & 35496.09 & 0.10 & 1132.94 & 320.0 & 41.82 \\
\hline & NF & 0.004 & 90.27 & 54011.98 & 0.06 & 388.71 & 80.0 & 9.09 \\
\hline & $\mathrm{TF}$ & 0.002 & 92.73 & 47345.61 & 0.08 & 1060.74 & 160.0 & 3.64 \\
\hline & UNF & 0.003 & 96.00 & 43703.12 & 0.10 & 2097.18 & 1280.0 & 10.91 \\
\hline & SF & 0.002 & 96.82 & 44342.77 & 0.13 & 1035.98 & 450.0 & 54.55 \\
\hline & USF & 0.001 & 96.67 & 46993.73 & 0.06 & 1673.56 & 900.0 & 4.44 \\
\hline \multirow[t]{7}{*}{ Summer } & MS & 0.002 & 92.8 & 48429.58 & 0.12 & 544.71 & 14.0 & 42.00 \\
\hline & UMS & 0.003 & 97.09 & 14162.95 & 0.09 & 390.91 & 16.0 & 49.09 \\
\hline & NF & 0.002 & 93.45 & 34444.11 & 0.04 & 389.52 & 8.0 & 5.45 \\
\hline & $\mathrm{TF}$ & 0.002 & 94.27 & 42191.83 & 0.06 & 544.15 & 10.0 & 10.91 \\
\hline & UNF & 0.001 & 97.36 & 40094.21 & 0.05 & 979.32 & 24.0 & 10.91 \\
\hline & SF & 0.001 & 98.36 & 27575.06 & 0.13 & 256.38 & 26.0 & 67.27 \\
\hline & USF & 0.001 & 94.89 & 36614.14 & 0.06 & 1444.21 & 36.0 & 11.11 \\
\hline \multirow[t]{7}{*}{ Fall } & MS & 0.003 & 96.73 & 5158.55 & 0.11 & 190.59 & 26.0 & 51.43 \\
\hline & UMS & 0.003 & 100 & 101.00 & 0.12 & 253.22 & 32.0 & 59.05 \\
\hline & NF & 0.002 & 96.82 & 8734.45 & 0.04 & 88.61 & 16.0 & 16.19 \\
\hline & $\mathrm{TF}$ & 0.005 & 97.36 & 7837.92 & 0.07 & 652.91 & 11.0 & 5.71 \\
\hline & UNF & 0.002 & 99.45 & 5187.37 & 0.08 & 722.17 & 14.0 & 9.52 \\
\hline & SF & 0.001 & 100 & 101.00 & 0.15 & 394.94 & 29.0 & 66.67 \\
\hline & USF & 0.001 & 97.89 & 2018.75 & 0.07 & 1950.98 & 213.0 & 15.29 \\
\hline
\end{tabular}


Table 5.3 Environmental data collected in spring, summer, and fall of 2016. Percentage stream shading, solar radiation, and cross-sectional area were measured at each main transect location and averaged here.

\begin{tabular}{cc|ccccccc}
\hline \hline \multicolumn{1}{c}{ Season } & Reach & $\begin{array}{c}\text { Mean } \\
\left(\mathrm{m}^{3} / \mathrm{s}\right)\end{array}$ & $\begin{array}{c}\text { Mean } \\
\text { Solar } \\
(\%)\end{array}$ & $\begin{array}{c}\text { Mean } \\
\text { Radiation } \\
\left(\mathrm{W} / \mathrm{m}^{2}\right)\end{array}$ & $\begin{array}{c}\text { Means } \\
\text { Sectional } \\
\text { Area }\left(\mathrm{m}^{2}\right)\end{array}$ & $\begin{array}{c}\text { Substrate } \\
\text { Diameter } \\
(\mathrm{mm})\end{array}$ & $\begin{array}{c}\text { Substrate } \\
\text { D-50 } \\
(\mathrm{mm})\end{array}$ & $\begin{array}{c}\text { Sedimentary } \\
\text { Substrate } \\
(\%)\end{array}$ \\
\hline Spring & MS & 0.017 & 95.27 & 58179.99 & 0.16 & 158.12 & 20.00 & 44.76 \\
& UMS & 0.012 & 93.45 & 38108.19 & 0.18 & 175.30 & 31.00 & 51.43 \\
& NF & 0.009 & 91.55 & 56425.53 & 0.12 & 45.69 & 15.00 & 10.48 \\
& TF & 0.010 & 91.64 & 47070.46 & 0.09 & 375.14 & 10.00 & 11.43 \\
& UNF & 0.011 & 98.45 & 44775.23 & 0.09 & 815.16 & 29.00 & 13.33 \\
& SF & 0.003 & 98.73 & 43321.37 & 0.19 & 216.78 & 44.00 & 77.14 \\
& USF & 0.001 & 96.78 & 46461.17 & 0.07 & 2319.70 & 4000.00 & 16.47 \\
\hline Summer & MS & 0.008 & 94.91 & 52378.22 & 0.10 & 180.45 & 24.00 & 60.95 \\
& UMS & 0.006 & 99.09 & 20131.12 & 0.17 & 139.53 & 24.00 & 63.81 \\
& NF & 0.004 & 95.73 & 33523.92 & 0.08 & 39.29 & 18.00 & 15.24 \\
& TF & 0.015 & 94.27 & 42617.22 & 0.10 & 121.36 & 31.00 & 26.67 \\
& UNF & 0.003 & 97.09 & 41939.36 & 0.08 & 744.34 & 39.00 & 14.29 \\
& SF & 0.002 & 98.82 & 26290.52 & 0.14 & 249.96 & 34.00 & 79.05 \\
& USF & 0.002 & 96.67 & 35956.15 & 0.07 & 1944.21 & 154.00 & 10.59 \\
\hline Fall & MS & 0.012 & 95.09 & 5158.55 & 0.18 & 85.13 & 39.00 & 46.67 \\
& UMS & 0.009 & 100.00 & 1282.02 & 0.24 & 87.90 & 32.00 & 62.86 \\
& NF & 0.020 & 95.82 & 8146.73 & 0.13 & 39.85 & 19.00 & 10.48 \\
& TF & 0.005 & 98.45 & 8984.46 & 0.09 & 333.51 & 16.00 & 7.62 \\
& UNF & 0.008 & 98.73 & 6011.66 & 0.12 & 745.91 & 33.00 & 16.19 \\
& SF & 0.003 & 99.91 & 939.88 & 0.14 & 257.62 & 58.00 & 84.76 \\
& USF & 0.001 & 97.89 & 2018.75 & 0.06 & 2225.13 & 4000.00 & 21.18 \\
\hline
\end{tabular}


It is difficult to make any immediate observations on biological condition based on the summary tables (Table 5.4, Table 5.5). Most of the values appear to be variable, with large differences between and within study reaches and no obvious discernable patterns. Mean FBI values indicated good to excellent water quality throughout the study reaches.

Table 5.4 Biological data collected in spring, summer, and fall of 2015. Density was calculated by dividing the total number of individuals collected at a study reach by the total area sampled. Biomass, Hilsenhoff Family Biotic Index (FBI), and Shannon's Diversity Index $\left(\mathrm{H}^{\prime}\right)$ were averaged for each study reach.

\begin{tabular}{cc|ccccccc}
\hline \hline \multirow{2}{*}{ Season } & $\begin{array}{c}\text { Study } \\
\text { Reach }\end{array}$ & $\begin{array}{c}\text { Density } \\
\left(\text { Individuals } / \mathrm{m}^{2}\right)\end{array}$ & $\begin{array}{c}\text { Biomass } \\
\left(\mathrm{mg} \mathrm{DM} / \mathrm{m}^{2}\right)\end{array}$ & $\begin{array}{c}\% \\
\text { EPT }\end{array}$ & $\begin{array}{c}\% \\
\text { Diptera }\end{array}$ & $\begin{array}{c}\text { Mean } \\
\text { FBI }\end{array}$ & $\begin{array}{c}\text { Mean } \\
\mathrm{H}^{\prime}\end{array}$ & $\begin{array}{c}\text { \% R-Strategist } \\
\text { Taxa }\end{array}$ \\
\hline & MS & 648 & 438.4 & 56.1 & 13.8 & 3.5 & 1.8 & 26.6 \\
& UMS & 1250 & 735.6 & 66.8 & 14.1 & 3.2 & 2.0 & 24.9 \\
& NF & 1069 & 1192.3 & 70.3 & 8.5 & 3.0 & 1.9 & 25.2 \\
& TF & 514 & 467.1 & 63.6 & 16.0 & 3.3 & 1.7 & 37.5 \\
& UNF & 601 & 606.2 & 72.0 & 11.4 & 3.1 & 1.7 & 35.0 \\
& SF & 1051 & 371.2 & 39.8 & 43.6 & 3.6 & 1.6 & 47.1 \\
& USF & 1078 & 571.8 & 44.7 & 41.3 & 3.5 & 1.6 & 50.6 \\
\hline \multirow{5}{*}{ Summer } & MS & 2156 & 1223.2 & 36.3 & 30.0 & 3.7 & 1.8 & 30.5 \\
& UMS & 3098 & 738.7 & 48.3 & 23.0 & 4.0 & 2.0 & 19.3 \\
& NF & 1939 & 779.7 & 58.0 & 18.1 & 3.8 & 2.1 & 29.5 \\
& TF & 1050 & 408.5 & 57.1 & 21.9 & 3.6 & 2.0 & 51.4 \\
& UNF & 1311 & 598.4 & 55.4 & 24.5 & 3.7 & 2.2 & 39.9 \\
& SF & 2017 & 652.1 & 35.8 & 34.1 & 3.7 & 1.7 & 16.7 \\
& USF & 2229 & 374.0 & 38.6 & 49.7 & 4.3 & 1.5 & 18.4 \\
\hline \multirow{6}{*}{ Fall } & MS & 1750 & 555.3 & 35.9 & 18.8 & 3.5 & 1.7 & 31.2 \\
& UMS & 1664 & 826.6 & 42.5 & 16.5 & 3.7 & 2.0 & 24.9 \\
& NF & 1418 & 901.1 & 54.9 & 5.5 & 3.1 & 1.9 & 11.0 \\
& TF & 667 & 316.5 & 33.7 & 5.4 & 3.3 & 1.6 & 7.9 \\
& UNF & 196 & 60.0 & 40.0 & 13.0 & 2.6 & 1.4 & 15.0 \\
& SF & 871 & 493.1 & 23.5 & 13.7 & 2.7 & 1.4 & 8.9 \\
& USF & 1111 & 197.7 & 52.9 & 21.7 & 3.0 & 1.7 & 24.7 \\
\hline
\end{tabular}


Table 5.5 Biological data collected in spring, summer, and fall of 2016. Density was calculated by dividing the total number of individuals collected at a study reach by the total area sampled. Biomass, Hilsenhoff Family Biotic Index (FBI), and Shannon's Diversity Index $\left(\mathrm{H}^{\prime}\right)$ were averaged for each study reach.

\begin{tabular}{cc|ccccccc}
\hline \hline \multirow{2}{*}{ Season } & $\begin{array}{c}\text { Study } \\
\text { Reach }\end{array}$ & $\begin{array}{c}\text { Density } \\
\left.\text { (Individuals } / \mathrm{m}^{2}\right)\end{array}$ & $\begin{array}{c}\text { Biomass } \\
\left(\mathrm{mg} \mathrm{DM} / \mathrm{m}^{2}\right)\end{array}$ & $\begin{array}{c}\% \\
\text { EPT }\end{array}$ & $\begin{array}{c}\% \\
\text { Diptera }\end{array}$ & $\begin{array}{c}\text { Mean } \\
\text { FBI }\end{array}$ & $\begin{array}{c}\text { Mean } \\
\mathrm{H}^{\prime}\end{array}$ & $\begin{array}{c}\text { \% R-Strategist } \\
\text { Taxa }\end{array}$ \\
\hline & MS & 2748 & 1165.7 & 66.7 & 14.4 & 3.6 & 1.7 & 45.2 \\
& UMS & 2060 & 855.6 & 63.8 & 18.8 & 3.8 & 1.8 & 42.0 \\
& NF & 736 & 271.9 & 58.6 & 30.9 & 3.4 & 1.5 & 35.4 \\
& TF & 207 & 100.3 & 62.3 & 20.3 & 3.3 & 1.4 & 33.5 \\
& UNF & 946 & 205.9 & 78.3 & 13.7 & 3.2 & 1.7 & 35.6 \\
& SF & 847 & 266.2 & 34.6 & 32.0 & 3.5 & 1.6 & 34.6 \\
& USF & 1310 & 332.8 & 25.6 & 69.4 & 4.7 & 1.3 & 72.4 \\
\hline \multirow{5}{*}{ Summer } & MS & 1788 & 2684.3 & 41.8 & 18.4 & 3.9 & 2.0 & 25.3 \\
& UMS & 1047 & 2628.5 & 54.8 & 15.5 & 3.7 & 1.8 & 21.7 \\
& NF & 1528 & 1113.9 & 70.5 & 10.9 & 3.5 & 2.1 & 19.3 \\
& TF & 927 & 844.4 & 64.1 & 19.6 & 3.9 & 2.1 & 31.3 \\
& UNF & 439 & 197.4 & 73.7 & 12.9 & 3.2 & 1.9 & 22.7 \\
& SF & 1176 & 936.9 & 47.6 & 19.1 & 3.0 & 1.9 & 19.9 \\
& USF & 1826 & 633.4 & 47.3 & 45.0 & 4.0 & 1.8 & 49.4 \\
\hline \multirow{2}{*}{ Fall } & MS & 2033 & 1349.1 & 60.9 & 15.1 & 3.5 & 2.1 & 36.1 \\
& UMS & 1015 & 421.4 & 51.8 & 8.9 & 3.6 & 2.0 & 30.4 \\
& NF & 1457 & 441.6 & 68.6 & 11.3 & 3.7 & 2.0 & 40.0 \\
& TF & 1499 & 985.8 & 50.7 & 19.6 & 3.6 & 2.1 & 28.5 \\
& UNF & 1396 & 414.1 & 43.5 & 44.2 & 3.8 & 2.0 & 50.0 \\
& SF & 2235 & 622.6 & 27.1 & 22.6 & 2.0 & 1.3 & 25.7 \\
& USF & 1929 & 274.0 & 39.1 & 46.7 & 3.9 & 1.8 & 53.8 \\
\hline
\end{tabular}




\subsection{Nonmetric Multidimensional Scaling}

Nonmetric multidimensional scaling (NMDS) was performed on two separate datasets: macroinvertebrate abundance data (family level taxonomic resolution) and functional feeding group composition. The association of environmental variables and macroinvertebrate abundance was evaluated using linear regressions in ordination space $(\alpha=0.05)$. This relatively higher significance level was used so that $\mathrm{R}$ would be more sensitive to any associations that may have existed in the study reaches. Water quality parameters were assessed in a separate analysis due to small sample sizes.

\subsubsection{Macroinvertebrate Abundance}

Family level abundance data was transformed using a $\log _{10}(x+1)$ transformation. The function metaMDS within R automatically selected to use a Bray-Curtis dissimilarity matrix. It was found that five dimensions returned the lowest stress model while still converging on a solution with acceptable stress $(S=0.13)$. MetaMDS automatically centered, rotated, and scaled the solution in ordination space.

Ordinating macroinvertebrate abundance dissimilarities in five-dimensional space produced a plot where closely ordinated families were more commonly observed together (Figure 5.1). The least common families were ordinated around the peripheral of the plot. 


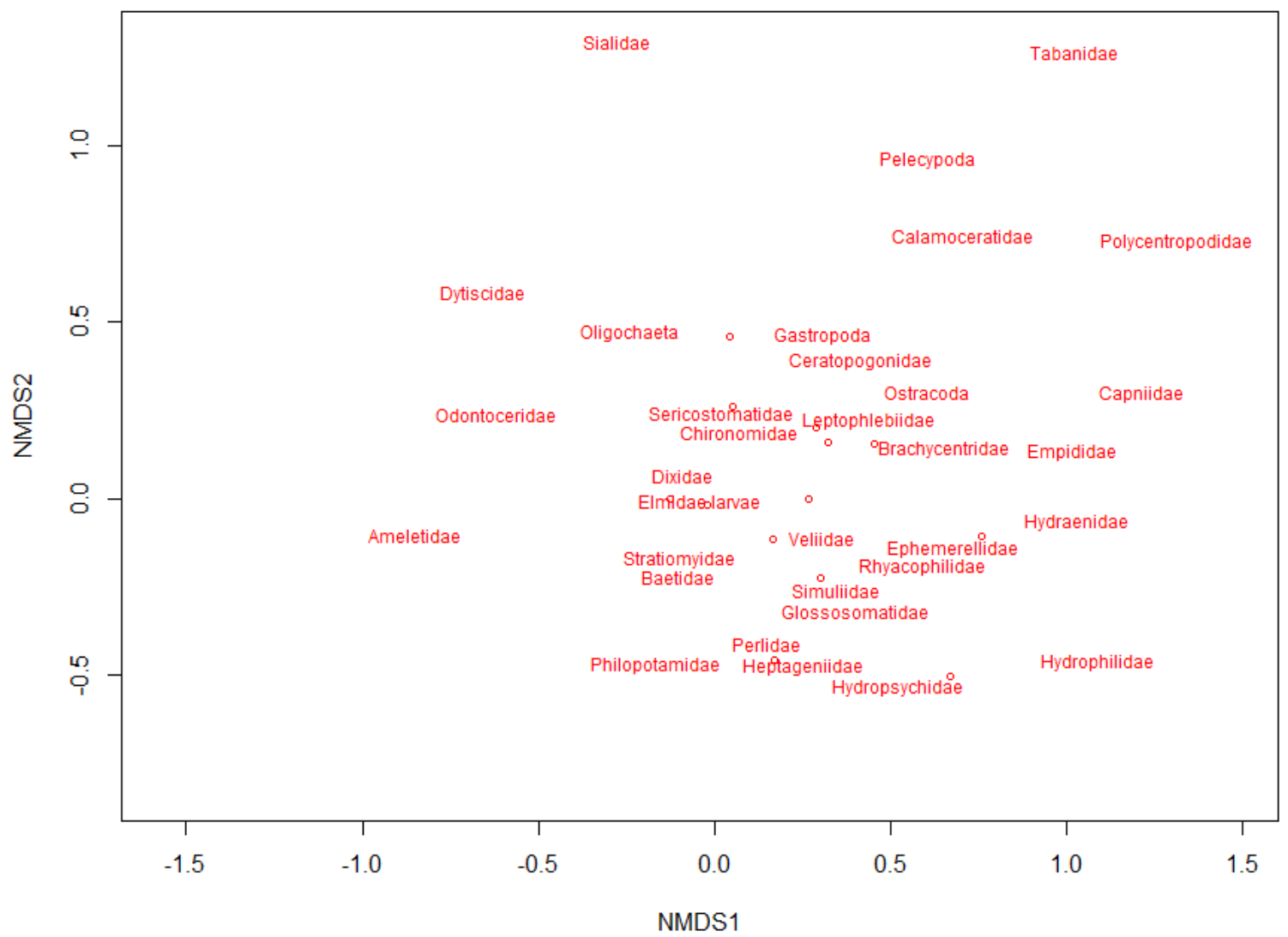

Figure 5.1 NMDS plot of macroinvertebrate community composition (relative abundance). Final stress $(S)=0.13$. Label priority was given to most abundant families. Lower priority families that were obscured by higher priority families were represented by points. Families oriented more closely together were commonly observed together at the same sampling locations. 
The abundance plot was fitted with $95 \%$ confidence interval ellipses for the weighted average of each study reach (Figure 5.2). There was a clear site level separation at the South Fork (SF) and Upper South Fork (USF) study reaches. Both ellipses were oriented over Chironomidae.

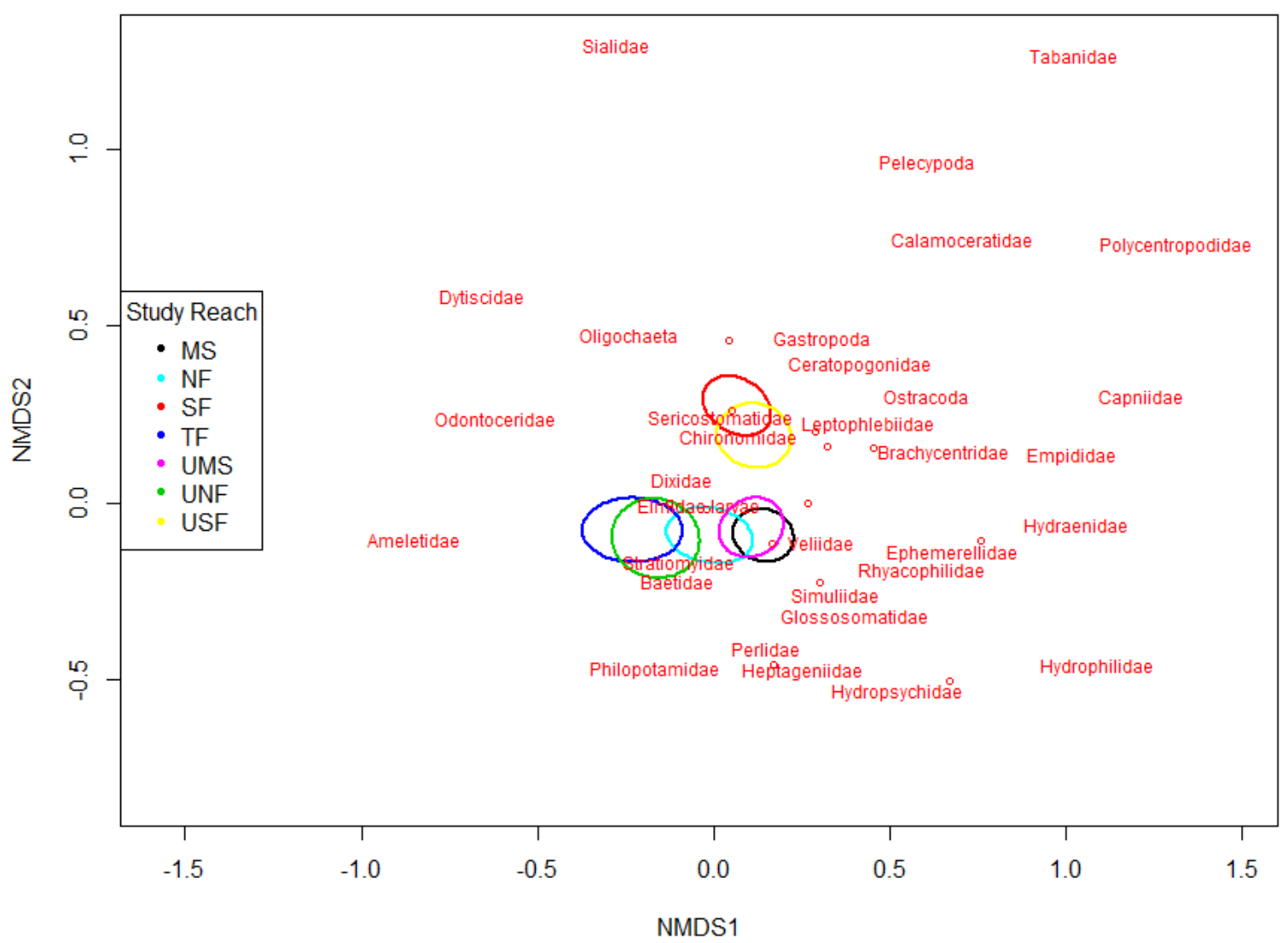

Figure 5.2 NMDS plot macroinvertebrate community composition (relative abundance) fitted with $95 \%$ confidence interval ellipses for the weighted average of each study reach. 
The ordination plot was then fitted with $95 \%$ confidence intervals of the weighted averages for each season sampled (Figure 5.3). There was a clear season level separation of spring samples from fall and spring samples which were oriented on top of each other at the origin.

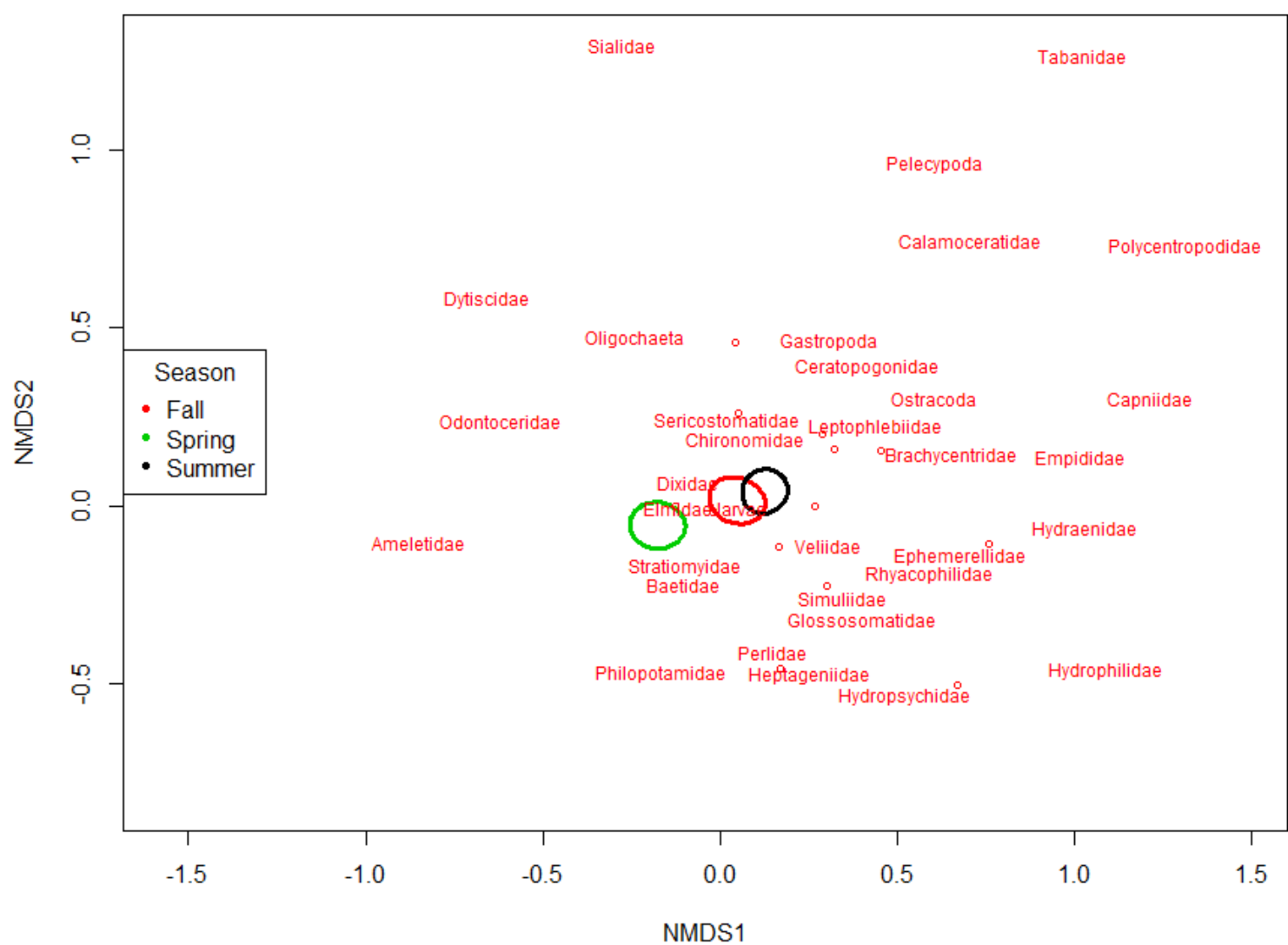

Figure 5.3 NMDS plot of macroinvertebrate community composition (relative abundance) fitted with $95 \%$ confidence interval ellipses for the weighted average of each season. 
Environmental variables fitted onto the abundance plot (Figure 5.4) revealed that cross-sectional area $\left(\mathrm{p}=0.001, \mathrm{R}^{2}=0.08\right)$, solar radiation $\left(\mathrm{p}=0.024, \mathrm{R}^{2}=0.02\right)$, and habitat type $\left(\mathrm{p}=0.001, \mathrm{R}^{2}=0.06\right)$ were each significantly associated with family abundances in ordination space. As would be expected, habitat type shifted from riffle to pool as cross-sectional area increased along the ordination vector arrow. The crosssectional area vector arrow was strongly associated with non-insect taxa. The riffle habitat type ellipse is oriented very close to most commonly observed taxon.

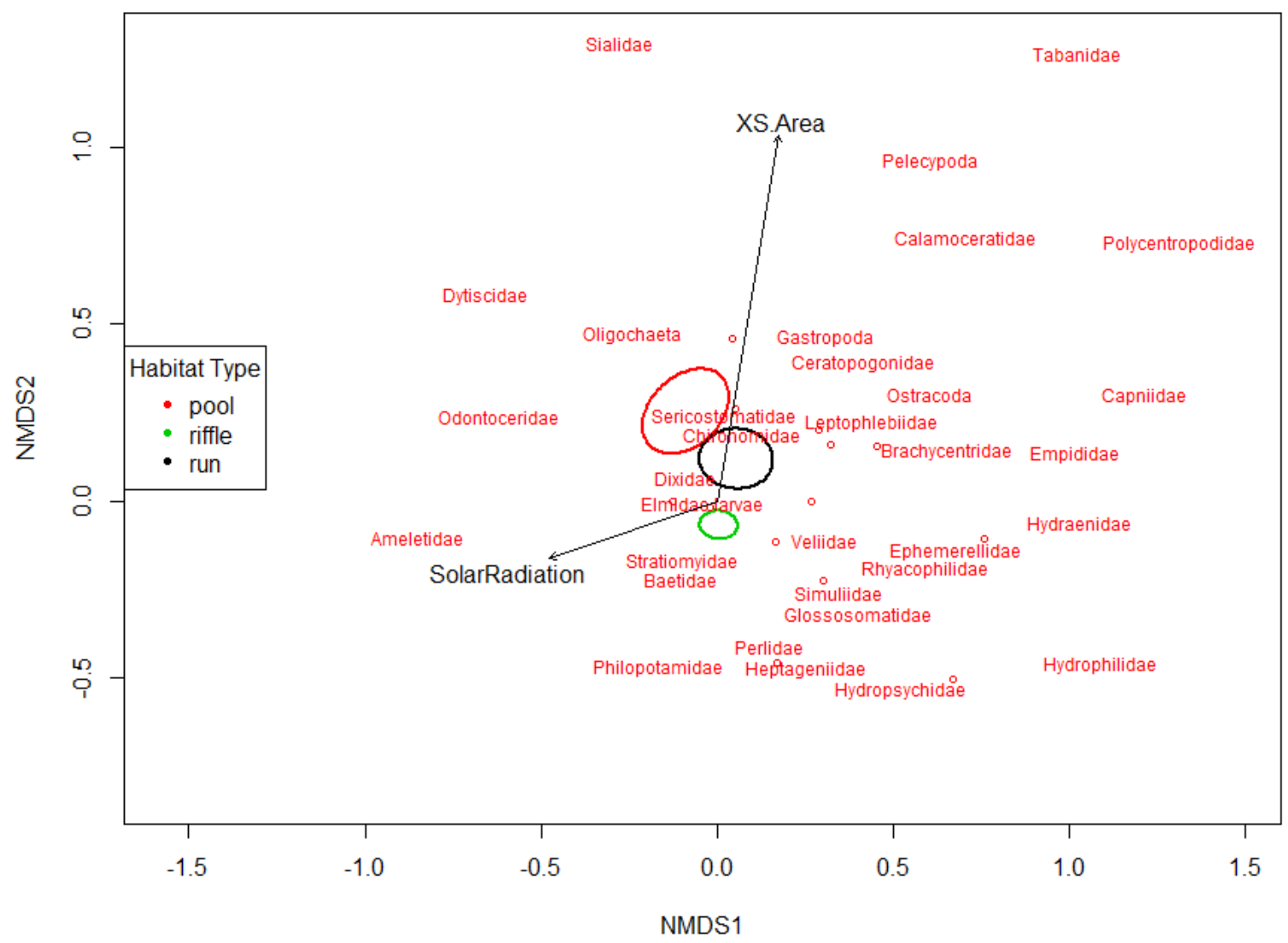

Figure 5.4 NMDS plot of macroinvertebrate community composition (relative abundance) fitted with significant environmental variables $(\alpha=0.05)$. The significant linear associations of cross-sectional area $\left(X S\right.$.Area; $\left.\mathrm{m}^{2}\right)\left(\mathrm{p}=0.001, \mathrm{R}^{2}=0.08\right)$ and solar radiation $\left(\mathrm{W} / \mathrm{m}^{2}\right)\left(\mathrm{p}=0.024, \mathrm{R}^{2}=0.02\right)$ data to macroinvertebrate abundance were represented by vector arrows, with the length and direction of each arrow representing the magnitude and direction of the association. The abundance plot was fitted with $95 \%$ confidence interval ellipses for the weighted average of each habitat type $\left(p=0.001, R^{2}=\right.$ 0.06). 
Water quality parameters were fitted onto the plot separately due to small sample sizes (Figure 5.5. Dissolved oxygen $(\%)\left(\mathrm{p}=0.02, \mathrm{R}^{2}=0.07\right)$ and $\mathrm{pH}\left(\mathrm{p}=0.003, \mathrm{R}^{2}=\right.$ 0.09) were both significantly associated with macroinvertebrate abundance in ordination space. The $\mathrm{pH}$ vector arrow was most strongly positively associated with non-insect taxa, whereas, percentage dissolved oxygen was positively correlated with proportion EPT taxa.

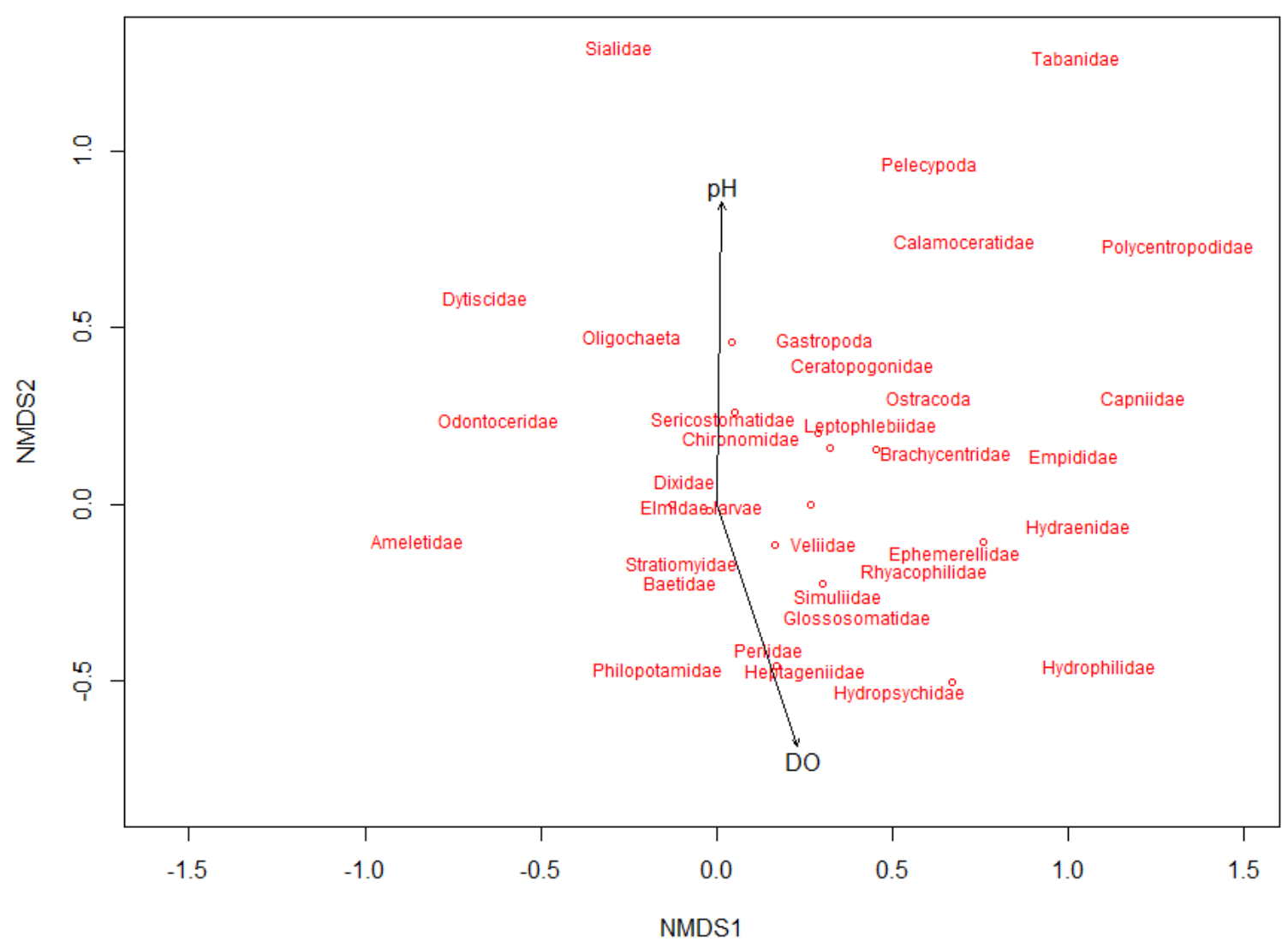

Figure 5.5 NMDS plot of macroinvertebrate community composition (relative abundance) fitted with significant water quality parameters $(\alpha=0.05)$. The significant linear associations of dissolved oxygen $(\%)\left(\mathrm{p}=0.02, \mathrm{R}^{2}=0.07\right)$ and $\mathrm{pH}\left(\mathrm{p}=0.003, \mathrm{R}^{2}=\right.$ 0.09 ) data to macroinvertebrate abundance was represented by vector arrows, with the length and direction of each arrow representing the magnitude and direction of the association. 


\subsubsection{Functional Feeding Group Composition}

Functional feeding group composition data was Wisconsin double standardization and square root transformed prior to analysis (Oksanen 2015). The function metaMDS again automatically selected to use a Bray-Curtis dissimilarity matrix. It was found that three dimensions returned the lowest stress model while still converging on a solution with acceptable stress $(S=0.11)$. MetaMDS automatically centered, rotated, and scaled the solution in ordination space.

Ordinating functional feeding group composition in three-dimensional space produced a plot where most commonly observed feeding strategists were oriented at the origin (Figure 5.6). The ranked orientation of the functional feeding groups placed the predator guild near the origin indicating that predator taxa was commonly observed with the other feeding guilds. The shredder guild was distant from the other feeding guilds in ordination space. This separation occurred along axis 2 while the other guilds were ordinated in a row along axis 1 , suggesting that relative shredder abundance was greater at some study reaches than others. 


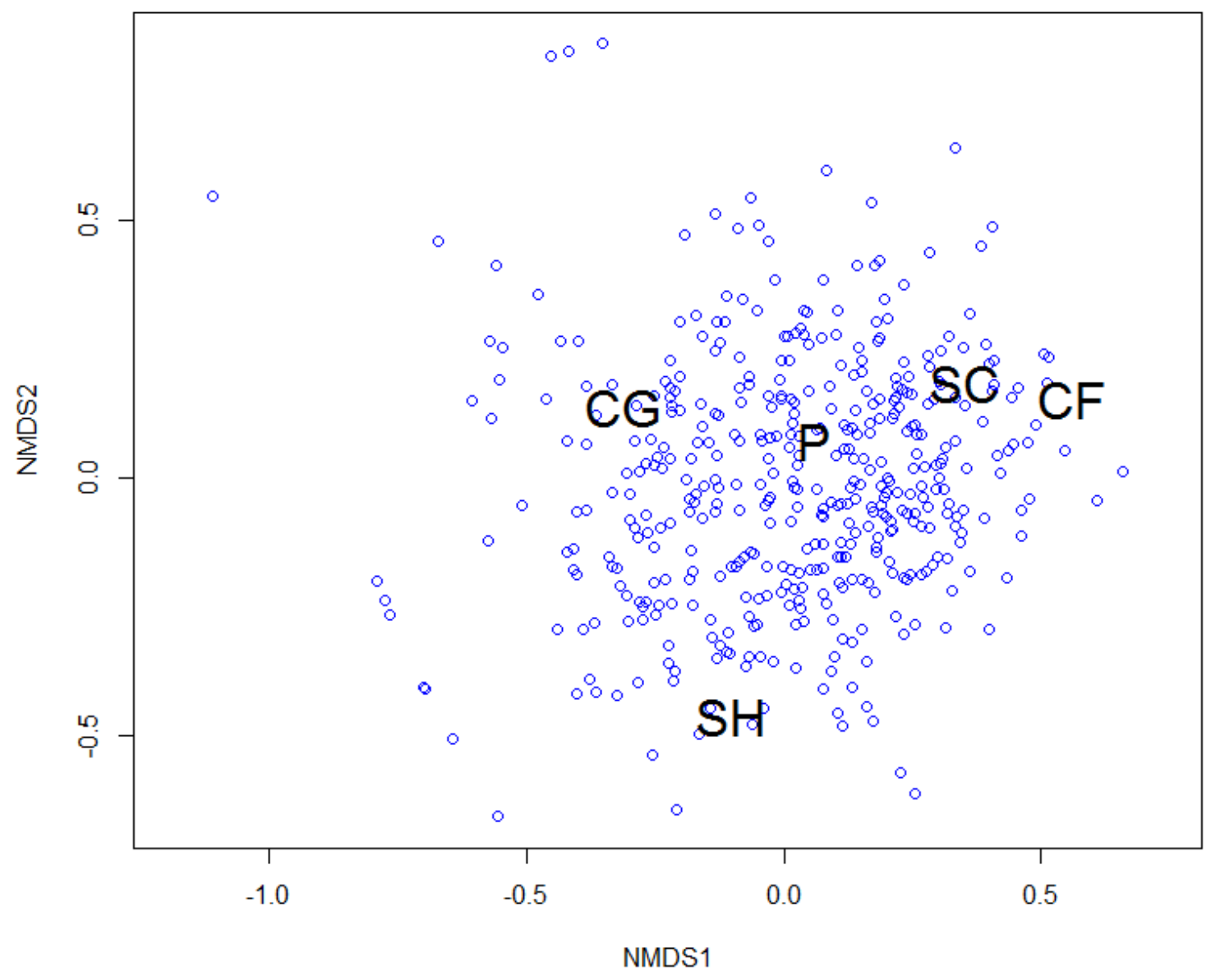

Figure 5.6 NMDS plot of functional feeding group composition. Stress $=0.11$. Functional feeding groups oriented more closely together were commonly observed together at the same sampling locations. 
After fitting ellipses representing $95 \%$ confidence intervals of the weighted averages of each season, it was apparent that spring and summer assemblages had similar functional feeding group compositions because they are overlapping (Figure 5.7). Fall assemblages appear to have unique feeding group compositions. Weighted averages begin closer to the shredder guild in the fall, then trend upward toward the predator and collector-gatherer guilds in the summer and fall.

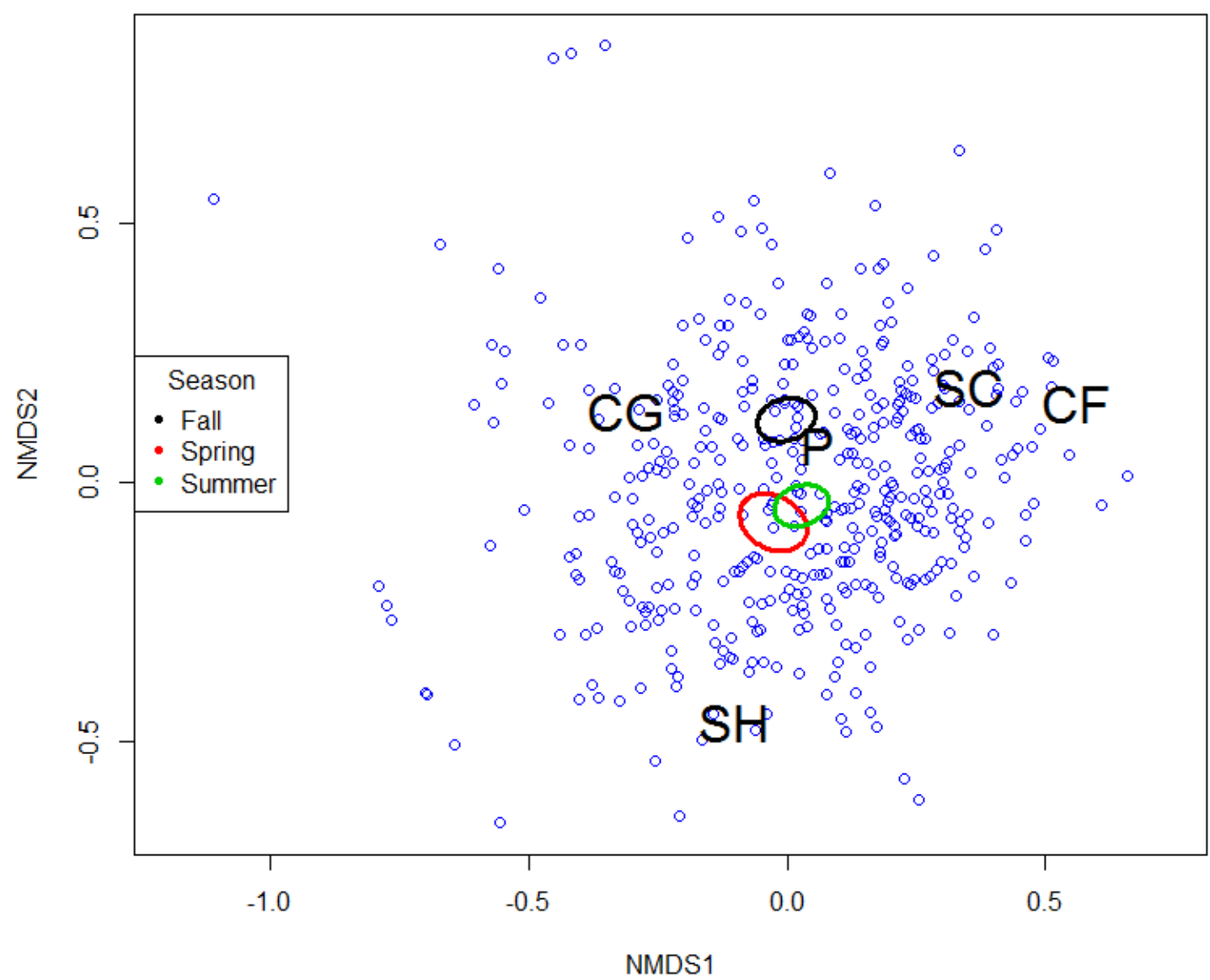

Figure 5.7 NMDS plot of functional feeding group composition fitted with $95 \%$ confidence interval ellipses for the weighted average of each season. 
Among the environmental variables examined, cross-sectional area $\left(p=0.001, R^{2}\right.$ $=0.05)$, solar radiation $\left(\mathrm{p}=0.001, \mathrm{R}^{2}=0.06\right)$, stream shading $\left(\mathrm{p}=0.038, \mathrm{R}^{2}=0.01\right)$, and habitat type $\left(p=0.001, R^{2}=0.09\right)$ were each significantly associated with functional feeding group composition in ordination space (Figure 5.8). As would be expected, habitat type shifted from riffle to pool as cross-sectional area increased along the ordination vector arrow. The cross-sectional area vector arrow pointed toward the area between collector-gatherer and shredder guilds. The solar radiation vector arrow pointed directly at the shredder guild. The riffle habitat type ellipse was oriented over the predator guild. 


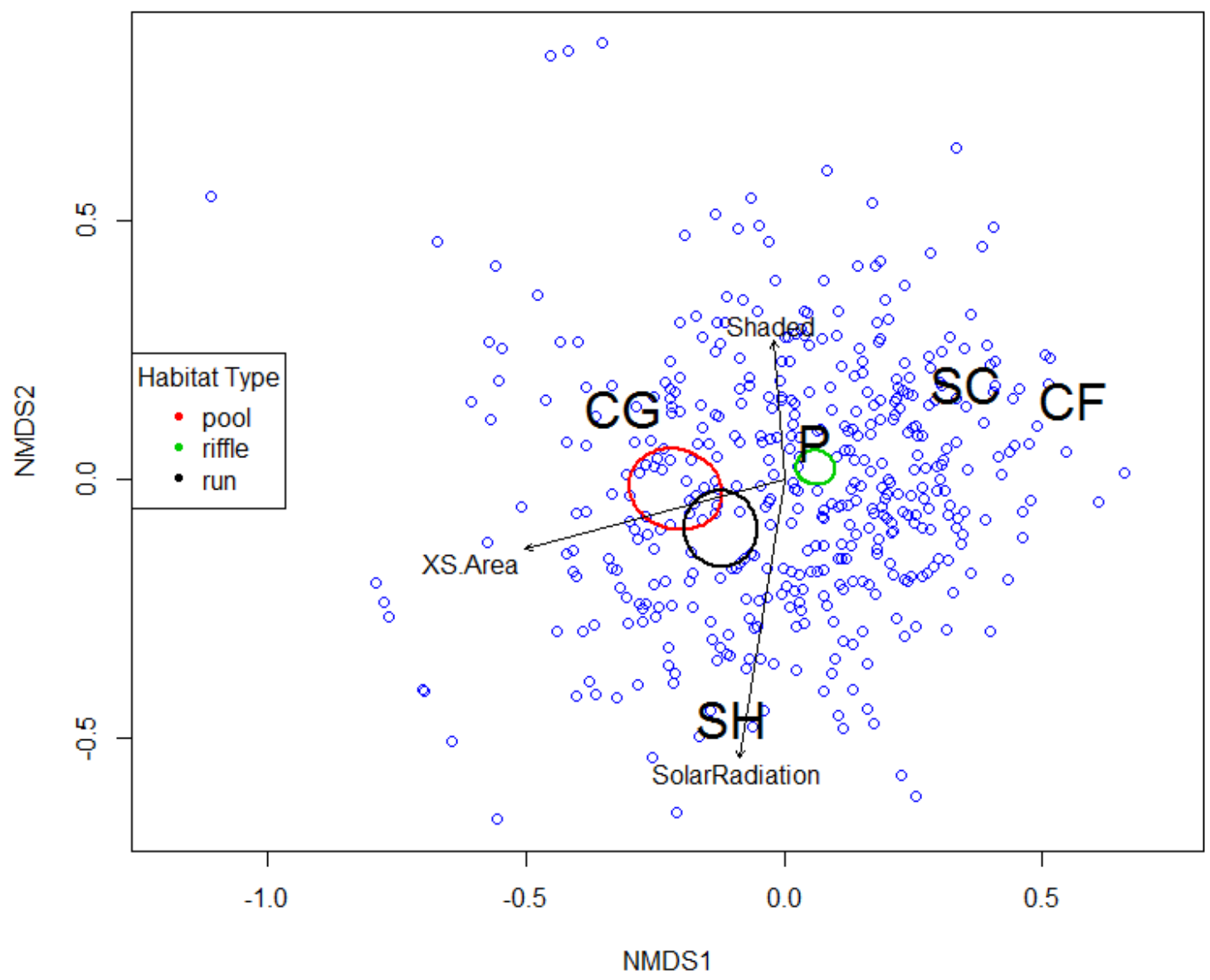

Figure 5.8 NMDS plot of functional feeding group composition fitted with significant environmental variables $(\alpha=0.05)$. The significant linear associations of percentage shaded $\left(p=0.038, R^{2}=0.01\right)$, solar radiation $\left(W / m^{2}\right)\left(p=0.001, R^{2}=0.06\right)$, and crosssectional area (XS.Area; $\left.\mathrm{m}^{2}\right)\left(\mathrm{p}=0.001, \mathrm{R}^{2}=0.05\right)$ data to functional feeding group composition were represented by vector arrows, with the length and direction of each arrow representing the magnitude and direction of the association. The abundance plot was fitted with $95 \%$ confidence interval ellipses for the weighted average of each habitat type $\left(\mathrm{p}=0.001, \mathrm{R}^{2}=0.09\right)$. 
Water quality parameters were fitted onto the plot separately due to smaller sample sizes (Figure 5.9). Temperature $\left({ }^{\circ} \mathrm{C}\right)$ and $\mathrm{pH}$ were each significantly associated with functional feeding group composition in ordination space. Stream $\mathrm{pH}$ was positively associated with the shredder feeding guild.

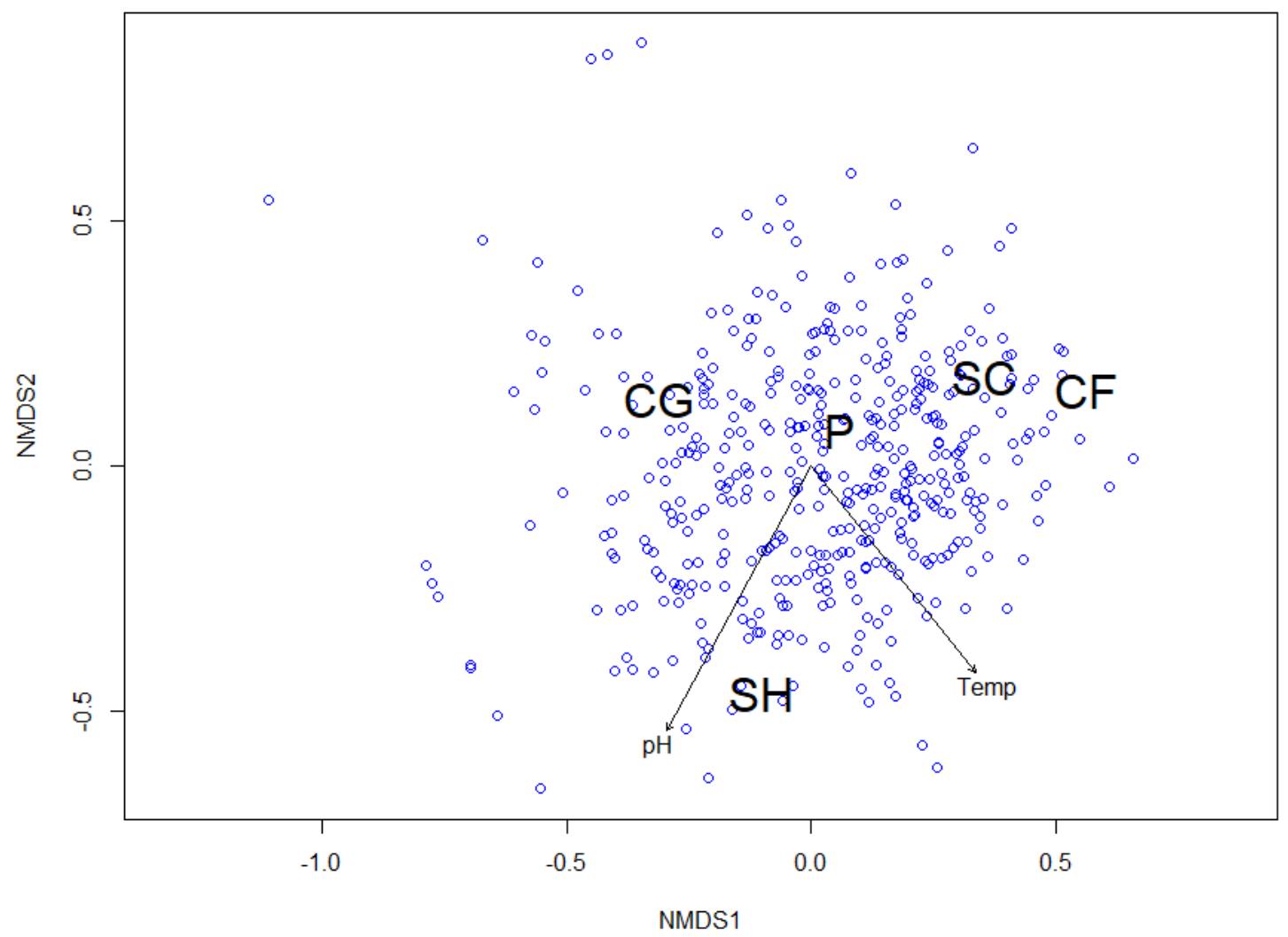

Figure 5.9 NMDS plot of functional feeding composition was fitted with significant water quality parameters $(\alpha=0.05)$. The linear fit of $\mathrm{pH}\left(\mathrm{p}=0.017, \mathrm{R}^{2}=0.07\right)$ and temperature $\left(\mathrm{p}=0.04, \mathrm{R}^{2}=0.05\right)$ data to functional feeding group was represented by vector arrows, with the length and direction of each arrow representing the magnitude and direction of the association. 


\subsection{Analysis of Variance Procedures}

Analysis of Variance (ANOVA) procedures were performed on three separate datasets: the study reach dataset, transect dataset, and water quality sub-dataset. A significance level of $\alpha=0.01$ was used for all ANOVA analyses to reduce the chance of Type I error. Response variables were transformed as necessary to meet the normality assumption (Appendix C).

\subsubsection{Study Reach Analysis}

The study reach analyses examined variability of biological metrics between reaches (Table 5.6). Each column in Table 5.6 represents a different model created using the study reach dataset; each model investigated the relationships of select environmental variables (independent variables) and a specific metric of macroinvertebrate community structure (response variable). The response variable transformation, adjusted $\mathrm{R}^{2}$, sample size $(\mathrm{N})$, and denominator degrees of freedom (Error DF) for each model are listed beneath the response variable. Significant environmental variables appear in bold typeface. The suite of data describing substrate characteristics of each study reach was unique to this dataset: these parameters included mean substrate diameter (mm), substrate D-50 (mm), and percentage sedimentary substrate. 
Table 5.6 ANOVA results of models created from the study reach dataset.

\begin{tabular}{|c|c|c|c|c|c|c|c|c|}
\hline Response & Density & $\begin{array}{c}\% \\
\text { EPT }\end{array}$ & $\%$ R-Strategist & \% Diptera & FBI & $\mathrm{H}^{\prime}$ & $\% \mathrm{SH}$ & $\begin{array}{c}\% \\
\text { CG }\end{array}$ \\
\hline Transformation & None & None & None & None & None & None & None & None \\
\hline Adjusted $\mathbf{R}^{2}$ & 0.35 & 0.59 & 0.38 & 0.59 & 0.42 & 0.39 & 0.76 & 0.29 \\
\hline $\mathbf{N}$ & 42 & 42 & 42 & 42 & 42 & 42 & 42 & 42 \\
\hline Error DF & 30 & 31 & 30 & 29 & 30 & 30 & 32 & 31 \\
\hline
\end{tabular}

\begin{tabular}{|c|c|c|c|c|c|c|c|c|}
\hline \multicolumn{9}{|c|}{ P-values } \\
\hline Study Reach & 0.005 & 0.001 & 0.292 & 0.005 & 0.061 & 0.091 & 0.006 & 0.008 \\
\hline Season & 0.102 & 0.112 & 0.230 & 0.352 & 0.002 & 0.002 & $<0.0001$ & 0.659 \\
\hline Mean Shaded (\%) & 0.684 & 0.765 & 0.833 & 0.325 & 0.552 & 0.587 & 0.581 & 0.299 \\
\hline Flow $\left(\mathbf{m}^{3} / \mathbf{s}\right)$ & 0.081 & 0.005 & - & - & - & 0.118 & - & - \\
\hline Mean Cross-Sectional Area $\left(\mathbf{m}^{2}\right)$ & 0.078 & - & 0.035 & - & 0.100 & - & - & - \\
\hline Mean Substrate Diameter (mm) & - & - & - & 0.026 & - & 0.160 & - & - \\
\hline Substrate D-50 (mm) & - & - & 0.008 & 0.003 & 0.031 & - & - & - \\
\hline Sedimentary Substrate $(\%)$ & - & - & & 0.098 & - & - & - & 0.101 \\
\hline
\end{tabular}

Note: Significant environmental variables $(\mathrm{p}<0.01)$ appear in bold.

Study reach was significantly associated with most of the reach-level macroinvertebrate metrics examined. Hilsenhoff’s Family Biotic Index (FBI) and Shannon's Diversity Index $\left(\mathrm{H}^{\prime}\right)$ were both significantly associated with season $(\mathrm{p}=0.002$ in both cases), with more pollutant-tolerant, diverse assemblages observed in the summer (Table C.7, Table C.8).

Macroinvertebrate density was found to be significantly associated with study reach. Highest densities were observed in the two Mainstem study reaches (mean $\pm \mathrm{SE}$ density $=1853.8 \pm 275.1$ individuals $/ \mathrm{m}^{2}$ at MS, and $1688.8 \pm 271.7$ individuals $/ \mathrm{m}^{2}$ at UMS) and lowest mean densities were observed in the Tranquility Flats $(810.7 \pm 263.0$ individuals $\left./ \mathrm{m}^{2}\right)$ and Upper North Fork $\left(815.0 \pm 250.5\right.$ individuals $\left./ \mathrm{m}^{2}\right)$ study reaches (Table C.1). Due to the nature of the analysis, the Tukey HSD test was not sensitive enough to detect a significant difference in mean density among the study reaches. However, an Ordered Differences Report indicated that the greatest difference in mean 
density existed between the Mainstem and Tranquility Flats study reaches with an adjusted p-value of 0.0126 .

There was a significant positive association $(\mathrm{p}=0.003)$ between median substrate size (D-50) and the proportion of the invertebrate assemblage represented by Diptera taxa in each study reach. Highest mean percentage Diptera taxa was observed in the South Fork $(27.5 \pm 11.2 \%)$ and Upper South Fork $(45.7 \pm 7.6 \%)$ study reaches (Table C.5).

Relative abundance of shredder taxa was significantly associated with study reach $(\mathrm{p}=0.006)$ and season $(\mathrm{p}<0.0001)$. Greatest mean relative abundance of shredders was observed in the spring $(26.9 \pm 1.6 \%)$, with significantly lower mean relative abundance observed in the fall $(8.4 \pm 1.7 \%)$ (Table C.10). Relative abundance of collector-gatherer taxa was found to be significantly associated with study reach $(\mathrm{p}=0.08)$ with highest abundances observed in Mainstem (60.9 $\pm 6.7 \%)$ and Upper Mainstem (62.9 $\pm 7.0 \%)$ study reaches (Table C.11). 


\subsubsection{Transect Analysis}

The transect analyses contain the largest datasets $(n=448)$ of all the models

created. The influence of stream shading and solar radiation on biological metrics were assessed in these models. Due to high multicollinearity, habitat type was included instead of channel cross-sectional area. Results from the transect-level ANOVA models are displayed in Table 5.7.

Table 5.7 ANOVA results of models created from the transect dataset.

\begin{tabular}{|l|c|c|c|c|c|c|c|c|c|c|c|}
\hline Response & Density & Biomass & $\begin{array}{c}\text { EPT } \\
\text { Taxa }\end{array}$ & $\%$ EPT & $\begin{array}{c}\% \text { R- } \\
\text { Strategist }\end{array}$ & $\begin{array}{c}\% \\
\text { Diptera }\end{array}$ & FBI & $\mathrm{H}^{\prime}$ & \%H & $\%$ CG & $\%$ P \\
\hline Transformation & $\log _{10}$ & $\log _{10}(x+1)$ & None & None & None & $\begin{array}{c}\text { Cube } \\
\text { Root }\end{array}$ & Cube & Cube & $\begin{array}{c}\text { Cube } \\
\text { Root }\end{array}$ & $\begin{array}{c}\text { Cube } \\
\text { Root }\end{array}$ & $\begin{array}{c}\text { Cube } \\
\text { Root }\end{array}$ \\
\hline Adjusted $\mathbf{R}^{2}$ & 0.29 & 0.36 & 0.18 & 0.43 & 0.35 & 0.38 & 0.31 & 0.24 & 0.31 & 0.12 & 0.17 \\
\hline $\mathbf{N}$ & 448 & 447 & 448 & 448 & 448 & 448 & 448 & 448 & 448 & 448 & 448 \\
\hline
\end{tabular}

\begin{tabular}{|l|r|r|r|r|r|r|r|r|r|r|r|}
\hline Study Reach & $<\mathbf{0 . 0 0 0 1}$ & $\mathbf{0 . 0 0 2}$ & $\mathbf{0 . 0 0 4}$ & $<\mathbf{0 . 0 0 0 1}$ & $<\mathbf{0 . 0 0 0 1}$ & $<\mathbf{0 . 0 0 0 1}$ & 0.014 & $<\mathbf{0 . 0 0 0 1}$ & $\mathbf{0 . 0 0 7}$ & $<\mathbf{0 . 0 0 0 1}$ & 0.367 \\
\hline Season & $<\mathbf{0 . 0 0 0 1}$ & $\mathbf{0 . 0 0 1}$ & $<\mathbf{0 . 0 0 0 1}$ & $<\mathbf{0 . 0 0 0 1}$ & $<\mathbf{0 . 0 0 0 1}$ & $<\mathbf{0 . 0 0 0 1}$ & $<\mathbf{0 . 0 0 0 1}$ & $<\mathbf{0 . 0 0 0 1}$ & $<\mathbf{0 . 0 0 0 1}$ & 0.723 & $\mathbf{0 . 0 0 0 4}$ \\
\hline Shaded \% & 0.570 & 0.675 & 0.156 & 0.795 & 0.054 & 0.770 & 0.020 & 0.023 & 0.337 & 0.294 & 0.574 \\
\hline Solar Radiation & 0.682 & 0.502 & 0.857 & 0.587 & 0.039 & 0.990 & 0.430 & 0.278 & 0.377 & - & 0.540 \\
\hline Habitat Type & 0.087 & 0.223 & $<\mathbf{0 . 0 0 0 1}$ & - & 0.264 & 0.080 & 0.080 & $<\mathbf{0 . 0 0 0 1}$ & 0.028 & 0.079 & 0.056 \\
\hline
\end{tabular}

Note: Significant environmental variables $(\mathrm{p}<0.01)$ appear in bold.

Both study reach and season were significantly associated with nearly all of the transect-level macroinvertebrate metrics examined. Only 2 of the 11 response variables (i.e. FBI and percentage predator taxa) were not significantly associated with study reach ( $p>0.01$ in all cases), and the only response variable not strongly influenced by season was percentage collector-gatherer taxa $(\mathrm{p}>0.72)$. Percentage Diptera taxa exhibited a strong site effect $(\mathrm{p}<0.0001)$ with greatest relative abundances observed in the Upper South Fork study reach $($ mean $=40.5 \pm 2.4 \%$; Table C.23). Habitat type was found to be a strong predictor of both the number of distinct EPT taxa $(\mathrm{p}<0.001)$ and invertebrate diversity $\left(\mathrm{H}^{\prime} ; \mathrm{p}<0.001\right)$, with riffle habitats supporting significantly higher averages of 
both. Neither percentage shade nor solar radiation were significantly associated with any of the response variables tested ( $p>0.02$ in all cases).

Both density and biomass were significantly associated with study reach and season. The Mainstem and Upper Mainstem study reaches supported the highest mean invertebrate density $\left(867.9 \pm 158.9\right.$ individuals $/ \mathrm{m}^{2}$ at $\mathrm{MS}$ and $1688.79 \pm 156.49$ individuals $/ \mathrm{m}^{2}$ at UMS $)$ and mean biomass $\left(247.4 \pm 24.7 \mathrm{mg} \mathrm{DM} / \mathrm{m}^{2}\right.$ at $\mathrm{MS}$ and $245.5 \pm$ $24.4 \mathrm{mg} \mathrm{DM} / \mathrm{m}^{2}$ at UMS) (Table C.12, Table C.14). Lower invertebrate mean density was observed at the Tranquility Flats study reach $\left(810.7 \pm 156.5\right.$ individuals $/ \mathrm{m}^{2}$; Table C.12) and lower mean biomass was observed at the Upper North Fork study reach (124.7 $\pm 24.4 \mathrm{mg} \mathrm{DM} / \mathrm{m}^{2}$; Table C.14). The highest invertebrate density and biomass values observed during the study occurred in the summer sample period (Table C.13).

Mean relative abundance of shredder taxa was greatest in the spring $(23.4 \pm 1.1 \%)$ and summer $(19.6 \pm 1.1 \%)$, with significantly lower mean relative abundances in the fall $(9.1 \pm 1.1 \%$; Table C.30). Greatest mean relative abundances of collector-gatherer taxa were observed in the two Mainstem study reaches $(63.1 \pm 2.1 \%$ at MS and $64.5 \pm 2.0 \%$ at UMS; Table C.31). Mean relative abundance of predator taxa was greatest in the fall $(10.4 \pm 0.6 \%)$ and summer $(8.0 \pm 0.6 \%)$, with significantly smaller relative abundances observed in the spring $(6.0 \pm 0.6 \%$; Table C.32).

\subsubsection{Water Quality Sub-Analysis}

Due to small sample sizes, the influence of water quality parameters on biological metrics was assessed in a set of sub-analyses of the transect dataset. Temperature $\left({ }^{\circ} \mathrm{C}\right)$, $\mathrm{pH}$, and dissolved oxygen (\%) were included in the transect dataset. The addition of these 
data increased the adjusted $\mathrm{R}^{2}$ values of the $\% \mathrm{EPT}, \%$ R-strategist, FBI, and $\mathrm{H}^{\prime}$ models. Results from the water quality ANOVA models are displayed in Table 5.8

Table 5.8 ANOVA results of models created from the water quality sub-dataset.

\begin{tabular}{|l|c|c|c|c|c|}
\hline Response & $\begin{array}{c}\text { EPT } \\
\text { Taxa }\end{array}$ & $\%$ EPT & $\begin{array}{c}\% \text { R- } \\
\text { Strategist }\end{array}$ & FBI & $\mathrm{H}^{\prime}$ \\
\hline Transformation & & & & & Cube \\
\hline Adjusted R & 0.09 & 0.47 & 0.47 & 0.37 & 0.29 \\
\hline $\mathbf{N}$ & 329 & 329 & 329 & 329 & 329 \\
\hline
\end{tabular}

P-values

\begin{tabular}{|c|c|c|c|c|c|}
\hline Study Reach & $<0.0001$ & $<0.0001$ & $<0.0001$ & $<0.0001$ & $<0.0001$ \\
\hline Season & 0.001 & 0.0098 & $<0.0001$ & 0.686 & $<0.0001$ \\
\hline Shaded \% & 0.619 & 0.603 & 0.058 & 0.014 & 0.300 \\
\hline Solar Radiation & 0.593 & 0.562 & 0.167 & 0.309 & 0.517 \\
\hline Habitat Type & $<0.0001$ & & & 0.685 & $<0.0001$ \\
\hline Temp & & & $<0.0001$ & $<0.0001$ & \\
\hline pH & 0.001 & $<0.0001$ & 0.088 & 0.345 & $<0.0001$ \\
\hline DO \% & & & & & \\
\hline
\end{tabular}

Note: Significant environmental variables $(\mathrm{p}<0.01)$ appear in bold.

Both the number of EPT taxa and the contribution of EPT taxa to the total macroinvertebrate community were significantly positively associated with $\mathrm{pH}$ (Table C.33, Table C.34). $\mathrm{pH}$ was also significantly positively associated with diversity $\left(\mathrm{H}^{\prime}\right.$, Table C.37). Temperature was found to be significantly positively associated with percentage R-strategist taxa and Hilsenhoff’s Family Biotic Index (FBI; Table C.35, Table C. 36). Dissolved oxygen was not significantly associated with any of the response variables tested ( $p>0.04$ in all cases) so it was removed from subsequent models. 


\section{CHAPTER 6. DISCUSSION}

\subsection{Spatiotemporal Patterns in Community Structure}

Macroinvertebrate community structure in Little Creek is highly variable through time and space. Nearly every macroinvertebrate metric tested was found to differ significantly among both the study reaches and seasons. The observed differences between the communities of each study reach indicate patterns in assemblage structure that reflect well-established concepts in trophic ecology.

The Upper Mainstem study reach consistently supported the most diverse macroinvertebrate assemblages and significantly more unique EPT families than the other study reaches. In contrast, the least diverse assemblages were observed in the South Fork and Upper South Fork study reaches where relatively distinct invertebrate communities existed. The samples collected at these study reaches were comprised of significantly higher proportions of dipteran taxa than the rest of the study reaches. This was reflected by the NMDS plot of macroinvertebrate abundances where South Fork and Upper South Fork study reaches exhibited a high degree of overlap in ordination space, centered at Chironomidae (Diptera). Chironomids are R-strategists with high fecundity and dispersal rates and were the most numerically abundant taxon due to high abundances in the South Fork study reaches. Seasonally, highest mean invertebrate density and biomass values were observed in the summer and lowest in the spring. Summer assemblages were found to be significantly more diverse and more tolerant to organic pollutants. This is likely due to the higher abundances multiple Diptera taxa (especially Psychodidae) observed during the summer season.

Significantly greater macroinvertebrate density and biomass was observed in the Mainstem and Upper Mainstem study reaches reflecting an increased availability of basal 
trophic resources (leaf litter) in these reaches. The upper reaches of forested headwater streams are typically highly oligotrophic and support food webs fueled by heterotrophic production and dominated by macroinvertebrate guilds that process detrital-based food resources (Cheshire et al. 2005, Cushing and Allan 2001, Gessner et al. 1999, Vannote et al. 1980). Greater relative abundances of shredders were observed in the three North Fork study reaches (i.e., NF, TF, and UNF); however, shredder relative abundance exhibited strong temporal variation which concurred with seasonal energy inputs. Specifically, shredder relative abundance was greatest in the spring following the deposition of CPOM left behind from winter storm flows and coincided with the seasonal catkin drop of riparian red alder trees. Collector-gatherers were most abundant in the Mainstem and Upper Mainstem study reaches and showed significant seasonal variation which inversely reflected shredder abundance; i.e., lowest abundances were observed in the spring with greater and more similar abundances observed in the summer and fall. The relative abundance of predatory invertebrates increased with seasonal density and biomass trends. Significantly lower predator abundance was observed in the spring and greater abundances in the summer and fall. The spatiotemporal patterns in the relative abundance of different feeding guilds represent a gradient of energy flow and follow established trends of energy distribution in lotic systems where bottom-up controls influence food web structure (McIntosh et al. 2005, Power 1992). Though it was not directly measured, it can be inferred by these spatial and seasonal trends that food resource availability is the foundation of macroinvertebrate community structuring in Little Creek. After shredder guilds make seasonal energy inputs available to downstream collector-gatherer guilds, 
these communities become significantly larger and increase food resource availability to predator guilds which in turn become significantly larger (Rosenberg and Resh 1993).

\subsection{Abiotic Drivers of Community Structure}

Riffle habitat types were found to support the most diverse communities with significantly higher numbers of distinct EPT taxa. Riffles provide suitable habitat for the majority of the observed macroinvertebrate families documented during this study (see Table 5.1). Habitat availability was especially influential in the South Fork and Upper South Fork study reaches. Median substrate size (D-50) was significantly and positively associated with both the percentages of Diptera and R-strategist taxa. Bedrock channel bottoms are common in the South Fork, including most of the Upper South Fork study reach, as evidenced by the consistently high mean substrate diameter and D-50 values. Taxa that prefer hygropetric habitats have greater available habitat in these areas (Boothroyd 2005). Larval Simuliidae have attachment disks on their posterior end that enable them to attach to hard, flat surfaces and filter feed with their labral fans. Chironomid larvae utilize hooks on their pupal abdomen to keep their silken cocoons attached within small holes in rock surfaces. The bedrock channel bottoms common in the South Fork, coupled with lower flow conditions and channel cross-sectional areas, served as ideal habitat for these taxa and contributed to their high relative abundances in both the South Fork and Upper South Fork reaches.

Percentage stream shading and solar radiation were not found to be significantly associated with the metrics of biological productivity examined in this study (i.e., density, biomass, and diversity). However, high stream shading levels existed throughout the watershed, offering little spatial variation in stream shading conditions. The small range 
of stream shading and solar radiation values increases the risk of explanatory impotence. It is possible that a significant association between shading and assemblage productivity exists in Little Creek but was not able to be observed because of dataset weaknesses.

\subsection{Predicting Instream Response to Canopy Manipulation}

If the purpose of a prescribed canopy manipulation is to provide a biological benefit, the specific end-goals must first be outlined. In the case of this project, which aims to advise a rule package that protects riparian function in anadromous watersheds, the desired end-goal would be a measurable benefit to downstream salmonid populations. The underlying premise of enhancing instream biological condition through canopy thinning is that riverine trophic interactions can be positively influenced by manipulating and enhancing energy inputs. The specific hypothesis is that thinning or removing a riparian canopy would let more light reach the streambed and increase instream autochthonous production as well as promote near-stream colonization of early successional tree species (e.g., red alder) that provide higher quality allochthonous food resources once mature. In lotic ecosystems like Little Creek that are predominantly fueled by allochthonous inputs, macroinvertebrates process, assimilate, and cycle allochthonous carbon to organisms at higher trophic levels. This ecosystem service is a critical link in the food chain and represents a means by which bottom-up pathways influence riverine food web structure and overall productivity. Whereas macroinvertebrate (i.e., secondary) production is controlled, in part, by the availability of detrital-based food resources, increasing direct energy inputs, in terms of both light and CPOM, may increase macroinvertebrate biomass and ultimately benefit aquatic and riparian predators. The success of riparian canopy management practices is then not only measured by an 
increase in macroinvertebrate biomass, but also by an increase in biomass of organisms of higher trophic levels such as juvenile salmonids. However, the methods utilized in this study did not quantify energy flow through these trophic levels or the interaction between allochthonous inputs and macroinvertebrate community structure. With the collected dataset, it can be inferred that macroinvertebrate community structure in Little Creek is strongly influenced by the availability of detrital basal energy sources. However, it would be difficult to confidently predict if macroinvertebrate biomass would increase as a result of riparian canopy manipulation or how manipulation would disrupt or enhance the quantity and quality of various carbon sources that serve as the energetic base of the instream food webs of Little Creek. Furthermore, the collected dataset cannot be used to estimate the extent to which macroinvertebrate density and biomass would need to increase to observe a significant positive response in downstream salmonid biomass. Little Creek is a relatively small drainage with limited available aquatic habitat in lowflow conditions, which are required for macroinvertebrate reproduction. Therefore, the opportunity for riparian management practices to increase macroinvertebrate biomass production may be constrained by biological carrying capacity in this basin.

Although this dataset cannot be used to predict instream response to riparian canopy manipulation, it provides a comprehensive biological baseline for the macroinvertebrate communities of Little Creek. Furthermore, these data may be used to identify the next steps that could be taken toward the development of riparian canopy management strategies that aim to enhance biological condition. Through extensive sampling, seasonal and spatial patterns in assemblage structuring have been described. Trends in functional feeding group composition have outlined general pathways of 
energy distribution at lower and intermediate trophic levels in Little Creek. Furthermore, areas of low biological productivity have been identified. Specifically, the Tranquility Flats study reach consistently had the lowest observed macroinvertebrate biomass and density of all the study reaches. It also supported significantly fewer families of EPT taxa. Therefore, this location offers the potential to test the feasibility of enhancing biological condition through manipulation of bottom-up controls in Little Creek. Such an experiment could be designed to describe trophic interactions in a forested headwater stream and address whether it would be possible for management practices to increase macroinvertebrate biomass. However, sampling protocols should be redesigned to better address biotic and abiotic relationships that structure macroinvertebrate assemblages in Little Creek and to quantify flows of energy and material across multiple trophic levels.

\subsection{Recommendations}

With two years of data collected and analyzed, experimental design and sampling methods can now be critically examined and optimized. The goal of optimization is to improve sampling efficiency while simultaneously increasing the explanatory power of collected data. This is done by removing insignificant independent variables, adapting the sampling regime based on temporal findings, and assessing the value of certain study reaches. Aside from the correlation with Dipteran abundance, the suite of substrate characteristics examined was found to be less influential to overall macroinvertebrate community structure than predicted, and these variables are candidates for exclusion from the sampling design. Hemispherical camera data should be collected alongside each macroinvertebrate sample to increase confidence in that dataset. This would also produce several potentially important metrics of riparian canopy structure (e.g., leaf area index, 
visible sky fraction, fraction of ground covered by canopy, and canopy uniformity) that were not included in this study. Key proxies of riverine productivity such as macroinvertebrate biomass, density, and diversity were significantly greater in summer sampling events. Therefore, depending on the study goals and hypothesis, sampling regime could be solely focused on the summer season. However, if future studies aim to continue monitoring distributions and biotic relationships of functional feeding groups, then sampling regime should remain as is. It is recommended to narrow the scope of the study reaches to the most representative reaches; namely the Mainstem, Tranquility Flats, Upper North Fork, and Upper South Fork study reaches. Additionally, sending macroinvertebrate samples to be identified at a certified Aquatic Bioassessment Laboratory would increase confidence in the dataset and increase taxonomic resolution because samples would be identified to the genus/species level (Level III).

A major limitation in the project sampling design is that basal energy sources or distribution were not measured directly. The purpose of a riparian canopy treatment would be to manipulate known trophic interactions. The present dataset indirectly addresses these interactions by describing spatial and temporal patterns of functional feeding group composition. However, measuring shifts in functional feeding group composition alone without examining actual food resources present in macroinvertebrate diets may lead to erroneous inferences regarding patterns of resource use by macroinvertebrates in food webs (Rosi-Marshall et al. 2016). It is recommended that more direct methods that quantitatively measure energy distribution along the channel gradient be employed in the future. Allochthonous input rates could be quantified with the use of leaf litter traps; leaf litter inputs can be collected at sampling sites for set time 
durations and then sorted, counted, and weighed by species and organ (Burnham et al. 1992). Autochthonous production could be determined by placing tiles (or other standardized substrates) at sampling sites, allowing them to incubate in the stream for three weeks, and analyzing the chlorophyll $a$ concentration via methanol extraction and spectrophotometrical analysis (Eros et al. 2012). Similarly, periphyton standing crops could be determined by measuring the ash-free dry weight (AFDM; a measure of carbon content) of periphytic material (Rounick and Gregory 1980). Calculating the autotrophic index (the ratio of AFDM to chlorophyll $a$ ) at representative study reaches would be instructive for determining whether autotrophic or heterotrophic sources were driving aquatic food webs (Camargo et al. 2005, Hill et al. 2000). Moreover, quantifying these potential energy sources would inform the relative importance of various bottom-up trophic pathways present in Little Creek.

Macroinvertebrate food resource utilization and preferences could also be directly assessed via natural abundance stable isotope analysis of key macroinvertebrate taxa and their presumed dominant food resources (Junker and Cross 2014, Post 2002).

Allochthonous and autochthonous inputs often have unique carbon to nitrogen isotope ratios that can be quantified in macroinvertebrate tissues via mass spectrometry, thus connecting trophic pathways of energy distribution (Yang et al. 2014, Zah et al. 2001). Employing these methods would directly quantify key trophic interactions in Little Creek and provide much clearer guidance to riparian management philosophy and practice. Ultimately, data produced from these methods would describe nutrient cycling between riparian vegetation and macroinvertebrate assemblages in Little Creek, providing strong observation-based evidence to guide management practices that aim to protect or enhance 
key trophic interactions. These methods may also be applied to similar, larger systems, such as Scotts Creek, where salmonid life cycles, salmonid biomass production, and biological carrying capacity are better understood. Conducting such a study in a system with existing long-term data that quantifies energy flow through various trophic levels would expedite the process of informing riparian management practices toward ecosystem enhancement. 


\section{CHAPTER 7. CONCLUSION}

\subsection{Summary}

The purpose of this project was to describe spatiotemporal variability in the benthic macroinvertebrate assemblages along the channel gradient of Little Creek. By characterizing longitudinal patterns of community structure, abiotic and biotic influences could be better understood. The overall goal of this study was to inform riparian canopy management strategies aimed at protecting or enhancing key trophic interactions that control biological productivity.

The benthic macroinvertebrate communities of Little Creek exhibited significant variability through time and space. A pattern of seasonal species replacements along the channel gradient was observed, indicating that a continuum of community adaptations was in effect. Macroinvertebrate communities in Little Creek were predominantly structured by the availability of detrital-based food resources and trends in assemblage composition reflected seasonal energy inputs. Macroinvertebrate communities at downstream sample sites were characterized by significantly greater abundances of taxa that rely on energy processing inefficiencies of upstream communities, consistent with ecological theory. The variability and distribution of macroinvertebrate assemblages in Little Creek aligned with established trophic relationships in allochthonous lotic ecosystems. However, the analyses using the collected dataset failed to identify key abiotic drivers of community structure and only provided indirect evidence of trophic relationships. Hence, though significant patterns in community structure were observed, the mechanisms behind these patterns remain uncertain. While it was predicted that stream shading would a key abiotic variable affecting macroinvertebrate community structure, shading was not found to be significantly associated with any of the metrics 
examined in this study. This is likely because the riparian zone in Little Creek is heavily shaded along the entire length of the channel. The small range of observations (i.e., coefficient of variation in percent shading among sites and seasons) made it difficult to correlate stream shading to any differences in biological condition. Consequently, while stream shading is likely an important factor affecting many key ecological functions in the Little Creek watershed, it remains uncertain how localized stream food webs will respond to riparian canopy manipulations.

\subsection{Project Contributions}

This dataset provided comprehensive baseline information concerning the macroinvertebrate communities in Little Creek and set the stage for future monitoring and research. The impacts of future environmental changes in Little Creek, whether natural or anthropogenic, can now be compared to a set of pre-existing data. Although biological responses to riparian canopy manipulation in Little Creek cannot be confidently predicted using this dataset, this study identified the Tranquility Flats study reach as being significantly less biologically productive than all other study reaches. Documented site level differences in total assemblage density and biomass at the Tranquility Flats study reach offer the highest potential for significant biological responses to be detected following ecosystem enhancement. The collected data also provided a reference for spatiotemporal variability of macroinvertebrate community structure in a forested headwater stream within California's coastal redwood belt. 


\subsection{Future Work and Opportunities}

The compiled database presented herein set the stage for future monitoring to further explore the trophic interactions that shape macroinvertebrate communities in Little Creek. Future monitoring efforts should directly describe energy pathways in selected study reaches to more accurately estimate potential for management to enhance ecosystem function. By measuring energy inputs and utilization through the study reaches, key trophic interactions can be identified. If a future riparian canopy manipulation were to be recommended, the Tranquility Flats study reach would provide the highest potential for significant biological responses to be detected because it was significantly less biologically productive than all other study reaches over the course of the study. Management activities may then be guided using evidence based observations. 


\section{REFERENCES}

Alvarez-Cabria, M, J. Barquin, and J. Antonio-Juanes. 2010. Spatial and seasonal variability of macroinvertebrate metrics: Do macroinvertebrate communities track river health?. Ecological Indicators 10: 370-379.

Andersron, R.S. 1994. Evolution of the Santa Cruz Mountains, California, through tectonic growth and geomorphic decay. Journal of Geophysical Research 99,20: 161-179.

Aristegi, L., O. Izagirre, and A. Elosegi. 2009. Comparison of several methods to calculate reaeration in streams, and their effects on estimation of metabolism. Hydrobiologia 635:113-124.

Armitage, P.D., K. Lattmann, N. Kneebone, and I. Harris. 2001. Bank profile and structure as determinants of macroinvertebrate assemblages-seasonal changes and management. Regulated Rivers: Research \& Management 17: 543-556.

Armitage, P.D., D. Moss, J.F. Wright, and M.T. Furse. 1983. The performance of a new biological water quality score system based on macroinvertebrates over a wide range of unpolluted running-water sites. Journal of Water Research 17:333-347.

Barbour, M.T., J. Gerritsen, B.D. Snyder, and J.B. Stribling. 1999. Rapid Bioassessment Protocols for Use in Streams and Wadable Rivers: Periphyton, Benthic Macroinvertebrates and Fish, Second Edition. EPA 841-B-99-002. U.S. EnvironmentalProtection Agency; Office of Water, Washington, D.C.

Beche, L., E. McElravy, and V. Resh. 2006. Long-term seasonal variation in the biological traits of benthic-macroinvertebrates in two Mediterranean-climate streams in California, U.S.A. Freshwater Biology 51:56-75.

Bellucci, C., M. Becker, M. Beauchene, and L. Dunbar. 2013. Classifying the health of Connecticut streams using benthic macroinvertebrates with implications for water management. Environmental Management 6:51.

Benke, A.C., A.D. Huryn, L.A. Smock, and J.B. Wallace. 1999. Length-mass relationships for freshwater macroinvertebrates in North America with particular reference to the southeastern United States. Journal of the North American Benthological Society 18: 308-343.

Billiter, B. 3,000-year-old connection claimed: Siberia tie to California tribes cited. Los Angeles Times January 01, 1985.

Bixby, R., S. Cooper, R. Gresswell, L. Brown, C. Dahm, and K. Dwire. 2015. Fire effects on aquatic ecosystems: an assessment of the current state of the science. Freshwater Science 34(4): 1340-1350. 
Boothroyd, I. 2005. Eumadicole midges - film stars of the freshwater world. Water \& Atmosphere 13(1): 24-25.

Botelho, L. 2016. Riparian Canopy Composition of Little Creek. Senior Project, Cal Poly SLO.

Brabb, E. 1989. Geologic map of Santa Cruz County, California. United States Geological Survey.

Briers, R. and J. Gee. 2004. Riparian forestry management and adult stream insects. Hydrology and Earth System Sciences 8:545-549.

Brinkhurst, C., S. McCormick, and S. Williamson. 2009. The Bug Book: A Guide to the Identification of Common Aquatic Benthic Macroinvertebrate Families of California and Western North America. McDonald \& Woodward.

Brodsky, K.A. 1980. Mountain torrent of the Tien Shan. Limnology and Oceanography 26(2): 400.

Bruce, J. F. 2002. Characterization and Analysis of Temporal and Spatial Variations in Habitat and Macroinvertebrate Community Structure, Fountain Creek Basin, Colorado Springs and Vicinity, Colorado, 1998-2001. U.S. Geological Survey Water-Resources Investigations Report 02-4093.

Burnham, R.J., S.L. Wing, and G.G. Parker. 1992. The reflection of deciduous forest communities in leaf litter: implications for autochthonous litter assemblages from the fossil record. Paleobiology 18(1): 30-49.

Buss, D., D. Baptista, and J. Nessimian. 2004. Substrate specificity, environmental degradation and disturbance structuring macroinvertebrate assemblages in neotropical streams. Hydrobiologia 518:179-188.

Buss, D. D. Baptista, M. Silveira, J. Nessimian, and L. Dorville. 2002. Influence of water chemistry and environmental degradation on macroinvertebrate assemblages in a river basin in south-east Brazil. Hydrobiologia 481(1): 125-136.

California Forest Practice Rules. 2017. California Department of Forestry and Fire Protection, Title 14, California Code of Regulations, Chapters 4, 4.5, and 10, Sacramento, CA.

Camargo, J.A., A. Alonso, and M. de la Puente. 2005. Eutrophication downstream from small reservoirs in mountain rivers of Central Spain. Water Research 39(14): 3376-3384.

Cheshire, K., L. Boyero, and R.G. Pearson. 2005. Food webs in tropical Australian streams: Shredders are not scarce. Freshwater Biology 50: 748-769. 
Clarke, K.R. 1993. Non-parametric multivariate analysis of changes in community structure. Australian Journal of Ecology 18: 117-143.

Courtney, L. and W. Clements. 1998. Effects of acidic pH on benthic macroinvertebrate communities in stream microcosms. Hydrobiologia 379: 135-145.

Cross, W., C. Baxter, E. Rosi-Marshall, R. Hall, T. Kennedy, K. Donner, H. Kelly, S. Seegert, K. Behn, and M. Yard. Food-web dynamics in a large river discontinuum. Ecological Monographs 83(3): 311-337.

Cross, W., J. Wallace, and A. Rosemond. 2007. Nutrient enrichment reduces constraints on material flows in a detritus-based food web. Ecology 88(10):2563-2575.

Cummins, K.W. 2002. Riparian-stream linkage paradigm. Verhandlungen des Internationalen Verein Limnologie 28: 49-58.

Cummins, K.W. and R.W. Merritt. 1996. Ecology and Distribution of Aquatic Insects. An Introduction to the Aquatic Insects of North America. Kendall/Hunt Publishing Company, Dubuque, Iowa. 74-86.

Cushing, C.E. and J.D. Allan. 2001. Streams: their ecology and life. Academic Press, San Diego. 366.

Dellamonica, Jake \#2708. 2009. Lockheed Fire INVF Report. Case \#09CACZU007246. State of California Department of Forestry \& Fire Protection.

Delta T Devices. 2013. HemiView Canopy Analysis Software. Delta-T Devices Ltd. Cambridge, UK. https://www.delta-t.co.uk/wp-content/uploads/2016/10/HMV1DS-9_ver-2.pdf

Eady, B., N. Rivers-Moore, and T. Hill. 2013. Relationship between water temperature predictability and aquatic macroinvertebrate assemblages in two South African streams. African Journal of Aquatic Science 38(2): 163-174.

Erman, D. and N. Erman. 1984. The response of stream macroinvertebrates to substrate size and heterogeneity. Hydrobiologia 108: 75-82.

Eros, T., P. Gustafsson, L.A. Greenberg, and E. Bergman. 2012. Forest-stream linkages: effects of terrestrial invertebrate input and light on diet and growth of brown trout (Salmo trutta) in a Boreal forest stream. PLoS ONE 7(5): e36462.

Faith, D.P., P.R. Minchin, and L. Belbin. 1987. Compositional dissimilarity as a robust measure of ecological distance. Vegetatio 69: 57-58.

Gessner, M.O., E. Chauvet, and M. Dobson. 1995. A perspective on leaf litter breakdown in streams. Oikos 85: 377-384. 
Glazier, D. 2012. Temperature affects food-chain length and macroinvertebrate species richness in spring ecosystems. Freshwater Science 31(2): 575-585.

Grab, S. 2014. Spatio-temporal attributes of water temperature and macroinvertebrate assemblages in the headwaters of the Bushmans River, southern Drakensberg. Water SA 40(1): 19-26.

Grace, M. and S. Imberger. 2006. Stream metabolism: Performing \& interpreting measurements. Water Studies Centre Monash University, Murray Darling Basin Commission and New South Wales Department of Environment and Climate Change. Available from http://www.sci.monash.edu.au/wsc/docs/tech-manualv3.pdf

Gray, L. and J. Ward. 1982. Effects of sediment releases from a reservoir on stream macroinvertebrates. Hydrobiologia 96:177-184.

Greenwood, J.L., A.D. Rosemond, J.B. Wallace, W.F. Cross, and H.S. Weyers. 2007. Nutrients stimulate leaf breakdown rates and detritivore biomass: bottom-up effects via heterotrophic pathways. Oecologia 151(4): 637-649.

Grialou, J., S. West, and R. Wilkins. 2000. The effects of clearcut harvesting and thinning on terrestrial salamanders. The Journal of Wildlife Management 64:105-113.

Griffith, M. and S. Perry. 1993. Colonization and processing of leaf litter by macroinvertebrate shredders in streams of contrasting $\mathrm{pH}$. Freshwater Biology 30(1): 93-103.

Hawkins, C., M. Murphy, and N.H. Anderson. 1982. Effects of canopy, substrate composition, and gradient on the structure of macroinvertebrate communities in Cascade Range streams of Oregon. Ecology 63:1840-1856.

Hawkins, C., H. Mykra, J. Oksanen, and J. Vander Laan. 2015. Environmental disturbance can increase beta diversity of stream macroinvertebrate assemblages. Global Ecology and Biogeography 24(4): 483-494.

Hilsenhoff, W.L. 1988. An improved biotic index of organic stream pollution. The Great Lakes Entomologist 20: 31-37.

Hill, B.H., W.T. Willingham, L.P. Parish, and B.H. McFarland. 2000. Periphyton community responses to elevated metal concentrations in a Rocky Mountain stream. Hydrobiologia 428(1): 161-169.

Jackson, R.C., S.M. Haggerty, C.A. Sturm, D.P. Batzer, and S.S. Cross. 2007. Headwater streams and timber harvest: channel, macroinvertebrate, and amphibian response and recovery. Journal of Forest Science 53:356-370. 
Jones, K., G.C. Poole, J.L. Meyer, W. Bimback, and E.A. Kramer. 2006. Quantifying expected ecological response to natural resource legislation: a case study of riparian buffers, aquatic habitat, and trout populations. Ecology and Society $11: 15$.

Junker, J. and W. Cross. 2014. Seasonality in the trophic basis of a temperate stream invertebrate assemblage: Importance of temperature and food quality. Limnology and Oceanography 59(2): 507-518.

Kiffney, P., J. Richardson, and J. Bull. 2004. Establishing light as a causal mechanism structuring stream communities in response to experimental manipulation of riparian buffer width. Journal of the North American Benthological Society 23: $542-555$.

Kominoski, J., L. Marczak, and J. Richardson. 2011. Riparian forest composition affects stream litter decomposition despite similar microbial and invertebrate communities. Ecology 92(1): 151-159.

Kreutzweiser, D., E. Muto, S. Holmes, and J. Gunn. 2010. Effects of upland clearcutting and riparian partial harvesting on leaf pack breakdown and aquatic invertebrates in boreal forest streams. Freshwater Biology 55:2238-2252.

Legendre, P. and L. Legendre. 1998. Numerical Ecology. Elsevier; Amsterdam: 853.

Lenat, D. and J. Crawford. 1994. Effects of land us on water quality and aquatic biota of three North Carolina Piedmont streams. Hydrobiologia 294(3): 185-199.

LeSage, C.M., R.W. Merritt, and M.S. Wipfli. 2005. Headwater riparian invertebrate communities associated with red alder and conifer wood and leaf litter in Southeastern Alaska. Northwest Science 79: 4.

Leunda, P., J. Oscoz, R. Miranda, and A. Arino. 2009. Longitudinal and seasonal variation of the benthic macroinvertebrate community and biotic indices in an undisturbed Pyrenean river. Ecological Indicators 9: 52-63.

Li, J., A. Herlihy, W. Gerth, P. Kaufmann, S. Gregory, S. Urquhart, and D.P. Larsen. 2001. Variability in stream macroinvertebrates at multiple spatial scales. Freshwater Biology 46(1): 87-97.

Lohr, A.J., R. Sluik, M.M. Olaveson, N. Ivorra, C.A. Van Gestel, A.M. Cornelis, and N.M. Van Straalen. Macroinvertebrate and algal communities in an extremely acidic river and the Kawah Ijen crater lake $(\mathrm{ph}<0.3)$, Indonesia. Hydrobiologia 165: 1-21.

Long, J. 2009. Emulating natural disturbance regimes as a basis for forest management: A North American view. Forest Ecology and Management 257:1868-1873. 
Louen, J. 2016. Hydrologic Characteristics of Summer Stream Temperatures in Little Creek and Scotts Creek at the Swanton Pacific Ranch. Master's thesis, Cal Poly SLO.

Lunde, K., M. Cover, R. Mazor, C. Sommers, and V. Resh. 2013. Identifying reference conditions and quantifying biological variability within benthic macroinvertebrate communities in perennial and non-perennial northern California streams. Environmental Management 51: 1262-1273.

Macdonald, E., C.J. Burgess, G.J. Scrimgeour, S. Boutin, S. Reedyk, and B. Kotak. 2004. Should riparian buffers be part of forest management based on emulation of natural disturbances? Forest Ecology and Management 187:185-196.

Malison, R.L. and C.V. Baxter. 2010. Effects of wildfire of varying severity on benthic stream insect assemblages and emergence. The North American Benthological Society 29(4): 1324-1338.

Marsh-McBirney, Inc. 1990. Flo-Mate ${ }^{\mathrm{TM}}$ Model 2000 Portable Flow Meter Instruction Manual. Marsh-McBirney, Inc., Frederick, MD. www.marsh-mcbirney.com

Mazor, R.D., and K. Schiff. 2007. Surface Water Ambient Monitoring Program (SWAMP) Report on the Penasquitos Hydrologic Unit. Surface Water Ambient Monitoring Program Final Report.

McCune, B. and J.B. Grace. 2002. Analysis of Ecological Communities. MjM Software Design; Gleneden Beach, Oregon: 300.

McIntosh, A.R., H.S. Greig, S.A. McMurtrie, P. Nystrom, and M.J. Winterbourn. 2005. Top-down and bottom-up influences on populations of a stream detritivore. Freshwater Biology 50(7): 1206-1218.

Melody, K. and J. Richardson. 2007. Riparian forest harvesting and its influence on benthic communities of small streams of sub-boreal British Columbia. Canadian Journal of Forest Resources 37:907-918.

Merritt, R. and K. Cummins. 2007. Trophic Relationships of Macroinvertebrates. Methods in Stream Ecology 587-593.

Miller, K.B. and P.D. Perkins. 2012. The diving beetle species Hydrotrupes palpalis Sharp 1882 (Coleoptera: Dytiscidae). The Coleopterists Bulletin 66(4): 371-377.

Minchin, P.R. 1987. An evaluation of relative robustness of techniques for ecological ordinations. Vegetatio 69: 89-107.

Montgomery, D.R. and J.M. Buffington. 1997. Channel-reach morphology in mountain drainage basins. Geological Society of America Bulletin 109(5): 596-611. 
Naiman, R.J., T.J. Beechie, L.E. Benda, D.R. Berg, P.A. Bisson, L.H. MacDonald, M.D. O'Connor, P.L. Olson, and E.A. Steel. 1992. Fundamental elements of ecologically healthy watersheds in the Pacific Northwest coastal ecoregion. Watershed management: balancing sustainability and change 127-188.

Norris, R.H. and A. Georges. 1993. Analysis and Interpretation of Benthic Macroinvertebrate Surveys. Freshwater Biomonitoring and Benthic Macroinvertebrates Chapman and Hall, New York 234-286.

Ode, P.R. 2007. Standard operating procedures for collecting benthic macroinvertebrate samples and associated physical and chemical data for ambient bioassessments in California. California State Water Resources Control Board. Surface Water Ambient Monitoring Program (SWAMP) Bioassessment SOP 1.

Oksanen, J. 2015. Multivariate Analysis of Ecological Communities in R: vegan tutorial. http://cc.oulu.fi/ jarioksa/opetus/metodi/vegantutor.pdf

Oliver, A.A., R.A. Dahlgren, D.B. Herbst, and M.T. Bogan. 2012. Short-term changes instream macroinvertebrate communities following a severe fire in the Lake Tahoe basin, California. Hydrobiologia 694:117-130.

Perkins, D.A. 2012. Evaluating Geomorphic Change in Little Creek Using Repeated Cross-Sectional and Longitudinal Profile Surveys. Master's Thesis, Cal Poly SLO.

Petersen, R.C. and K.W. Cummins. 1974. Leaf processing in a woodland stream. Freshwater Biology 4: 343-368.

Peterson, D.A. and J.R. Zumberge. 2006. Comparison of Macroinvertebrate Community Structure between Two Riffle-Based Sampling Protocols in Wyoming, Colorado, and Montana, 2000-2001. USGS National Water-Quality Assessment Program Scientific Investigations Report 2006-5117.

Pickett, S.T.A. and M.L. Cadenasso. 2002. The ecosystem as a multidimensional concept: meaning, model, and metaphor. Ecosystems 5: 1-10.

Picolo, J.J. and M.S. Wipfli. 2002. Does red alder (Alnus rubra) in upland riparian forests elevate macroinvertebrate and detritus export from headwater streams to downstream habitats in southeastern Alaska?. Canadian Journal of Fisheries and Aquatic Sciences 59: 503-513.

Post, D.M. 2002. Using stable isotopes to estimate trophic position: models, methods, and assumptions. Ecology 83(3): 703-718.

Power, M.E. 1992. Top-down and bottom-up forces in food webs: Do plants have primacy?. Ecology 73(3): 733-746. 
R Core Team. 2017. R: A language and environment for statistical computing. $\mathrm{R}$ Foundation for statistical computing. Vienna, Austria. https://www.R-project.org/

Reid, D., J. Quinn, and A. Wright-Stow. 2010. Responses of stream macroinvertebrate communities to progressive forest harvesting: influences of harvest intensity, stream size and riparian buffers. Forest Ecology and Management 260:1804-1815.

Resh, V.H., L.A. Beche, J.E. Lawrence, R.D. Mazor, E.P. McElravy, A.P. O'Dowd, D. Rudnick, and S.M. Carlson. 2013. Long-term population and community patterns of benthic macroinvertebrates and fishes in Northern California Mediterraneanclimate streams. Hydrobiologia 719: 93-118.

Richardson, J.S., C.R. Shaughnessy, and P.G. Harrison. 2004. Litter breakdown and invertebrate association with three types of leaves in a temperate rainforest stream. Hydrobiologia 159: 309-325.

Richardson, J.S., R.E. Bilby, and C.A. Bondar. 2006. Organic matter dynamics in small streams of the Pacific northwest. Journal of American Water Resources Association 41: 921-934.

Robinson, C.T. and M.O. Gessner. 2000. Nutrient addition accelerates leaf breakdown in an alpine springbrook. Oecologia 122: 258-263.

Rosenberg, D. and V. Resh. 1993. Introduction to freshwater biomonitoring and benthic macroinvertebrates. Freshwater Biomonitoring 1:1-9.

Rosi-Marshall, E., K. Vallis, C. Baxter, and J. Davis. 2016. Retesting a prediction of the River Continuum Concept: autochthonous versus allochthonous resources in the diets of invertebrates. Freshwater Science 35(2): 534-543.

Rosi-Marshall, E., H. Wellard Kelly, R. Hall, and K. Vallis. 2016. Methods for quantifying aquatic macroinvertebrate diets. Freshwater Science 35(1): 229-236.

Rounick, J.S. and S.V. Gregory. 1981. Temporal changes in periphyton standing crop during an unusually dry winter in streams of the Western Cascades, Oregon. Hydrobiologia 83(2): 197-205.

Sabo, J., J. Bastow, and M. Power. 2002. Length-mass relationships for adult aquatic and terrestrial invertebrates in a California watershed. Jounral of the North American Benthological Society 21(2): 336-343.

SAS Institute Inc. 2016. JMP 13.0.0 Software. Cary, NC. https://www.jmp.com/en_us/software.html

Scaramozzino, J.M. 2015. Una Lequa Cuadrada: Exploring the History of Swanton Pacific Ranch and Environs. Master's thesis, Cal Poly SLO. 
Scotts Creek Watershed Council. 2003. Scotts Creek Watershed Assessment Volume 1.

Shaffi, B., W.J. Price, G.W. Minshall, and C. Holderman. 2013. Characterizing benthic macroinvertebrate community responses to nutrient addition using NMDS and BACI analyses. Annual Conference on Applied Statistics in Agriculture 2013-25 ${ }^{\text {th }}$ Annual Conference Proceedings 64-79

Smock, L.A. 1980. Relationships between body size and biomass of aquatic insects. Freshwater Biology 10: 375-383.

Sokal, R.R. and F.J. Rohlf. 1981. Biometry: The principles and practice of statistics in biological research. Freeman and Company, San Francisco 776.

Solar Pathfinder. 2017. Solar Pathfinder ${ }^{\mathrm{TM}}$. Linden, TN. https://www.solarpathfinder.com/PF

Strahler, A.N. 1957. Quantitative analysis of watershed geomorphology. Transactions of the American Geophysical Union. 38(6): 913-920.

Stephens, S.L. and D.L. Fry. 2005. Fire history in coast redwood stands in the Northeastern Santa Cruz Mountains, California. Fire Ecology 1(1): 2-19.

Swanton Pacific Railroad Society. Photos.

Swanton Pacific Ranch. 2015. Swanton Pacific Ranch Management Plan. https://contentcalpolyedu.s3.amazonaws.com/spranch/1/documents/2015_1026_S wanton_Pacific_Ranch_Management_Plan.pdf

SWC (Sound Watershed Consulting). 2008. Scientific literature review of forest management effects on riparian functions for anadromous salmonids. Final Report prepared for the California State Board of Forestry and Fire Protection. Oakland, CA. 328.

Theobald, D. 2014. Evaluation of Red Alder Mortality in the Little Creek Watershed Following the 2009 Lockheed fire. Master's thesis, Cal Poly SLO.

Tonkin, J.D. 2014. Drivers of macroinvertebrate community structure in unmodified streams. PeerJ 2:e465; DOI 10.7717/peerj.465.

USGS. 2017.California Drought. https://ca.water.usgs.gov/data/drought/

Vannote, R., G. Minshall, K. Cummins, J. Sedell, and C. Cushing. 1980. The River Continuum Concept. Canadian Journal of Fisheries and Aquatic Sciences 37: 130137 
Veraart, A.J., A.M. Romani, E. Tornes, and S. Sabater. 2008. Algal response to nutrient enrichment in forested oligotrophic streams. Journal of Phycology 44: 564-572.

Verkaik, I., N. M. Vila-Escale, M. Rieradevall, C. Baxter, P. Lake, G. Minshall, P. Reich, N. Prat. 2015. Stream macroinvertebrate community responses to fire: Are they the same in different fire-prone biogeographic regions?. Freshwater Science 34(4): 1527-1541.

Wallace, J.B and J.R. Webster. 1996. The role of macroinvertebrates in stream ecosystem function. Annual Reviews: Entomology 41: 115-139.

Ward, J.V. 1992. Aquatic insect ecology: biology and habitat. Wiley, New York 456.

Wellard Kelly, H.A., E. Rosi-Marshall, T. Kennedy, R. Hall, W. Cross, and C. Baxter. 2013. Macroinvertebrate diets reflect tributary inputs and turbidity-driven changes in food availability in the Colorado River downstream of Glen Canyon Dam. Freshwater Science 32 (2): 397-410.

West, J. 2016. Traversing Swanton Road. https://arboretum.ucsc.edu/pdfs/TraversingSwanton.pdf

White, J., D. Hannah, A. House, S. Beatson, A. Martin, and P. Wood. Macroinvertebrate responses to flow and stream temperature variability across regulated and nonregulated rivers. Ecohydrology 10(1): 1-21.

White, R. A. 2010. Accuracy of Forest Road and Stream Channel Characteristics Derived From Lidar in Forested Mountain Conditions. Master's thesis, Cal Poly SLO.

Wood, P. J. and P. D. Armitage. 1997. Biological effects of fine sediment in the logic environment. Journal of Environmental Management 21:203-217.

Worcester, K. 2005. Water quality monitoring in central California: The Central Coast Ambient Monitoring Program. California and the World Ocean Conference 2002, Proceedings of the Conference 379-386.

Yang, C., G. Wilkinson, J. Cole, S. Mako, and M. Pace. 2014. Assigning hydrogen, carbon, and nitrogen isotope values for phytoplankton and terrestrial detritus in aquatic food web studies. Inland Waters 4(2): 233-242.

Zah, R., R. Burgherr, S.M. Bernasconi, and U. Uehlinger. 2001. Stable isotope analysis of macroinvertebrates and their food sources in a glacier stream. Freshwater Biology 46: 871-882.

Zilli, F.L. and M.R. Marchese. 2011. Patterns in macroinvertebrate assemblages at different spatial scales. Implications of hydrological connectivity in a large floodplain river Hydrobiologia 663: 245-257. 


\section{APPENDICES}

\section{Appendix A.}

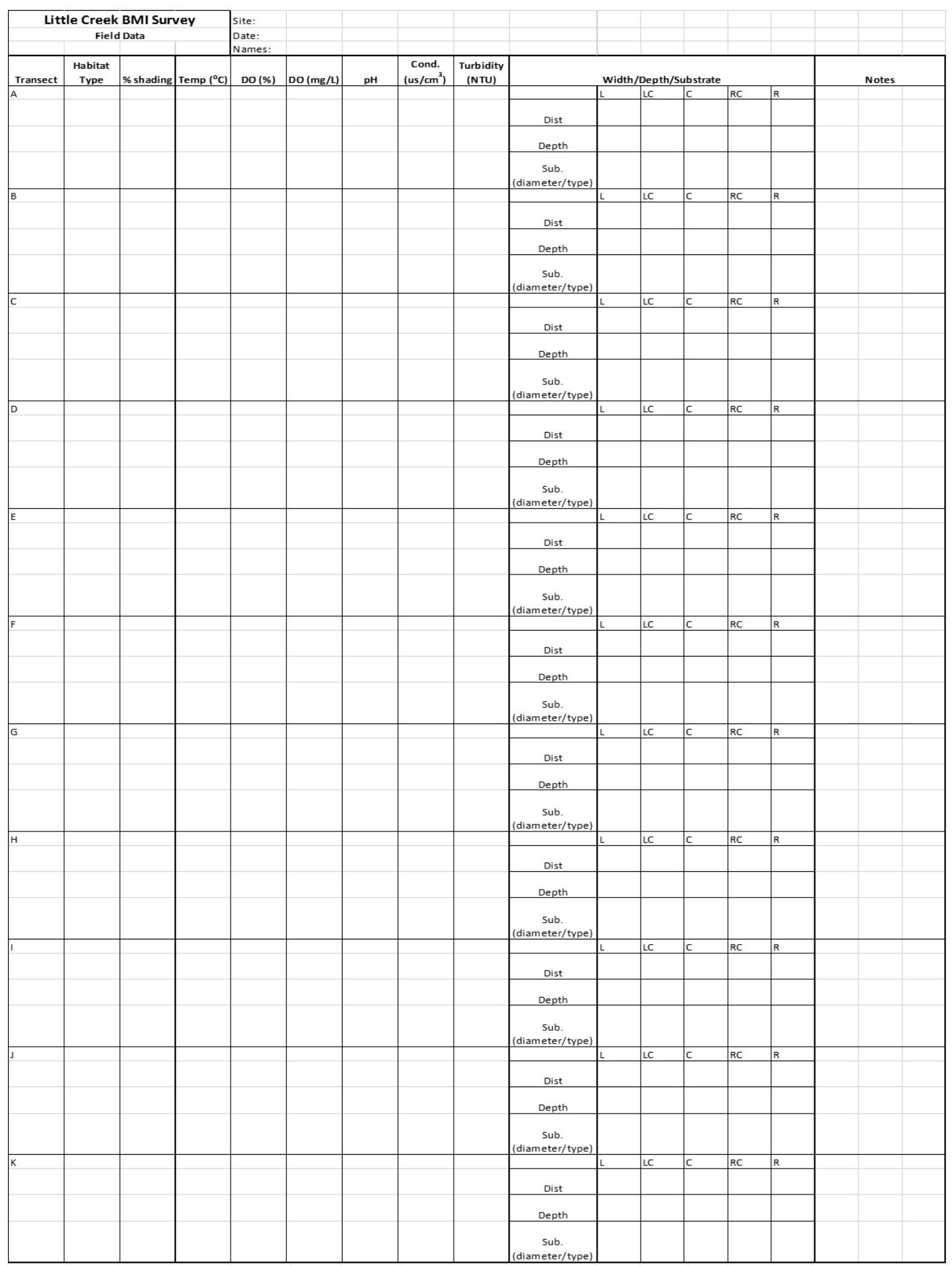

Figure A.1 Frontside of field data sheet. 

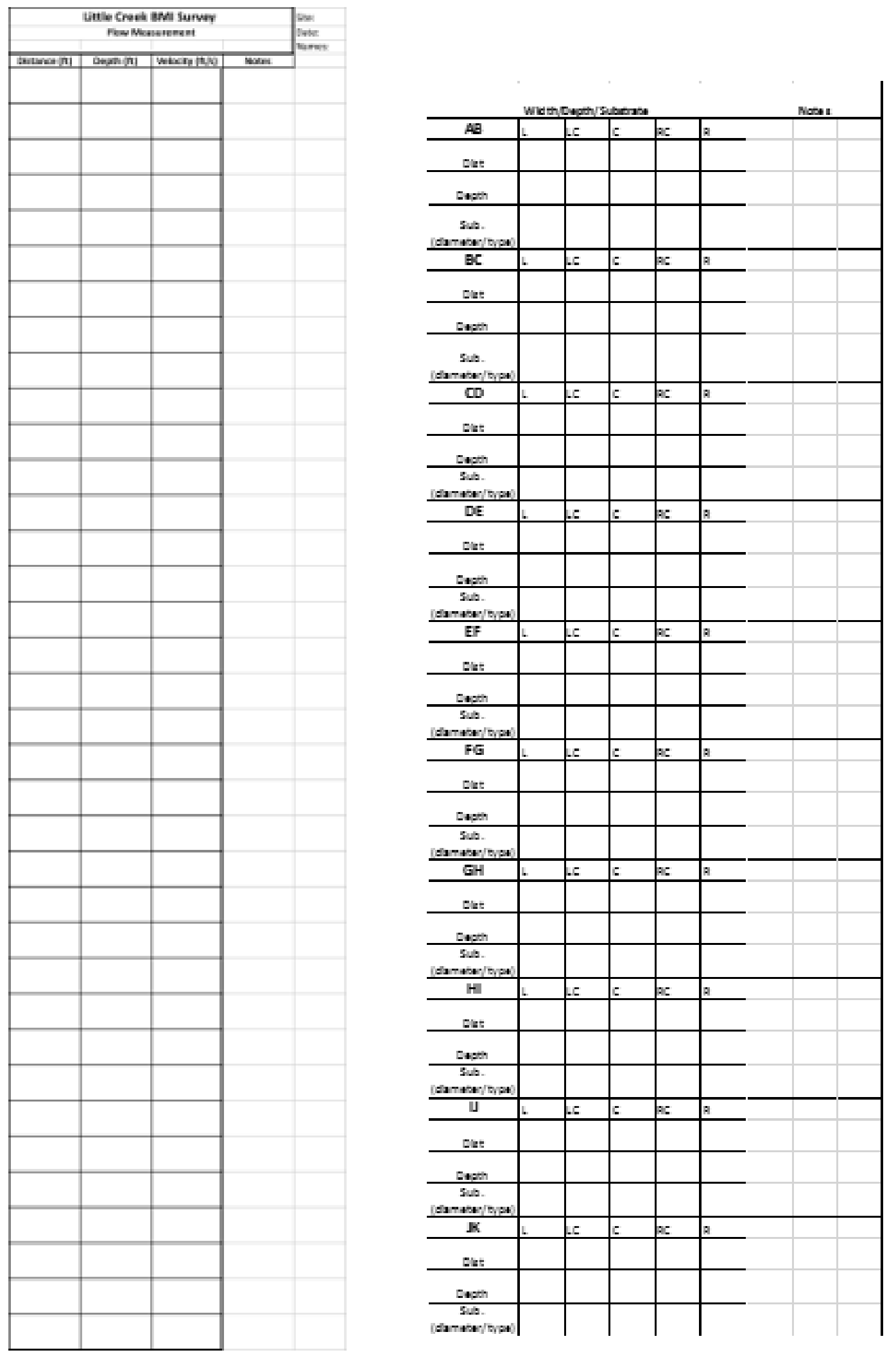

Figure A.2 Backside of field data sheet. 


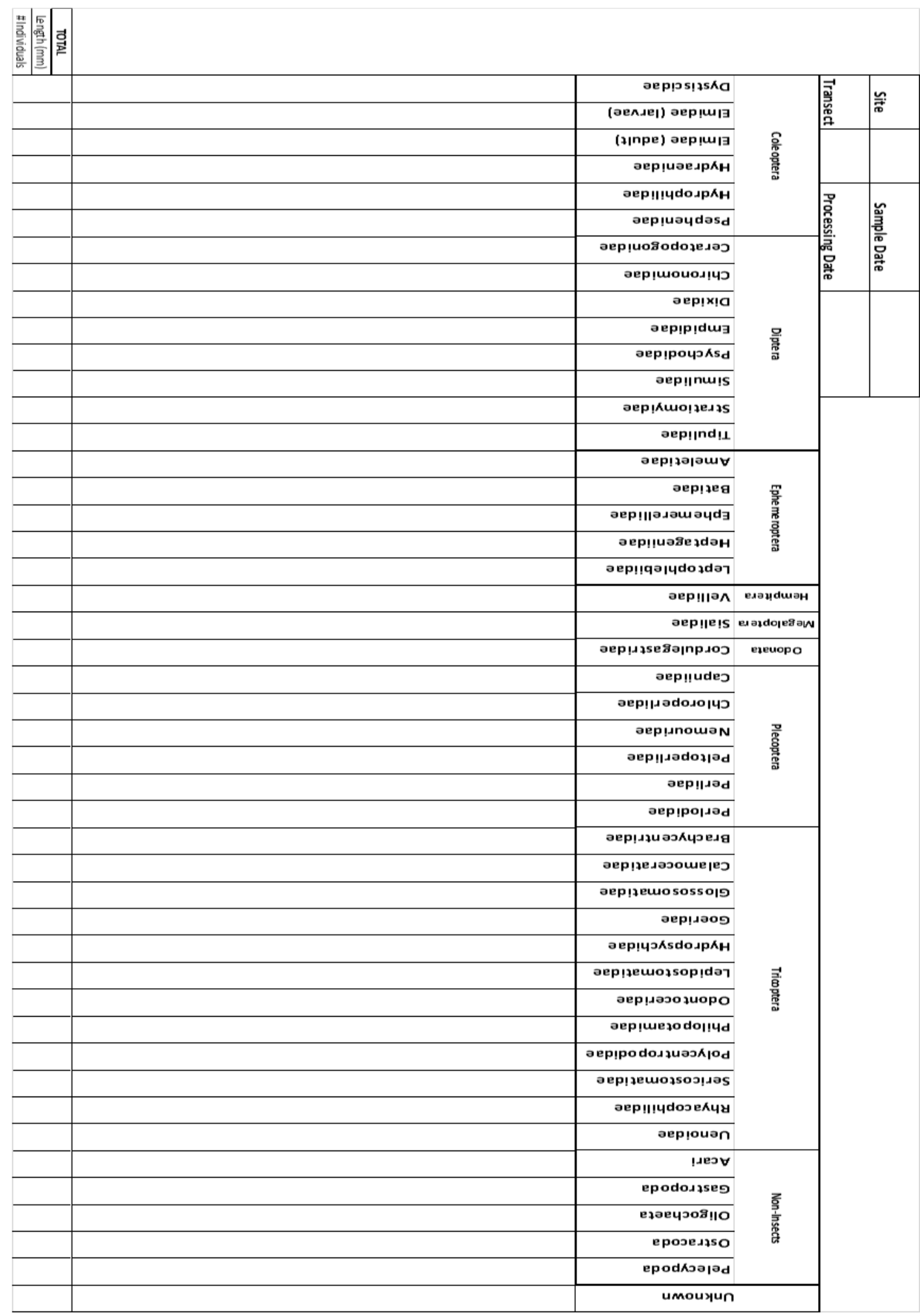

Figure A.3 Laboratory processing data sheet. 


\section{Appendix B.}

Additional NMDS plots of macroinvertebrate abundance

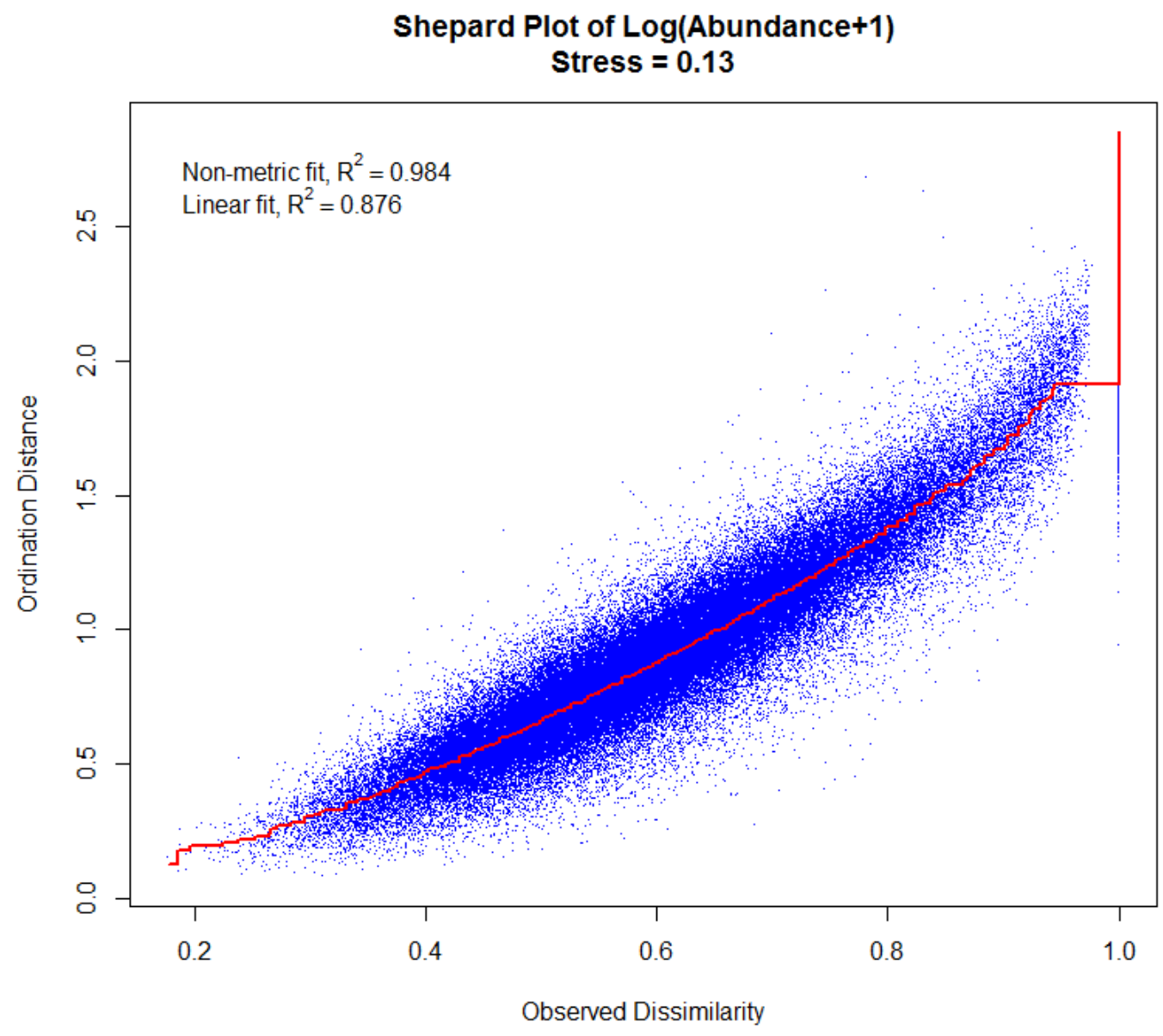

Figure B.1 Shepard plot of macroinvertebrate community composition. 


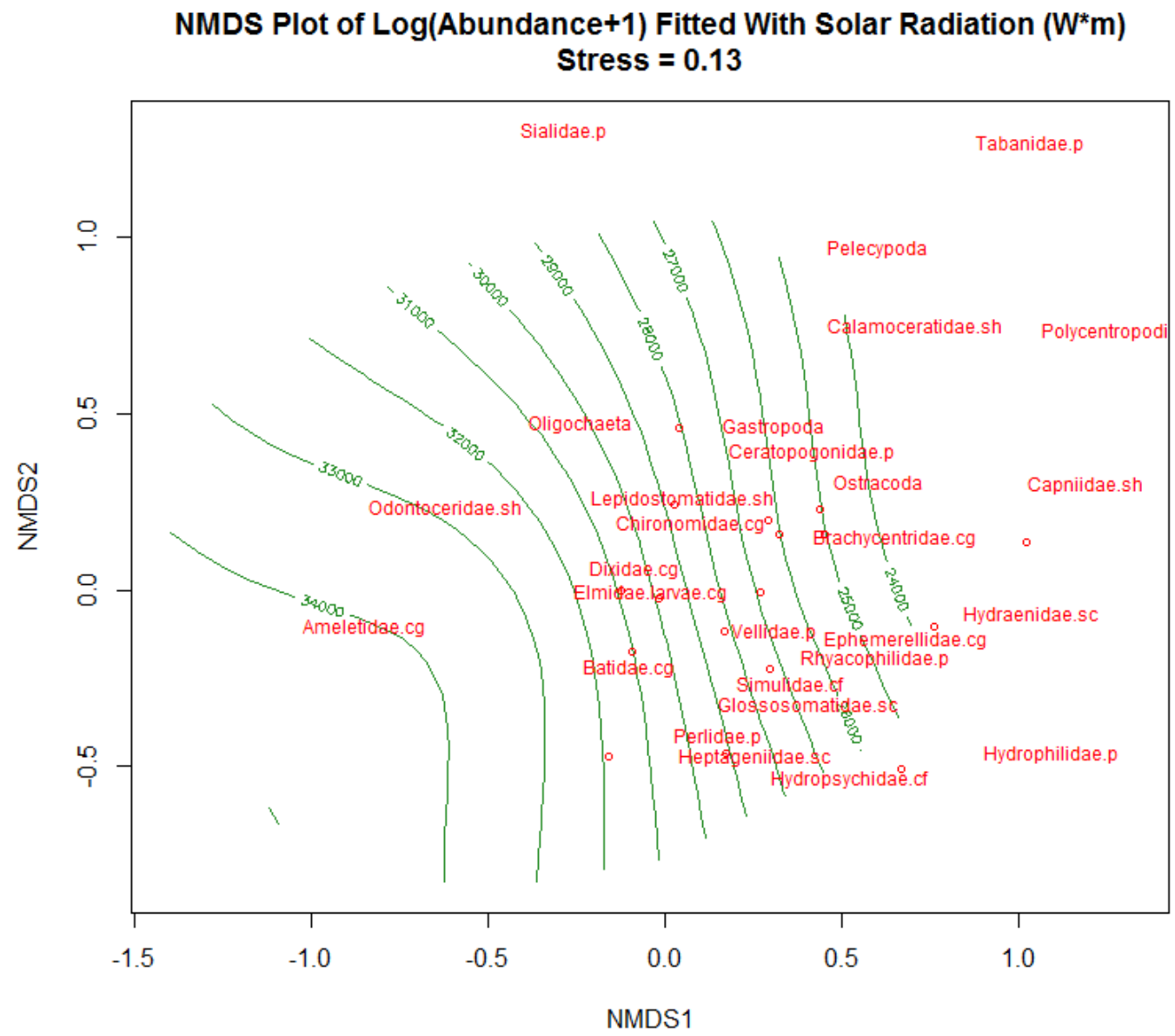

Figure B.2 NMDS plot of macroinvertebrate abundance fitted with solar radiation $\left(\mathrm{W}^{*} \mathrm{~m}^{2}\right)$. 


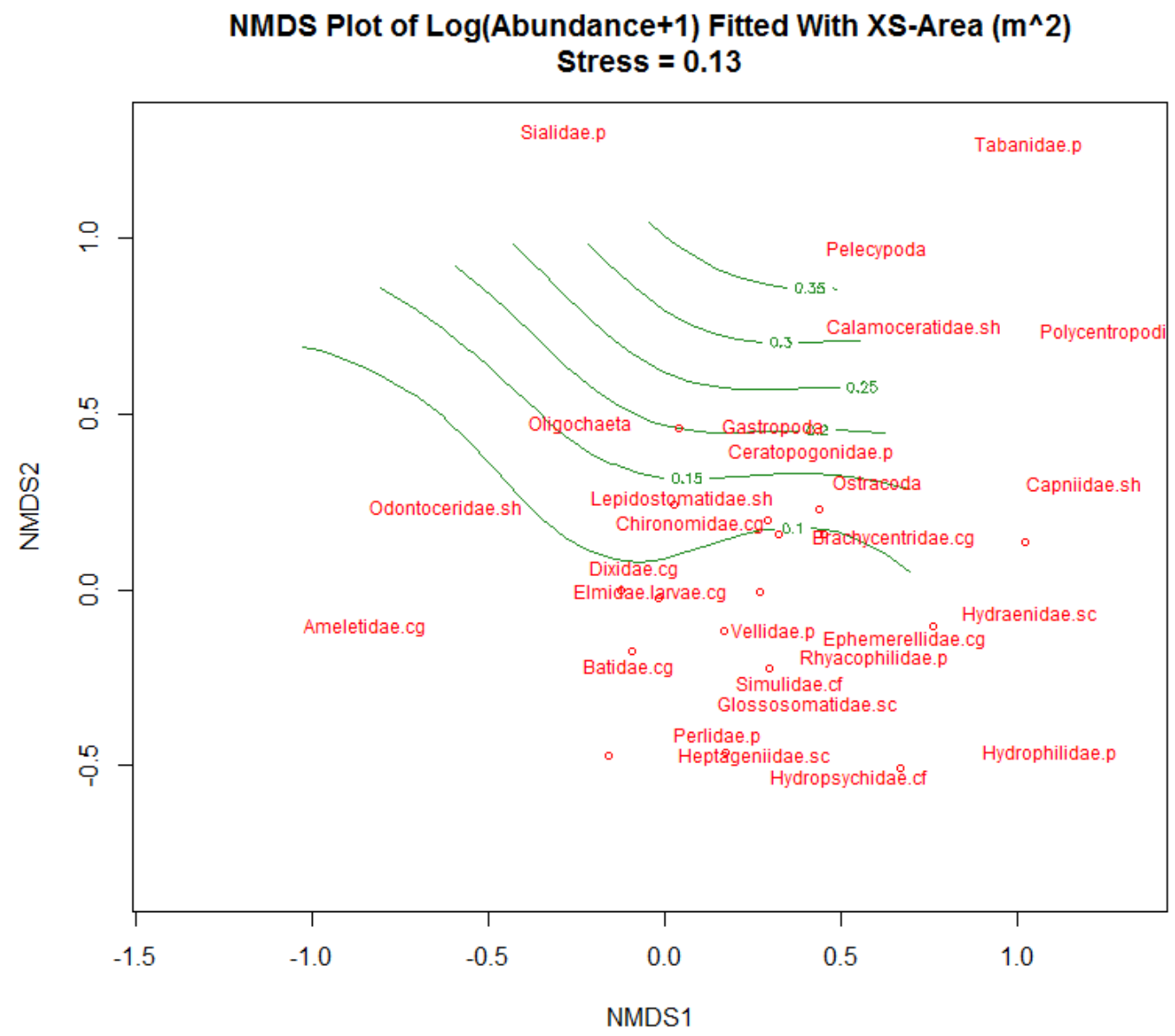

Figure B.3 NMDS plot of macroinvertebrate abundance fitted with cross-sectional area $\left(\mathrm{m}^{2}\right)$. 


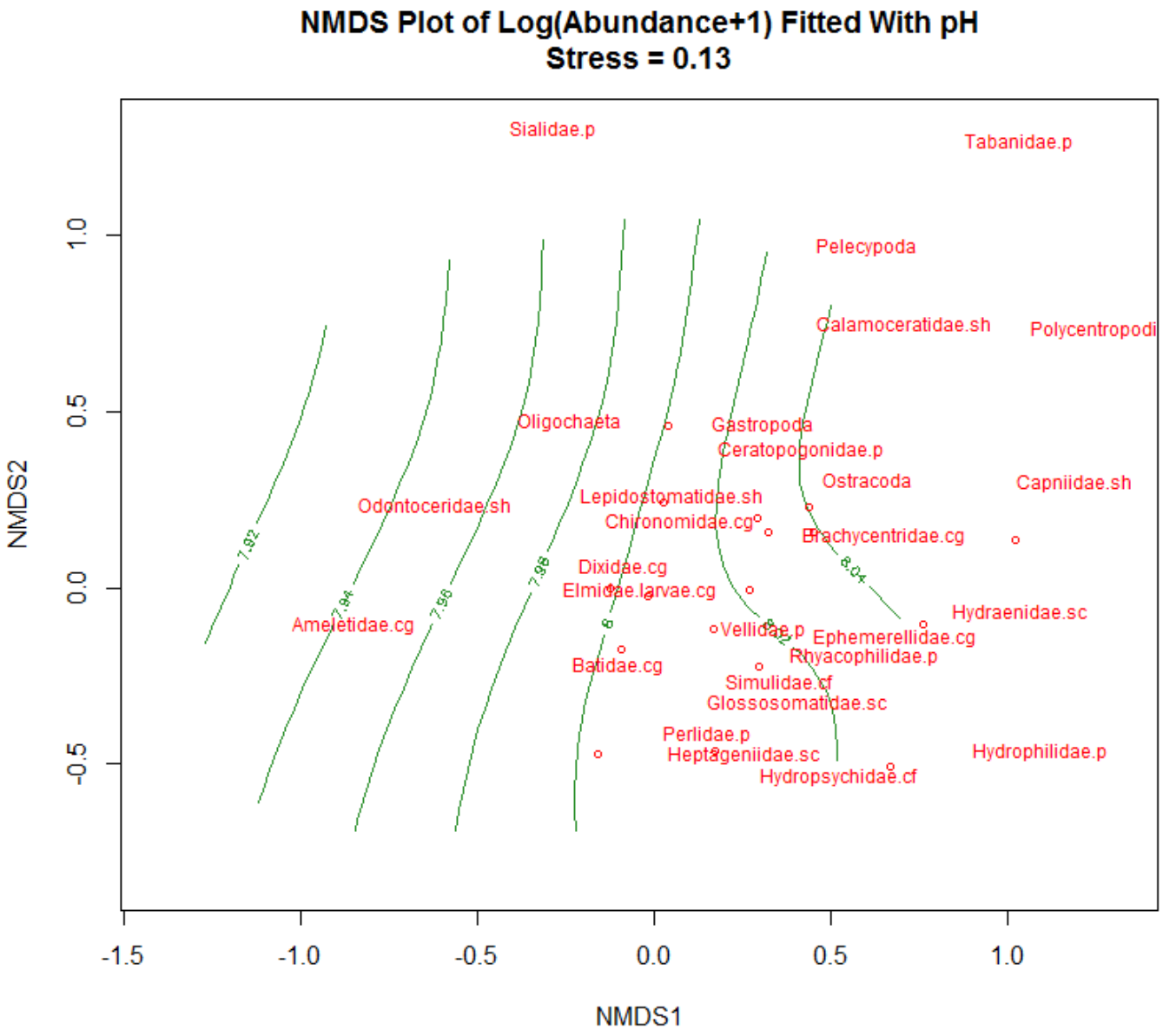

Figure B.4 NMDS plot of macroinvertebrate abundance fitted with $\mathrm{pH}$. 
NMDS Plot of Log(Abundance+1) Fitted With Dissolved Oxygen (\%) Stress $=0.13$

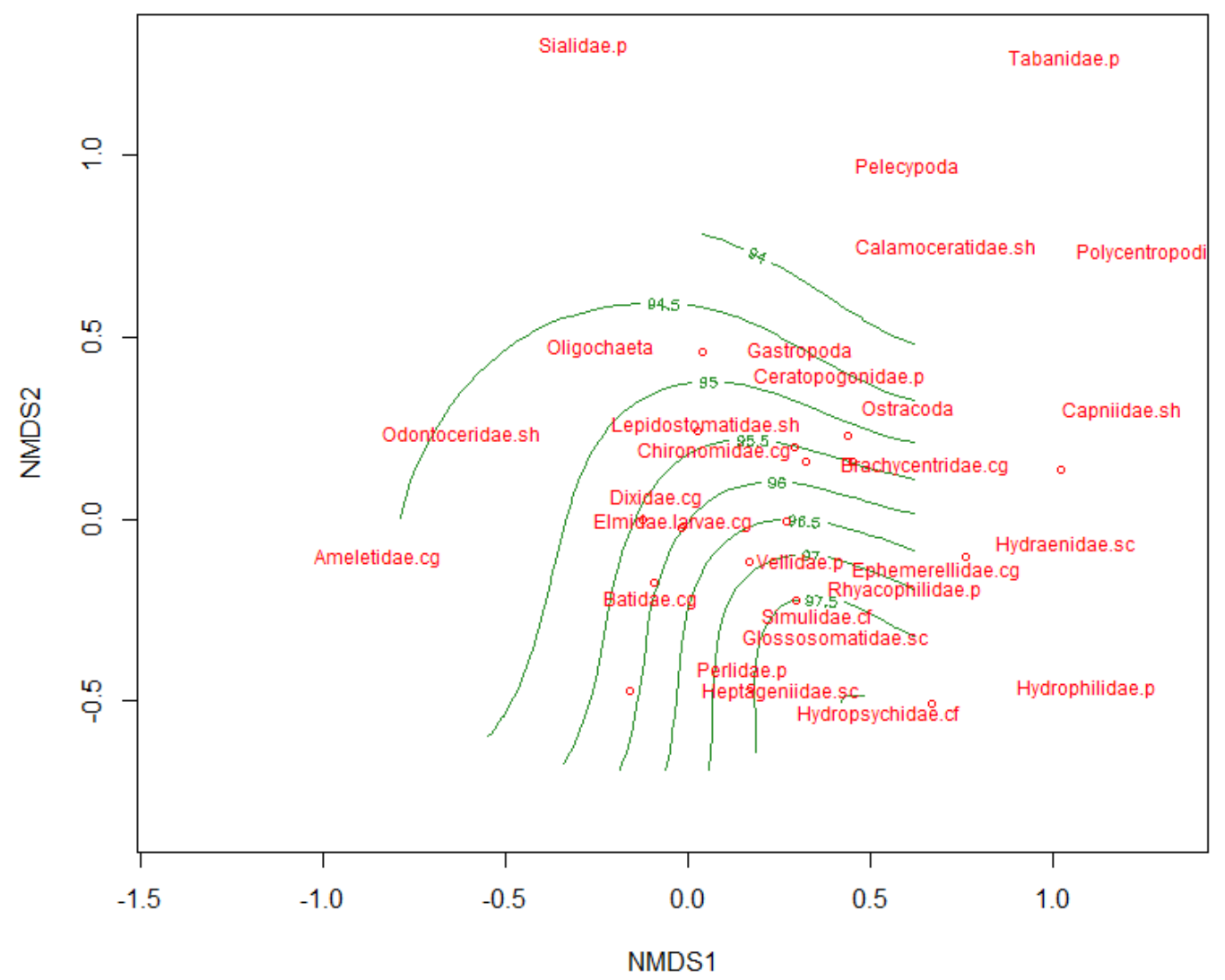

Figure B.5 NMDS plot of macroinvertebrate abundance fitted with dissolved oxygen (\%). 
Additional NMDS plots of functional feeding group composition

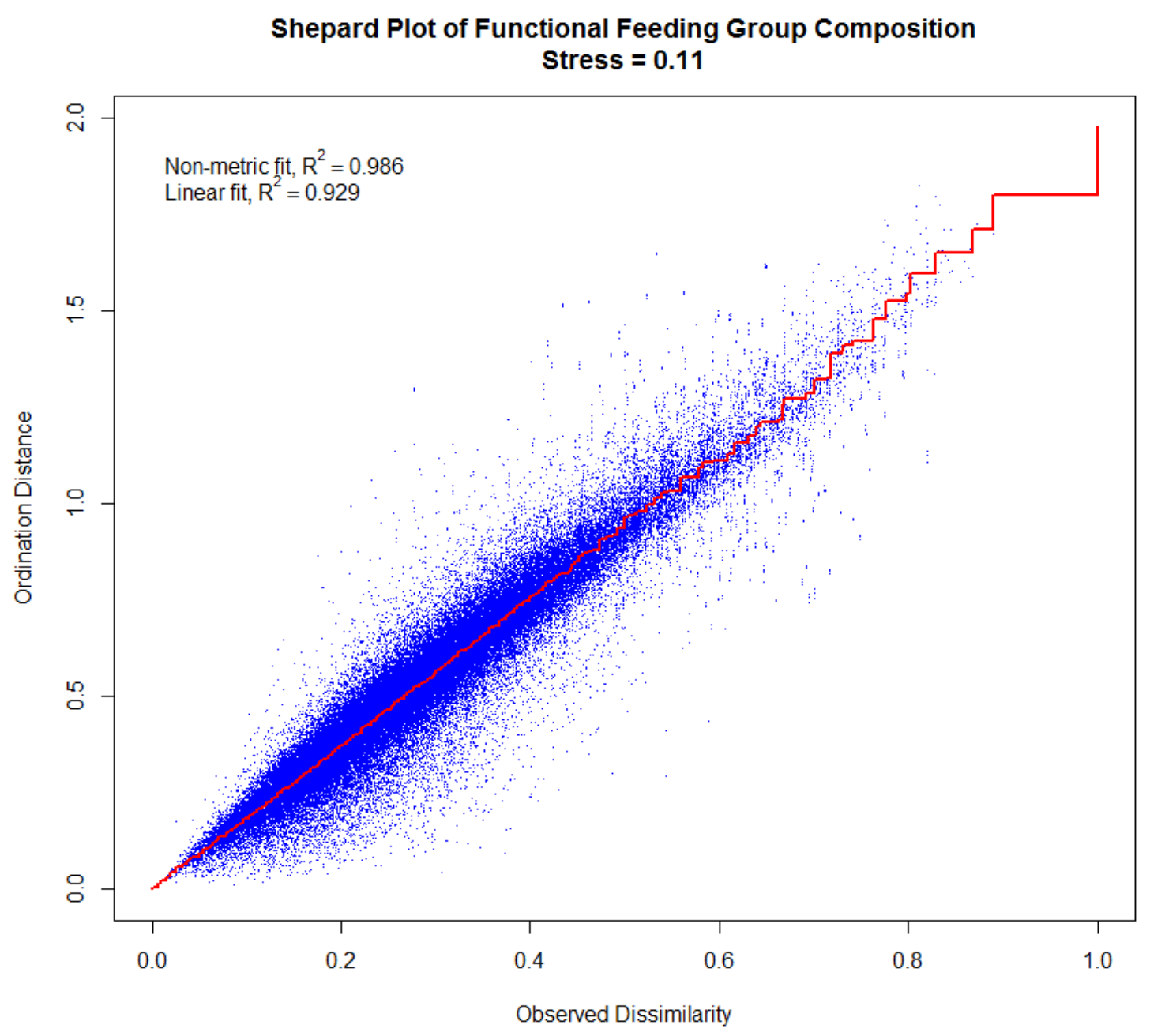

Figure B.6 Shepard plot of functional feeding group composition. 


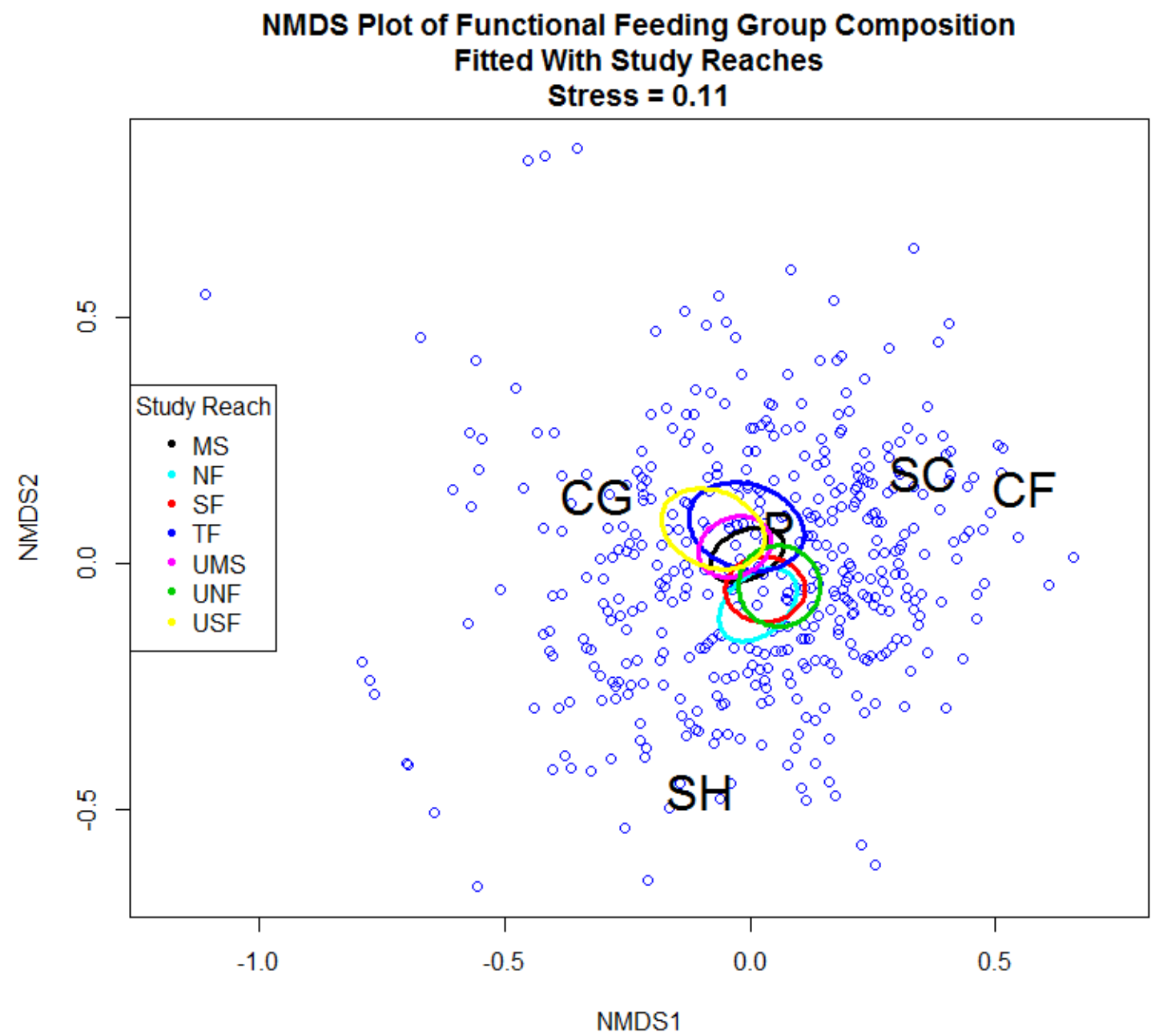

Figure B.7 NMDS plot of functional feeding group composition fitted with fitted with $95 \%$ confidence interval ellipses for the weighted average of each study reach. 


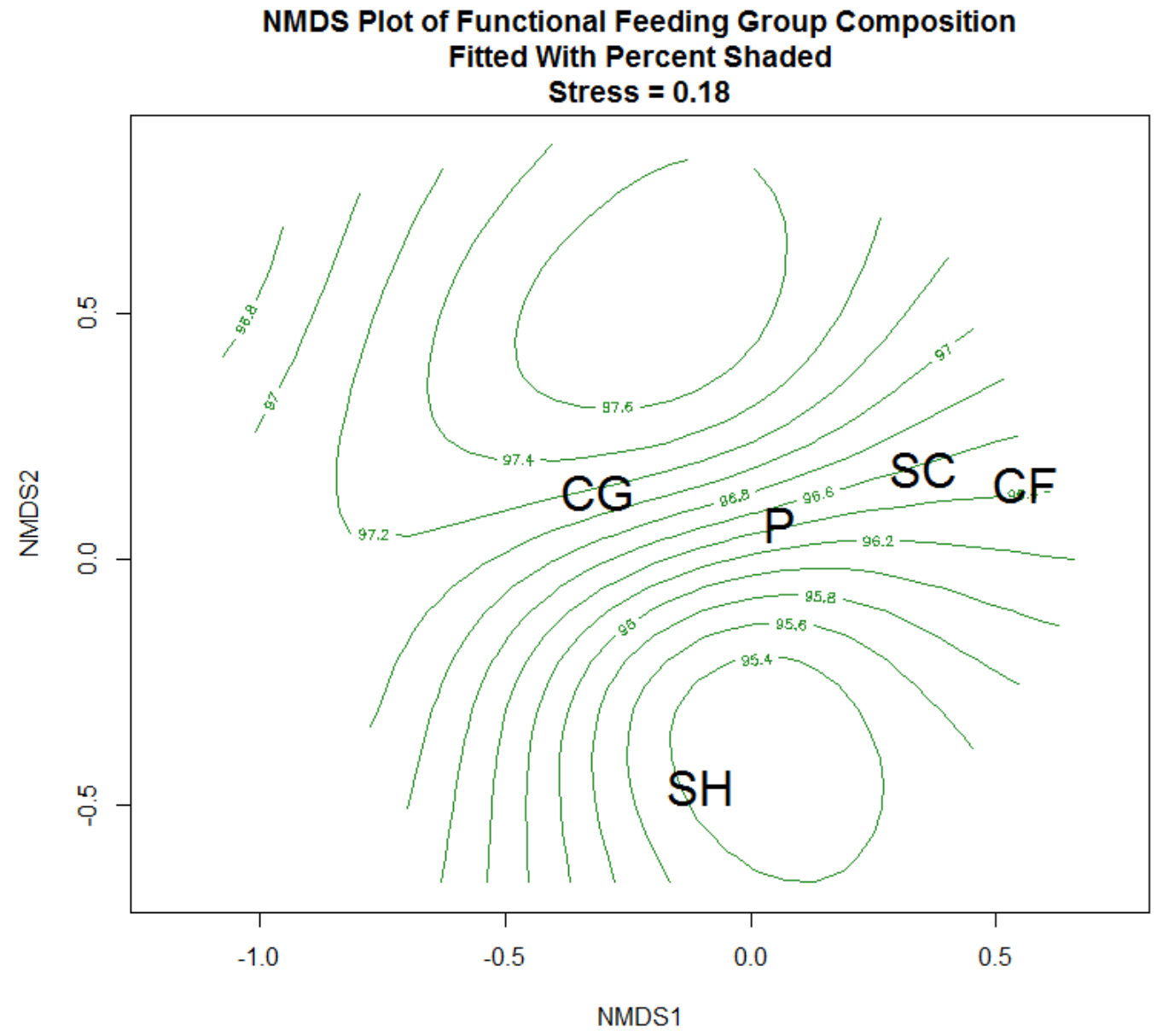

Figure B.8 NMDS plot of functional feeding group composition fitted with percent shaded. 


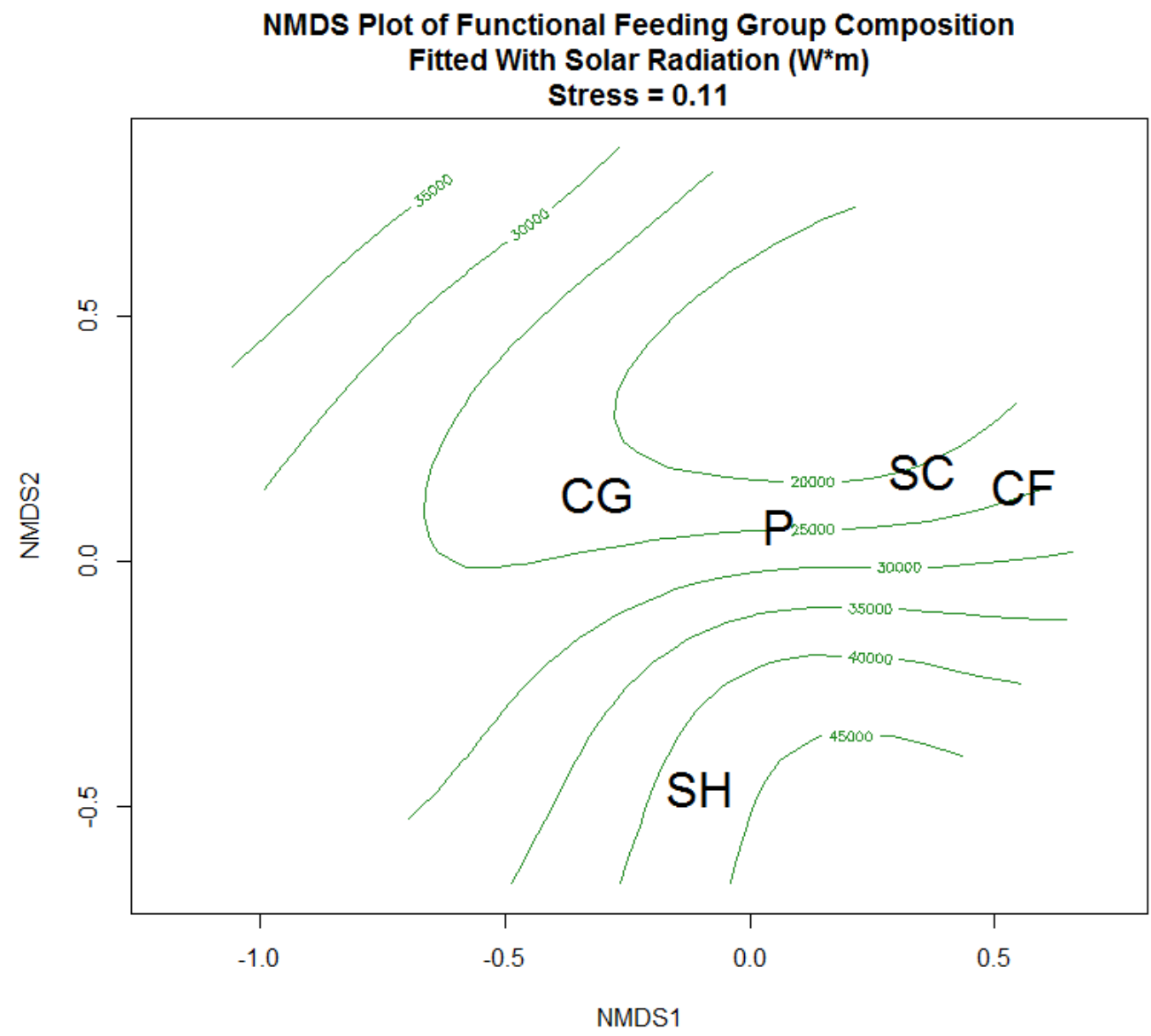

Figure B.9 NMDS plot of functional feeding group composition fitted with solar radiation. 


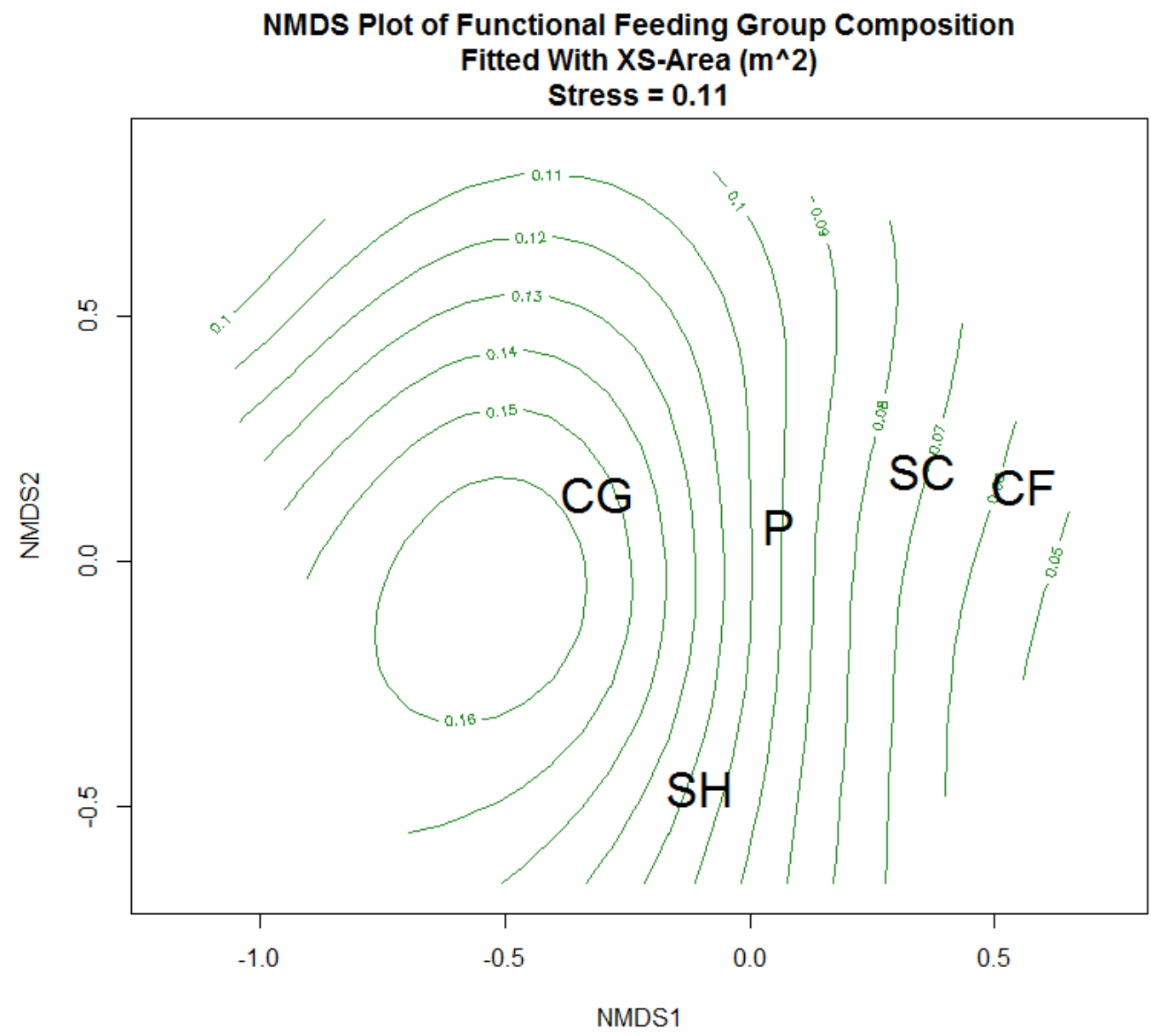

Figure B.10 NMDS plot of functional feeding group composition fitted with crosssectional area $\left(\mathrm{m}^{2}\right)$. 


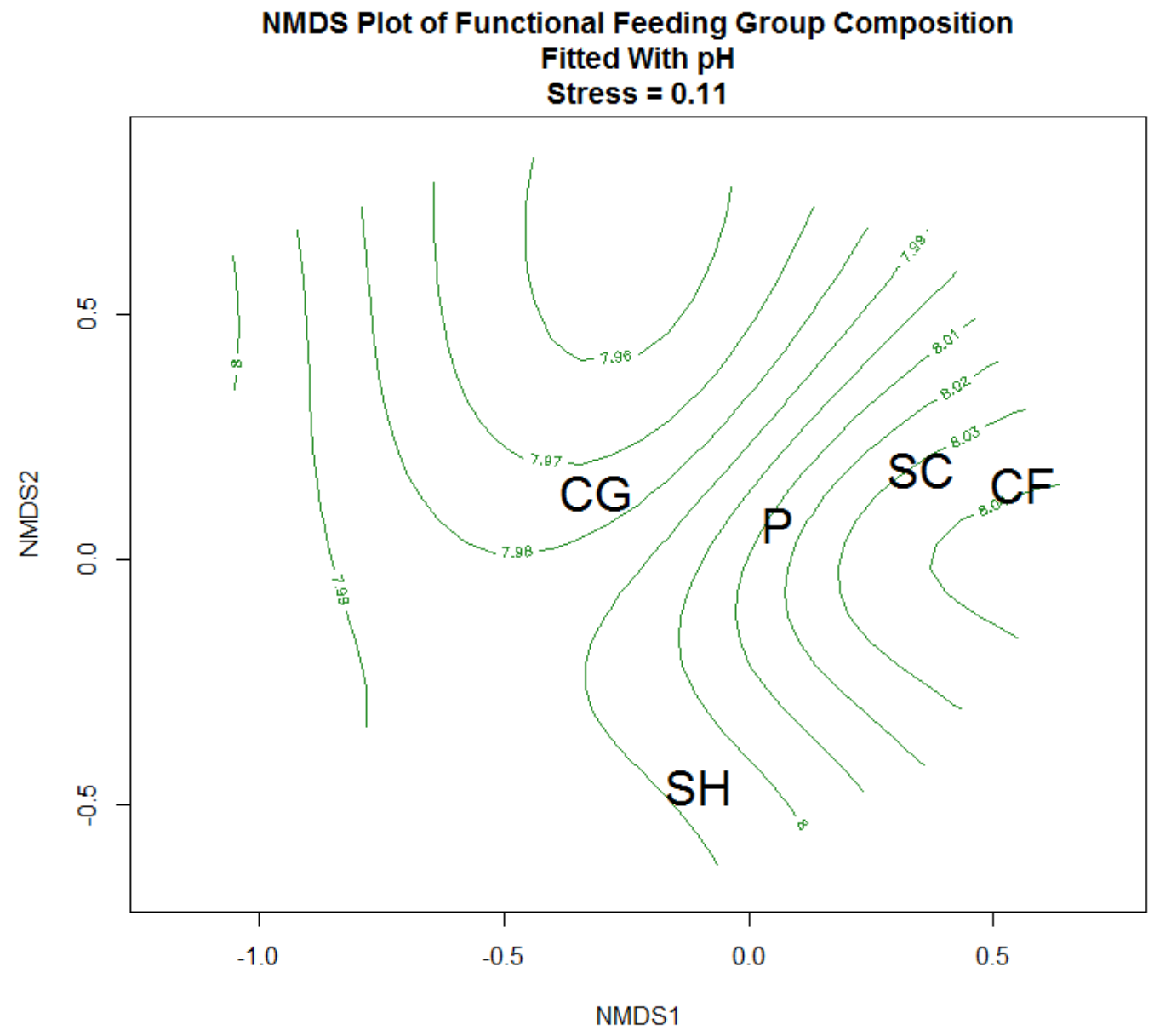

Figure B.11 NMDS plot of functional feeding group composition fitted with $\mathrm{pH}$. 


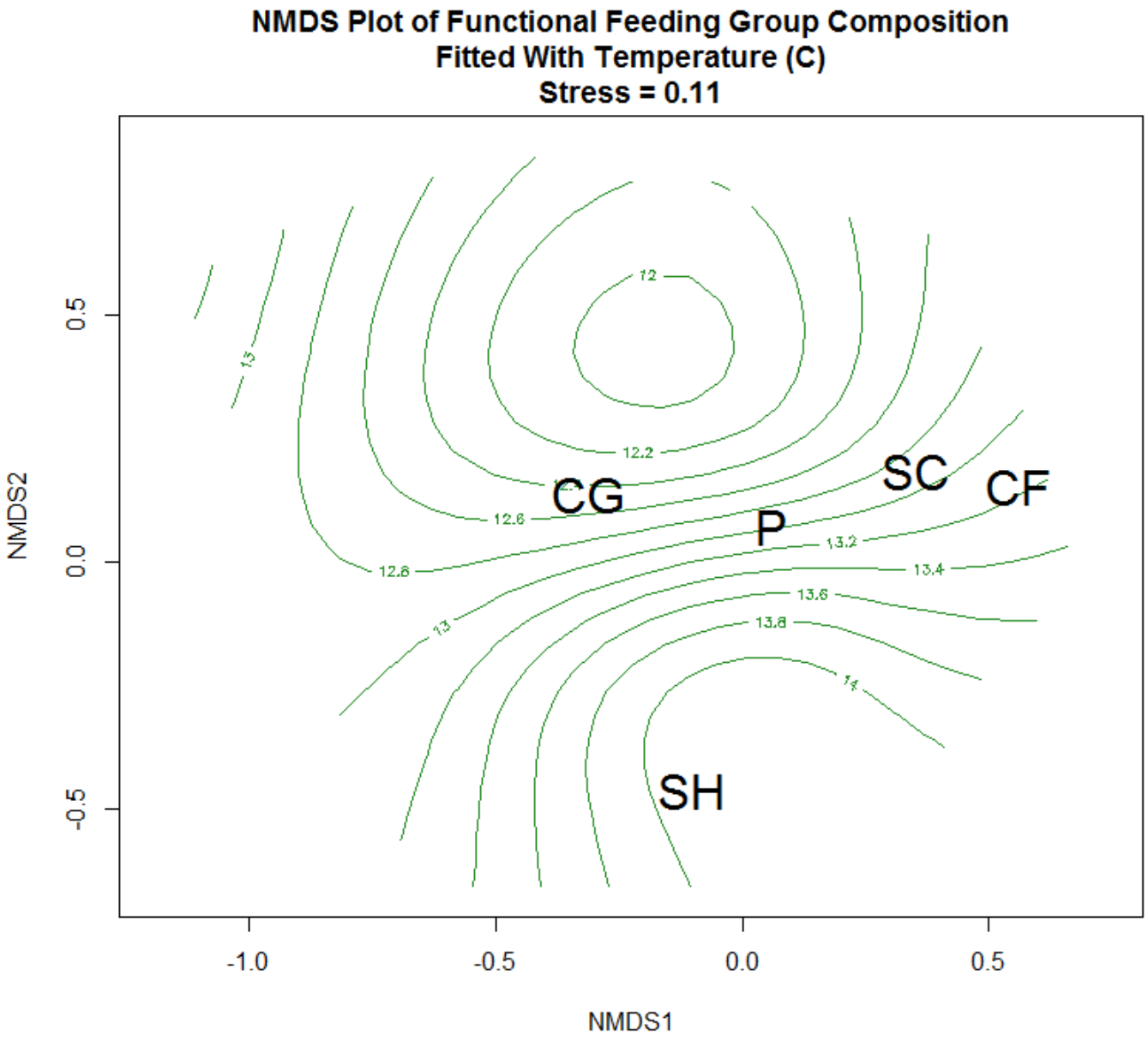

Figure B.12 NMDS plot of functional feeding group composition fitted with temperature $\left({ }^{\circ} \mathrm{C}\right)$. 


\section{$R$ vegan code}

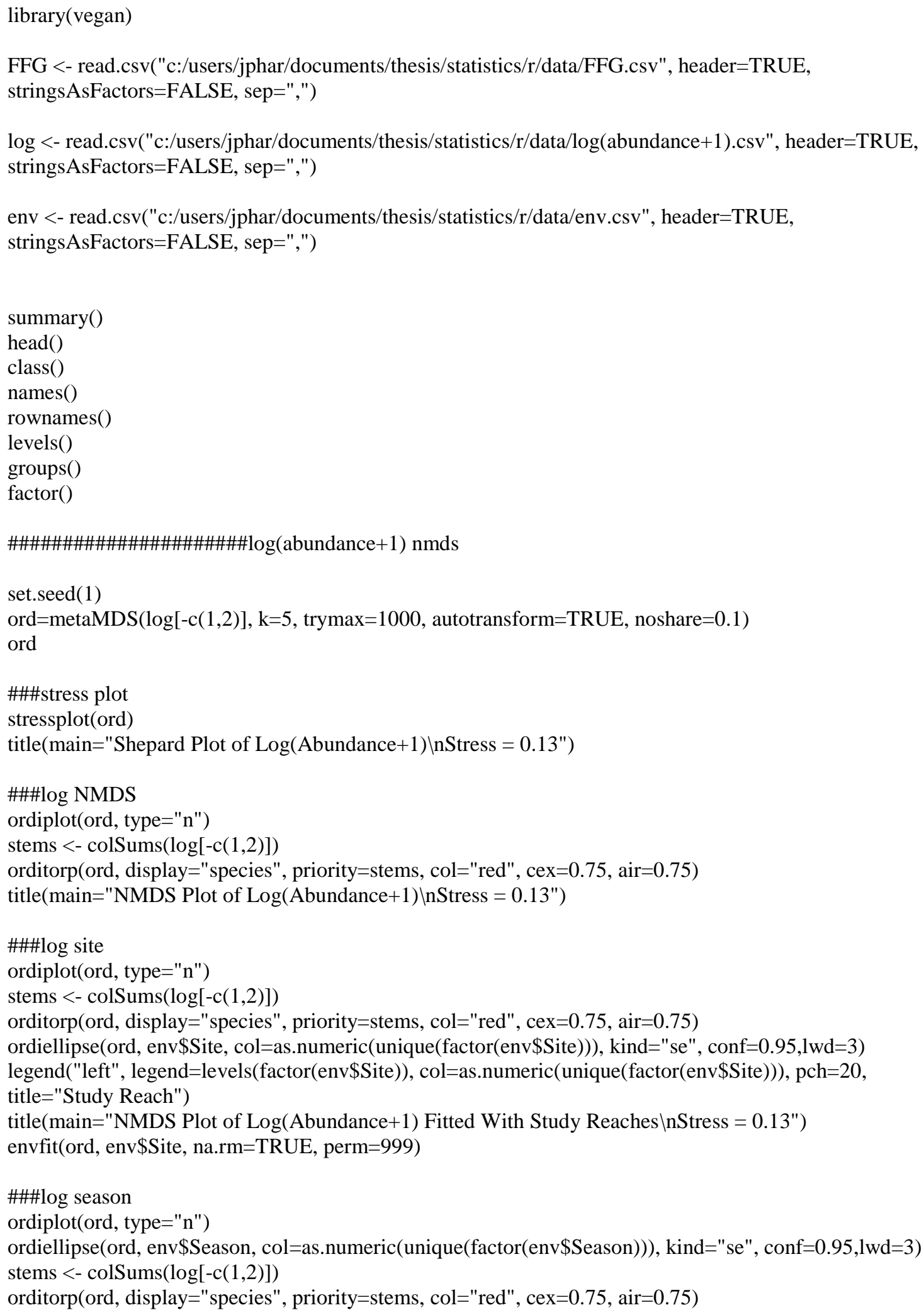


legend("left", legend=levels(factor(env\$Season)), col=as.numeric(unique(factor(env\$Season))), pch=20, title="Season")

title(main="NMDS Plot of Log(Abundance+1) Fitted With Season $\backslash n$ Stress = 0.13")

\#\#\#log environmental variables

ordiplot(ord, type="n")

ordiellipse(ord, env\$Habitat, col=as.numeric(unique(factor(env\$Season))), kind="se", conf=0.95,lwd=2)

stems <- colSums $(\log [-\mathrm{c}(1,2)])$

orditorp(ord, display="species", priority=stems, col="red", cex $=0.75$, air $=0.75$ )

fit <- envfit(ord, env[c(4,5,6,7,11)], na.rm=TRUE, perm=999)

fit

plot(fit, p.max $=0.05$, col="black")

legend("left", legend=levels(factor(env\$Habitat)), col=as.numeric(unique(factor(env\$Habitat))), pch=20, title="Habitat Type")

title(main="NMDS Plot of Log(Abundance+1) Fitted With Environmental Variables $\operatorname{lnStress}=0.13 ")$

\#\#\#log solar radiation overlay

ordiplot(ord, type="n")

ordisurf(ord, env\$SolarRadiation, add=TRUE, col="forestgreen")

stems <- colSums $(\log [-\mathrm{c}(1,2)])$

orditorp(ord, display="species", priority=stems, col="red", cex=0.75, air=1.0)

envfit(ord, env\$SolarRadiation, na.rm=TRUE, perm=1000, display="sites")

title(main="NMDS Plot of $\log \left(\right.$ Abundance+1) Fitted With Solar Radiation $\left(\mathrm{W}^{*} \mathrm{~m}\right) \backslash \mathrm{nStress}=0.13$ ")

\#\#\#log XS Area overlay

ordiplot(ord, type="n")

ordisurf(ord, env\$XS.Area, add=TRUE, col="forestgreen")

stems <- colSums $(\log [-\mathrm{c}(1,2)])$

orditorp(ord, display="species", priority=stems, col="red", cex=0.75, air $=1.0$ )

envfit(ord, env\$XS.Area, na.rm=TRUE, perm=1000, display="sites")

title(main="NMDS Plot of Log(Abundance+1) Fitted With XS-Area $\left.\left(\mathrm{m}^{\wedge} 2\right) \backslash \mathrm{nStress}=0.13 "\right)$

\#\#\#log water quality

ordiplot(ord, type="n")

stems <- colSums $(\log [-\mathrm{c}(1,2)])$

orditorp(ord, display="species", priority=stems, col="red", cex $=0.75$, air $=0.75$ )

fit <- envfit(ord, env[c $(8,9,10)]$, na.rm=TRUE, perm=999)

fit

plot(fit, p.max $=0.05$, col="black", row.names=TRUE)

title(main="NMDS Plot of $\log ($ Abundance+1) Fitted With Water Quality DatalnStress $=0.13 ")$

\#\#\#log pH overlay

ordiplot(ord, type $=" n ")$

ordisurf(ord, env $\$ \mathrm{pH}$, add=TRUE, col="forestgreen")

stems <- colSums $(\log [-\mathrm{c}(1,2)])$

orditorp(ord, display="species", priority=stems, col="red", cex=0.75, air=1.0)

envfit(ord, env\$pH, na.rm=TRUE, perm=1000, display="sites")

title(main="NMDS Plot of Log(Abundance+1) Fitted With pH\nStress = 0.13")

\#\#\#log DO overlay

ordiplot(ord, type $=" n ")$

ordisurf(ord, env\$DO, add=TRUE, col="forestgreen")

stems <- colSums $(\log [-\mathrm{c}(1,2)])$

orditorp(ord, display="species", priority=stems, col="red", cex=0.75, air $=1.0$ )

envfit(ord, env\$DO, na.rm=TRUE, perm=1000, display="sites")

title("left", main="NMDS Plot of Log(Abundance+1) Fitted With Dissolved Oxygen (\%)\nStress = 0.13") 


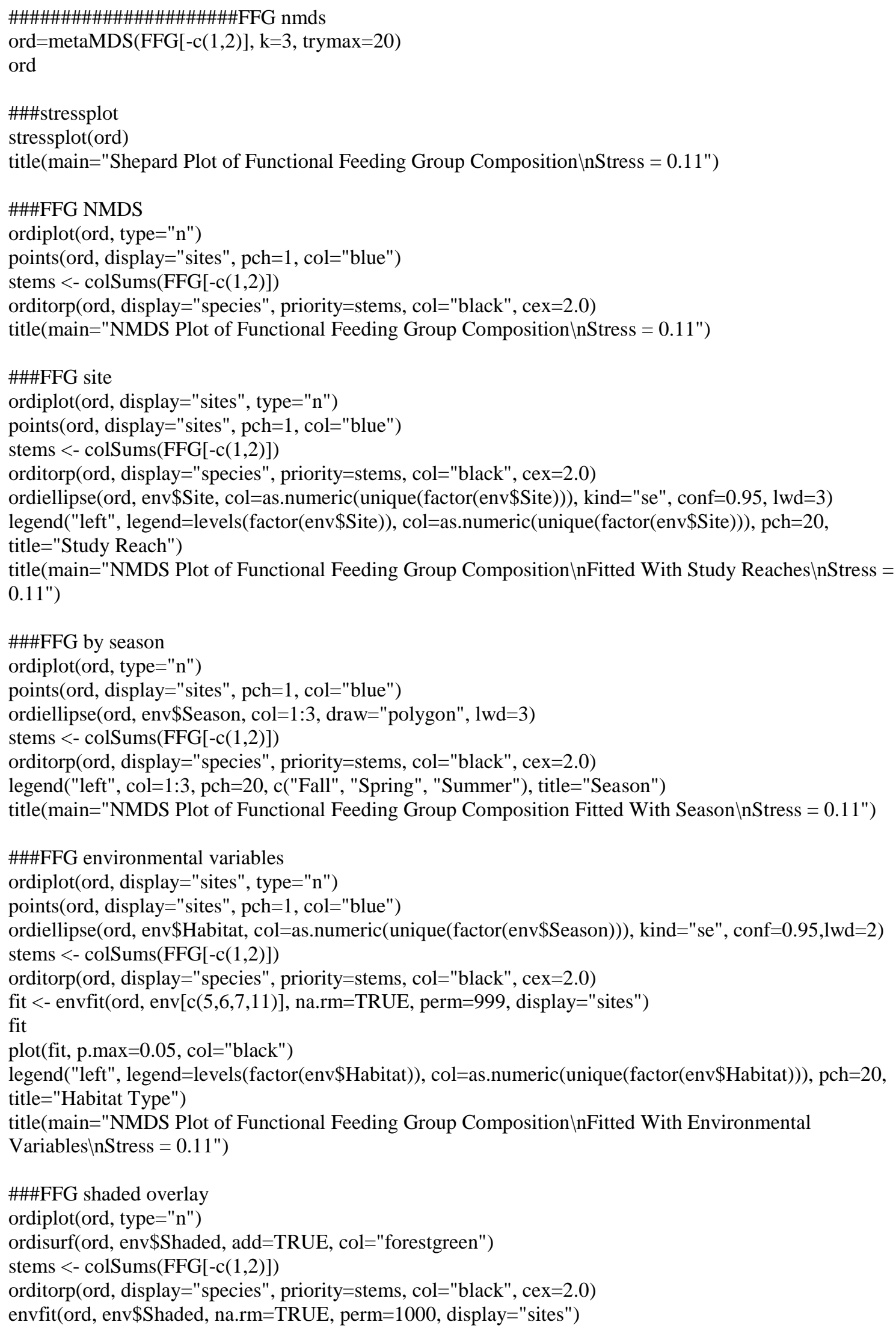


title(main="NMDS Plot of Functional Feeding Group Composition\nFitted With Percent Shaded $\backslash n S t r e s s=$ $0.18 ")$

\#\#\# FFG solar radiation overlay

ordiplot(ord, type $=" n ")$

ordisurf(ord, env\$SolarRadiation, add=TRUE, col="forestgreen")

stems <- colSums(FFG[-c(1,2)])

orditorp(ord, display="species", priority=stems, col="black", cex $=2.0$ )

envfit(ord, env\$SolarRadiation, na.rm=TRUE, perm=1000, display="sites")

title(main="NMDS Plot of Functional Feeding Group Composition InFitted With Solar Radiation

$\left(\mathrm{W}^{*} \mathrm{~m}\right) \backslash \mathrm{n}$ Stress $\left.=0.11 "\right)$

\#\#\#FFG XS Area overlay

ordiplot(ord, type="n")

ordisurf(ord, env\$XS.Area, add=TRUE, col="forestgreen")

stems $<-$ colSums(FFG[-c $(1,2)])$

orditorp(ord, display="species", priority=stems, col="black", cex=2.0)

envfit(ord, env\$XS.Area, na.rm=TRUE, perm=1000, display="sites")

title(main="NMDS Plot of Functional Feeding Group Composition $\backslash n$ Fitted With XS-Area $\left(\mathrm{m}^{\wedge} 2\right) \backslash \mathrm{nStress}=$ $0.11 ")$

\#\#\#FG water quality

ordiplot(ord, type="n")

points(ord, display="sites", pch=1, col="blue")

stems $<-$ colSums(FFG[-c $(1,2)])$

orditorp(ord, display="species", priority=stems, col="black", cex=2.0)

fit <- envfit(ord, env[c $(8,9,10)]$, na.rm=TRUE, perm=999)

fit

plot(fit, p.max=0.1, col="black", row.names=TRUE)

title(main="NMDS Plot of Functional Feeding Group Composition\nFitted With Water Quality

DatalnStress $=0.11 "$ )

\#\#\#FFG pH overlay

ordiplot(ord, type="n")

ordisurf(ord, env $\$ \mathrm{pH}$, add=TRUE, col="forestgreen")

stems <- colSums(FFG[-c $(1,2)])$

orditorp(ord, display="species", priority=stems, col="black", cex=2.0)

envfit(ord, env\$pH, na.rm=TRUE, perm=1000, display="sites")

title(main="NMDS Plot of Functional Feeding Group Composition \nFitted With pH\nStress = 0.11")

\#\#\#FFG temp overlay

ordiplot(ord, type $=" n ")$

ordisurf(ord, env\$Temp, add=TRUE, col="forestgreen")

stems <- colSums(FFG[-c(1,2)])

orditorp(ord, display="species", priority=stems, col="black", cex=2.0)

envfit(ord, env\$Temp, na.rm=TRUE, perm=1000, display="sites")

title(main="NMDS Plot of Functional Feeding Group Composition $\backslash n$ Fitted With Temperature $(C) \backslash n S t r e s s=$ $0.11 ")$

\#\#\#FFG DO overlay

ordiplot(ord, type="n")

ordisurf(ord, env\$DO, add=TRUE, col="forestgreen")

stems $<-$ colSums(FFG[-c $(1,2)])$

orditorp(ord, display="species", priority=stems, col="black", cex=2.0)

envfit(ord, env\$DO, na.rm=TRUE, perm=1000, display="sites") 
title(main="NMDS Plot of Functional Feeding Group Composition \nFitted With Dissolved Oxygen $(\%)$ (nStress $\left.=0.11^{\prime \prime}\right)$ 


\section{Appendix C.}

Additional ANOVA figures and tables from the study reach dataset

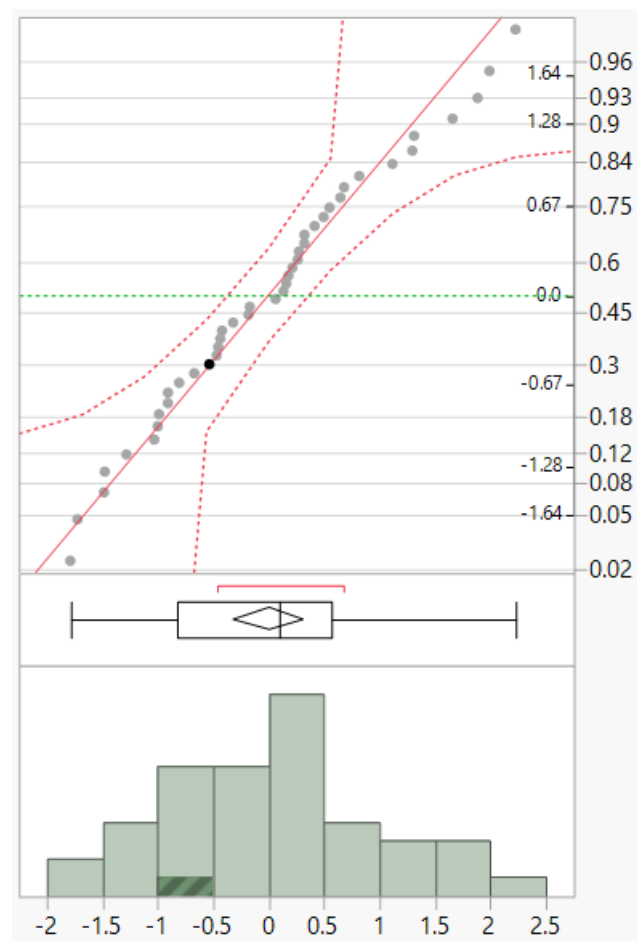

Figure C.1 Distribution of studentized residuals of the Density model from the study reach dataset.

Table C.1 Tukey HSD test results for differences in mean macroinvertebrate density among the study reaches.

\begin{tabular}{c|l|c|c|c|c}
\hline \hline Level & Letters & $\begin{array}{c}\text { Least Sq. } \\
\text { Mean }\end{array}$ & Std. Error & Lower 99\% & Upper 99\% \\
\hline MS & A & 1923.9 & 275.1 & 1167.3 & 2680.4 \\
UMS & A & 1883.4 & 271.7 & 1136.2 & 2630.6 \\
SF & A & 1728.3 & 346.8 & 774.7 & 2681.9 \\
USF & A & 1475.6 & 252.2 & 782.1 & 2169.2 \\
NF & A & 1162.6 & 296.0 & 348.7 & 1976.5 \\
UNF & A & 673.6 & 250.5 & -15.1 & 1362.4 \\
TF & A & 625.4 & 263.0 & -97.8 & 1348.7
\end{tabular}




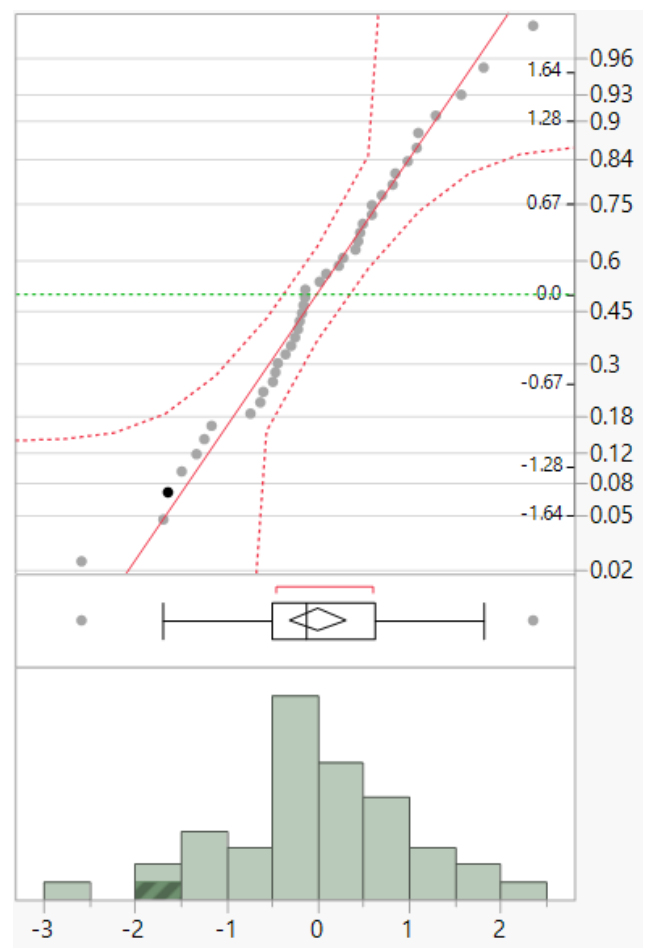

Figure C.2 Distribution of studentized residuals of the \%EPT model from the study reach dataset.

Table C.2 Tukey HSD test results for differences in mean \% EPT among the study reaches.

\begin{tabular}{c|l|c|c|c|c}
\hline \hline Level & Letters & $\begin{array}{c}\text { Least Sq. } \\
\text { Mean }\end{array}$ & Std. Error & Lower 99\% & Upper 99\% \\
\hline UNF & A & 61.8 & 4.1 & 50.4 & 73.2 \\
NF & AB & 61.1 & 4.6 & 48.4 & 73.8 \\
UMS & AB & 53.4 & 4.0 & 42.4 & 64.4 \\
TF & AB & 53.3 & 4.1 & 42.0 & 64.6 \\
USF & AB & 45.8 & 4.0 & 34.8 & 56.9 \\
MS & AB & 45.1 & 4.6 & 32.4 & 57.8 \\
SF & B & 39.0 & 4.9 & 25.6 & 52.4
\end{tabular}

Table C. 3 Parameter coefficient of flow $\left(\mathrm{m}^{3} / \mathrm{s}\right)$ as a predictor of \% EPT.

\begin{tabular}{c|c|c|c|c}
\hline \hline Parameter & Estimate & Std. Error & t Ratio & P-value \\
\hline Flow (CMS) & 1110.1 & 369.8 & 3 & 0.005
\end{tabular}




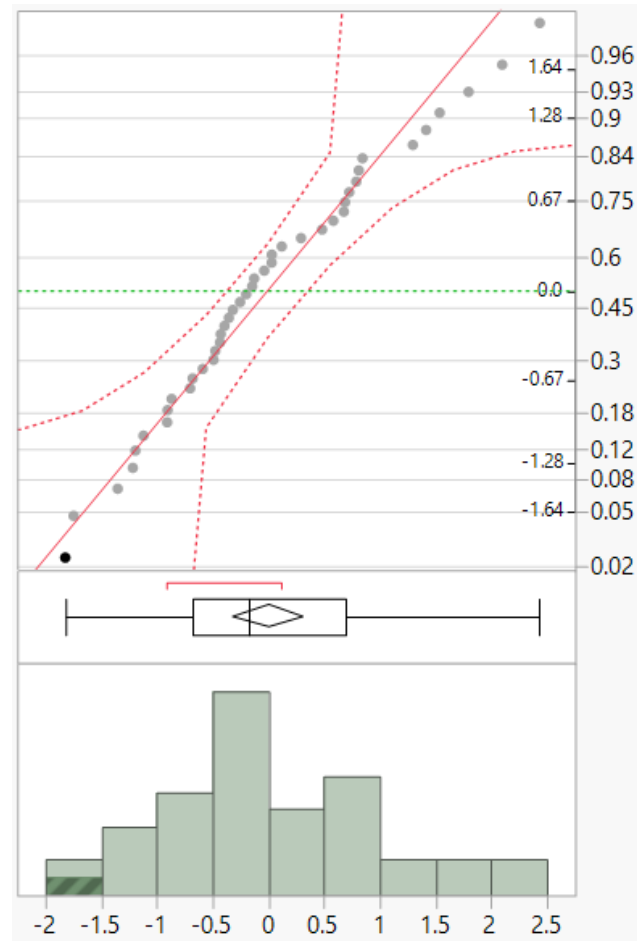

Figure C.3 Distribution of studentized residuals of the \% R-strategist model from the study reach dataset.

Table C.4 Parameter coefficient estimate of D-50( $\mathrm{mm})$ as a predictor of \% R-strategist.

\begin{tabular}{c|c|c|c|c}
\hline \hline Parameter & Estimate & Std. Error & t Ratio & P-value \\
\hline D-50 (mm) & 0.007 & 0.003 & 2.83 & 0.008
\end{tabular}




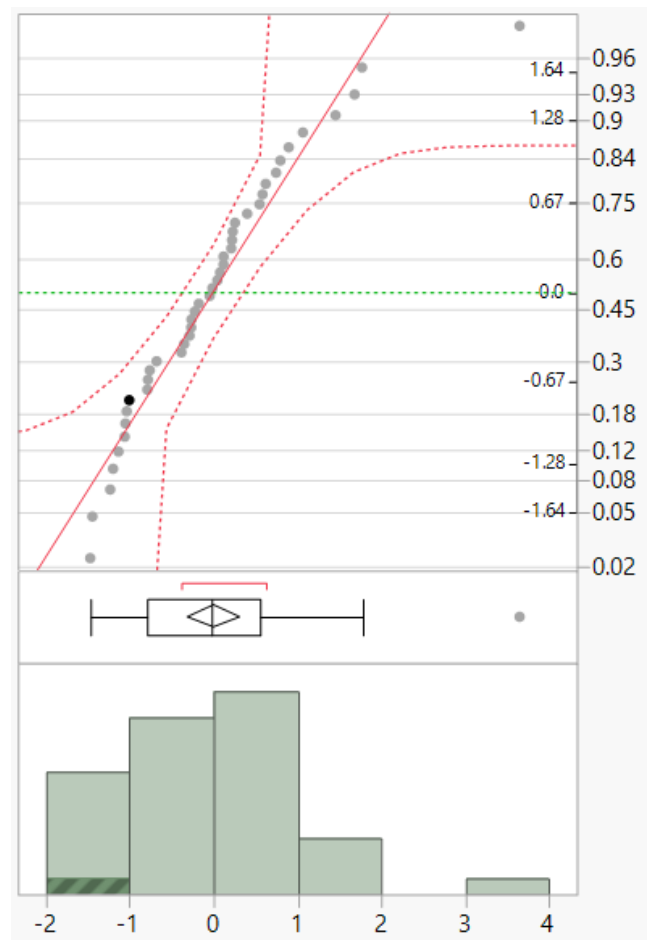

Figure C.4 Distribution of studentized residuals of the \%Diptera model from the study reach dataset.

Table C.5 Tukey HSD test results for differences in mean \% Diptera among the study reaches.

\begin{tabular}{c|l|c|c|c|c}
\hline \hline Level & Letters & $\begin{array}{c}\text { Least Sq. } \\
\text { Mean }\end{array}$ & Std. Error & Lower 99\% & Upper 99\% \\
\hline SF & AB & 46.9 & 11.2 & 16.1 & 77.7 \\
USF & A & 44.9 & 7.6 & 24.0 & 65.7 \\
UMS & AB & 25.8 & 6.9 & 6.9 & 44.7 \\
MS & AB & 21.0 & 6.2 & 4.0 & 38.0 \\
UNF & B & 18.3 & 6.4 & 0.8 & 35.8 \\
TF & B & 5.5 & 7.1 & -14.2 & 25.2 \\
NF & B & -3.4 & 8.8 & -27.6 & 20.8
\end{tabular}

Table C.6 Parameter coefficient estimate of D-50 (mm) as a predictor of \% Diptera.

\begin{tabular}{c|c|c|c|c}
\hline \hline Parameter & Estimate & Std. Error & t Ratio & $\begin{array}{c}\text { P- } \\
\text { value }\end{array}$ \\
\hline D-50 (mm) & 0.008 & 0.003 & 3.28 & 0.003
\end{tabular}




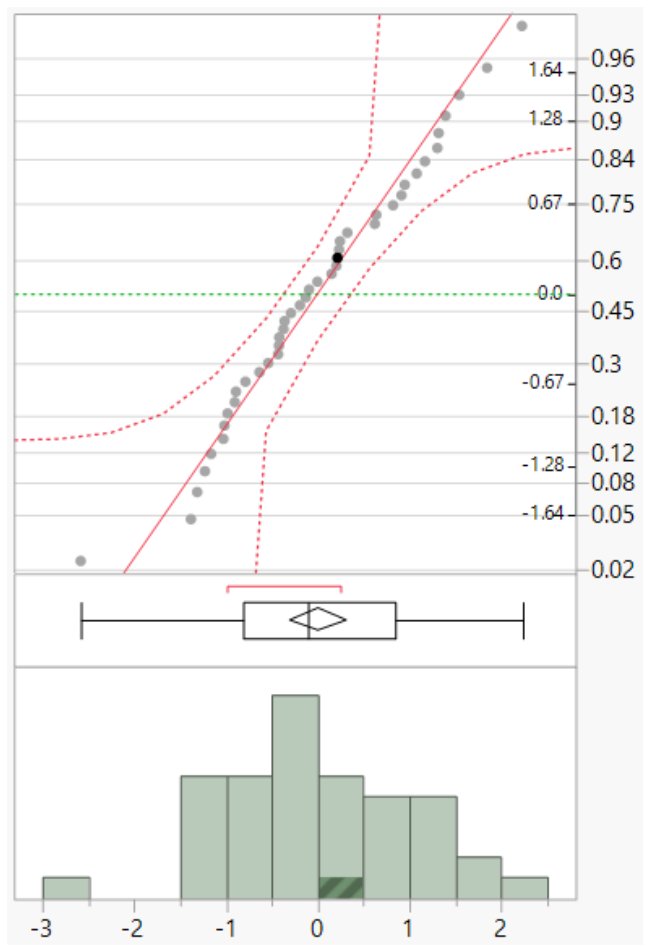

Figure C.5 Distribution of studentized residuals of the FBI model from the study reach dataset.

Table C.7 Tukey HSD test results for differences in mean FBI among the study reaches.

\begin{tabular}{c|l|c|c|c|c}
\hline \hline Level & Letters & $\begin{array}{c}\text { Least Sq. } \\
\text { Mean }\end{array}$ & Std. Error & Lower 99\% & Upper 99\% \\
\hline Summer & A & 3.8 & 0.1 & 3.5 & 4.1 \\
Spring & AB & 3.5 & 0.1 & 3.1 & 3.8 \\
Fall & B & 3.2 & 0.1 & 2.8 & 3.5
\end{tabular}




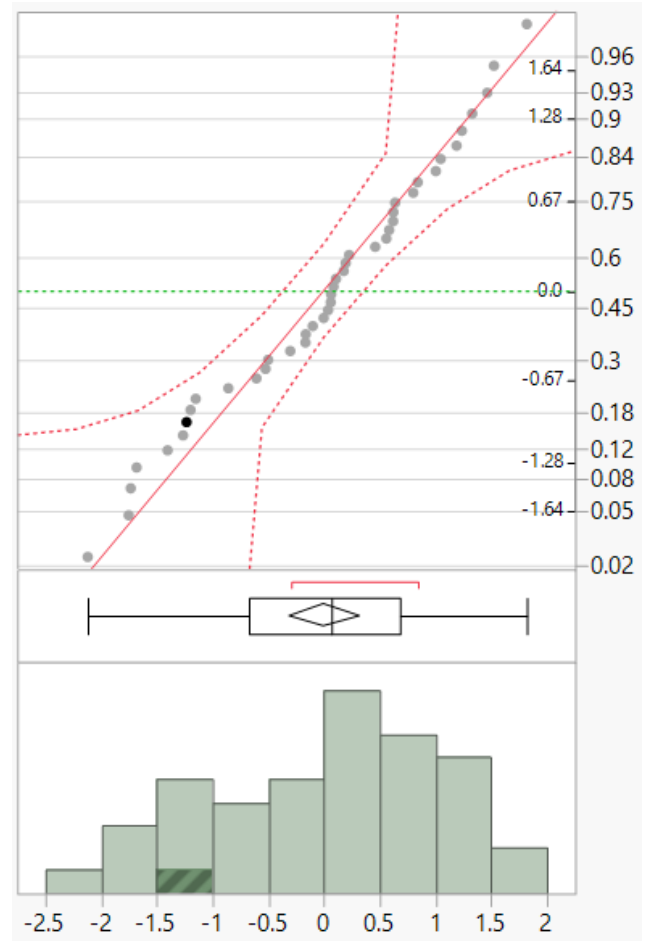

Figure C.6 Distribution of studentized residuals of the $\mathrm{H}^{\prime}$ model from the study reach dataset.

Table C.8 Tukey HSD test results for differences in mean $\mathrm{H}^{\prime}$ among the study reaches.

\begin{tabular}{c|l|c|c|c|c}
\hline \hline Level & Letters & $\begin{array}{c}\text { Least Sq. } \\
\text { Mean }\end{array}$ & Std. Error & Lower 99\% & Upper 99\% \\
\hline Summer & A & 2.0 & 0.1 & 1.8 & 2.1 \\
Fall & AB & 1.8 & 0.1 & 1.6 & 2.0 \\
Spring & B & 1.6 & 0.1 & 1.4 & 1.8
\end{tabular}




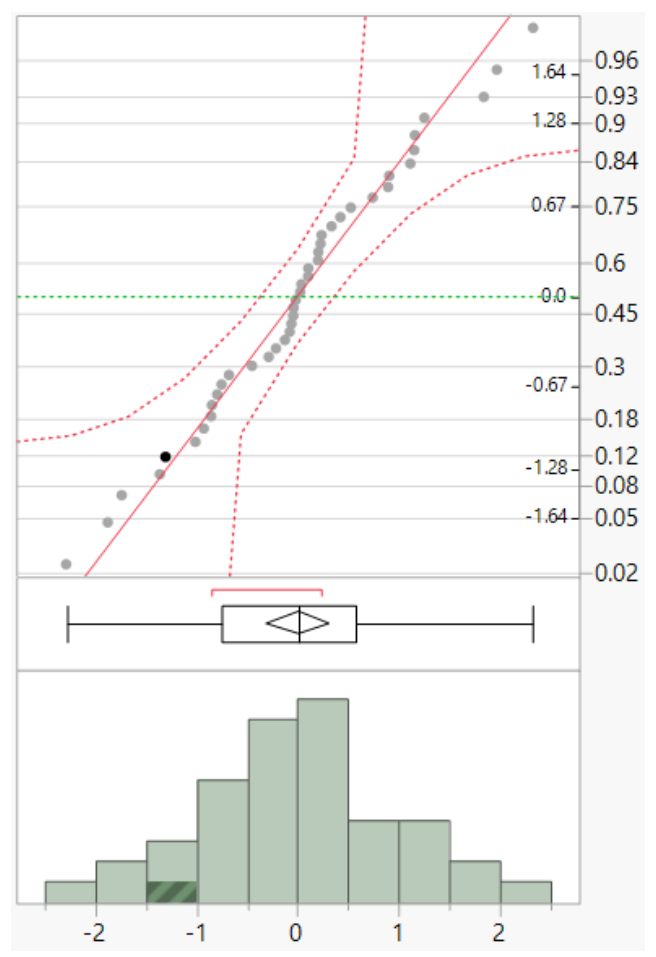

Figure C.7 Distribution of studentized residuals of the $\% \mathrm{SH}$ model from the study reach dataset.

Table C.9 Tukey HSD test results for differences in mean \% SH among the study reaches.

\begin{tabular}{c|l|c|c|c|c}
\hline \hline Level & Letters & $\begin{array}{c}\text { Least Sq. } \\
\text { Mean }\end{array}$ & Std. Error & Lower 99\% & Upper 99\% \\
\hline UNF & A & 23.8 & 2.1 & 17.9 & 29.7 \\
NF & A & 23.4 & 2.4 & 16.9 & 29.9 \\
TF & A & 20.3 & 2.1 & 14.5 & 26.1 \\
SF & A & 17.9 & 2.4 & 11.3 & 24.6 \\
UMS & A & 17.4 & 2.1 & 11.8 & 23.1 \\
MS & A & 15.2 & 2.3 & 8.9 & 21.4 \\
USF & A & 14.3 & 1.9 & 9.0 & 19.6
\end{tabular}

Table C.10 Tukey HSD test results for differences in mean \% SH among seasons.

\begin{tabular}{c|l|c|c|c|c}
\hline \hline Level & Letters & $\begin{array}{c}\text { Least Sq. } \\
\text { Mean }\end{array}$ & Std. Error & Lower 99\% & Upper 99\% \\
\hline Spring & A & 26.3 & 1.6 & 21.9 & 30.7 \\
Summer & A & 21.3 & 1.3 & 17.9 & 24.8 \\
Fall & B & 9.1 & 1.7 & 4.4 & 13.7
\end{tabular}




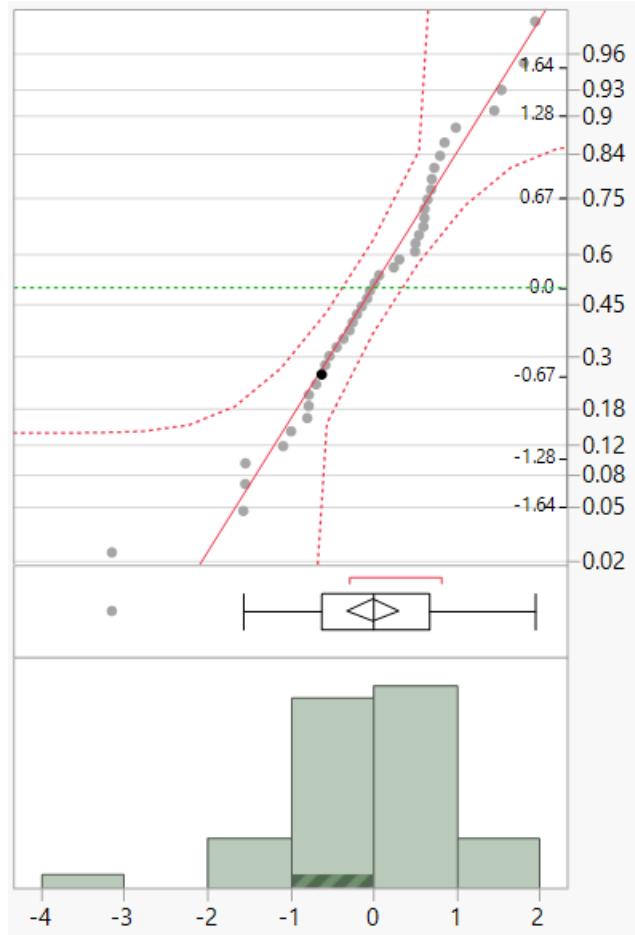

Figure C.8 Distribution of studentized residuals of the \% CG model from the study reach dataset.

Table C.11 Tukey HSD test results for differences in mean \% CG among the study reaches.

\begin{tabular}{c|l|c|c|c|c}
\hline \hline Level & Letters & $\begin{array}{c}\text { Least Sq. } \\
\text { Mean }\end{array}$ & Std. Error & Lower 95\% & Upper 95\% \\
\hline UMS & A & 71.1 & 7.0 & 51.8 & 90.4 \\
MS & A & 70.7 & 6.7 & 52.2 & 89.2 \\
SF & A & 56.7 & 10.8 & 27.1 & 86.3 \\
USF & A & 51.7 & 6.4 & 34.1 & 69.2 \\
NF & A & 46.7 & 6.8 & 28.1 & 65.3 \\
TF & A & 46.5 & 6.6 & 28.4 & 64.6 \\
UNF & A & 38.7 & 7.0 & 19.5 & 58.0
\end{tabular}


$\underline{\text { Additional ANOVA figures and tables from the transect dataset }}$

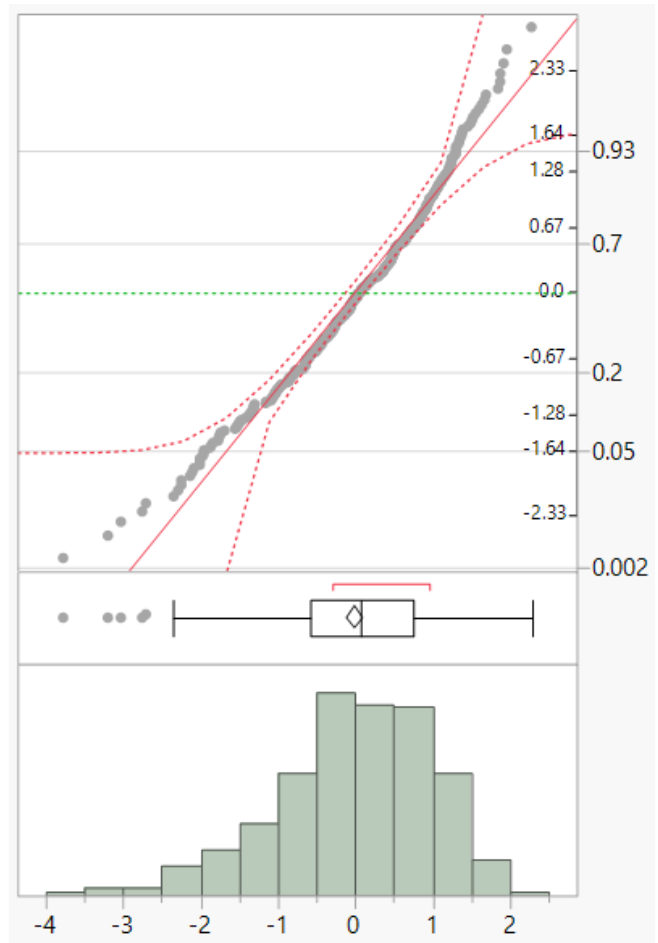

Figure C.9 Distribution of studentized residuals of the Density model from the transect dataset.

Table C.12 Tukey HSD test results for differences in mean log10(density) among the study reaches.

\begin{tabular}{c|l|c|c|c|c}
\hline \hline Level & Letters & $\begin{array}{c}\text { Least Sq. } \\
\text { Mean }\end{array}$ & $\begin{array}{c}\text { Std. } \\
\text { Error }\end{array}$ & $\begin{array}{c}\text { Lower } \\
99 \%\end{array}$ & $\begin{array}{c}\text { Upper } \\
99 \%\end{array}$ \\
\hline MS & A & 1255.4 & 0.2 & 816.9 & 1929.4 \\
UMS & A & 1168.7 & 0.2 & 770.2 & 1773.3 \\
USF & AB & 1098.7 & 0.2 & 695.7 & 1735.4 \\
SF & AB & 1047.7 & 0.2 & 684.7 & 1603.1 \\
NF & ABC & 782.9 & 0.2 & 508.6 & 1205.0 \\
UNF & BC & 509.5 & 0.2 & 335.8 & 772.8 \\
TF & C & 448.5 & 0.2 & 290.3 & 692.9
\end{tabular}

Table C.13 Tukey HSD test results for differences in mean log10(density) among seasons.

\begin{tabular}{c|c|c|c|c|c|}
\hline \hline & & Least Sq. & Std. & Lower & Upper \\
Level & Letters & Mean & Error & $99 \%$ & $99 \%$ \\
\hline
\end{tabular}




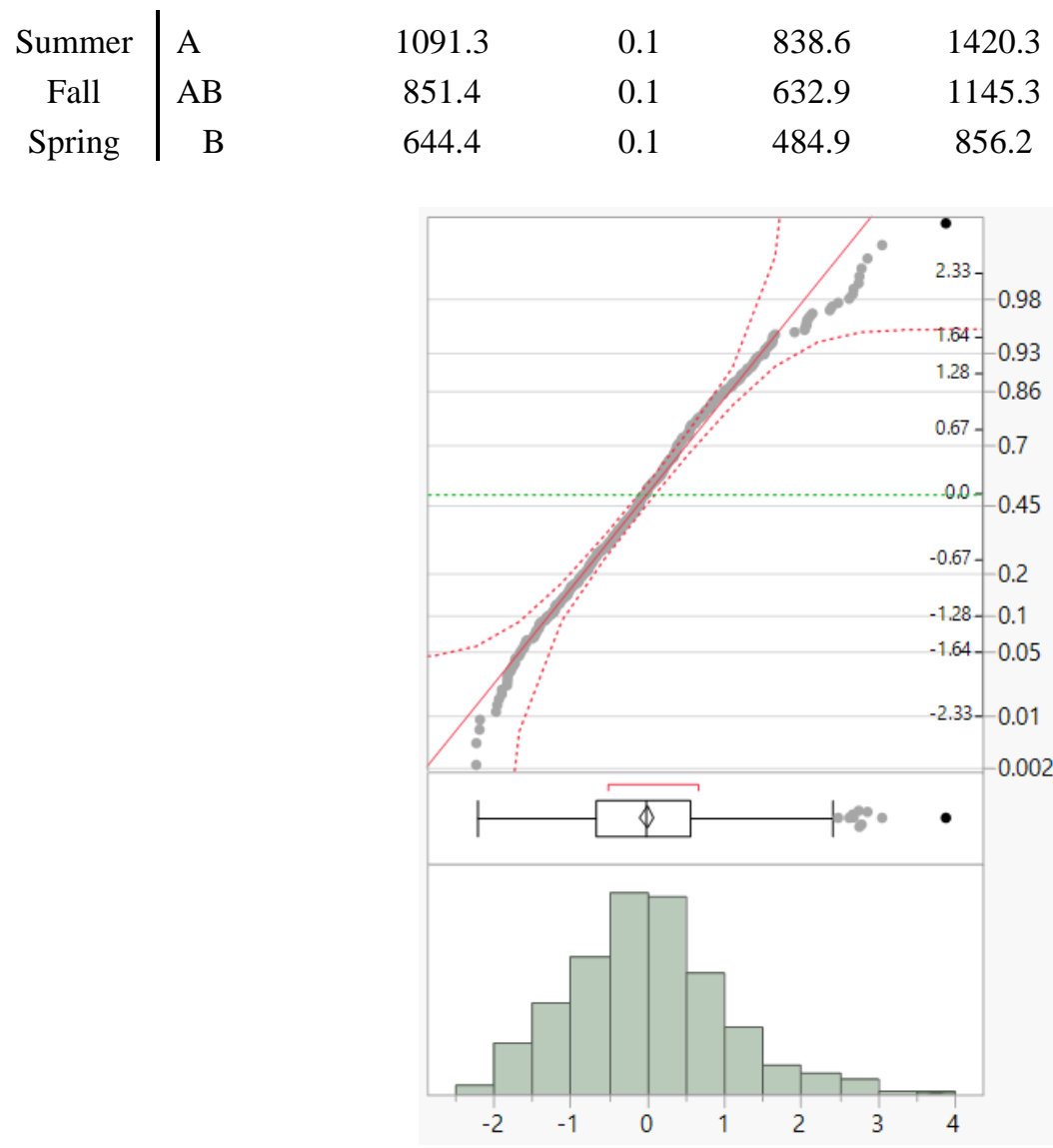

Figure C.10 Distribution of studentized residuals of the Biomass model from the transect dataset.

Table C.14 Tukey HSD test results for differences in mean log10(biomass+1) among the study reaches.

\begin{tabular}{c|l|c|c|c|c|}
\hline \hline Level & Letters & $\begin{array}{c}\text { Least Sq. } \\
\text { Mean }\end{array}$ & $\begin{array}{c}\text { Std. } \\
\text { Error }\end{array}$ & $\begin{array}{c}\text { Lower } \\
99 \%\end{array}$ & $\begin{array}{c}\text { Upper } \\
99 \%\end{array}$ \\
\hline UMS & A & 5.1 & 0.2 & 4.7 & 5.5 \\
MS & A & 5.0 & 0.2 & 4.6 & 5.5 \\
USF & A & 5.0 & 0.2 & 4.5 & 5.4 \\
SF & A & 4.8 & 0.2 & 4.4 & 5.3 \\
NF & A & 4.6 & 0.2 & 4.2 & 5.1 \\
TF & A & 4.4 & 0.2 & 3.9 & 4.8 \\
UNF & A & 4.3 & 0.2 & 3.9 & 4.7
\end{tabular}


Table C.15 Tukey HSD test results for differences in mean $\log 10$ (biomass+1) among seasons.

\begin{tabular}{c|l|c|c|c|c|}
\hline \hline Level & Letters & $\begin{array}{c}\text { Least Sq. } \\
\text { Mean }\end{array}$ & $\begin{array}{c}\text { Std. } \\
\text { Error }\end{array}$ & $\begin{array}{c}\text { Lower } \\
99 \%\end{array}$ & $\begin{array}{c}\text { Upper } \\
99 \%\end{array}$ \\
\hline Summer & A & 5.0 & 0.1 & 4.7 & 5.2 \\
Fall & AB & 4.8 & 0.1 & 4.5 & 5.1 \\
Spring & B & 4.5 & 0.1 & 4.2 & 4.8
\end{tabular}

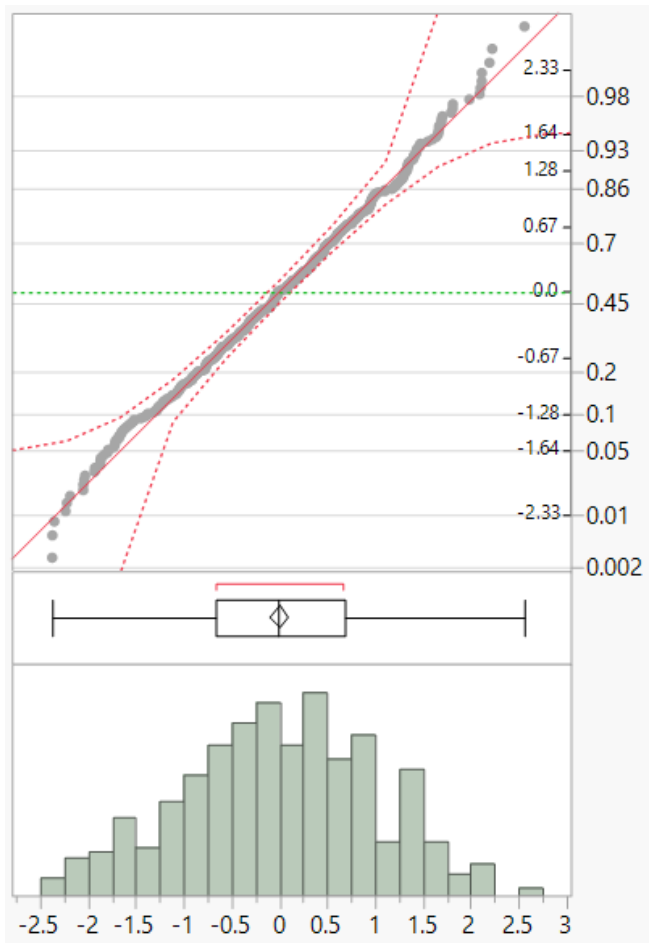

Figure C.11 Distribution of studentized residuals of the EPT taxa model from the transect dataset.

Table C.16 Tukey HSD test results for differences in mean EPT taxa among the study reaches.

\begin{tabular}{c|l|c|c|c|c|}
\hline \hline Level & Letters & $\begin{array}{c}\text { Least Sq. } \\
\text { Mean }\end{array}$ & $\begin{array}{c}\text { Std. } \\
\text { Error }\end{array}$ & $\begin{array}{c}\text { Lower } \\
99 \%\end{array}$ & $\begin{array}{c}\text { Upper } \\
99 \%\end{array}$ \\
\hline UMS & A & 8.0 & 0.4 & 6.9 & 9.1 \\
MS & AB & 7.8 & 0.4 & 6.7 & 8.9 \\
NF & AB & 7.2 & 0.4 & 6.1 & 8.3 \\
USF & AB & 6.8 & 0.4 & 5.6 & 8.0 \\
UNF & AB & 6.6 & 0.4 & 5.6 & 7.7 \\
SF & AB & 6.4 & 0.4 & 5.3 & 7.5
\end{tabular}


\begin{tabular}{l|lllll} 
TF & B & 5.9 & 0.4 & 4.8 & 7.0
\end{tabular}

Table C.17 Tukey HSD test results for differences in mean EPT taxa among seasons.

\begin{tabular}{c|l|c|c|c|c|}
\hline \hline Level & Letters & $\begin{array}{c}\text { Least Sq. } \\
\text { Mean }\end{array}$ & $\begin{array}{c}\text { Std. } \\
\text { Error }\end{array}$ & $\begin{array}{c}\text { Lower } \\
99 \%\end{array}$ & $\begin{array}{c}\text { Upper } \\
99 \%\end{array}$ \\
\hline Fall & A & 7.8 & 0.3 & 7.0 & 8.7 \\
Summer & A & 7.4 & 0.3 & 6.6 & 8.1 \\
Spring & B & 5.7 & 0.3 & 4.9 & 6.5
\end{tabular}

Table C.18 Tukey HSD test results for differences in mean EPT taxa among habitat types.

\begin{tabular}{c|l|c|c|c|c|}
\hline \hline Level & Letters & $\begin{array}{c}\text { Least Sq. } \\
\text { Mean }\end{array}$ & $\begin{array}{c}\text { Std. } \\
\text { Error }\end{array}$ & $\begin{array}{c}\text { Lower } \\
95 \%\end{array}$ & $\begin{array}{c}\text { Upper } \\
95 \%\end{array}$ \\
\hline riffle & A & 7.7 & 0.2 & 7.3 & 8.2 \\
run & AB & 7.3 & 0.4 & 6.3 & 8.3 \\
pool & B & 5.8 & 0.4 & 4.7 & 6.9
\end{tabular}

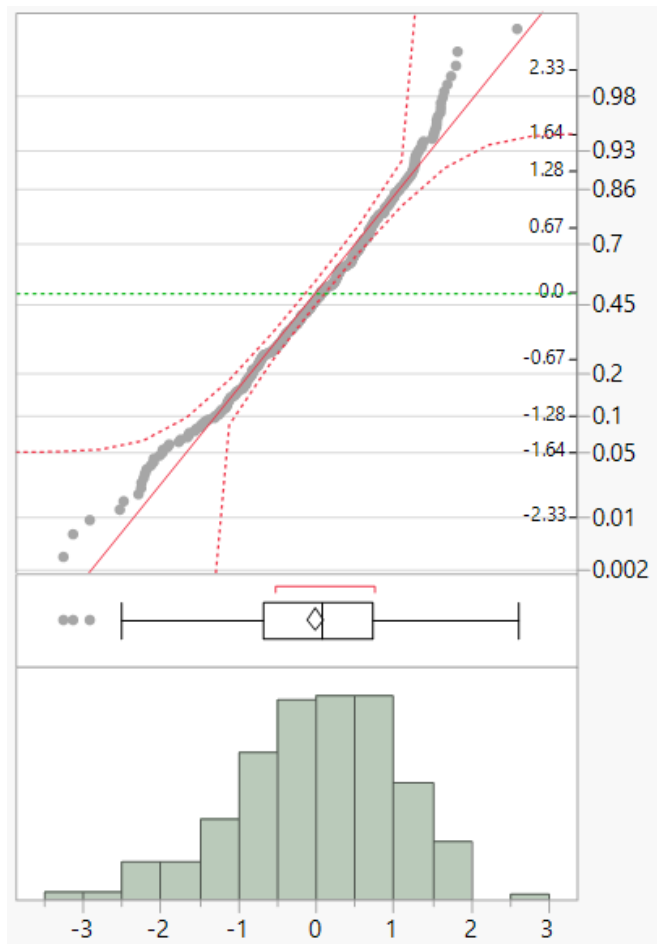

Figure C.12 Distribution of studentized residuals of the \% EPT model from the transect dataset. 
Table C.19 Tukey HSD test results for differences in mean percentage EPT among the study reaches.

\begin{tabular}{c|l|c|c|c|c|}
\hline \hline Level & Letters & $\begin{array}{c}\text { Least Sq. } \\
\text { Mean }\end{array}$ & $\begin{array}{c}\text { Std. } \\
\text { Error }\end{array}$ & $\begin{array}{c}\text { Lower } \\
99 \%\end{array}$ & $\begin{array}{c}\text { Upper } \\
99 \%\end{array}$ \\
\hline UNF & A & 65.4 & 3.2 & 57.0 & 73.8 \\
NF & A & 63.0 & 3.2 & 54.5 & 71.4 \\
TF & AB & 54.5 & 3.2 & 46.1 & 62.9 \\
UMS & AB & 53.5 & 3.2 & 45.0 & 62.0 \\
MS & AB & 50.1 & 3.2 & 41.6 & 58.7 \\
USF & BC & 44.0 & 3.5 & 34.7 & 53.3 \\
SF & C & 32.8 & 3.2 & 24.4 & 41.3
\end{tabular}

Table C.20 Tukey HSD test results for differences in mean percentage EPT among seasons.

\begin{tabular}{c|l|c|c|c|c|}
\hline \hline Level & Letters & $\begin{array}{c}\text { Least Sq. } \\
\text { Mean }\end{array}$ & $\begin{array}{c}\text { Std. } \\
\text { Error }\end{array}$ & $\begin{array}{c}\text { Lower } \\
99 \%\end{array}$ & $\begin{array}{c}\text { Upper } \\
99 \%\end{array}$ \\
\hline Spring & A & 57.9 & 1.9 & 53.0 & 62.9 \\
Summer & B & 51.4 & 1.7 & 47.0 & 55.8 \\
Fall & B & 46.4 & 2.0 & 41.1 & 51.7
\end{tabular}

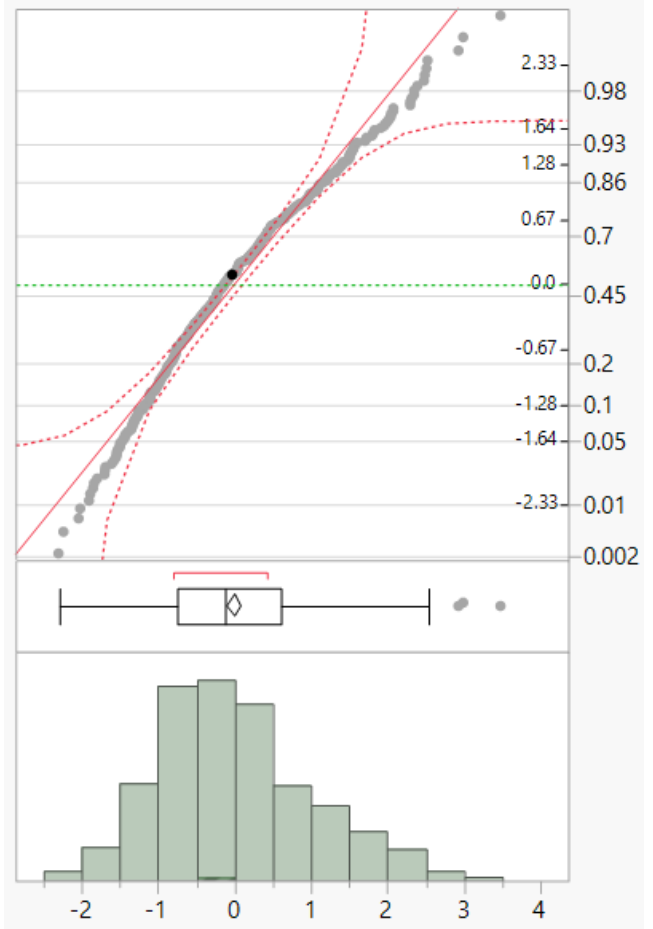

Figure C.13 Distribution of studentized residuals of the \% R-strategist model from the transect dataset. 
Table C.21 Tukey HSD test results for differences in mean percentage R-strategist taxa among the study reaches.

\begin{tabular}{c|l|c|c|c|c|}
\hline \hline Level & Letters & $\begin{array}{c}\text { Least Sq. } \\
\text { Mean }\end{array}$ & $\begin{array}{c}\text { Std. } \\
\text { Error }\end{array}$ & $\begin{array}{c}\text { Lower } \\
99 \%\end{array}$ & $\begin{array}{c}\text { Upper } \\
99 \%\end{array}$ \\
\hline USF & A & 49.0 & 2.9 & 41.2 & 56.8 \\
MS & B & 34.8 & 2.8 & 27.5 & 42.2 \\
UMS & B & 31.5 & 2.7 & 24.4 & 38.6 \\
UNF & B & 31.4 & 2.7 & 24.3 & 38.5 \\
TF & B & 29.2 & 2.8 & 21.7 & 36.6 \\
NF & B & 28.5 & 2.8 & 21.1 & 35.8 \\
SF & B & 24.8 & 2.7 & 17.6 & 32.1
\end{tabular}

Table C.22 Tukey HSD test results for differences in mean percentage R-strategist taxa among seasons.

\begin{tabular}{c|l|c|c|c|c|}
\hline \hline Level & Letters & $\begin{array}{c}\text { Least Sq. } \\
\text { Mean }\end{array}$ & $\begin{array}{c}\text { Std. } \\
\text { Error }\end{array}$ & $\begin{array}{c}\text { Lower } \\
99 \%\end{array}$ & $\begin{array}{c}\text { Upper } \\
99 \%\end{array}$ \\
\hline Spring & A & 39.3 & 1.8 & 34.5 & 44.1 \\
Summer & B & 30.4 & 1.7 & 26.0 & 34.9 \\
Fall & B & 28.5 & 1.9 & 23.5 & 33.5
\end{tabular}

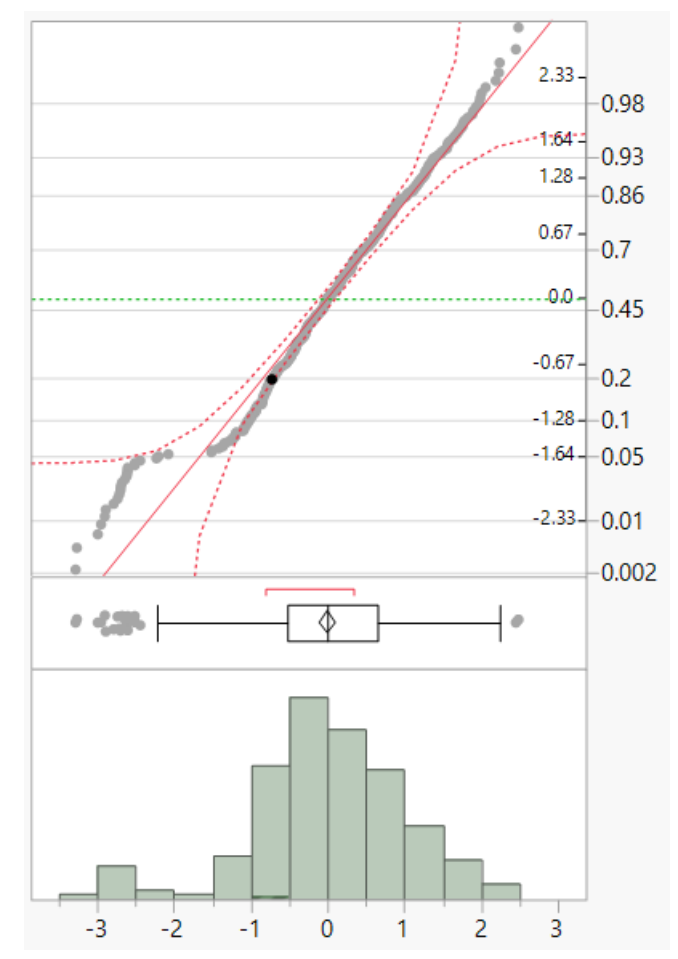

Figure C.14 Distribution of studentized residuals of the \% Diptera model from the transect dataset. 
Table C.23 Tukey HSD test results for differences in mean cube root transformed percentage Diptera among the study reaches.

\begin{tabular}{c|l|c|c|c|c|}
\hline Level & Letters & $\begin{array}{c}\text { Least Sq. } \\
\text { Mean }\end{array}$ & $\begin{array}{c}\text { Std. } \\
\text { Error }\end{array}$ & $\begin{array}{c}\text { Lower } \\
99 \%\end{array}$ & $\begin{array}{c}\text { Upper } \\
99 \%\end{array}$ \\
\hline USF & A & 3.4 & 0.2 & 2.9 & 3.8 \\
SF & AB & 2.8 & 0.2 & 2.4 & 3.2 \\
MS & B & 2.5 & 0.2 & 2.1 & 2.9 \\
UMS & B & 2.5 & 0.1 & 2.1 & 2.9 \\
UNF & B & 2.4 & 0.1 & 2.0 & 2.8 \\
NF & B & 2.4 & 0.2 & 1.9 & 2.8 \\
TF & B & 2.3 & 0.2 & 1.9 & 2.7
\end{tabular}

Table C.24 Tukey HSD test results for differences in mean cube root transformed percentage Diptera among seasons.

\begin{tabular}{c|l|c|c|c|c|}
\hline \hline Level & Letters & $\begin{array}{c}\text { Least Sq. } \\
\text { Mean }\end{array}$ & $\begin{array}{c}\text { Std. } \\
\text { Error }\end{array}$ & $\begin{array}{c}\text { Lower } \\
99 \%\end{array}$ & $\begin{array}{c}\text { Upper } \\
99 \%\end{array}$ \\
\hline Summer & A & 2.8 & 0.1 & 2.6 & 3.0 \\
Spring & AB & 2.6 & 0.1 & 2.3 & 2.8 \\
Fall & B & 2.4 & 0.1 & 2.2 & 2.7
\end{tabular}

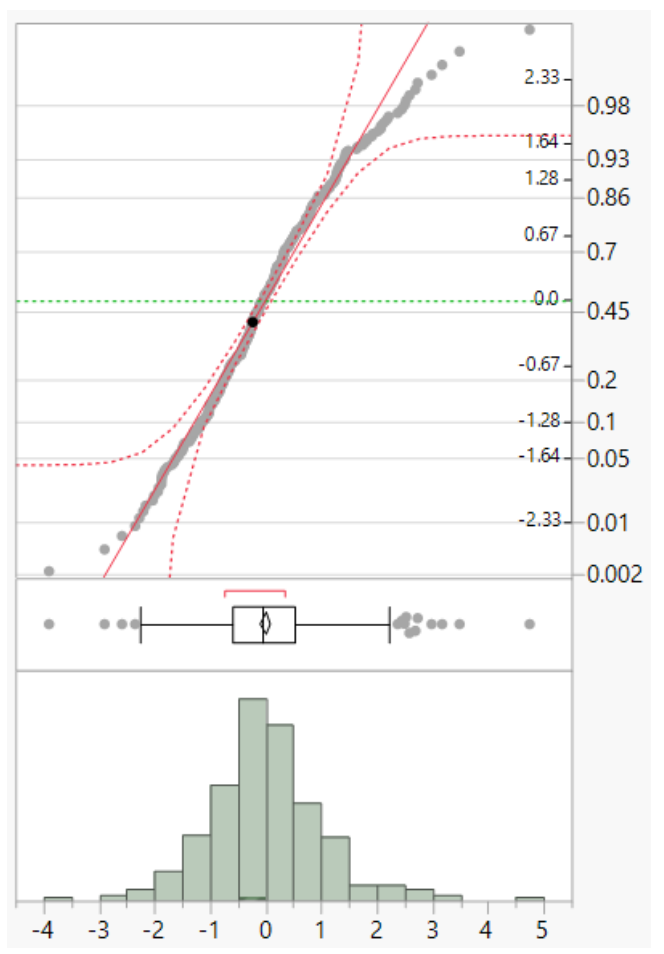

Figure C.15 Distribution of studentized residuals of the FBI model from the transect dataset. 
Table C.25 Tukey HSD test results for differences in mean cube transformed FBI among seasons.

\begin{tabular}{c|l|c|c|c|c|}
\hline \hline Level & Letters & $\begin{array}{c}\text { Least Sq. } \\
\text { Mean }\end{array}$ & $\begin{array}{c}\text { Std. } \\
\text { Error }\end{array}$ & $\begin{array}{c}\text { Lower } \\
99 \%\end{array}$ & $\begin{array}{c}\text { Upper } \\
99 \%\end{array}$ \\
\hline Summer & A & 61.4 & 3.7 & 51.8 & 71.0 \\
Spring & AB & 53.6 & 4.0 & 43.3 & 64.0 \\
Fall & B & 44.6 & 4.1 & 33.9 & 55.4
\end{tabular}

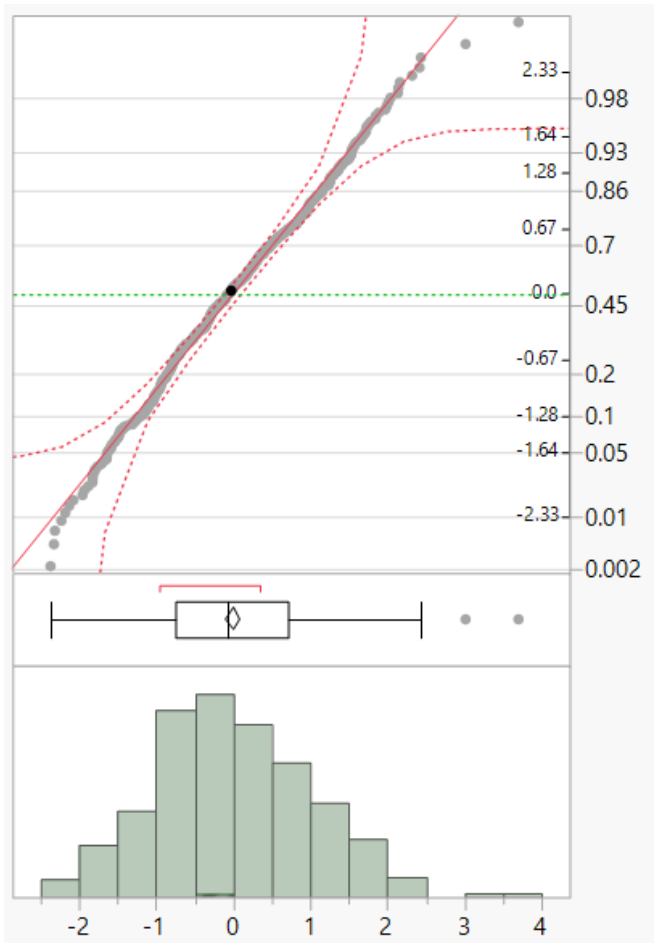

Figure C.16 Distribution of studentized residuals of the $\mathrm{H}^{\prime}$ model from the transect dataset.

Table C.26 Tukey HSD test results for differences in mean cube transformed $\mathrm{H}^{\prime}$ among the study reaches.

\begin{tabular}{c|l|c|c|c|c|}
\hline \hline Level & Letters & $\begin{array}{c}\text { Least Sq. } \\
\text { Mean }\end{array}$ & $\begin{array}{c}\text { Std. } \\
\text { Error }\end{array}$ & $\begin{array}{c}\text { Lower } \\
99 \%\end{array}$ & $\begin{array}{c}\text { Upper } \\
99 \%\end{array}$ \\
\hline UMS & A & 7.0 & 0.4 & 5.8 & 8.2 \\
NF & A & 6.6 & 0.5 & 5.4 & 7.9 \\
UNF & A & 6.4 & 0.4 & 5.2 & 7.6 \\
TF & AB & 6.3 & 0.5 & 5.1 & 7.5 \\
MS & AB & 6.2 & 0.5 & 5.0 & 7.5 \\
USF & AB & 4.8 & 0.5 & 3.5 & 6.1
\end{tabular}



\begin{tabular}{l|l} 
SF & B
\end{tabular}
4.2
0.5
2.9
5.4

Table C.27 Tukey HSD test results for differences in mean cube transformed $\mathrm{H}^{\prime}$ among seasons.

\begin{tabular}{c|l|c|c|c|c|}
\hline \hline Level & Letters & $\begin{array}{c}\text { Least Sq. } \\
\text { Mean }\end{array}$ & $\begin{array}{c}\text { Std. } \\
\text { Error }\end{array}$ & $\begin{array}{c}\text { Lower } \\
99 \%\end{array}$ & $\begin{array}{c}\text { Upper } \\
99 \%\end{array}$ \\
\hline Summer & A & 7.1 & 0.3 & 6.3 & 7.9 \\
Fall & AB & 5.9 & 0.4 & 5.0 & 6.9 \\
Spring & B & 4.8 & 0.3 & 3.9 & 5.6
\end{tabular}

Table C.28 Tukey HSD test results for differences in mean cube transformed $\mathrm{H}^{\prime}$ among habitat type.

\begin{tabular}{c|l|c|c|c|c}
\hline \hline Level & Letters & $\begin{array}{c}\text { Least Sq. } \\
\text { Mean }\end{array}$ & $\begin{array}{c}\text { Std. } \\
\text { Error }\end{array}$ & $\begin{array}{c}\text { Lower } \\
99 \%\end{array}$ & $\begin{array}{c}\text { Upper } \\
99 \%\end{array}$ \\
\hline riffle & A & 7.3 & 0.2 & 6.8 & 7.8 \\
pool & B & 5.3 & 0.5 & 4.1 & 6.5 \\
run & B & 5.2 & 0.4 & 4.1 & 6.3
\end{tabular}

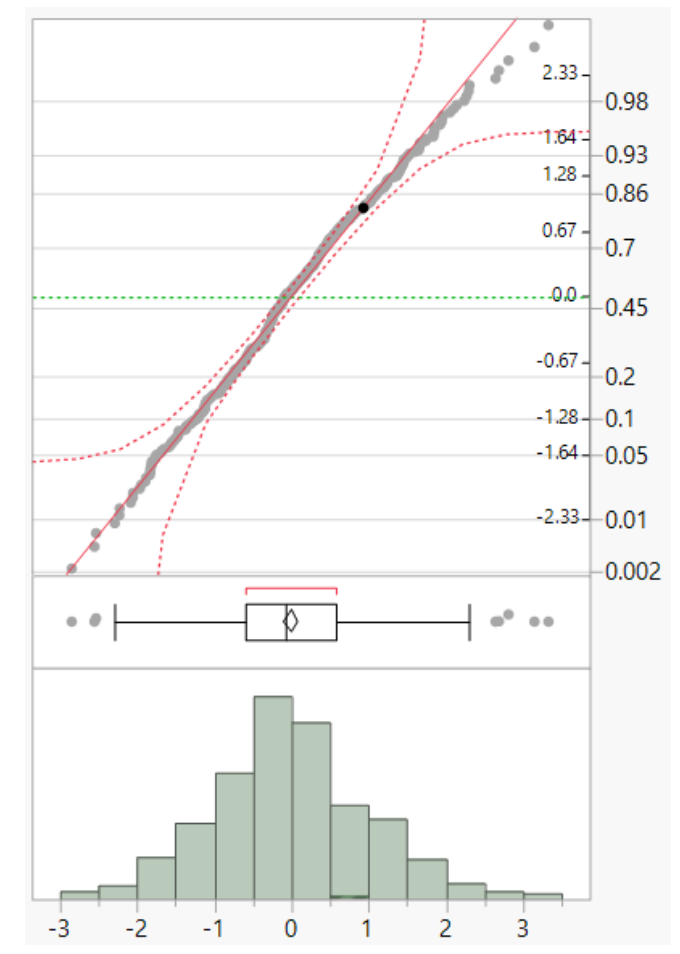

Figure C.17 Distribution of studentized residuals of the \%SH model from the transect dataset. 
Table C.29 Tukey HSD test results for differences in mean cube root transformed relative shredder abundance among the study reaches.

\begin{tabular}{c|l|c|c|c|c|}
\hline \hline Level & Letters & $\begin{array}{c}\text { Least Sq. } \\
\text { Mean }\end{array}$ & $\begin{array}{c}\text { Std. } \\
\text { Error }\end{array}$ & $\begin{array}{c}\text { Lower } \\
99 \%\end{array}$ & $\begin{array}{c}\text { Upper } \\
99 \%\end{array}$ \\
\hline NF & A & 2.7 & 0.1 & 2.3 & 3.1 \\
UNF & A & 2.6 & 0.1 & 2.3 & 3.0 \\
SF & A & 2.5 & 0.1 & 2.1 & 2.8 \\
MS & A & 2.2 & 0.1 & 1.9 & 2.6 \\
UMS & A & 2.2 & 0.1 & 1.9 & 2.6 \\
TF & A & 2.2 & 0.1 & 1.8 & 2.5 \\
USF & A & 2.1 & 0.1 & 1.7 & 2.5
\end{tabular}

Table C.30 Tukey HSD test results for differences in mean cube root transformed relative shredder abundance among the habitat types.

\begin{tabular}{c|l|c|c|c|c|}
\hline \hline Level & Letters & $\begin{array}{c}\text { Least Sq. } \\
\text { Mean }\end{array}$ & $\begin{array}{c}\text { Std. } \\
\text { Error }\end{array}$ & $\begin{array}{c}\text { Lower } \\
99 \%\end{array}$ & $\begin{array}{c}\text { Upper } \\
99 \%\end{array}$ \\
\hline Spring & A & 2.6 & 0.1 & 2.4 & 2.9 \\
Summer & A & 2.6 & 0.1 & 2.4 & 2.8 \\
Fall & B & 1.8 & 0.1 & 1.6 & 2.1
\end{tabular}

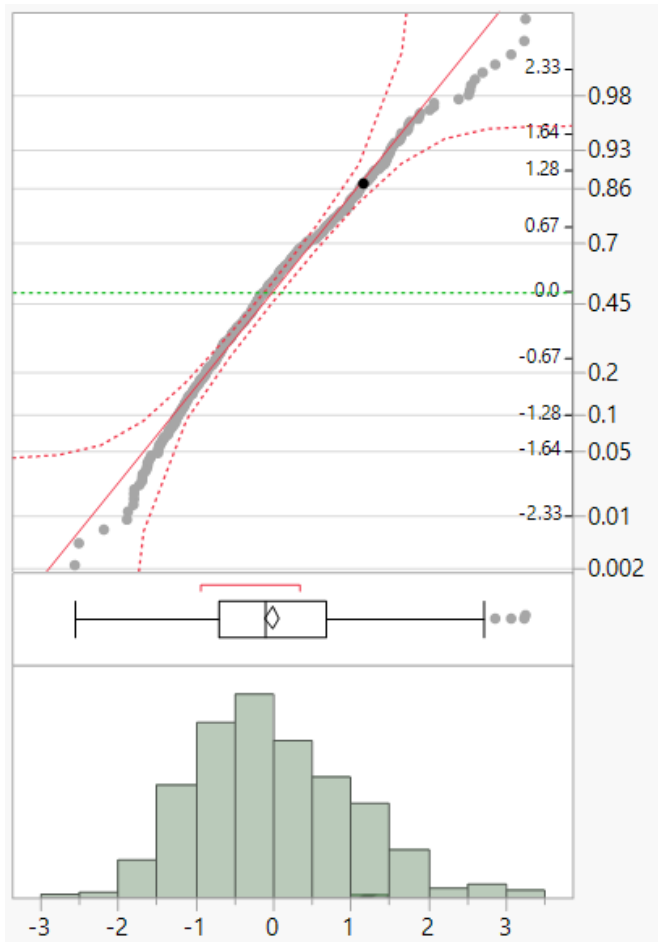

Figure C.18 Distribution of studentized residuals of the \%CG model from the transect dataset. 
Table C.31 Tukey HSD test results for differences in mean cube root transformed relative collector-gatherer abundance among the study reaches.

\begin{tabular}{c|l|c|c|c|c|}
\hline \hline Level & Letters & $\begin{array}{c}\text { Least Sq. } \\
\text { Mean }\end{array}$ & $\begin{array}{c}\text { Std. } \\
\text { Error }\end{array}$ & $\begin{array}{c}\text { Lower } \\
99 \%\end{array}$ & $\begin{array}{c}\text { Upper } \\
99 \%\end{array}$ \\
\hline UMS & A & 4.0 & 0.1 & 3.9 & 4.2 \\
MS & A & 4.0 & 0.1 & 3.8 & 4.2 \\
USF & AB & 3.9 & 0.1 & 3.7 & 4.1 \\
TF & AB & 3.8 & 0.1 & 3.7 & 4.0 \\
NF & ABC & 3.7 & 0.1 & 3.6 & 3.9 \\
UNF & BC & 3.6 & 0.1 & 3.4 & 3.8 \\
SF & C & 3.4 & 0.1 & 3.3 & 3.6
\end{tabular}

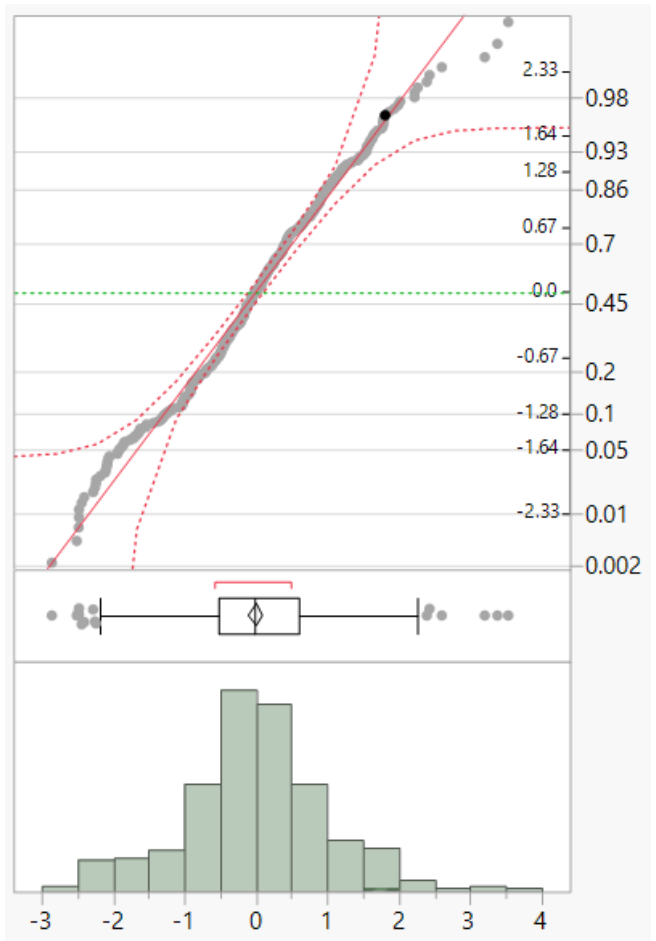

Figure C.19 Distribution of studentized residuals of the \%P model from the transect dataset. 
Table C.32 Tukey HSD test results for differences in mean cube root transformed relative predator abundance among seasons.

\begin{tabular}{c|l|c|c|c|c|}
\hline \hline Level & Letters & $\begin{array}{c}\text { Least Sq. } \\
\text { Mean }\end{array}$ & $\begin{array}{c}\text { Std. } \\
\text { Error }\end{array}$ & $\begin{array}{c}\text { Lower } \\
99 \%\end{array}$ & $\begin{array}{c}\text { Upper } \\
99 \%\end{array}$ \\
\hline Fall & A & 1.9 & 0.1 & 1.7 & 2.1 \\
Summer & A & 1.7 & 0.1 & 1.5 & 1.9 \\
Spring & B & 1.5 & 0.1 & 1.3 & 1.7
\end{tabular}

Additional ANOVA figures and tables from the water quality sub-dataset

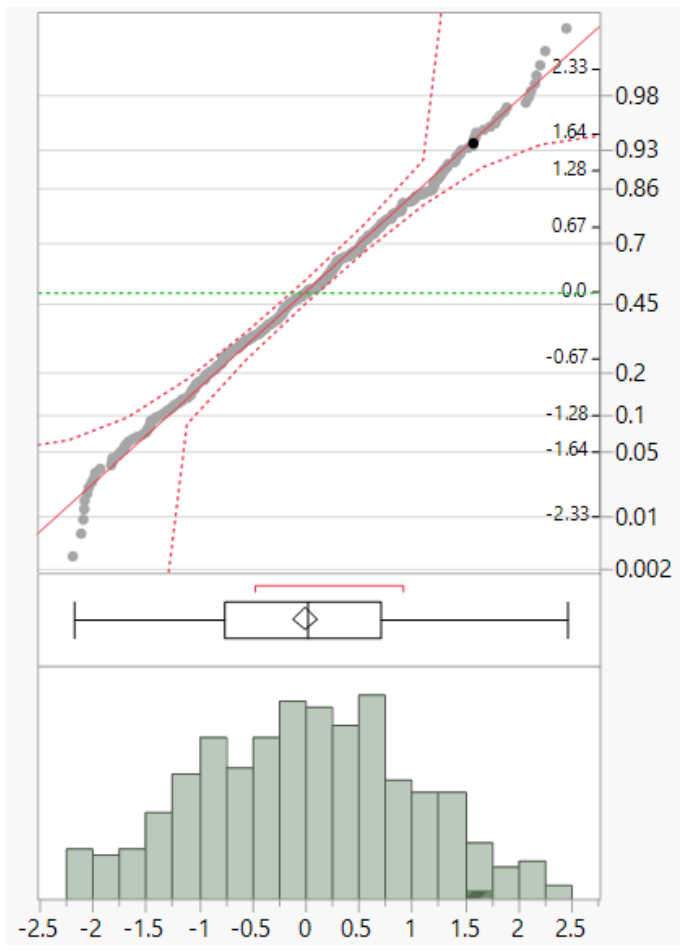

Figure C.20 Distribution of studentized residuals of the EPT taxa model from the water quality sub-dataset. 
Table C.33 Parameter coefficient estimate of $\mathrm{pH}$ as a predictor of EPT taxa.

\begin{tabular}{l|c|c|c|c}
\hline \hline Parameter & Estimate & $\begin{array}{c}\text { Std. } \\
\text { Error }\end{array}$ & t Ratio & P-value \\
\hline $\mathrm{pH}$ & 3.4 & 1 & 3.4 & 0.0009
\end{tabular}

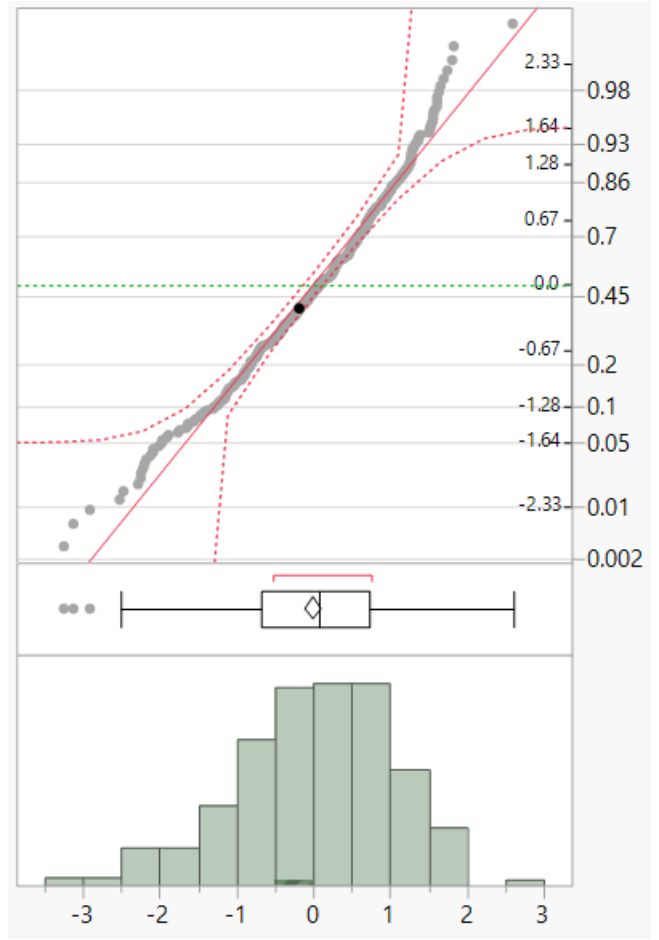

Figure C.21 Distribution of studentized residuals of the \% EPT model from the water quality sub-dataset.

Table C.34 Parameter coefficient estimate of $\mathrm{pH}$ as a predictor of \% EPT.

\begin{tabular}{l|c|c|c|c}
\hline \hline & & Std. & & \\
Parameter & Estimate & Error & t Ratio & P-value \\
\hline $\mathrm{pH}$ & 28.1 & 6.1 & 4.62 & 0.00001
\end{tabular}




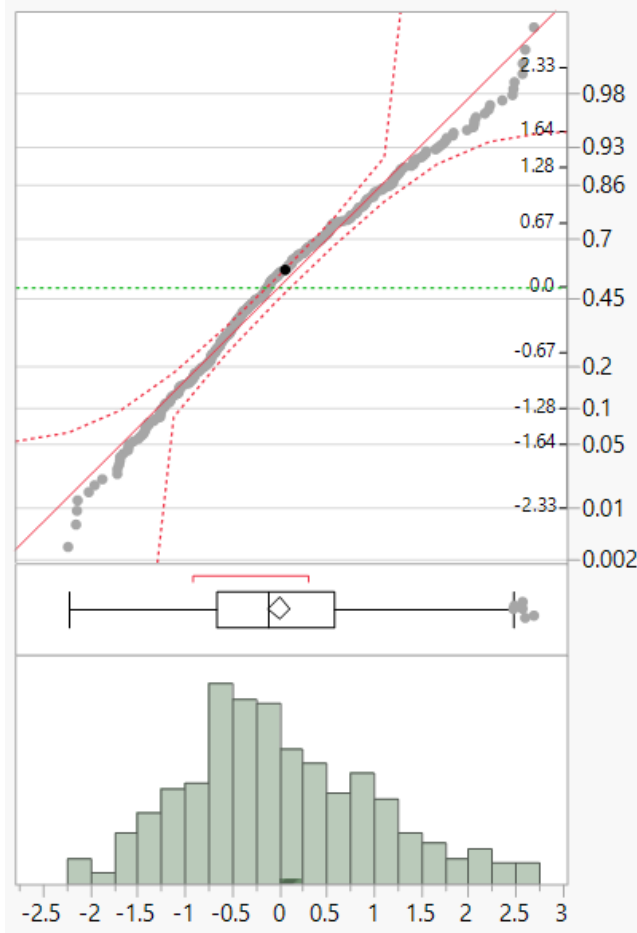

Figure C.22 Distribution of studentized residuals of the \% R-strategist model from the water quality sub-dataset.

Table C.35 Parameter coefficient estimate of temperature $\left({ }^{\circ} \mathrm{C}\right)$ as a predictor of $\% \mathrm{R}$ strategist.

\begin{tabular}{l|c|c|c|c}
\hline \hline Parameter & Estimate & $\begin{array}{c}\text { Std. } \\
\text { Error }\end{array}$ & t Ratio & P-value \\
\hline Temp & 3.7 & 0.9 & 1.7 & 0.00002
\end{tabular}




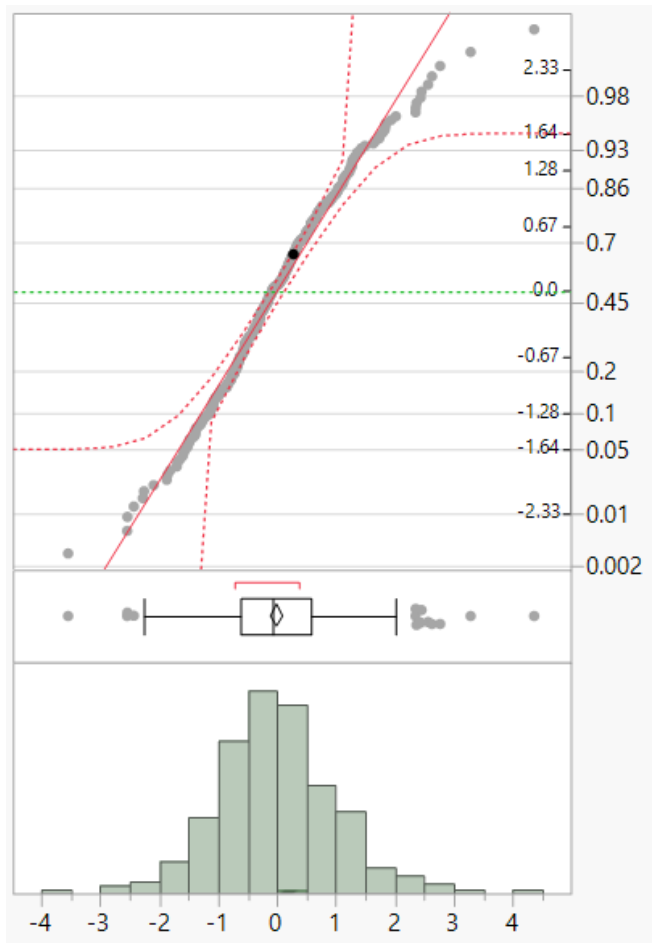

Figure C.23 Distribution of studentized residuals of the FBI model from the water quality sub-dataset.

Table C.36 Parameter coefficient estimate of temperature $\left({ }^{\circ} \mathrm{C}\right)$ as a predictor of FBI.

\begin{tabular}{l|c|c|c|c}
\hline \hline Parameter & Estimate & $\begin{array}{c}\text { Std. } \\
\text { Error }\end{array}$ & t Ratio & P-value \\
\hline Temp & 0.2 & 0.04 & 3.72 & 0.00025
\end{tabular}




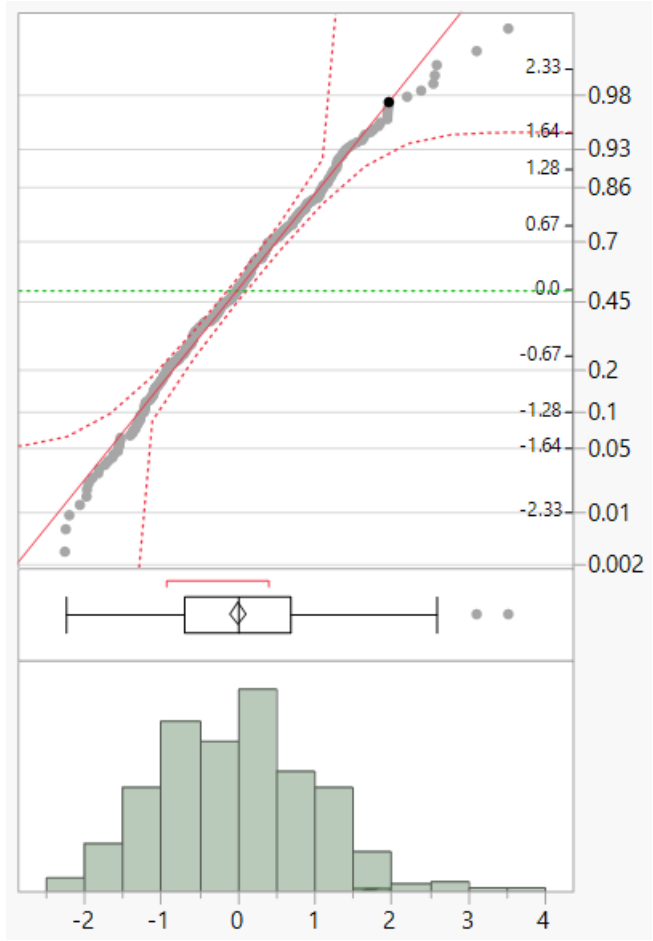

Figure C.24 Distribution of studentized residuals of the $\mathrm{H}^{\prime}$ model from the water quality sub-dataset.

Table C.37 Parameter coefficient estimate of $\mathrm{pH}$ as a predictor of $\mathrm{H}^{\prime}$.

\begin{tabular}{l|c|c|c|c}
\hline \hline Parameter & Estimate & $\begin{array}{c}\text { Std. } \\
\text { Error }\end{array}$ & t Ratio & P-value \\
\hline $\mathrm{pH}$ & 3.8 & 1.1 & 3.5 & 0.00049
\end{tabular}




\section{Appendix D.}

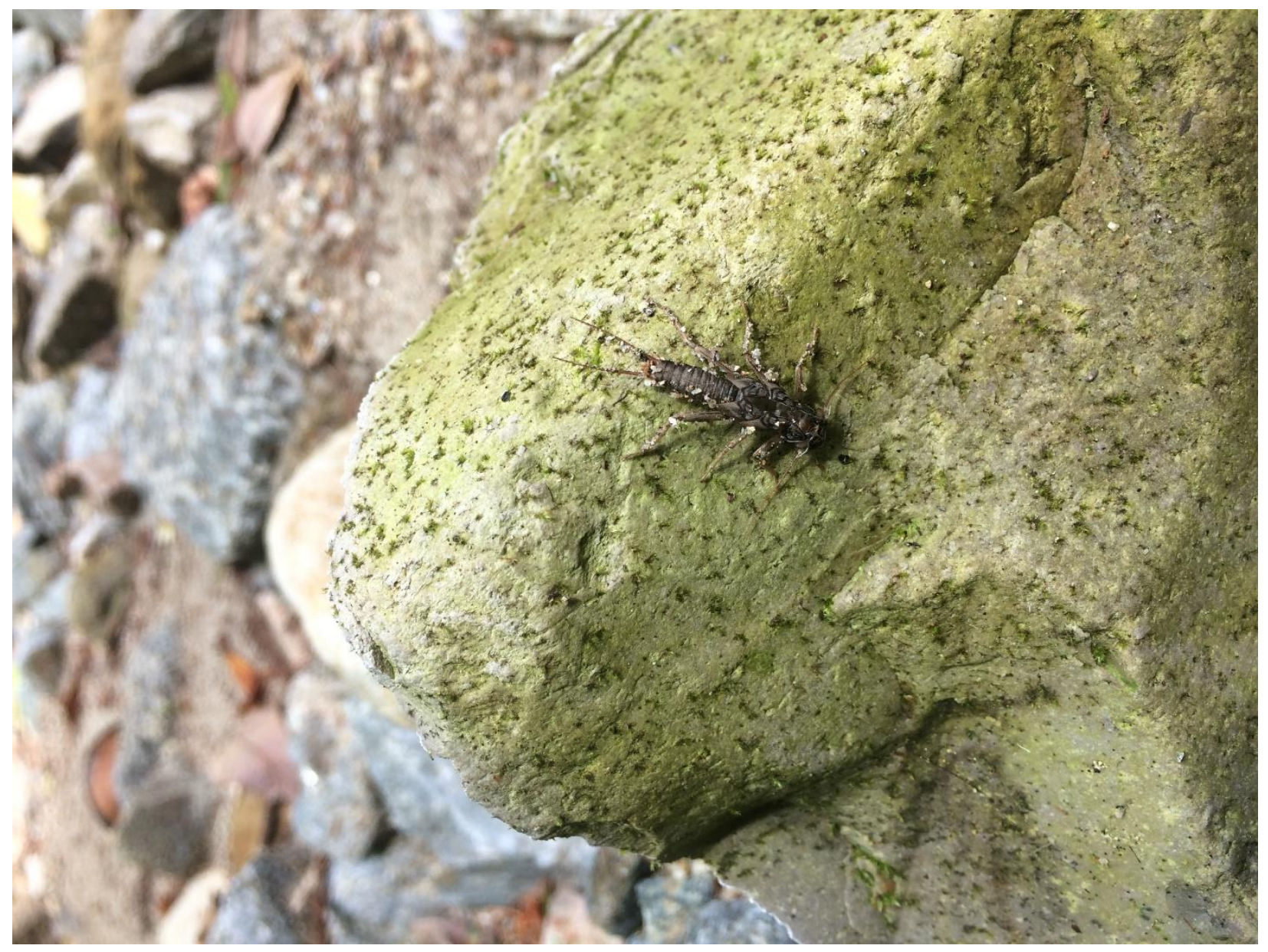

Figure D.1 Exoskeleton of a stonefly (Plecoptera: Perlidae). 


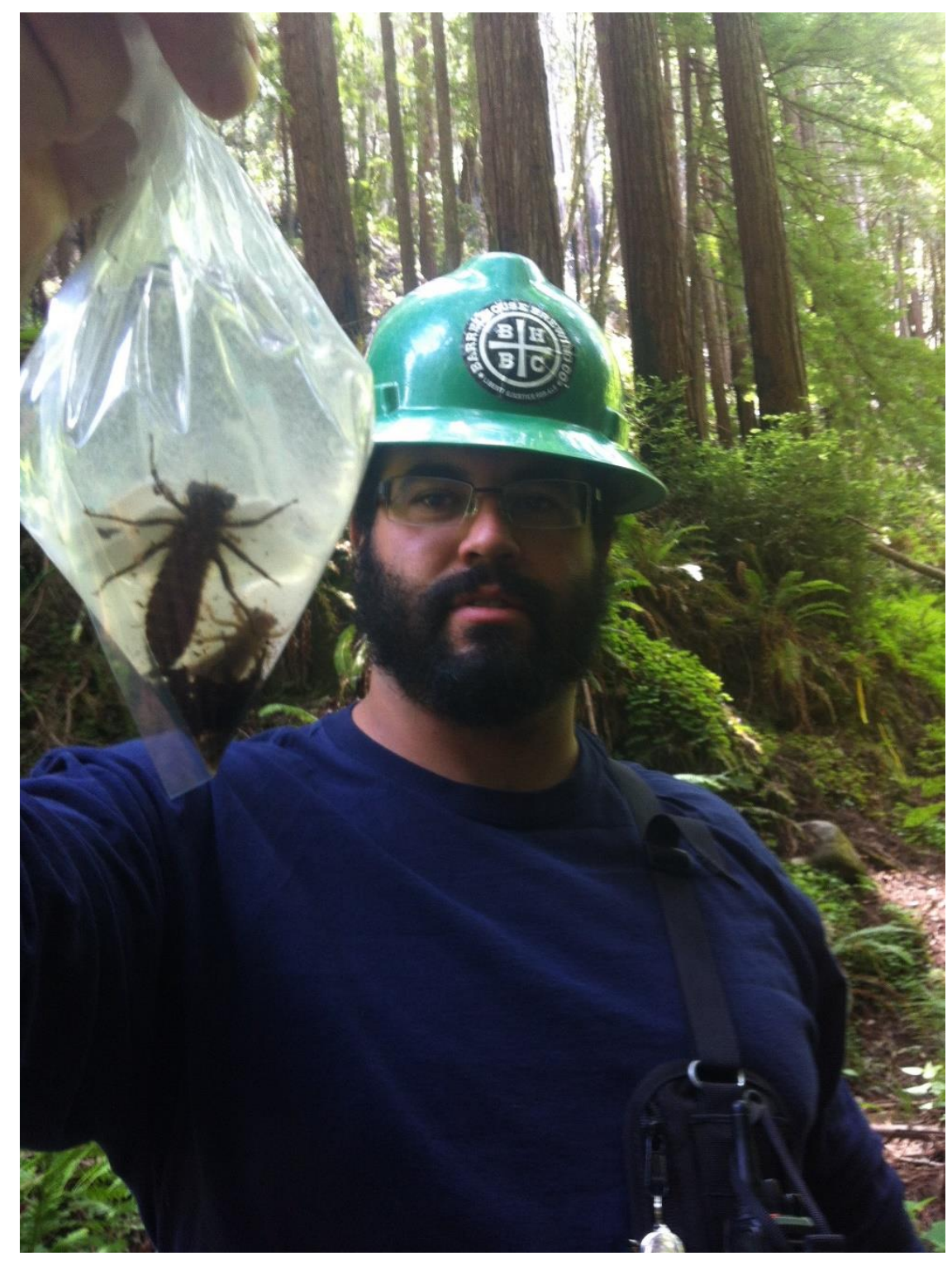

Figure D.2 Nick Macias with two dragonfly (Odonata: Cordulegastridae) pupae collected at the Mainstem study reach. 


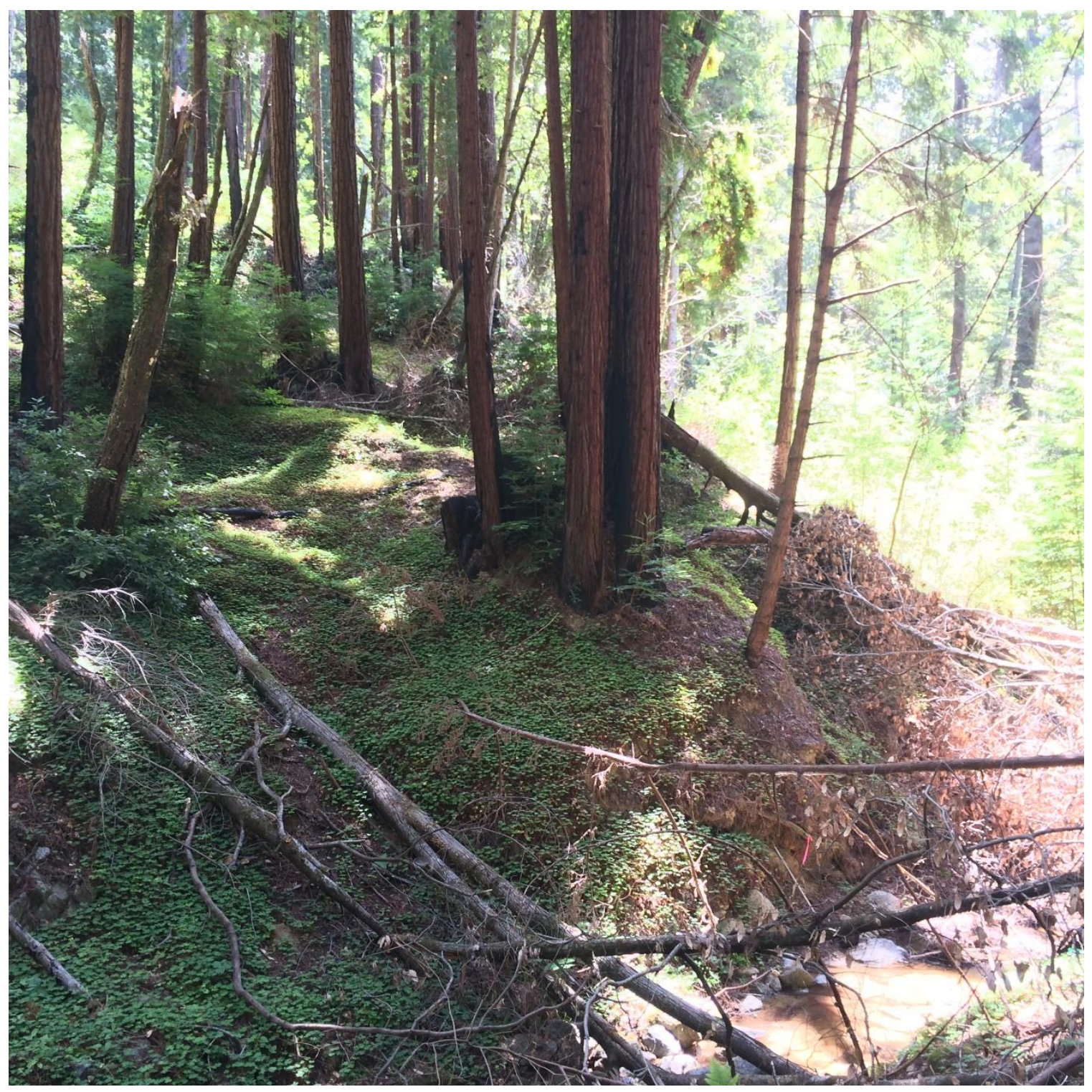

Figure D.3 Tranquility Flats study reach at sampling location TF-J. 


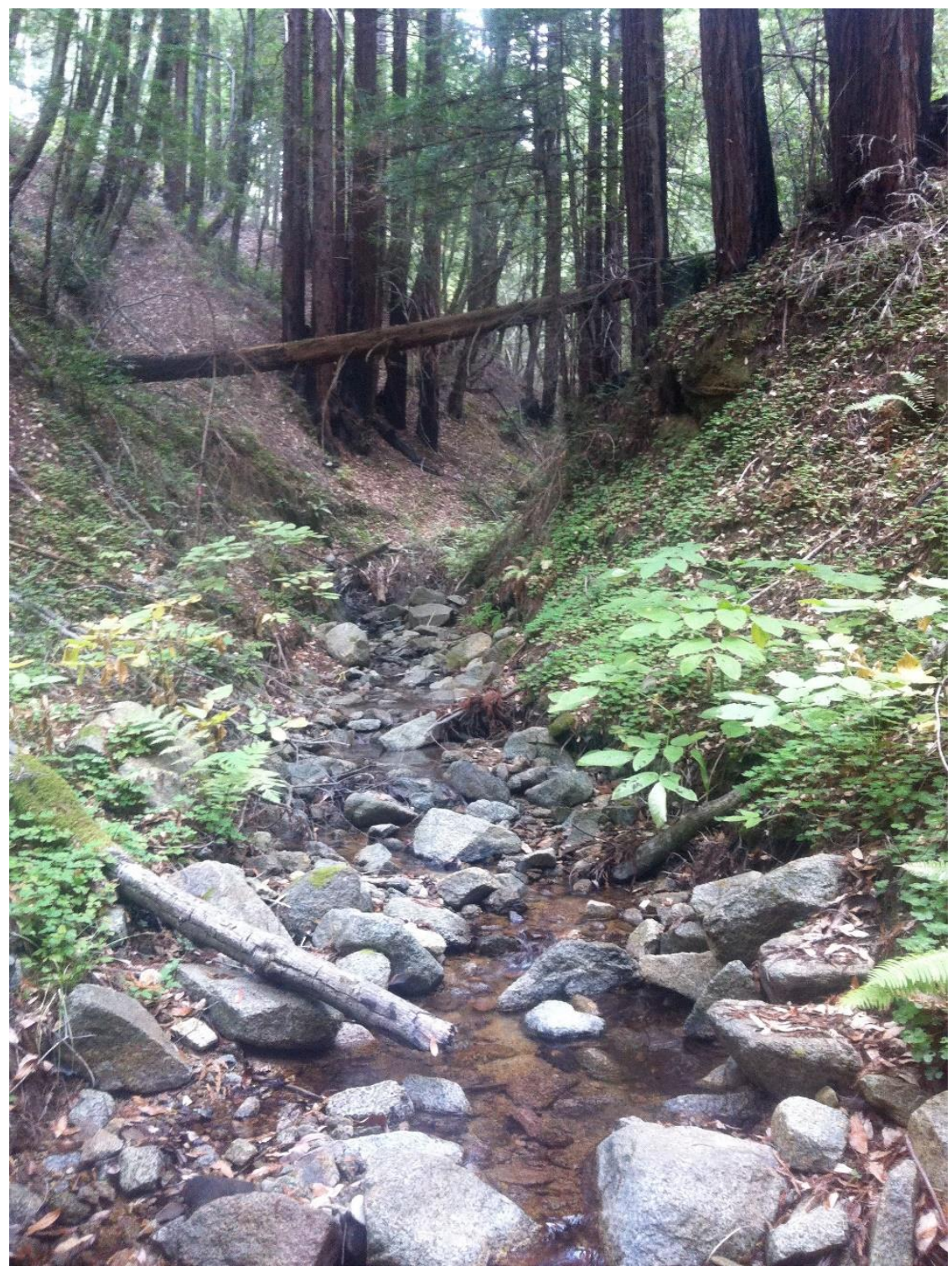

Figure D.4 Looking upstream at the North Fork study reach. 


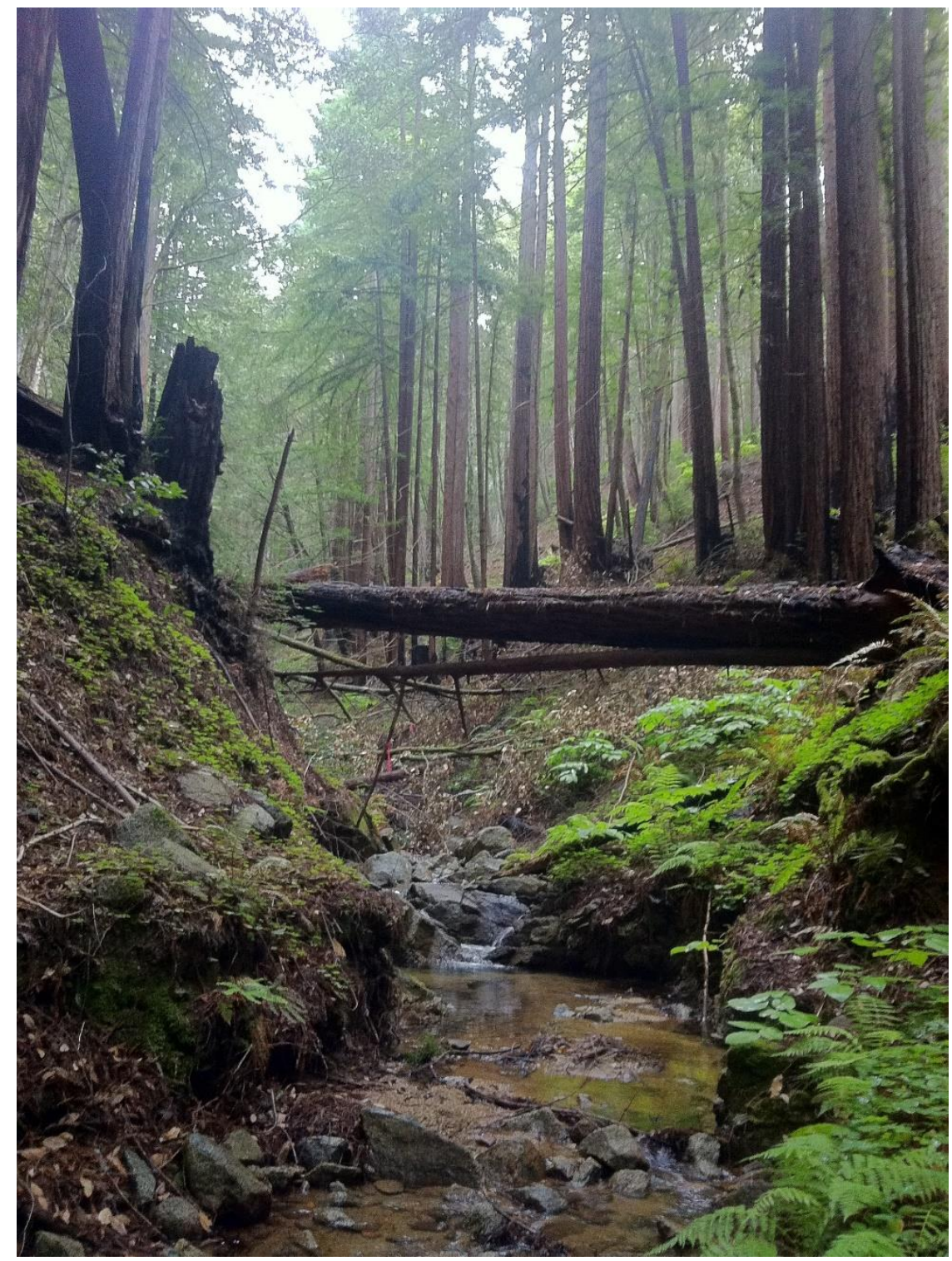

Figure D.5 Looking upstream at the Upper North Fork study reach. 


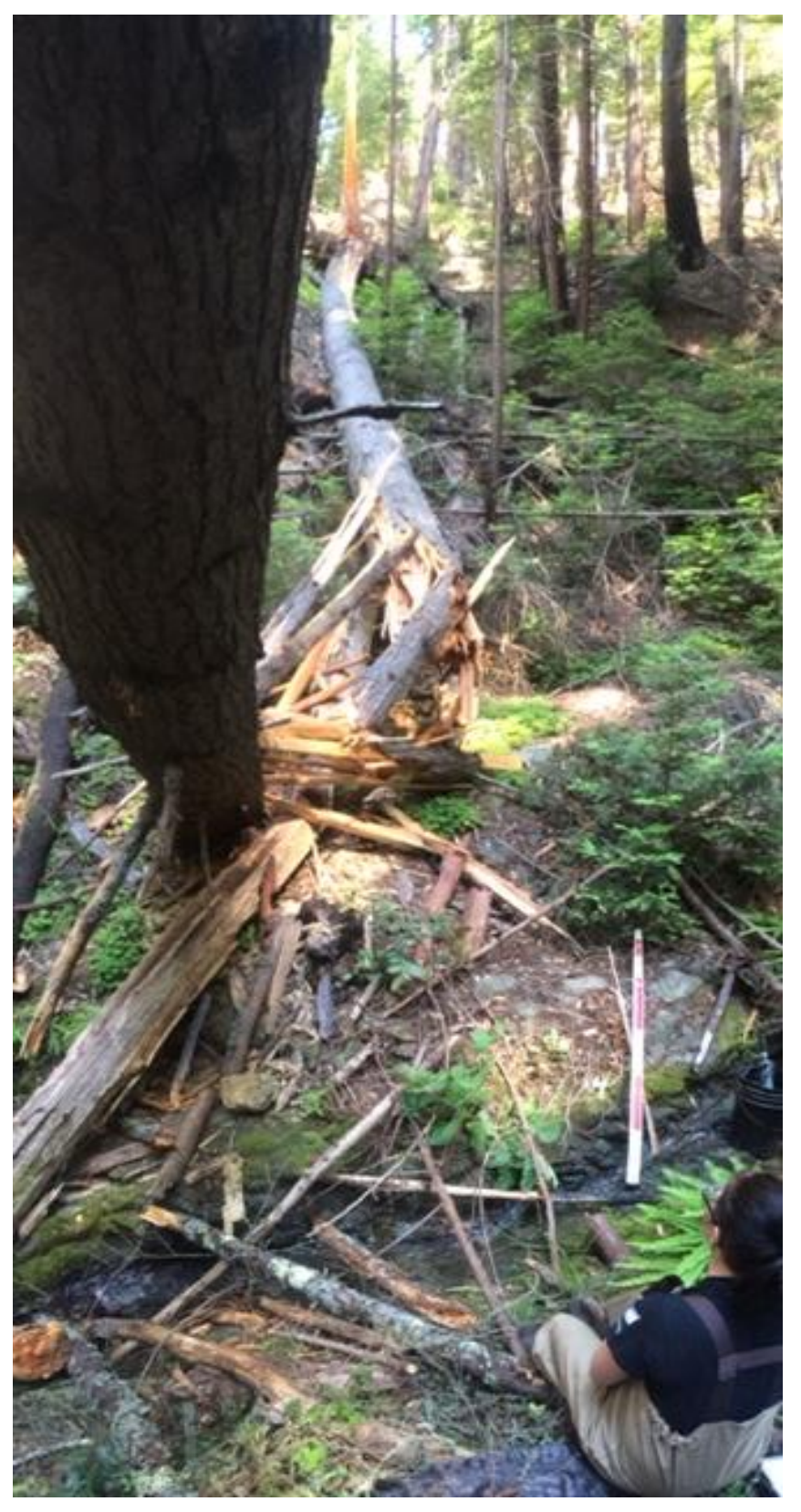

Figure D.6 Large woody debris at the Upper South Fork study reach. 


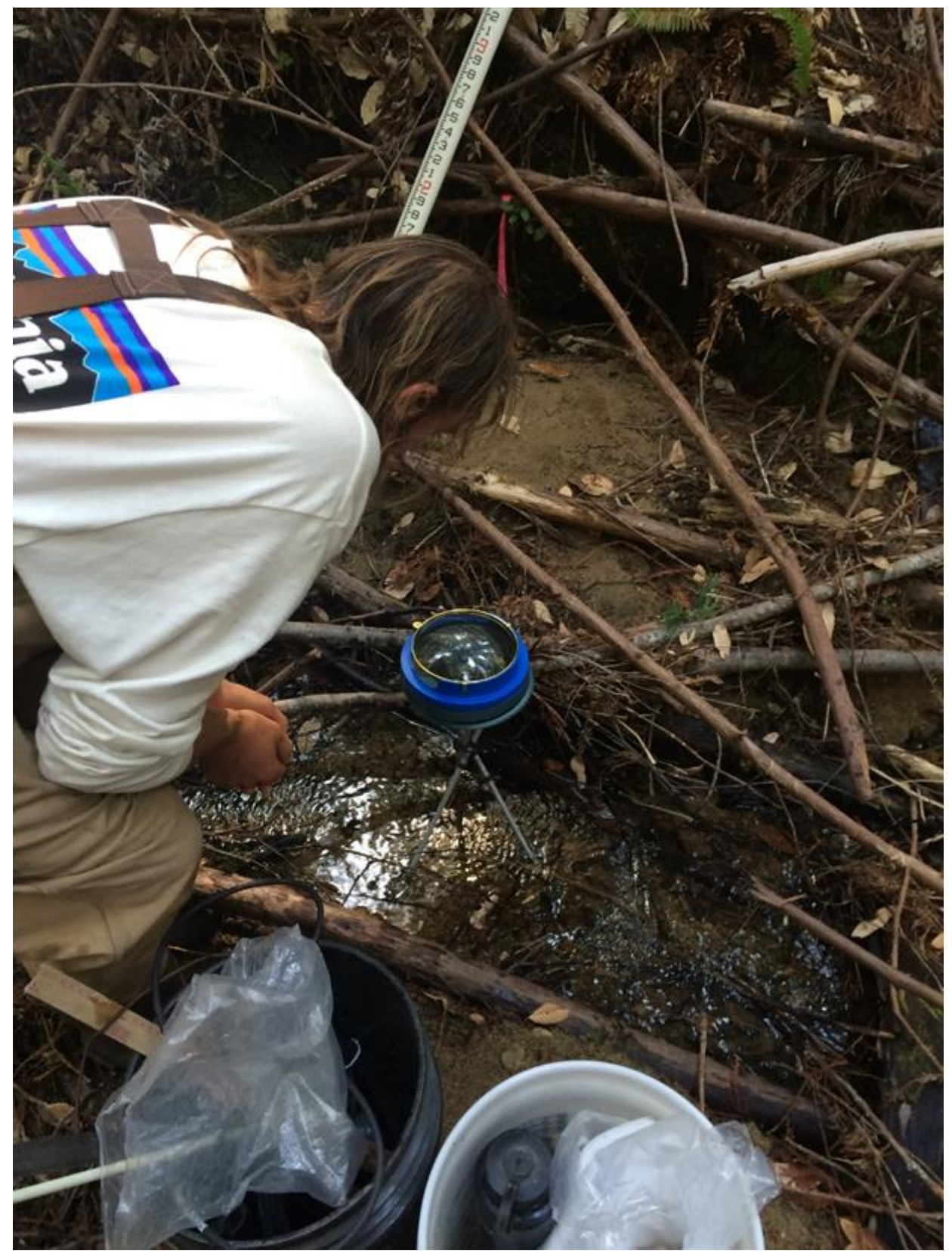

Figure D.7 Brian Clark collecting stream shading data with the Solar PathfinderTM at the Upper South Fork study reach. 